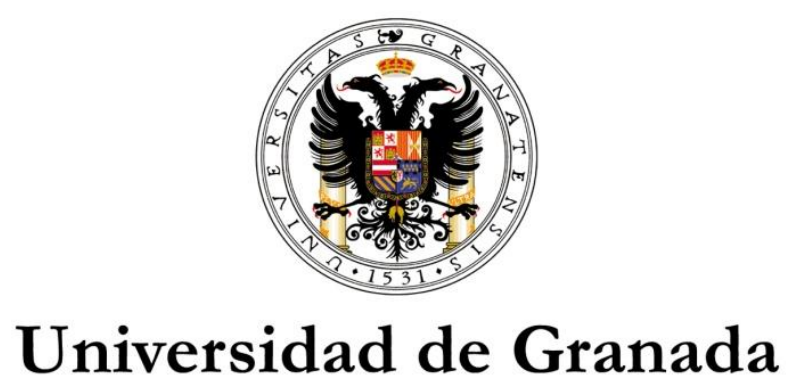

Facultad de Filosofía y Letras

Trabajo de Fin de Máster (TFM) / MA dissertation

Máster en literatura y lingüística inglesas / MA in English Literature and Linguistics

\title{
Information structure violations in passive constructions at the syntax-discourse interface by advanced L2 English learners
}

\author{
Alumna: Priscila López-Beltrán Forcada \\ Supervisores: Cristóbal Lozano (Departamento de Filología Inglesa, UGR) y Alfonso Palma \\ (Departamento de Psicología Experimental, UGR)


1 INTRODUCTION

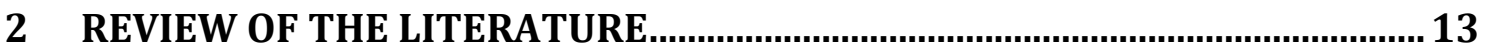

2.1 Language-internal and language-external interfaces ....................................................13

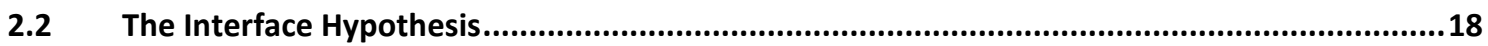

2.3 Information Structure and the Syntax-Discourse interface: an exploration of passive sentences

2.4 Acquisition and processing of the information structure of passives at the syntax-discourse interface

2.5 Research Questions and Predictions

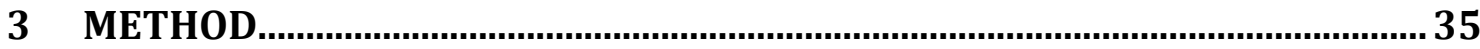

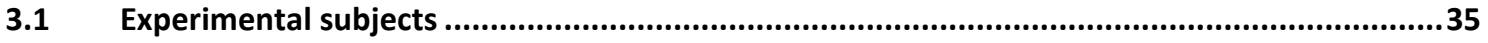

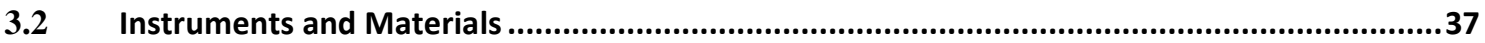

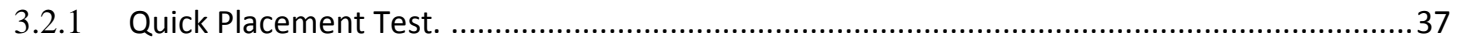

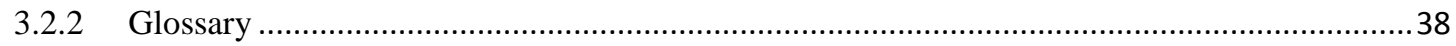

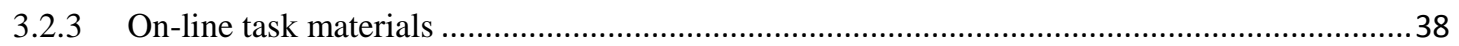

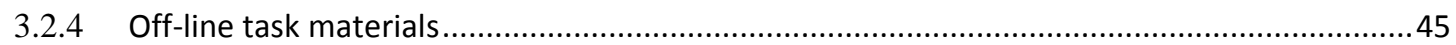

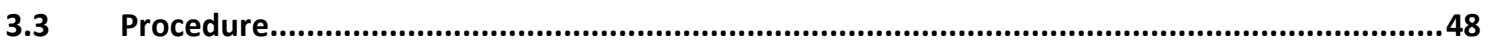

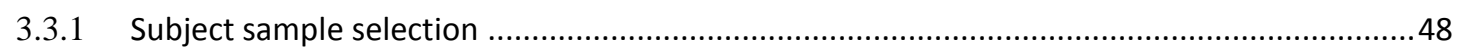

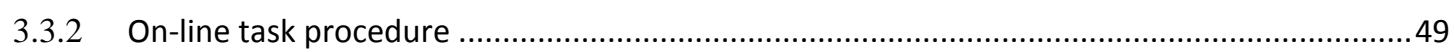

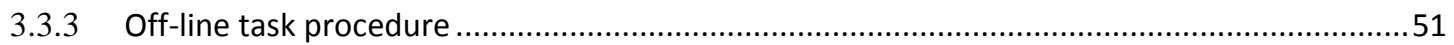

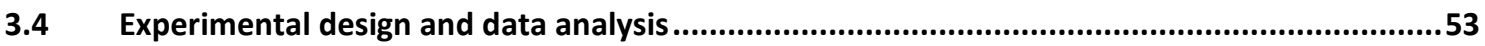

4 RESULTS

4.1 ON-LINE TASK RESULTS

4.1.1 Contrast of the processing of active and passive sentences, both congruent and incongruent,

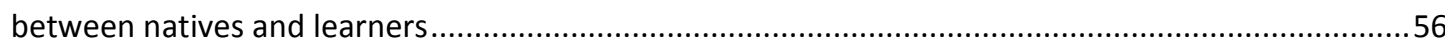

4.1.1.1 [Contrast A1] Active Sentences: sentence1 vs. \#sentence 3.......................................56

4.1.1.2 [Contrast A2] Passive Sentences: sentence4 vs. \#sentence2 ..........................................58

4.1.2 Contrast of the processing of agent entities given and new in active and passive sentences

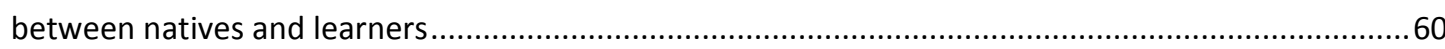

4.1.2.1 [Contrast B1] Active sentences: segment1 (E1: agent) vs. \#sentence 3 .......................61

4.1.2.2 [Contrast B2] Passive sentences: segment3 (E1: agent) in \#sentence2 vs. sentence 4 ...63

4.1.3 Contrast of the processing of patient entities given and new in active and passive sentences between learners and natives................................................................................................65

4.1.3.1 [Contrast C1] Active sentences: segment3 (E2: patient) in \#sentence3 vs. sentence1 ...65 
4.1.3.2 [Contrast C2] Passive sentences: segment1 (E2:patient) in sentence4 vs. \#sentence2 ..68

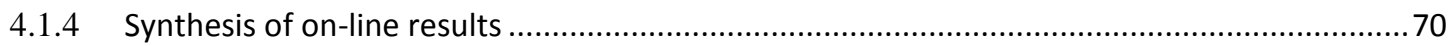

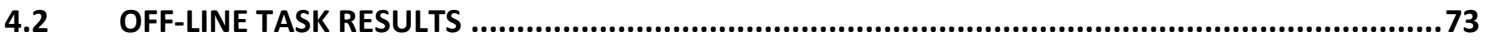

4.2.1 [Contrast D1] Contrast in agent contexts: agent1 vs. \#agent2 ............................................... 73

4.2.2 [Contrast D2] Contrast in patient contexts: \#patient3 vs. patient 4 .......................................75

4.2.3 [Contrast D3] Contrast in distractor contexts: distractor1 vs. \#distractor2 .............................81

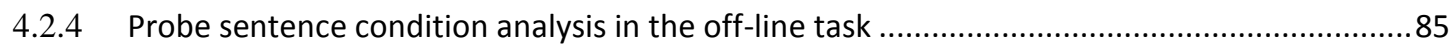

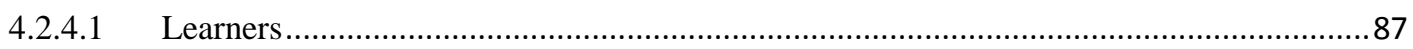

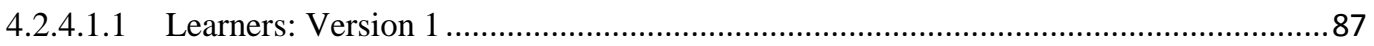

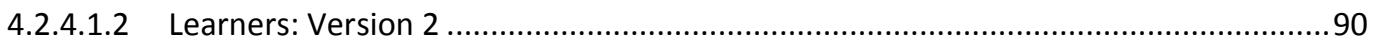

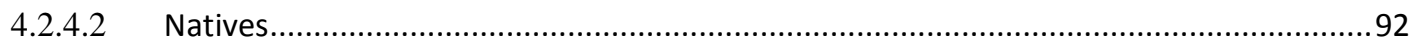

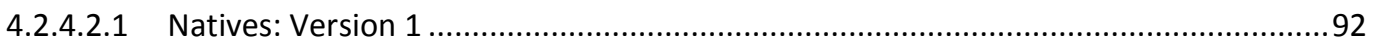

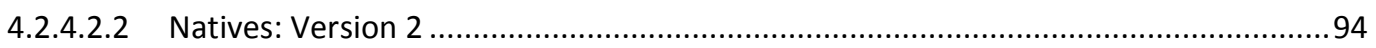

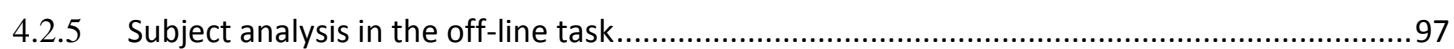

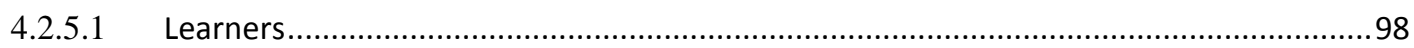

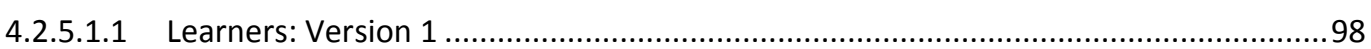

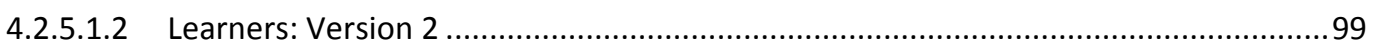

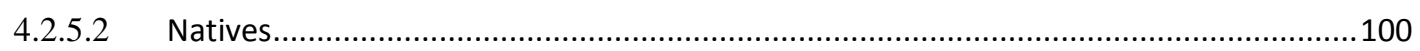

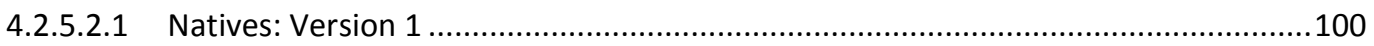

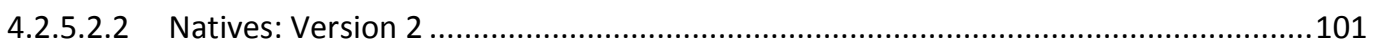

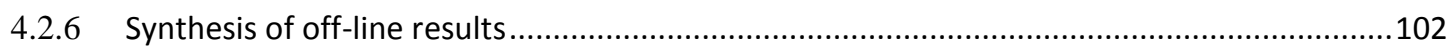

5 CONCLUSION................................................................................................... 105

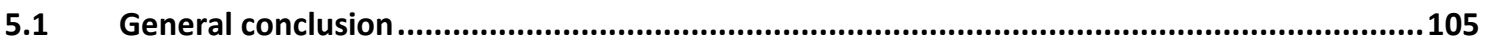

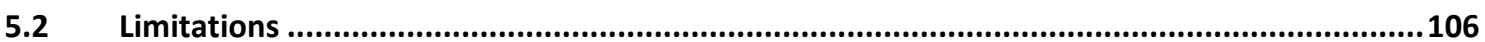

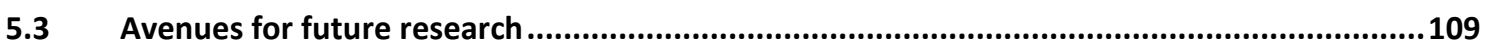

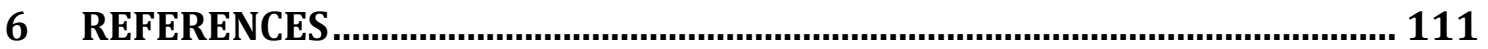

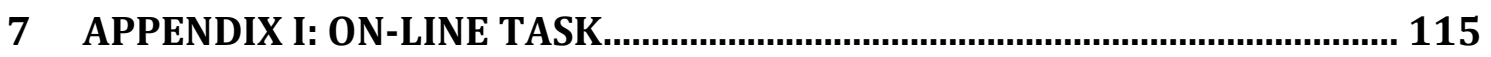

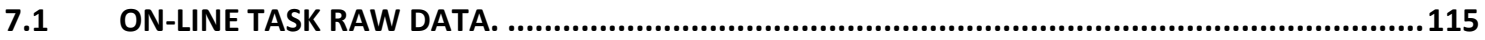

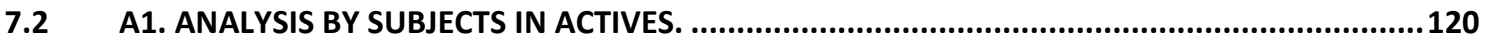

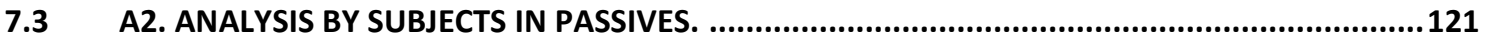

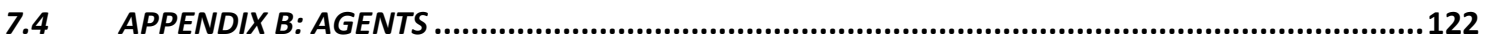

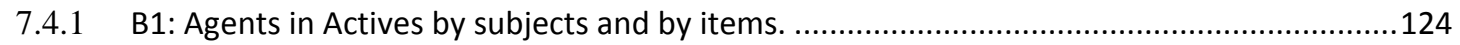

7.4.2 B2. Agents in Passives by subjects and by items..........................................................125

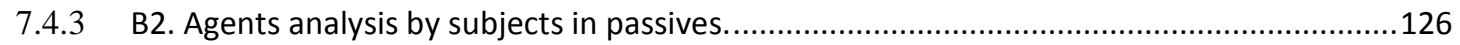

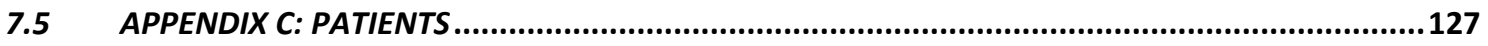

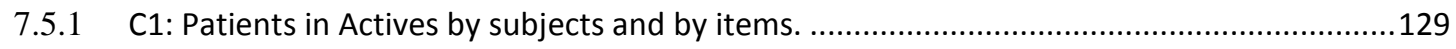

7.5.2 C2. Patients in Passives by subjects and by items.............................................................130 


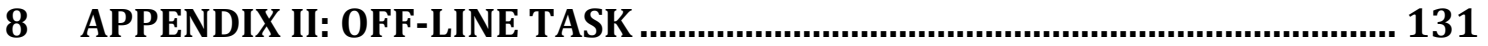

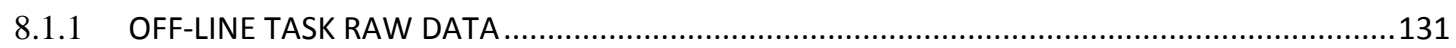

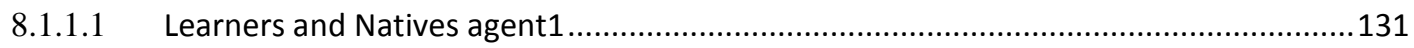

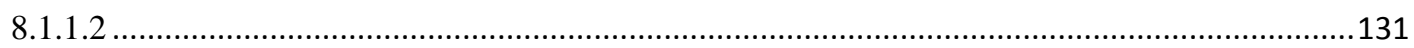

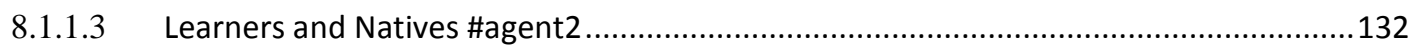

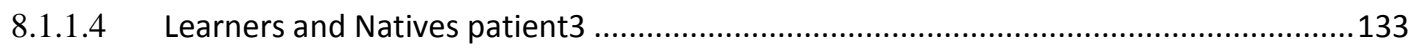

8.1.1.5 Learners and Natives \#patient4 .................................................................................134

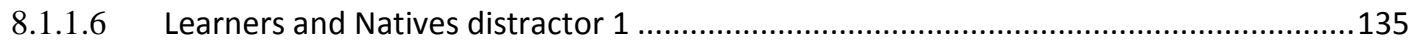

8.1.1.7 Learners and Native \#distractor2 ................................................................... 136

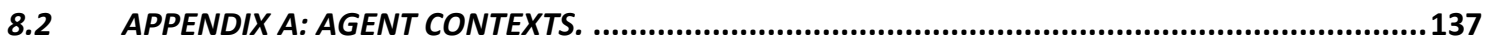

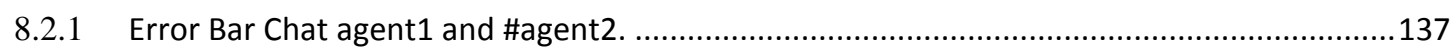

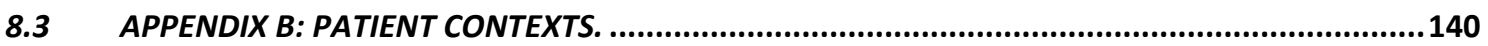

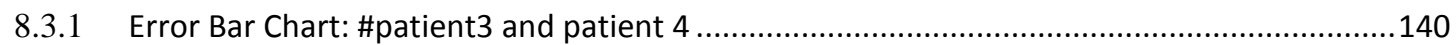

8.3.2 Test of Within Subjects Contrast................................................................................ 142

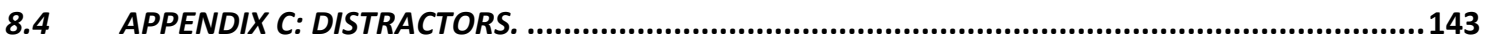

8.4.1 Error Bar Chart: distractor1 and \#distractor2 ............................................................. 143

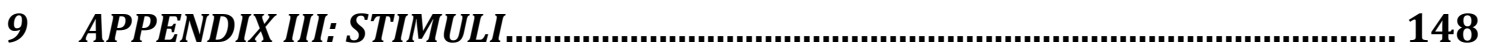

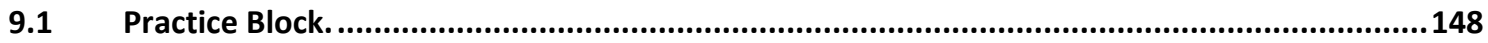

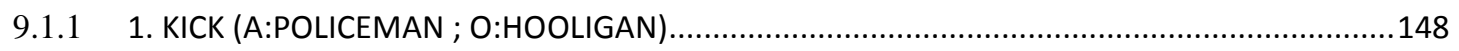

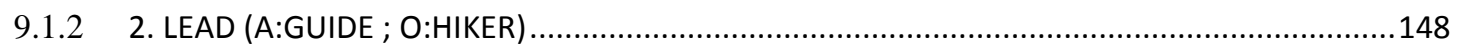

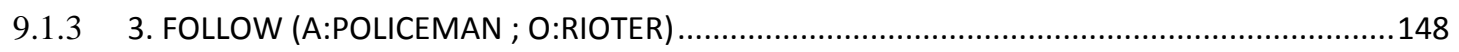

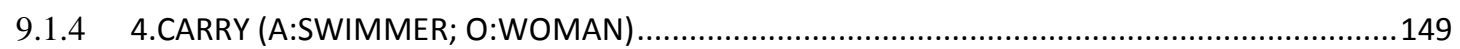

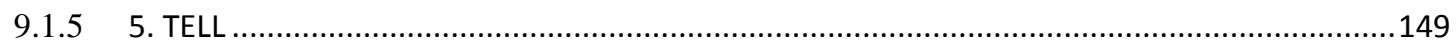

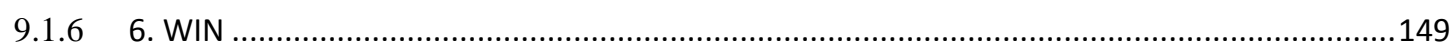

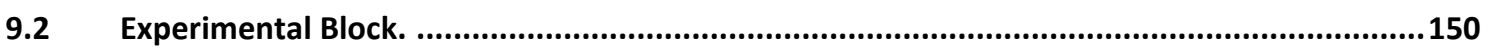

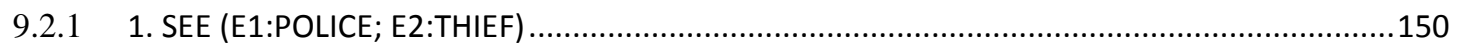

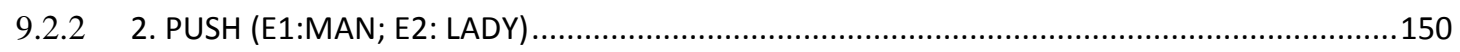

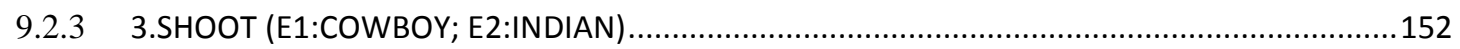

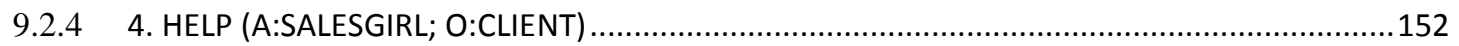

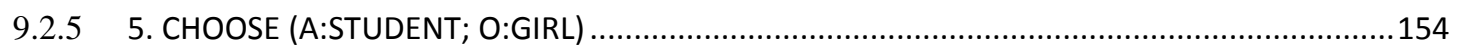

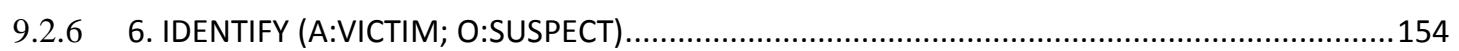

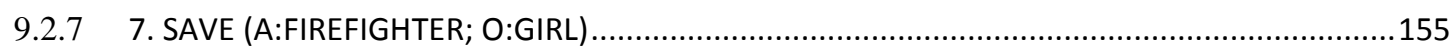

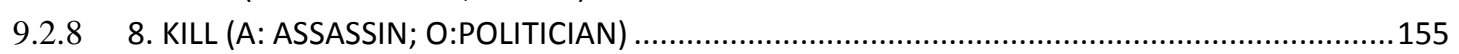

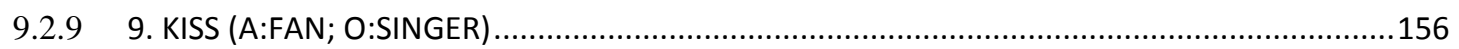

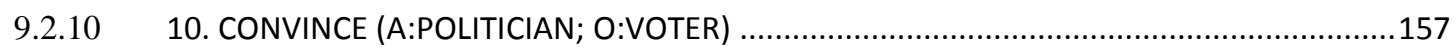

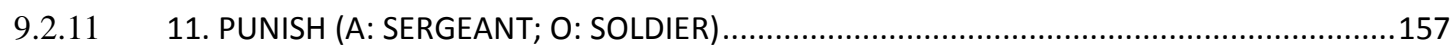

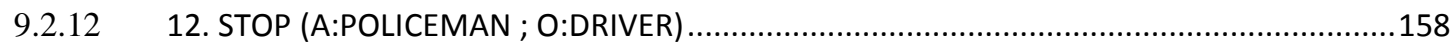

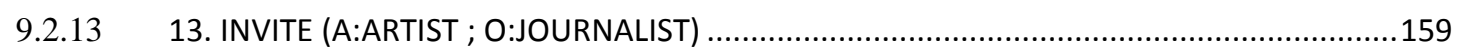

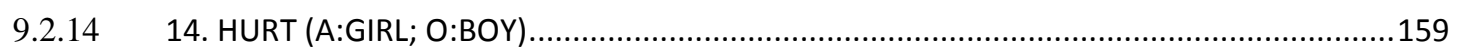

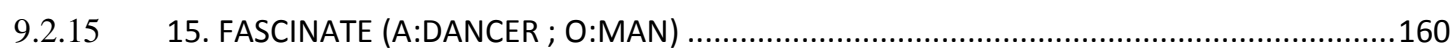

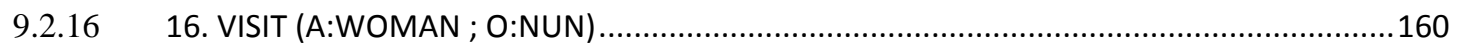

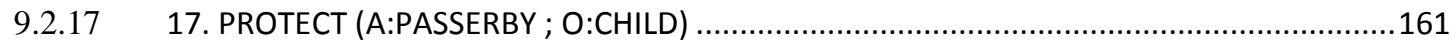

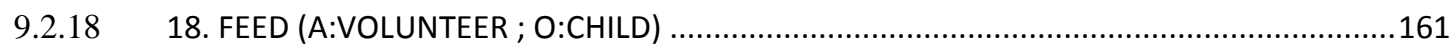

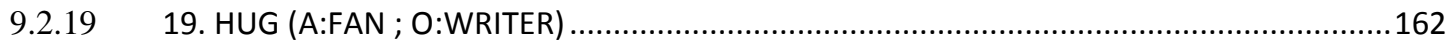




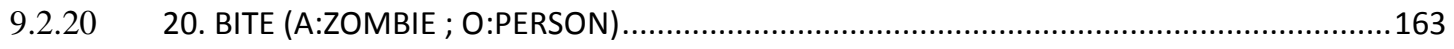

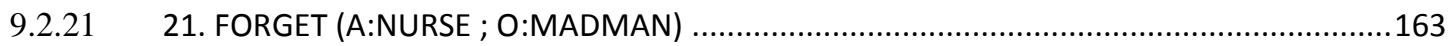

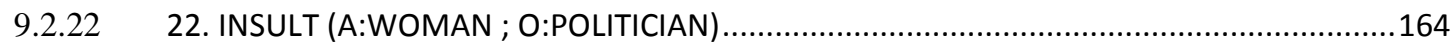

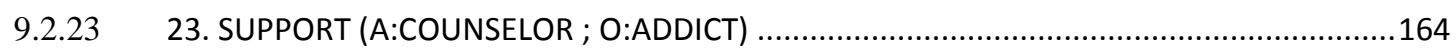

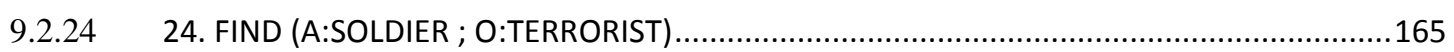

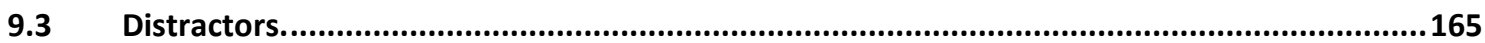

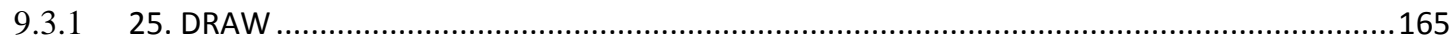

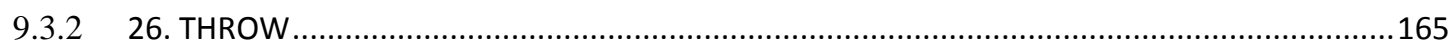

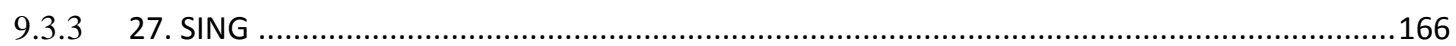

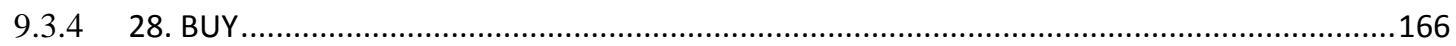

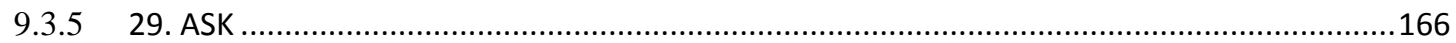

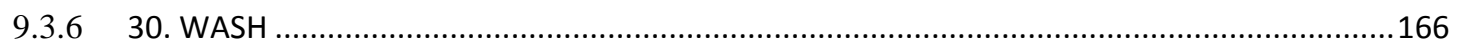

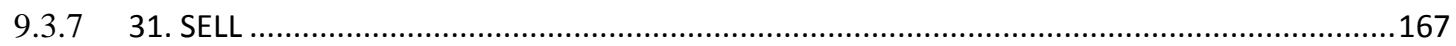

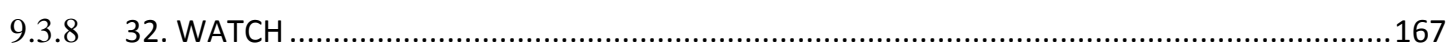

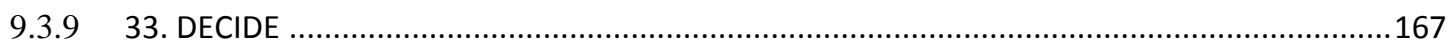

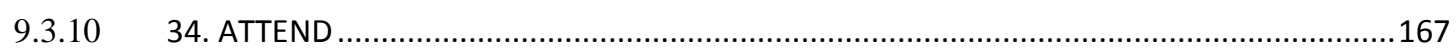

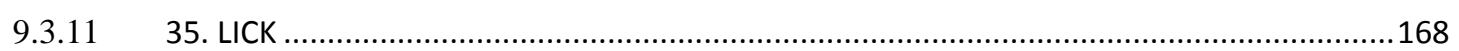

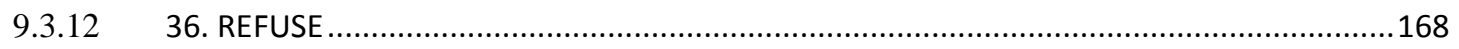

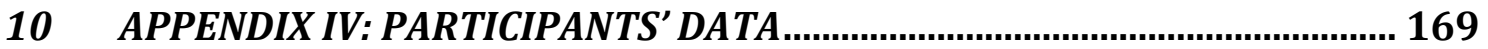

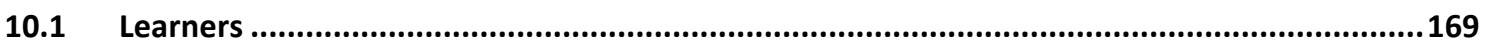

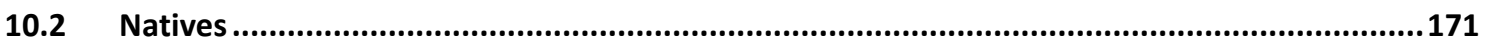

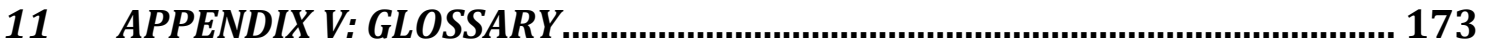

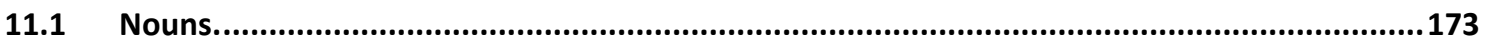

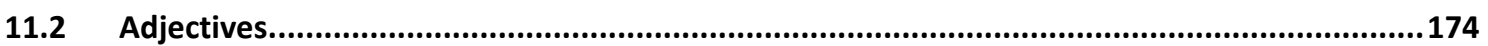

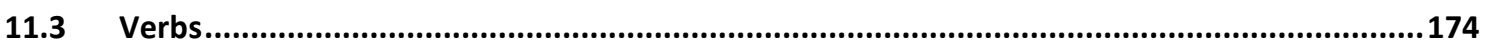




\section{ABSTRACT}

In the recent history of linguistics, there have been several theories that have attempted to give a full account of the functional architecture of the mind. One of the most important was Fodor's in the 1980s. In line with his theory of the modularity of mind, Sorace and Filiaci (2006) put forward the Interface Hypothesis (IH from now onwards). It originally proposed that language structures involving an interface between syntax and other cognitive domains are less likely to be acquired completely than structures involving an internal interface (e.g., lexicon-syntax) and that external interfaces acquisition are problematic and lead to residual deficits even in very advanced stages of L2 development. Researchers have concentrated mostly on the syntax-discourse interface as it has turned out to cause more deficits because it requires speakers to integrate syntactic information with information about the discourse status of different entities.

This study focuses on the way a group of 12 very advanced L2 English learners and another 12 native speakers of English manage the informational distribution of passive (vs. active) constructions. Much research has been conducted on passives regarding their acquisition and instruction in both L1 and L2, in adults as well as in children, but there are no studies that analyse in depth its informational distribution, as far as we are concerned.

As such, in the present dissertation, the topic of research is the processing and knowledge of information in passive constructions by means of two tasks. On the one hand, an on-line task has been designed that will test the participants' processing, and on the other, an off-line task that will test their knowledge. The decision to use two different types of task is based on a series of predictions made by the $\mathrm{IH}$. According to this hypothesis, learners will experience processing deficits that will show in the on-line task, as they need to integrate more elements, which takes a higher toll on their working memories, whereas no deficits will be experienced in the off-line task, and they will behave in a native-like manner. 
Therefore, the predictions are as follows: (i) in the on-line task, learners will show higher Reading Times when processing sentences whose information structure has been violated, and (ii) in the off-line task, learners will show higher acceptability rates for those sentences whose information structure has not been violated.

All in all the results obtained and analysed in this study support the general predictions of $\mathrm{IH}$, as well as the ones present in this dissertation, and shed light on the otherwise underexplored area of information structure distribution and processing of passive sentences in L2 English acquisition, fitting into the body of literature produced up to now on the syntax-discourse interface and adding valuable information on passive constructions. The data gathered also provide new findings on how both learners and natives process passive constructions at the syntax-discourse level and point out the deficits in said processing, adding to the corpora of interface knowledge. 


\section{INTRODUCTION}

In the recent history of linguistics, there have been several theories that have attempted to give a full account of the functional architecture of the mind. In the 1980s, Jerry Fodor revived the idea of the modularity of the mind according to which the linguistic competence of humans should be seen as a series of cognitive faculties consisting of semi-autonomous modules, which have their own specific structural and organizational properties (Fodor, 1983), but which may also interact with each other.

In 2006, Antonella Sorace and Francesa Filiaci put forward the Interface Hypothesis (IH from now onwards). The IH was an attempt to account for patterns of non-convergence and residual optionality found at very advanced stages of adult second acquisition. It originally proposed that language structures involving an interface between syntax and other cognitive domains are less likely to be acquired completely than structures that do not involve this interface. More recent versions of the IH (Tsimpli, 2004; Sorace and Filiaci, 2006; Sorace and Serratrice, 2009; Sorace, 2011) propose a distinction between internal interfaces, those mediating between narrow syntax and the other linguistic modules (phonology, morphology, semantics), and external interfaces, those mediating between syntax and other cognitive modules (discourse, pragmatics).

As a primary example of an external interface, researchers have mostly concentrated on the syntax-discourse interface, which will be the focus of this study. The claim is that "this interface is the major source of difficulty, causing delays in L1 acquisition, failure in bilingual and L2 acquisition, as well as indeterminacy of judgments and residual optionality even at near-native levels of acquisition" (Slabakova and Ivanov, 201: 638). The fact that predicted deficits at this interface apply to both natives (L1) and (very) advanced learners (L2) accounts for the subject choice of this study. As this dissertation deals with second language acquisition, on the one hand, a group of 12 near-native L2 English learners was selected. The predictions made on this study are based on their behaviour, as opposed to that of a group of 12 native speakers of English to be used as control group. 
Crucially, the aforementioned complications are mainly due to the fact that processing syntax-discourse interface phenomena requires the processors to integrate syntactic information with information about the discourse status of different entities, which takes a high toll in their processing resources. This is on-line task will be used (which measures processing costs in terms of reaction time) and an off-line task (which measures knowledge in terms of acceptability rates). These two types of tasks (which will be discussed in detailed in section 3) will provide us with different kinds of data about the linguistic behaviour of participants at the syntax-discourse interface. The online task gathers information on real-time processing (knowledge), whereas the off-line, having no time limit, sheds light on the participants' metalinguistic knowledge through performance. Moreover, the main research question in this study is based on a prediction made by the IH (Sorace, 2011) mainly, that near-native learners will show deficits only in on-line tasks.

This is due to the fact that they need to integrate informational and syntactic knowledge at the same time. That is, when processing at the syntax-discourse interface, learners' brains must combine, simultaneously, information on the syntactic features of the elements present in the utterance, as well as discursive information such as status, topic, focus, etc. On the contrary, they will behave in a native-like way in off-line tasks, as the aforementioned integration does not take place simultaneously. Thanks to the lack of time-limit in off-line tasks, learners can make use of their metalinguistic knowledge, which lowers the processing toll on their working memories, thus allowing them to reach native-like levels of performance. As such, the crucial question is whether the results of this study will indeed support this prediction.

The linguistic structure that is the focus of research in this study is passive sentences when constrained at the syntax-discourse interface. Passives are tightly linked with the concept of information packaging or information structure (Halliday, 1967). In linguistics, information structure describes "the way in which information is formally packaged within a sentence" (Lambrecht, 1996). There are, broadly, two main patterns in which information can be arranged in English: given-new and new-given. The stimuli in the two experiment in this study (cf. Table 1) were specifically designed to illustrate these possible informational distributions. 
As it can be seen (cf. Table 1), every stimulus consists of two contexts (agent and patient), each one introduces an entity (E1: policeman/thief,) with which the following probe sentences will deal. This first entity (E1), in pink, is new information, that is, it has not been mentioned before and it is, therefore, unknown to the reader. The subsequent probe sentences will follow one of the two informational patterns mentioned above: sentences 2 and 3 are informationally incongruent (\#new-given) with the previous context as they present in first instance an entity (E2) which is new information; whereas sentences 1 and 4 are congruent (given-new) as they present an entity (E1) that is old information, that is, it has already been mentioned and it is known by the reader. Thus, by means of manipulating information-structure structures like the one above in both an on-line and an off-line task, information of the participants' processing (competence and knowledge) of these congruent and incongruent constructions will be gathered to analyse deficits and differences in their behaviour as predicted by the IH.

\begin{tabular}{|l|l|l|}
\hline \multicolumn{2}{|l|}{ SEE (A:POLICEMAN; O:THIEF) } & INFOSTRUCTURE / SYNTAX \\
\hline CONTEXT & PROBE SENTENCES & Active: Given / New: \\
\hline Agent: & $\begin{array}{l}\checkmark(1) \text { The policeman saw a thief while } \\
\text { trying to steal a car. }\end{array}$ & $\mathrm{S}_{\text {given }} \mathrm{V}_{\text {active }} \mathrm{O}_{\text {new }}$ \\
\cline { 2 - 3 } $\begin{array}{l}\text { A policeman was } \\
\text { patrolling the city } \\
\text { streets at night. He } \\
\text { heard a strange noise. }\end{array}$ & $\begin{array}{l}\text { \# (2) A thief was seen by the policeman } \\
\text { while trying to steal a car. }\end{array}$ & Passive: New / Given \\
\hline $\begin{array}{l}\text { Patient: } \\
\text { A thief planned to do } \\
\text { something illegal. He } \\
\text { was hidden in a dark } \\
\text { street. }\end{array}$ & $\begin{array}{l}\text { \# (3) A policeman saw the thief while } \\
\text { trying to steal a car. }\end{array}$ & $\mathrm{O}_{\text {new }} \mathrm{V}_{\text {passive }} \mathrm{A}_{\text {given }}$ \\
\cline { 2 - 3 } & $\begin{array}{l}\checkmark(4) \text { The thief was seen by a policeman } \\
\text { while trying to steal a car. }\end{array}$ & $\mathrm{S}_{\text {new }} \mathrm{V}_{\text {active }} \mathrm{O}_{\text {given }}$ \\
\hline
\end{tabular}

Table 1. Stimuli template for information structure

$=$ given info

$=$ new info

The table above shows that the stimuli combine active and passive constructions (probe sentences). The reason behind this is that there exist a series of syntactic constructions which scholars refer to as information packaging constructions. "These constructions characteristically have a more basic counterpart differing not in truth conditions or illocutionary meaning, but in the way the informational content is presented" (Birner, 2002: 1365). The passive is, indeed, one such construction. 
Much research has been conducted (Crawford, 2012; Messenger, Branigan and McLean, 2011) on passives regarding their acquisition and instruction in both L1 and L2 (Myhill, 2010). This type of construction has elicited much interest as it has always proved to be problematic for learners of English even though it is fairly common in this language. However, to our knowledge, there is no research on the knowledge and processing of the information structure distribution of passives in L2 English acquisition.

The only light that research has shed on the subject is that: "because the passive is an argument-reversing construction, it requires that its syntactic subject represent information that is at least as familiar within the discourse as that presented by the byphrase NP. Thus, when the information status of the relevant NP is reversed infelicity results." (Ward and Birner, 2004: 170). This constraint requires that any passive construction instantiates the structure given-new. See the following example:

\section{[1]}

The academic year has just begun and teachers are very busy finding out which classes they will have to teach. Mr. Joe won't teach this year as he has found out he is seriously ill.

i. Mr. Joe will not be teaching this year due to his illness.

ii. $\quad$ \#He will be substituted by the new teacher. ${ }^{1}$

Thus, if the final sentence of the context ( $M r$ won't teach [...] seriously ill) were to be substituted by one of the sentences below, (i) would be pragmatically correct because its first entity, Mr. Joe, is already old information presented in the previous context, thus conforming to the pattern given-new. However, in (ii) both entities, He and the new teacher, are presented as old information but only one of them is old, namely He. In fact, the teacher should have been presented as a teacher, the indefinite article denoting its new status.

\footnotetext{
${ }^{1}$ It is important to point out that "*" stands for ungrammaticality, whereas "\#" stands for apragmaticality. This is relevant because one condition does not necessarily entail the other. That is, a pragmatically infelicitous sentence needs not be grammatically incorrect and vice versa.
} 
This example is relevant as it exemplifies that the variability of definite/indefinite article is of special importance to the present study as will be explained in further detail in future sections.

The structure of this dissertation is as follows: in the following section in this study, Review of the literature, is explained in detail the theoretical principles upon which this research is based. This section deals with findings and discussions on the modularity of mind, interface theory, information packaging and passive construction studies up to now. Right after this, and considering the theoretical matters already debated, comes the Method section in which are presented the participants that took part in this study, the instruments and materials used in the experimental design, the procedures followed to administer the experiments to the subjects and, finally, the variables and statistical analyses used. The Results section is divided into two different parts, one for each experiment (online and offline experiments). In the next section, Conclusion, is presented a conclusion with and analysis and synthesis of the overall results of the study as well as an explanation its limitations and considerations for possible future research derived from it. Finally, the dissertation includes several appendixes in which all the raw data as well as the whole set of stimuli is presented, so that the reader can have access to further information that may help in the understanding of the results provided. 


\section{REVIEW OF THE LITERATURE}

This section contains a literature review of the theoretical bases of this dissertation. In section 2.1

is discussed the proposal that the mind is modular and the notion of interface, which is crucial for the current study. Next (section 2.2) discusses several proposals about how the linguistic computational module (syntax) interfaces with other modules: languageinternal modules and language-external modules. This leads to the $\mathrm{IH}$, which will serve as the starting point to test the hypotheses of this dissertation about how advanced learners of L2 English process linguistic structures (passive sentences) which are regulated at the syntax-discourse interface. Next (section 2.3) deals with information structure, which is crucial for the understanding of how passive (vs. active) sentences are regulated at the syntax-discourse interface by information-structure notions like topic and focus. Finally (section 2.4) the study of the acquisition and processing of passives is set within the framework of the dissertation at hand, presenting the research questions and hypotheses.

\subsection{Language-internal and language-external interfaces}

A central question in cognitive science deals with the parts or processes of which the mind is composed. A crucial aspect of this quest for defining how the human brain works has been the development of information-processing theories of mental phenomena, which are anchored in the theory of computation. This theory claims that the human mind and/or brain is an information processing system and that thinking is a form of computing. As such, the mind is envisaged as a " a machine that derives output representations of the world from input representations" (Rothman and Slabakova, 2011: 570). 
However, this is not the only linguistic explanation of mental processes. In 1983, the publication of Fodor's The Modularity of Mind started a debate that has continued to the present day. In this book, he proposed a particular account of mental structure in which information-processing modules of a very specific kind play a central role (central processes).

Fodor introduced his concept of modularity by using a list of eight features he thought might be typical of modular systems, these included: (1) domain specificity, (2) encapsulation, (3) mandatory operation (automaticity), (4) inaccessibility to consciousness, (5) speed, (6) shallow outputs, (7) fixed neural localization, and (8) characteristic breakdown patterns.

His model has been widely criticised. Other researchers, especially evolutionary psychologists (Cosmid es and Tooby, 1994; Pinker, 1997; Sperber, 1994) proposed that, "contrary to the Fodorian view that only peripheral systems such as vision are modular, many or most information-processing systems in the mind might be modular as well. These included what Fodor would have called central processes, such as those underlying reasoning, judgment, and decision making” (Barrett and Kurzban, 2006: 628).This proposal, sometimes known as the massive modularity thesis, has generated enormous controversy, including many attempts to demonstrate that it must be wrong.

Leaving behind purely theoretical considerations and paying closer attention to more linguistic areas, the modular approach poses that speakers of a language have a grammar at their disposal, consisting of several modules: syntax, semantics, and phonology, as well as a pragmatic system. Thus, the interaction between the three grammatical modules, as well as the interaction of these modules with the pragmatic system is often referred to as interface. Of particular interest for this study is the interaction between syntax and pragmatics/discourse, also known as the syntaxdiscourse interface.

The general idea that a core computational system interfaces with other domains has been argued since 1981, when Chomsky put forward his tripartite model of Principles and Parameters (cf. Figure 1) (Chomsky, 1981, 1986). 

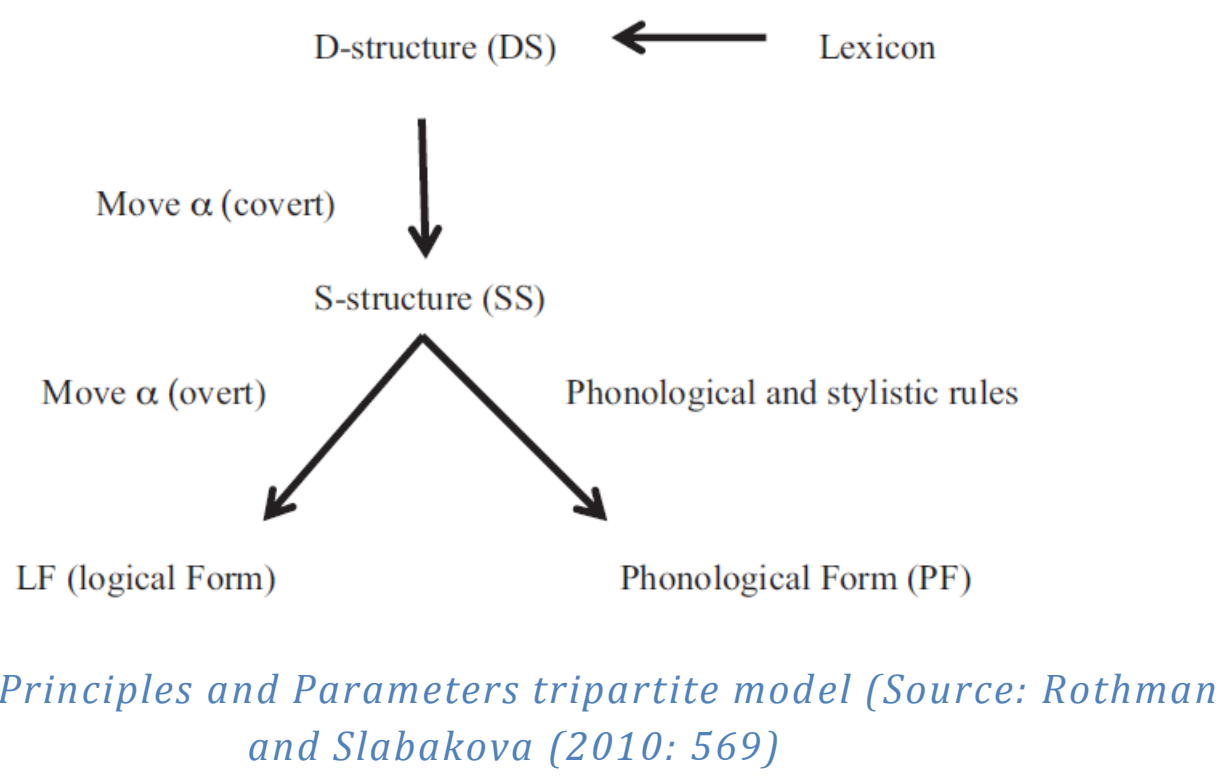

This notion was adapted overtime with the coming of the Minimalist Programme (Chomsky, 1995). Within this model, interfaces share two common organisational domains: a semantic component/conceptual-intentional interface and a phonological component/articulatory-perceptual interface (cf. Figure 1). These notions attempt to deal with the correlations between the linguistic sign (e.g., sound) and the linguistic message (i.e., meaning) more straightforwardly (Chomsky, 2000).

Nevertheless, interfaces need to go beyond the inner workings of how grammar interacts with the lexicon (internal interface), as it is clear that language mainly interacts with discourse and extralinguistic context (external interfaces). According to Bos et al, (2004: 105): “ sub-modules of linguistic systems and other areas of cognition not specific to language are not entirely independent of each other but necessarily integrate information to make the interaction between sound, structure and meaning possible."

Research in the last decade has studied how interfaces might be set-up and interact. For example, Jackendoff (2002) argues that it is an oversimplification to treat $\mathrm{LF}$ and $\mathrm{PF}$ as the only interfaces, proposing instead a " parallel architecture whereby there are multiple interfaces, internally and externally, operating in tandem" (cited in White, 2011: 579). In his system, there are interface rules which provide correspondence between different types/levels of representation. 
As an alternative, Reinhart (2006) proposes that syntax is a computational system that itself embodies an interface between independent mental systems, including concepts, context inference, and the sensory-motor system (cf. Figure 2).

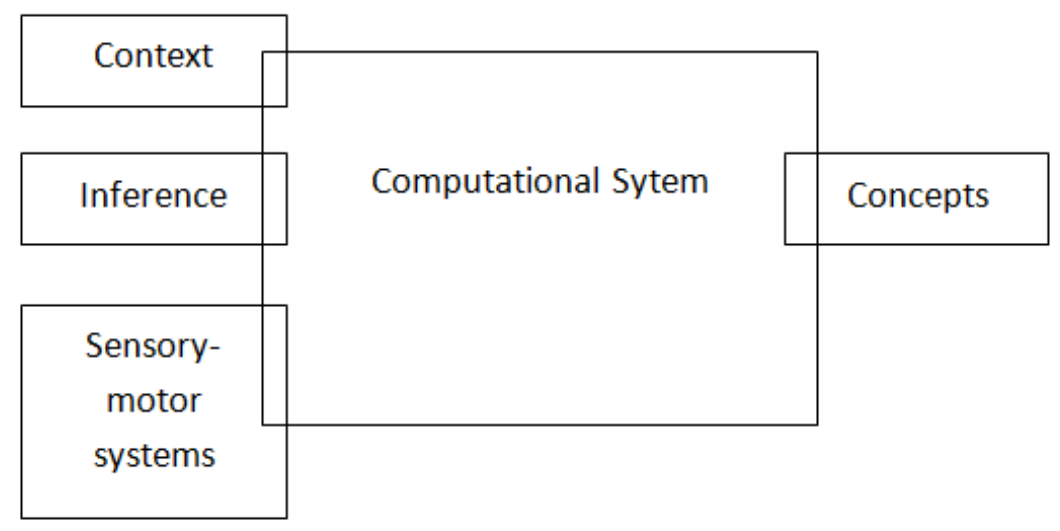

Figure 2. Reinhart's linguistic model of interface architecture (Source: Rothman and Slabakova (2011: 569)

Following Chomsky's (Chomsky 1995, 2005) recent proposals an updated version of his Y-model is shown in Figure 3, where can be observed some of the ideas discussed in the models above: the internal interface between the lexicon and the computational system (syntax) and two external interfaces: one between syntax and the sensory-motor module, and another one between syntax and the conceptual-intentional system. Most authors (see the rest of the authors below in this section) typically consider the syntaxdiscourse interface as a (sub)type of the syntax-CI interface. 


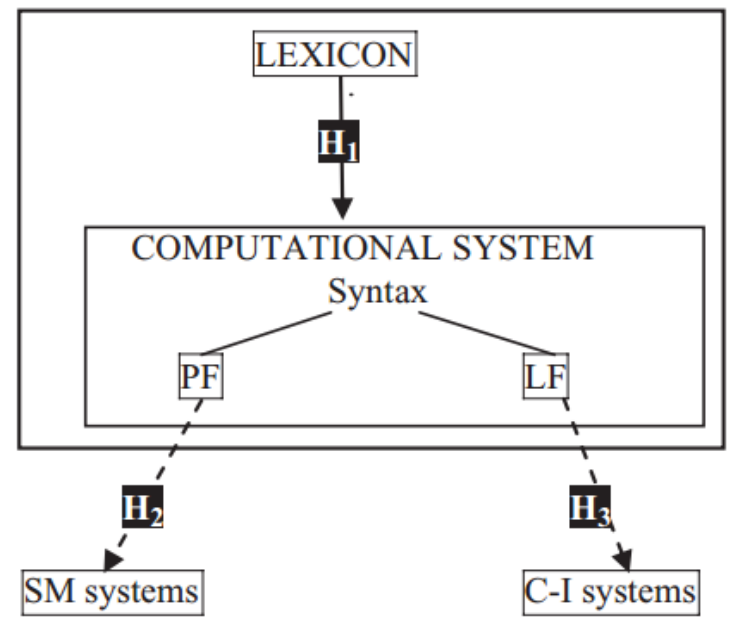

Figure 3. Model of language-interface architecture (Source: Lozano and Mendikoetxea, 2010: 476) 


\subsection{The Interface Hypothesis}

In 2006, Antonella Sorace and Francesca Filiaci put forward the IH. It was an attempt to account for patterns of non-convergence and residual optionality found at very advanced stages of adult second language acquisition. It originally proposed that language structures involving an interface between syntax and other cognitive domains are less likely to be acquired completely than structures that do not involve this interface. At the same time, the IH was extended to bilingual first language acquisition and to the very early stages of L1 attrition, which exhibit optionality in precisely the same structures. As such, the testing of this hypothesis proves to be of vital importance for any linguist interested in the psycholinguistic aspect of language acquisition.

Research carried out by Sorace and her colleagues has addressed the IH in three different domains, including simultaneous bilingual (Serratrice, Sorace\& Paoli, 2004), first language attrition (Tsimpli, Sorace, Heycock \& Filiaci, 2004) and near-native L2 ultimate attainment by L2 speakers who did not acquire their languages simultaneously (Sorace \& Filiaci, 2006). Converging results from these domains have been reported, which " suggest vulnerability of linguistic phenomena relating to the syntax-discourse interface, as exemplified by optionality, instability and indeterminacy" (White, 2011: 577-578).

In her revision of research done so far on the IH (Sorace, 2011: 2), refers to some work as constituing "unwarranted extensions" of the IH. In her own words, "criticisms of the IH sometimes ignore the fact that it is not about intermediate stages of L2 development". One reason for this exclusion, might be that during the course of L2 acquisition, L2 learners may have difficulties in other areas which might mask the predicted effects of the $\mathrm{IH}$. Hence, the participant sample used for the present experiment will consist only of L2 English learners whose proficiency level is nearnative, as well as native speakers of English themselves used as a control group. 
More recent versions of the IH propose a distinction between internal interfaces, those between narrow syntax and the other linguistic modules (phonology, morphology, semantics, etc,) and external interfaces, those between syntax and other cognitive modules. According to Sorace (2011: 9), "there is sufficient evidence for important developmental differences between linguistic structures that require conditions of formal nature within the grammar, and structures that require the integration of contextual factors."

The syntax-discourse interface is the one including all constructions whose meaning computation and acceptability depend on information coming from the previous discourse. "Properties that are calculated at this interface include preverbal and postverbal subjects in languages like Spanish and Italian, the use of overt subjects in Topic Shift contexts, binding of pronouns, clitic doubling of topicalized objects, etc" (Rothman and Slabakova, 2011: 571). The complications brought up by this interface are mainly due to the fact that processing phenomena at this level requires the processors to integrate syntactic information with information about the discourse status of different entities.

Many studies dealing with the syntax-discourse interface focus on pronoun resolution (Lozano, 2009; Sorace \& Filiaci, 2006). As a subject point, Lozano (2009) studied the acquisition of features that license overt/null referential pronominal subjects in English-speaking learners of L2 Spanish using the CEDEL2 (Corpus Escrito Del Español L2). He argues that, although this formal property is acquired early, learners show deficits with the discursive features that license their distribution in the discourse even at advanced and end-states. His final data showed that deficits at the syntaxdiscourse interface are observable in the distribution of overt and null pronominal subjects in the discourse but, unlike previous research, it has been shown that deficits are selective, affecting mainly third person animate only, while the rest of the pronominal paradigm remains stable. 
Similar studies have been carried out regarding word order alternations at the syntax-discourse interface (Hertel, 2003; Lozano, 2009). These analyses have proved that L2 learners experience difficulties integrating syntactic and discursive information in order to resolve the pronoun as efficiently as native speakers. As a subject point, Hertel (2003) investigated the acquisition of Spanish word order by native speakers of English. She specifically considered the development of sensitivity to the distinct interpretations of subject-verb (SV) vs. verb-subject (VS) order, as determined by lexical verb class (unaccusative and unergative verbs) and discourse structure. His participants included a native speaker control group and learners at four proficiency levels. Results obtained through the administration of a contextualized production task indicated that " beginning learners transferred the SV order of English for all structures. Intermediate learners showed a gradual increase in the production of lexically and discourse-determined inversion, although their data was also characterized by indeterminacy and variability. The advanced learners demonstrated sensitivity to the word order effects of unaccusativity and discourse factors, but also tended to overgeneralize inversion to unergative verbs in a neutral discourse context" (Hertel, 2003: 273). But note that most of the studies at the syntax-discourse interface relate the knowledge of the constraints of such interface. There is still relatively little research about the processing.

But, according to Sorace's IH, what could make learner processing less efficient than native processing? Hopp (2009: 466), for example, argues that this deficit phenomenon occurs because "the L2 invokes a higher cognitive load than the L1, since the degree of automaticity in comprehending the L2 [...] falls short of L1 efficiency due to both comparatively less practice in processing the L2 and the effort devoted to the continuous suppression of the L1 in L2 processing."

However, basing herself on several empirical studies (Sorace and Serratrice, 2009; Sorace \& Filiaci, 2006) Sorace (2011) gives a twofold account for these complications: (i) learners' knowledge of, or access, to computational constraints within the language module is less detailed and/or less automatic; (ii) they have fewer general cognitive resources to deploy the integration of different types of information (e.g., integrating syntactic with discursive information). 
Much research provides evidence that accessing and integrating two levels of representation (e.g., syntax-semantics, syntax-pragmatics) is much more costly than accessing only the syntactic level (narrow syntax) (for an overview, see Sorace 2011, White, 2009, 2011).

An alternative view on the nature of the bilingual problem is that it might be one of " cognitive resource allocation in the calculation of syntax-discourse dependencies rather than resource limitation" (Sorace, 2011: 23). Resource allocation has been defined as the ability to flexibly direct attentional resources as a function of the complexity of the incoming material. The effect of resource misallocation is that bilinguals may occasionally direct attention to the "wrong referent [in anaphora resolution with pronominal subjects] which delays them and prevents successful integration of information and ultimately successful interpretation/encoding of anaphoric dependencies" (Sorace, 2011: 23).

Therefore, in so far as learners, especially near-native speakers, have problems, these are likely to be associated only with certain interfaces (i.e., external interfaces). The IH considers the syntax-discourse interface to provide " a significant source or residual but lasting non-nativeness in the grammars of endstate L2 speakers, revealed in the form of indeterminacy, optionality and long-term L1 effects" (White, 2011: 578). As such, the experiments used in this dissertation have been designed to test this interface specifically.

The fact that it is indeed the "integration of discoursive information" that causes deficits at the syntax-discourse interface, is tightly linked with the concept of information packaging or information structure (Halliday, 1967). In linguistics, information structure describes "the way in which information is formally packaged within a sentence" (Lambrecht, 1996:3). Thus, the object of study of the present dissertation is the processing of information structure within the syntaxdiscourse interface, that is, to analyse how L2 learners integrate syntactic and discursive information. 


\subsection{Information Structure and the Syntax-Discourse interface: an exploration of passive sentences}

One of the primary factors that contribute to the coherence and cohesion of discourse is the existence of "informational links" between utterances and context. The function of these links is to facilitate the processing of discourse by helping the speaker/hearer to establish relationships between different discursive entities. There are a series of linguistic forms that mark such relationships. For example, "the use of the definite articles marks the referent of a noun phrase as being individuable within the discourse model, and thereby cues the listener to the likelihood that the entity in question has been previously evoked [...]; thus, the listener will look for an appropriate referent among his or her store of already evoked information rather than constructing a new discourse entity (Ward and Birner, 2004: 153):

[2]

An artist was showing his paintings for the first time in an exhibition. He wanted to appear in the local newspaper.

(i) The artist invited a journalist to the exhibition.

(ii) \#The artist invited the journalist to the exhibition.

The example above shows that whenever the entity introduced is new-information, it is preceded by the indefinite article $a(n)$, whereas it is preceded by the definite article the, when it is old-information. Thus, (i) conforms to a informationally congruent pattern as the old-information constituent that has already been mentioned in the context is accompanied by the indefinite article, whereas the new-information element, unknown to the hearer, is accompanied by the indefinite article. On the contrary, (ii) is incongruent as the informationally new constituent is also preceded by the and, therefore, treated as old.

In this vein, speakers use a wide array of non-canonical syntactic constructions to mark the information status (new/given) of their elements. As such "the speaker's choice of construction serves to structure the informational flow of the discourse (Ward and Birner, 2004: 153). 
The key factors that determine how information is structured in English are the discourse information status and hearer-status (cf. Table 2) (Prince, 1992: 313). Therefore, it is non-canonical syntactic constructions that mark the information they package according to the above-mentioned factors.

\begin{tabular}{|c|c|c|}
\hline & Hearer-old & Hearer-new \\
\hline Discourse-old & Previously evoked & (Non-occurring) \\
\hline Discourse-new & Not evoked but known & Brand-new \\
\hline
\end{tabular}

Table 2. Information Structure distribution (Source: Prince, 1992: 315)

English structures discourse on the basis of a new-old or new-given pattern (i.e., discourse familiarity). As such, following Prince's taxonomy (cf. Table 2), information status is subdivided into four different categories that interact with each other. On the one hand, there is the categorisation of information from the point of view of discourse, that is, considering the previous context information is discourse-old if it has already been mentioned, whereas it is discourse-new if it is novel.

On the other hand, there is the categorisation from the point of view of the hearer's knowledge, that is, information is hearer-new if the hearer has not come across it before, whereas it is hearer-old if it is already known to the hearer. The following examples (taken from Ward and Birner, 2004: 156) should help in the understanding of these concepts:

[3]

The President gave a speech today, and in it he offered a new tax plan.

In this example the NP the President represents the information that is discourse-new but hearer-old, whereas the NP a speech represents information that is both discourse and hearer-new, and the pronoun it represents information that is old in both subjects. 
[4]

The President's present term of office expires January 1. He will be succeeded by Bush $J r$.

This example contains a passive construction and is, therefore, illustrative for the object of study of this dissertation. In this subject, the NP the President represents the information that is both discourse and hearer-new, but the pronoun $\mathrm{He}$ represents information that is old in both subjects. Additionally, note that a passive sentence (He will be succeeded by Bush $J r$ ) is preferable to its active counterpart (Bush $J r$ will succeed him) since the passive presents a given-new pattern (He=given/known information, Bush $J r=$ new/unknown information), which is the typical informationstructure pattern in English, but the active sentence would represent a new-given pattern, which is unusual in English. Below will be discussed the issue of the given-new pattern and active vs. passive sentences.

Despite the seeming simplicity of the examples above, givenness has proved to be an elusive concept in that extensive research has failed to identify a unitary notion of oldness that works for all of the non-canonical constructions. Since the early Prague School work on syntax and discourse, researchers have provided evidence on the association between sentence positions and givenness in discourse.

Prince (1981) describes this notion in terms of assumed familiarity, based on the fact that the speaker structures information within discourse on the grounds of what s/he assumed is known to the hearer. Prince's taxonomy of givenness covers several statuses such as brand-new information, inferable information, unused information and previously evoked information. Later on, this taxonomy is rephrased according to discourse-old/and hearer-old/new (cf. Table 2) (Prince, 1992).

Therefore, when dealing with information structure, there is a series of concepts which must be familiar, namely: focus, topic and weight. The focus of a clause is the constituent bearing the strongest, or "nuclear", stress. It is presented as the most informative element in the clause. It typically represents addressee-new information and the focus-frame (rest of the proposition) is addressee-old information. 
[5]
A: What did Gonzalo get for his birthday?
B: He was given a new car by his father.

The topic of a clause is what the clause is about. This is also a difficult concept to delimit, as English does not provide any explicit syntactic marking of the topic of a clause:

[6]
A: Was Gonzalo given a bike for his birthday?
$\mathrm{B}:$ No, it was a car that he was given for his birthday.

The weight of a constituent is a matter of its length and syntactic and morphological complexity. It may affect the constituent's position in the clause.

[7]
ia. Oscar was picked up by his mother.
b. *Oscar was picked by his mother up.
iia. Oscar was picked up by his mother yesterday morning.
b. * Oscar was picked by his mother yesterday morning up.

In (i) the particle up may precede or follow the object NP. However, where the NP is heavy, there is a clear preference for the particle to come first (ii). Weight is also connected with familiarity status: "heavy constituents are more likely to be new than old. Entities that have already been introduced into the discourse and hence are old can typically be referred to by relatively short and simple expressions" (Ward, Birner, and Huddleston, 2002: 1373). 
Because passive constructions are the object of study in this dissertation, something must be said about non-canonical constructions, also called information packaging constructions. It has been pointed out that "these constructions characteristically have a more basic counterpart differing not in truth conditions or illocutionary meaning, but in the way the informational content is presented" (Ward, Birner \& Huddleston, 2002: 1365). Compare, for example:

[8]

\section{CANONICAL}

ia. Laura baked a cake.

iia. Six men were in the train.

\section{NON CANONICAL}

ib. A cake was baked by Laura.

iib. There were six men in the train.

In each pair, (b) is an instance of an information packaging construction, whereas (a) represents its canonical (SVO) counterpart. In each pair, the truth conditions and illocutionary force are the same. Therefore, syntax makes available different ways of saying the same thing, with "the various versions differing in the way the content is organised informationally" (Ward, Birner \& Huddleston, 2002: 1365).

The main constructions considered as non-canonical are the following (taken from Ward \& Birner, 2004: 153-174):

[9]

\begin{tabular}{|c|c|c|}
\hline i. & PREPOSING & This one she accepted / She accepted this one. \\
\hline ii. & POSTPOSING & $\begin{array}{l}\text { I made without delay all / I made all changes you } \\
\text { the changes you wanted / wanted without delay. }\end{array}$ \\
\hline iii. & INVERSION & On board were two nurses / Two nurses were on board. \\
\hline iv. & EXISTENTIAL & There is a frog in the pool / A frog is in the pool. \\
\hline v. & EXTRAPOSITION & It's clear that he's guilty / That he's guilty is clear. \\
\hline vi. & $\begin{array}{l}\text { LEFT } \\
\text { DISLOCATION }\end{array}$ & $\begin{array}{l}\text { The money I gave her, /That money I gave her, } \\
\text { it must have disappeared. /must have disappeared. }\end{array}$ \\
\hline ii. & $\begin{array}{l}\text { RIGHT } \\
\text { DISLOCATION }\end{array}$ & $\begin{array}{l}\text { They're still here / The people from next door } \\
\text { the people from next door. / are still here. }\end{array}$ \\
\hline & CLEFT & It was you who broke it. / You broke it. \\
\hline$i x$ & PASSIVE & The car was taken by Kim. / Kim took the car. \\
\hline
\end{tabular}


As such, we see that sometimes the differences between an information packaging construction and its canonical counterpart are only a matter of syntactic order. However, in some others it is a matter of how semantic elements match syntactic functions.

Thus, according to Ward, Birner and Huddleston (2002: 1366) " constructions [8i-iii] involve reordering, while the others all affect a realignment of semantic and syntactic elements. In [8i-iii] the non-canonical version can be regarded as less basic than its default counterpart in that the order is not only less frequent but subject to pragmatic constraints that do not apply to the defualt version. In [8iv-ix] the noncanonical version is syntactically less basic by virtue of its greater sytactic complexity; the realignment is accompanied by the addition of one or more elements..."

As mentioned before, this study will focus specifically on passive constructions. When considering passive constructions a suitable structural description of the system of voice must be provided (later on its information-structure description will be addressed).

According to Huddleston and Pullum (2005: 240) "a system of voice is one where the terms differ as to how the syntactic functions are aligned with semantic roles [...] The general terms active and passive are based on the semantic role of the subject in clauses expressing actions". Therefore, the system of voice provides a different way of aligning the two major NPs in a clause with the syntactic functions and of selecting their order of appearance in relation with their familiarity status. Let us consider the following example:

[10]

ACTIVE

The thief stole the car. Subject

DO

\section{PASSIVE}

The car was stolen by the thief. Subject
Agent 
In the active sentence, the element the thief, which performs the function of subject, is aligned with the role of agent. However, in the passive counterpart, it is aligned with a passive role, that of patient.

Also, the sentences above illustrate the three main constituents present in any passive construction: (i) an agent (this semantic role may vary depending on the verb), (ii) a syntactic subject, and (iii) a by-phrase, also called internalised complement.

There are large-scale structural differences between an active clause and its passive counterpart, namely: (i) the subject of the active appears in the passive as the complement of the preposition, (ii) the object of the active appears as the subject of the passive, (ii) the verb of the active sentence appears in the passive in its participle form, and (iv) the passive contains one more verb, the auxiliary be.

On the one hand, the element performing the subject of the active sentences will serve the function of complement of the preposition by in the passive counterpart. The by-phrase constituent is also known as internalised complement. It receives such name because although it is outside the VP in the active, it becomes a verbal after passivisation takes place.

On the other hand, the element performing the role of Direct Object (most commonly) in the active becomes the subject of the passive. That is, "just as the external complement of the active, subject, appears internal to the VP in the passive, so the internal complement of the active, DO, appears external in the passive, i.e., it appears as subject" (Ward, Birner and Huddleston, 2002: 1428-1429).

Finally, considering the verb itself, the participle is an invariant feature of passive constructions and it is always accompanied by a form of the verb to be which takes the inflection of the active verb. 
Primarily, the passive takes two basic forms: on the one hand there is the long passive, where the agent is expressed in a by-phrase. On the other, there is the short passive, where the agent is left unexpressed. Also, whereas long passives maintain the same info as their active counterpart but in a different order, short passives do not really have an exact active counterpart, because active sentences will encode some information about the subject that is not explicitly encoded in the short passive, even if part or all of it is implied or suggested. However, this is a syntactic definition. Long and short passives do have differences from an information-structure point of view.

Regarding short passives, there can be no requirement as to the information status of the by-phrase in relation to the subject, because the former is omitted. Nevertheless, long passives hold a major constraint, that is: the felicity of a long passive requires that the subject not represent information that is newer in the discourse than the NP governed by the word by in the internalised complement. Hence:

A policeman was patrolling the city streets at night. He was paying close attention while doing his round because he was in a very dangerous zone.

$i$. He saw a thief while trying to steal a car.

ii. A thief was seen by him while trying to steal a car.

In (i) the personal pronoun he represents old (given) information, whereas the discourse-new information begins with a thief while...This represents the more canonical given-new pattern. However, in (ii) this pattern is reversed to \#new-given. A thief (marked as new-information by the indefinite article $a$ ) is placed in initial position in the sentence despite the fact that it has not been mentioned before, and the oldinformation element him appears in second position, thus resulting in the infelicity of the sentence. 
This constraint accounts for three of the major features of long passives: (i) the choice of the long passive can to a large extent be accounted for by the principle of endweight, i.e. the tendency to place heavy elements towards the end of the clause. As such, there's a clear tendency for the subject to be shorter than the agent phrase in long passives, (ii) there is a tendency for NPs expressing given material to precede those expressing new material (i.e., given-new principle), and (iii) there is a tendency for definite NPs (which represent discourse-old information) to precede indefinite NPs (which represent discourse-new information), in accordance with the given-new principle.

These theoretical explanations are supported by evidence provided by corpus findings. Consider, for example, Biber et al's (1999: 941) (cf. Table 3):

\begin{tabular}{|c|c|c|c|}
\hline subject & given & $\begin{array}{l}\text { agent phrase } \\
\text { given/new }\end{array}$ & new \\
\hline given & 而 & 而 & 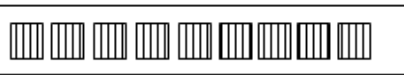 \\
\hline given/new & 图图 & 图 & 而山向向血 \\
\hline new & 图 & 图 & 䘏向山 \\
\hline \multicolumn{4}{|c|}{ 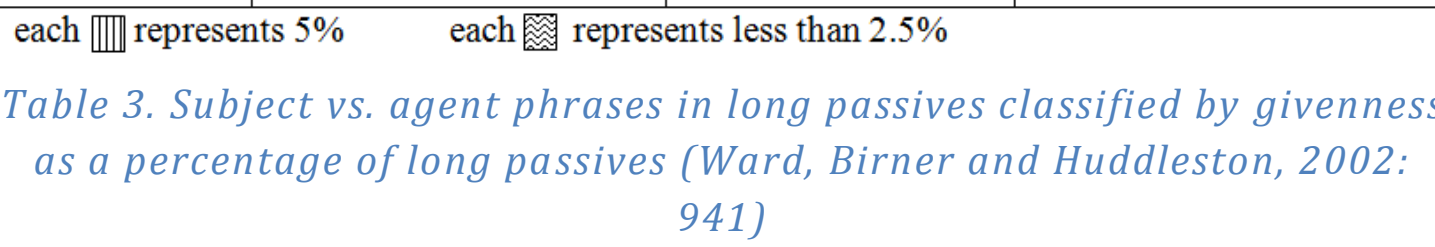 } \\
\hline
\end{tabular}

This table (cf. Table 3 ) shows that subjects vary more in information status than agent phrases, that is, about $90 \%$ of agent phrases bring new information. Also it shows that, in the majority of subjects, the subject has a higher level of givennes than the agent phrase.

The latter feature was especially considered when designing the stimuli for the experiments on this study which researches long dynamic passives with monotransitive verbs. The two following examples are taken from the set of experimental stimuli that was administered to the participants: 
[12]

A boy was in a playground. Suddenly, he couldn't find his ball.

i. $\quad$ The boy hurt a girl because she had taken his ball.

ii. \# A girl was hurt by the boy because she had taken his ball.

[13]

A zombie was very hungry. He was looking for human flesh in a camping site.

i. $\quad$ The zombie bit a person in the arm.

ii. \# A person was bitten by the zombie in the arm.

In both examples, (i) follows the pattern given-new and is, therefore, congruent with the previous context by presenting in first place an entity that has already been mentioned. This entity (policeman, zombie) is preceded by the definite article the as it is discourseold. Regarding (ii), is it incongruent with the previous context (\#) as it presents the structure new-given. The NPs thief/person are preceded by the indefinite article $a$ as they are discourse-new. Thus, these entities are not expected to be placed in initial position when they have not been mentioned before. This variability of definite/indefinite articles will be crucial in the design of the two experiments. 


\subsection{Acquisition and processing of the information structure of passives at the syntax-discourse interface}

All in all, it is clear from the present review that interfaces, information structure and passives have been widely studied and revisited in the theoretical literature, but little is known about their acquisition (and their processing) in the literature. Thus, this dissertation aims at researching the acquisition and processing of the information structure of passive (vs. active) constructions within the framework of the IHThis remains a largely underexplored area.

In order to do so, two different types of experiments have been designed to be administered to the two groups of subjects. On the one hand there is an on-line experiment consisting of a Self-Paced Reading task, aimed at gathering real-time processing data from the participants' processing in the form of Reading Time (RT) measurements. The second is an off-line experiment involving a Contextualised Paired Acceptability Judgement Task, with no time limit, aimed at gathering competence (knowledge) data from the participants by using a 5-points Likert rating scale.

The reason behind the choice of designing two different experiments is closely related with the research questions and predictions in this dissertation. Research on the field of L2 processing (Hopp, 2006, 2009) has documented differences in real-time (online) sentence processing between very advanced or near-native L2 learners and native speakers.

Several studies suggest that L2 sentence comprehension might differ from native processing "due to a shortage of computational resources for integrating different types of grammatical information on-line rather than due to fundamentally different linguistic representations or processing mechanisms in L2 parsing [...] computational difficulties in L2 processing of grammar cause L2 ultimate attainment to fall short of nativelikeness, even though the grammatical representations and processing mechanisms of L2 learners may be fully native-like" (Hopp, 2009: 464). Sorace attributes these differences to what she calls the Processing resource allocatiom account which looks at differences between bilinguals and monolinguals at the level of processing strategies required in the use of interface structures in real time. 
Under this account, "the hypothesis is that bilinguals are less efficient than monolinguals in the integration of multiple sources of information" (Sorace, 20011: 15). In this vein, she predicts that very advanced and near-native learners will experience processing deficits at the syntax-discourse interface which will be obvious in the on-line task as they need to integrate simultaneously syntactic and discursive information. Because this "double integration" puts a greater strain on their working memory and general processing capacity, it is not expected that these participants show higher RTs than natives, for example.

By contrast, no deficits are predicted in the off-line task as learners can make use of both their linguistic and metalinguistic knowledge which reduces pressure on the processing capacities enabling them to behave in more native-like ways. Thus, it is expected that learners' rating patterns be similar to those of native speakers. 


\subsection{Research Questions and Predictions}

Based on the explanation provided above, the predictions are that (cf. Table 4), on the one hand, in the on-line task, learners will show higher RTs when processing syntactically similar pairs of sentences whose information structures have been violated in one of the member of the pair: $(1)<(3)$ for the active and $(4)<(2)$ for the passive. If this is the subject, then the IH would be supported as it would indicate that learners have RT deficits when processing information structure violations and behave differently to natives, who (in theory) should not show processing deficits in this task. On the other hand, in the off-line task, learners are not predicted to have deficits, so they will show higher acceptability rates for those sentences whose information structure has not been violated: $(1)>(2)$ and $(3)<(4)$.

That is, given the same prior context, participants prefer obeying information structure than violating it, independently of whether the compliance appears in an active or passive sentence.

\begin{tabular}{|l|l|l|l|}
\hline \multicolumn{2}{|c|}{} & Syntax \\
\cline { 3 - 4 } \multicolumn{2}{|c|}{} & Active & Passive \\
\hline \multirow{2}{*}{$\begin{array}{l}\text { Info } \\
\text { structure }\end{array}$} & $\checkmark$ Given-New & $\checkmark(1)$ The policeman saw a thief & $\checkmark(4)$ The thief was seen by a policeman \\
\cline { 2 - 4 } & \#New-Given & $\#(3)$ A policeman saw the thief & $\#(2)$ A thief was seen by the policeman \\
\hline
\end{tabular}

Table 4. Predictions

Therefore, this study aims at giving an answer to the following research questions: At the syntax-discourse interface, are L2 learners sensitive to info structure violations in a native-like way? Will findings support the IH that predicts deficits while processing and integrating syntactic and discursive knowledge (on-line task) but native-like knowledge in the off-line task?

In short, if it can be shown that learners behave in a non-native manner in the on-line task but in a native-like manner in the off-line task, then, not only the IH, but the current predictions, would be fully supported. These descriptions are fully explained in section 3.4 Experimental design and data analysis. 


\section{METHOD}

\subsection{Experimental subjects}

In this section is presented all the information concerning the experimental subjects who participated in this study. Right below you can see two tables detailing the biodata of each participant. Each table refers to a different group, namely: Spanish L2 English near-native learners (cf. Table 5) and English native speakers (cf. Table 6).

\begin{tabular}{|c|c|c|c|}
\hline Subject & Initials & Gender & Age \\
\hline 1 & PLO & Male & 22 \\
\hline 2 & MRR & Male & 23 \\
\hline 3 & EGZ & Female & 23 \\
\hline 4 & TSR & Female & 25 \\
\hline 5 & MLGP & Female & 24 \\
\hline 6 & MVR & Female & 23 \\
\hline 7 & NALI & Male & 24 \\
\hline 8 & EJP & Female & 29 \\
\hline 9 & ACV & Male & 24 \\
\hline 10 & CMO & Male & 23 \\
\hline 11 & CCR & Male & 24 \\
\hline 12 & AJGG & Male & 22 \\
\hline
\end{tabular}

Table 5. Biodata of Spanish

L2 English learners

\begin{tabular}{|c|c|c|c|}
\hline Subject & Initials & Gender & Age \\
\hline 13 & BJO & Male & 73 \\
\hline 14 & PAJ & Female & 70 \\
\hline 15 & LAG & Female & 65 \\
\hline 16 & KP & Female & 69 \\
\hline 17 & IM & Male & 75 \\
\hline 18 & PEH & Female & 71 \\
\hline 19 & PW & Male & 76 \\
\hline 20 & HMLH & Female & 77 \\
\hline 21 & MCA & Male & 69 \\
\hline 22 & DMP & Female & 67 \\
\hline 23 & RPN & Male & 70 \\
\hline 24 & LAM & Female & 67 \\
\hline
\end{tabular}

Table 6. Biodata of English natives speakers

The participants of this experiment have been twelve Spanish learners of L2 English with near-native proficiency level, and twelve native speakers of English (L1). The learner sample (cf. Table 5) was gathered among students of the Universities of Granada and Málaga. They were all between 22 and 29 years old and were currently coursing an M.A on English in either university.

As for native speakers (control group) (cf. Table 6), they were either residents or regular tourists in Spain with various degrees of L2 knowledge of Spanish. Their ages varied between 65 and 77 . 
It is evident that the age gap between the learner and native sample is quite relevant. However, this study counted with serious time limits, so the choice of subjects was limited to those who showed the higher availability within the established deadlines.

The effect that aging could have on the native speakers' results was indeed taken into account. As such, a new measure, the RT rate, was implemented in order to counteract this aging effect. This will be explained in detail in section 3.4 Experimental design and data analysis.

Considering the experiment of this study is a reading, and therefore visual, task; it is relevant to point out that none of the subjects had any visual impairment and all of them could perform the experiment effortlessly. 


\subsection{Instruments and Materials}

The following materials have been used in the elaboration of this dissertation.

\subsubsection{Quick Placement Test.}

The selection criteria used to select the learner sample was their proficiency level. A Quick Placement Test, developed by Oxford University, was used to measure their proficiency levels ranging from A1 (starter/elementary) all the way to C2 (proficiency/near-native).

This test consists of a series of multiple choice exercises administered through reading tasks Figure 4. QPT task simple Figure 4) which test the grammatical knowledge of the subjects.

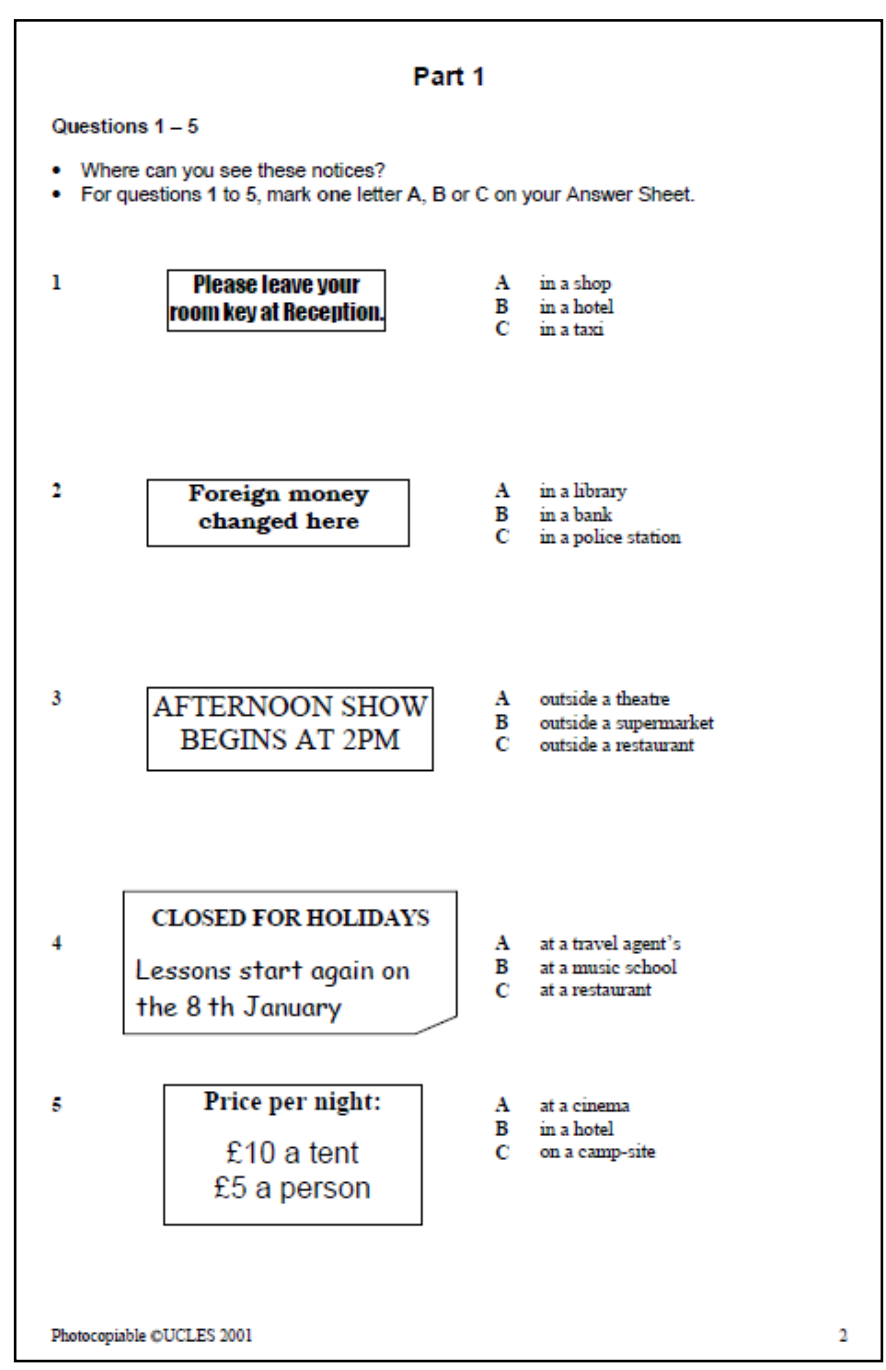

Figure 4. QPT task simple 


\subsubsection{Glossary}

A glossary containing three different lists (nouns, adjectives and adverbs) of all the words used in the experiment was elaborated in order to ensure that learners were familiar with all the vocabulary (see Appendix V).

This is due to that fact that it is crucial to minimize the effect lack of knowledge, processing load, and lexical access problems could have on the subjects' performance.

\subsubsection{On-line task materials}

\begin{tabular}{|l|l|l|}
\hline SEE (A:POLICEMAN; O:THIEF) & VERIFICATION SENTENCE \\
\hline CONTEXT & $\begin{array}{l}\checkmark \text { (1) The policeman saw a thief while } \\
\text { trying to steal a car. }\end{array}$ & The policeman saw a thief. \\
$\begin{array}{l}\text { A policeman was } \\
\text { patrolling the city } \\
\text { streets at night. He } \\
\text { heard a strange noise. }\end{array}$ & $\begin{array}{l}\#(2) \text { A thief was seen by the policeman } \\
\text { while trying to steal a car. }\end{array}$ & $\begin{array}{l}\text { A thief was seen by the } \\
\text { policeman. }\end{array}$ \\
\hline $\begin{array}{l}\text { Patient: } \\
\text { A thief planned to do } \\
\text { something illegal. He } \\
\text { was hidden in a dark } \\
\text { street. }\end{array}$ & $\begin{array}{l}\checkmark(4) \text { A policeman saw the thief while } \\
\text { trying to steal a car. }\end{array}$ & $\begin{array}{l}\text { A policeman was trying to } \\
\text { steal a car. }\end{array}$ \\
\cline { 2 - 4 } & $\begin{array}{l}\text { a car. } \\
\text { shing to steal }\end{array}$ & $\begin{array}{l}\text { The thief was trying to rob a } \\
\text { bank. }\end{array}$ \\
\end{tabular}

\section{Table 7. Stimulus template}

Table 7 shows the structure of the material used in the on-line task presented to the experimental subjects. Each stimulus consists of two sections: (i) a context plus a probe sentence, and (ii) a verification sentence.

Agent and Patient contexts were designed depending on the role that the entity presented in the context performed on the probe sentence. This probe sentence was either in the active or in the passive voice. 
Regarding the elaboration of the contexts, each of them is divided into two different parts: $\left[A(n) \mathrm{NP}_{\mathrm{i}} \underline{\mathrm{V}}_{\mathrm{xpast}} \ldots\right]$ Pronoun $\left.\underline{\mathrm{V}}_{\mathrm{xpast}} \ldots\right]$

$$
\text { Part1 Part2 }
$$

Part 1 begins with an indefinite article followed by the entity (E1) about which something will be said, plus a verb in the past tense. In this sense, the explanation is that this entity was doing or did something. Part 2 starts with a pronoun referring to a discourse-old (E1+ the) entity and serves to complete the context with the extra information needed for it to be a useful guiding thread:

[14]

CONTEXT

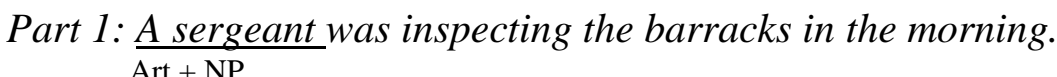

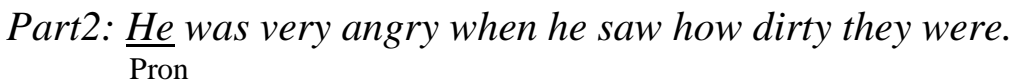

Every context is linked to two probe sentences one in the active voice and one in the passive. As such, every Agent context is paired with two probes agent1 probe in the active and agent 2 in the passive; whereas every Patient context is paired with patient 3 probe in the passive and patient4 in the active.

Finally, the verification sentence consists of a simple declarative statement in the affirmative that corroborates the information provided with the previous story (probe + context).

All contexts are stereotypical and facilitate the "generation of a typical mental model" (Johnson-Laird, 1983), which helps to imagine the entities and spaces where such situation may take place. In this sense, what is created, based on the contextual information, is a mental model of the corresponding situation. 
Thus, the information given in the Agent context (policeman), although the thief is not mentioned, is congruent with one of the possible situation models that this context generates. Then, this situation model takes concrete and coherent form by means of the probe sentence (policeman/thief template).

The same can be said about the information provided by the Patient context (thief) in which the contextual information and the probe sentence lead to the same situation model.

Therefore, although both contexts are independent of each other, they are part of the same situation model. In this way, it is possible to minimise the cost of the processing in the subjects' working memory, as mental models help in the activation of entities in the subject's memories, which is a crucial aspect to ensure that the RT readings are as reliable as possible.

It is important that the entities in these contexts must not be unique, in other words, there is a need for contexts with a certain degree of variability between the participating entities. For example:

A terrorist was hiding in a rooftop. He was preparing his gun.

\section{$i$. The terrorist killed the President \\ ii.\# The terrorist killed a President.}

In this sense, every noun chosen to play the role of E1 or E2 must be pragmatically correct when used not only in the context, but also in the probe sentence. It is the subject that the contexts used in this study do not allow a construction like \#a president to be pragmatically correct when used in a probe sentence, as there would always be only one President.

That is, there is no possibility of variation between definite and indefinite article to express the change in information status that is crucial to this experiment. Therefore, these scenarios have been excluded from the experimental design. 
There is also a crucial constraint concerning verbal selection. As mentioned before, the context will be followed by two active/passive counterpart probe sentences tightly connected with it. Due to this, the verb chosen can only be transitive, as passivisation is not feasible with intransitive verbs. Nevertheless, for the present study, it was decided to restrict verb choice even more and only use monotransitive verbs. By adhering exclusively to monotransitive verbs, it is guaranteed that the only argument that can possibly be selected by the verb is the NP already selected (e.g., policeman, thief). Once again, this helps diminish the burden on the subjects' working memory, as they do not have to employ processing resources in computing if the verb could have selected a second argument and, if so, what would it have been. Additionally, in order to minimize distractions, verbs were controlled for tense: the past tense was used throughout in the contexts as well as in the probe sentences. Finally, choice of verbs has been based on varied corpus research on verbal elements common in passive contexts. An example of such research is Kim and McDonough's (2008: 183) (cf. Figure 5):

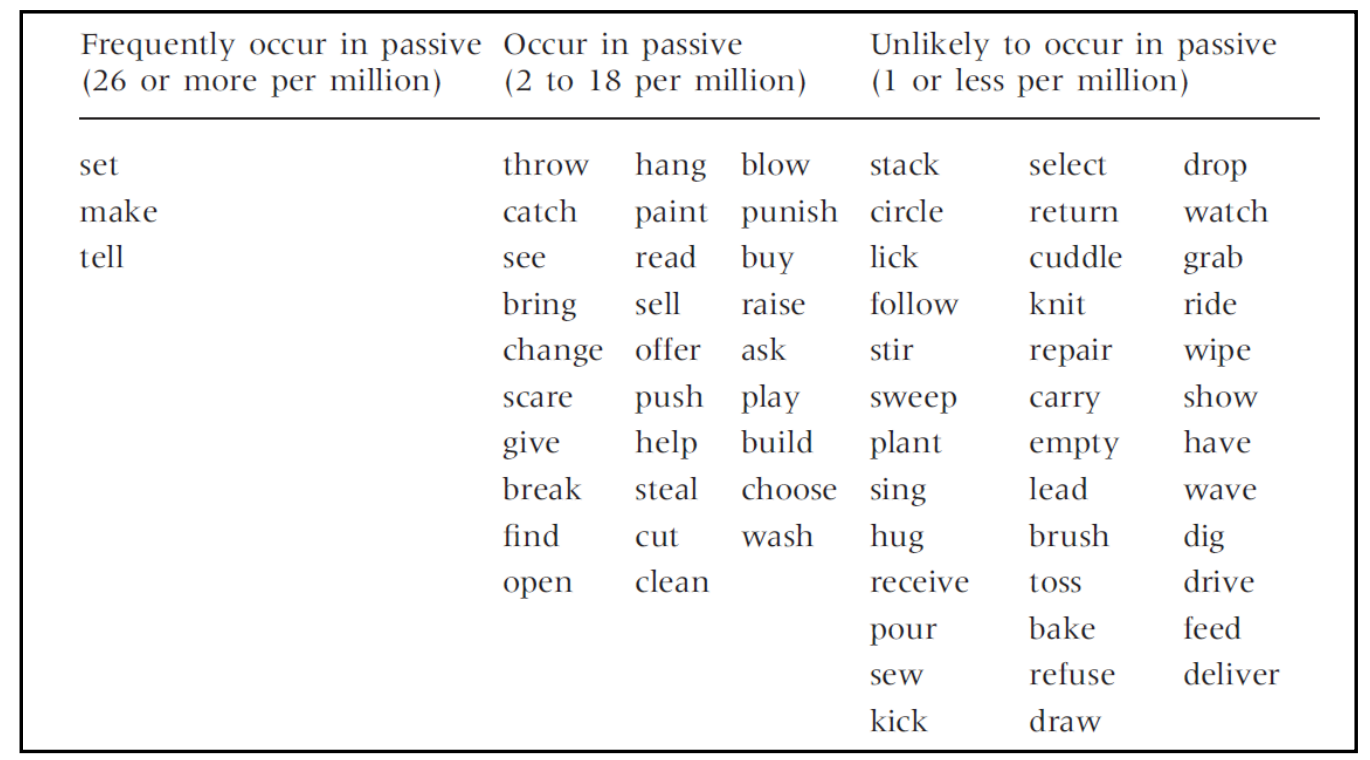

Figure 5. Kim and McDonough's table for frequently passivised verbs

From the point of view of information structure distribution, which is of utmost importance to this study, each context contains a discourse-new entity (NPs policeman and thief) preceded by the definite article $a$. They are then followed by two probe sentences, one of them is informationally congruent with it, whereas the other is not. 
As such, the template would be read as follows: (1) agentl condition, where the probe sentence containing the now discourse-old entity policeman (E1) is followed by a discourse-new entity thief (E2), thus conforming to the congruent given-new information structure pattern; (2) \#agent2 condition, which presents an incongruent new-given pattern as a discourse-new entity thief (E2) is presented before a discourseold entity policeman (E1); (3) \#patient3 condition also follows an incongruent newgiven pattern as the discourse-new entity policeman (E2) is presented before the discourse-old entity thief (E1), (4) finally, in patient4 condition discourse-old entity thief (E1) is presented before the discourse-new entity policeman (E2), therefore conforming to the congruent pattern given-new. All in all, it is evident that the probes of each context (agent1 \& agent 2 , patient $3 \&$ patient 4 ) are their exact reverse, from the point of view of information status and structure, but all the lexical components are the same.

Regarding the truth conditions and the information status of entities (E1, E2), these are not violated as they are constant in each pair. The structure of the probe sentences would be as follows: $\left[\mathrm{NP}_{\mathrm{i}} \mathrm{V}_{\text {xpast }}\right.$ Adjunct.]
1) Agent contexts:
$\checkmark(1)$ the $E 1_{\text {agent }}$
$\mathrm{V}$
$\mathrm{V}_{\text {pass }}$ by
a $E 2_{\text {patient }}$
the $E 1_{\text {agent }}$
Adjunct
\# (2) a E2 patient
$\mathrm{V}$
$\mathrm{V}_{\text {pass }}$ by
the $\mathrm{E} 2$ patient
Adjunct
2) Patient contexts: $\#(1)$ a $E 1_{\text {agent }}$
\[ (2) \text { the } \mathrm{E} 2_{\text {patient }} \]
E1 $1_{\text {agent }}$
Adjunct

But note that, while truth conditions and the information status of entities are not violated, the information structure is violated in both syntactic structures (active vs. passive).

An adjunct was included as the last element in the probe sentence (cf. Table 7), both in the active (after the object) and the passive (after the by-phrase). The content of this element must of course be pragmatically and syntactically coherent with the sentence it belongs to, as well as with the previous discourse present in the context. 
Nevertheless, it is not of ultimate importance as, although it will be added in the RT measures, the most relevant segments for RT rate computation are those including information status relevant entities (s1 and s3), whereas the adjunct is placed in s4 and is used only when calculating the total RT. For this reason, adjuncts have been included to prevent syntactic and semantic processes of integration that take place at the end of the sentence (Kamide, Scheepers and Altmann, 2003).

The weight of the sentences has been controlled both in the context and the probes, they are not too long in order to shorten the distance between entities and minimise the burden on working memory, as the participant needs to retrieve the information about the sentence that has already been mentioned in the context in order to correctly process the probe.

The experiment also contains a series of fillers (cf. Table 8) or distractors whose functions is to break any possible pattern that the subject may have perceived in the stimuli so that s/he remains oblivious to the goal and nature of the experiment:

\begin{tabular}{|c|c|c|}
\hline CONTEXT & PROBE SENTENCES & $\begin{array}{l}\text { VERIFICATION } \\
\text { SENTENCE }\end{array}$ \\
\hline $\begin{array}{l}\text { Anne Phillips had just found } \\
\text { out that she had won the } \\
\text { lottery. She was very happy } \\
\text { and excited. }\end{array}$ & $\begin{array}{l}\text { Anne told her mother the } \\
\text { good news. } \\
\text { It was Anne who told her } \\
\text { mother the good news. }\end{array}$ & Anne Phillips won the lottery. \\
\hline
\end{tabular}

Table 8. Filler template

Fillers also count with a context, two probe sentences and a verification sentence. Nevertheless, they were not applied the same strict design criteria as experimental stimuli because their main purpose is, as explained above, to distract the subject from the experiment's target.

Verification statements on the comprehension of every sentence in the experiment were also created (cf. Table 9). These verification sentences have been included in order to keep participants focused on the task of reading and comprehending instead of just mechanically pressing the button. Said statements were designed so that half of them were true and half false, in order to counterbalance the experiment, and 
they followed the same information structure pattern as the preceding sentence. These statements verified information on the agent, patient and the action or circumstances that took place.

\begin{tabular}{|c|c|c|}
\hline CONTEXT & PROBE SENTENCE & VERIFICATION SENTENCE \\
\hline $\begin{array}{l}\text { A hooligan was at a } \\
\text { football match and his } \\
\text { team was losing. He got } \\
\text { very violent and started a } \\
\text { fight. }\end{array}$ & $\begin{array}{l}\text { The hooligan kicked a } \\
\text { policeman because he } \\
\text { was being violent. }\end{array}$ & $\begin{array}{l}\text { The hooligan hugged a } \\
\text { policeman. }\end{array}$ \\
\hline
\end{tabular}

Table 9. Experimental stimulus plus verification sentence template

In total, 28 experimental contexts and 14 fillers were created for the final structure of the experiment which had two different blocks, practice and experimental, each with a set of stimuli.

The practice block consists of six items in total: four experimental stimuli and two filler sentences. On the other hand, the experimental block consists of thirty-six elements in total: 24 experimental stimuli and 12 filler sentences. Therefore, the experiment contains, in total, 36 stimuli, plus the corresponding verification sentence for each condition:

Agent contexts: $\checkmark$ sentence 1 - Active sentence (6)

Agent contexts: \# sentence 2- Passive sentence (6)

Patient contexts: \#sentence 3 - Active sentence (6)

Patient contexts: $\checkmark$ sentence $4-$ Passive sentence (6)

Fillers (12)

36 Stimuli 
As such, four versions have been made so that each subject gets to see each verb in one of the conditions above. As all the stimuli are multiples of four, each subject will see, in total, six verbs in each condition, plus the twelve fillers, which are the same in every version.

Two auditory signals were created, (i) a warning sound, to mark the passing from one stimulus to the next, in 32 bits wav format (stereo), $22.050 \mathrm{~Hz}$ sampling frequency and $250 \mathrm{~ms}$ of duration. Its peak of intensity is around $440 \mathrm{~Hz}$ and its bandwidth $300 \mathrm{~Hz}$; (ii) a feedback sound, to mark that the choice made regarding the true/false nature of the verification sentence was incorrect, in wav 16 bits format (stereo), $44.100 \mathrm{~Hz}$ sampling frequency and $900 \mathrm{~ms}$ of duration. This is quite a complex sound with varied intensity peaks that encompasses a wide arrange of frequencies. They were created with the software Audacity®, versión 2.0.5, which is a free access on-line platform.

The software used to implement this experiment was OpenSesame (Mathôt \& Theeuwes, 2012) which is a graphical, open-source experiment builder for the social sciences.

\subsubsection{Off-line task materials}

The set of stimuli designed was the same for each task, so the explanation provided above applies here as well.

The experiment layout was that of a context and two probes shown at the same time in the form of a questionnaire elaborated by means of the software LimeSurvey (Schmitz, 2010) (cf. Figure 6). The main difference with the on-line task is the absence of a verification sentence. 


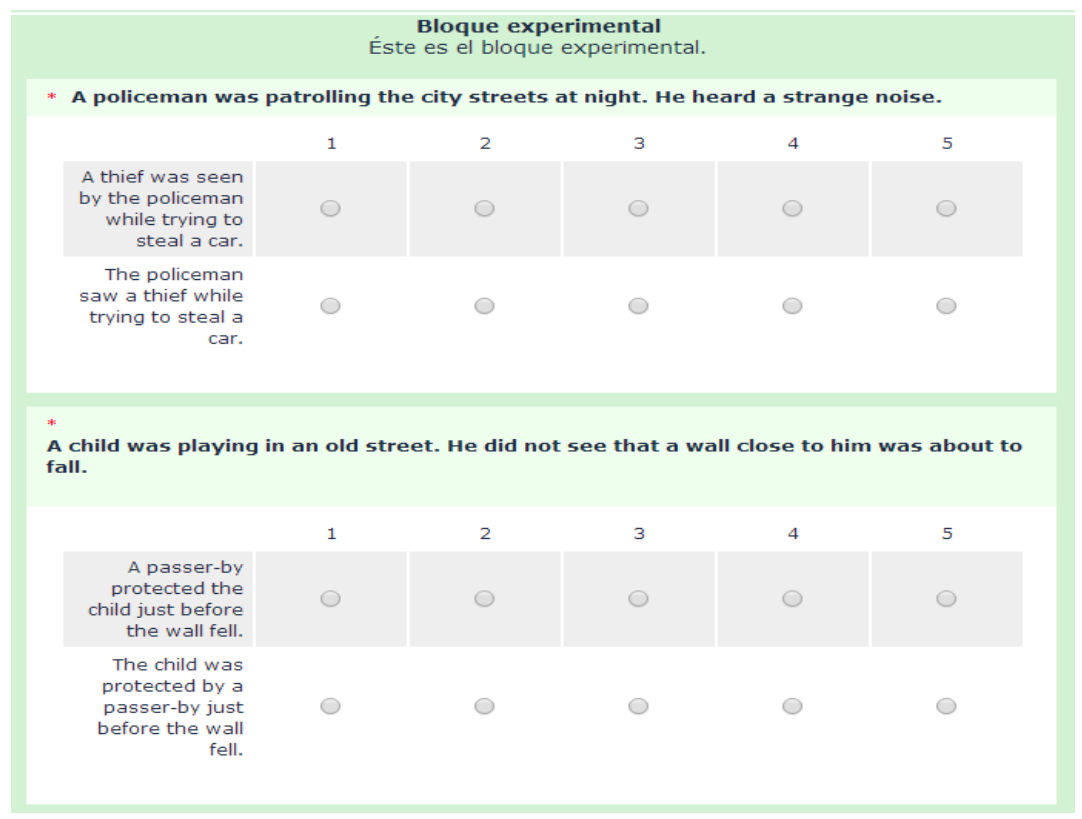

Figure 6. Off-line task questionnaire

The off-line method used in this study will be a Contextualised Paired Acceptability Judgement Task, which consists of a context immediately followed by a pair of sentences, both to be judged on their adequacy and naturalness according to the previous context. As these sentences are presented both at the same time, unlike in the on-line task, they represent two possible options for one context. One of them is in the passive and the other in the active; both sentences are grammatically correct, but only one of them is pragmatically felicitous (50\% of the subjects passive, other $50 \%$ active).

This time, however, only two versions of the experiment were created. Crucially, whereas in the on-line experiment subjects went through all the four possible conditions (agent1, \#agent2, \#patient3, patient4) separately, the contrast in the off-line task is between passive and active sentences, as such, each subject will see two sentences for every context, which reduces the versions needed to half. As such, in version 1, subjects will see patient contexts for verbs 1-12 and agent contexts for verbs 13-24, plus fillers (which remain the same in every version); and for version two vice versa: 
V01: Agent contexts: $\checkmark$ sentence 1- Active sentence Agent contexts: \#sentence 2- Passive sentence verbs 1-12 Patient contexts: \#sentence 3- Active sentence Patient contexts: $\checkmark$ sentence 4- Passive sentence $\}$ verbs 13-24

V02: Patient contexts: \#sentence 3- Active sentence Patient contexts: $\checkmark$ sentence 4 - Passive sentence Agent contexts: $\checkmark$ sentence $1-$ Active sentence Agent contexts: \#sentence 2- Passive sentence

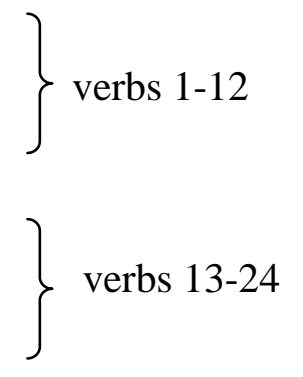

As mentioned above, there is no need for verification sentences as it is not necessary to ensure that the participants are reading comprehensively because they have all the time they need to process these stimuli and can make use of their metalinguistic knowledge as this is not a real-time processing task. 


\subsection{Procedure}

\subsubsection{Subject sample selection}

The sample used in this experiment is twofold: on the one hand, a group of 12 Spanish L2 English learners was selected taking into special consideration the requirements of the IH that all of them had near-native proficiency levels. On the other hand, 12 native speakers of English were selected as control group.

Before the tasks, all learner participants completed a Quick Placement Oxford Test to establish their proficiency level. This task took about ten minutes and only those participants with near-native scores were selected (cf. Table 10 ). Once their proficiency levels were tested, out of the 18 people tested, 12 were selected according to their proficiency level (C2, that is, over 53/60 in QPT). There are two participants whose level is borderline C2 (52/60 and 51/60) who were also included in the experiment, mainly due to subject shortage issues. ${ }^{2}$

\begin{tabular}{|c|c|c|c|}
\hline Subject & Initials & $\begin{array}{c}\text { QTP } \\
\text { result }\end{array}$ & Proficiency level \\
\hline 1 & PLO & $58 / 60$ & $\mathrm{C} 2$ \\
\hline 2 & MRR & $57 / 60$ & $\mathrm{C} 2$ \\
\hline 3 & EGZ & $56 / 60$ & $\mathrm{C} 2$ \\
\hline 4 & TSR & $55 / 60$ & $\mathrm{C} 2$ \\
\hline 5 & MLGP & $57 / 60$ & $\mathrm{C} 2$ \\
\hline 6 & MVR & $55 / 60$ & $\mathrm{C} 2$ \\
\hline 7 & NALI & $56 / 60$ & $\mathrm{C} 2$ \\
\hline 8 & EJP & $55 / 60$ & $\mathrm{C} 2$ \\
\hline 9 & ACV & $52 / 60$ & $\mathrm{C} 1$ \\
\hline 10 & CMO & $55 / 60$ & $\mathrm{C} 2$ \\
\hline 11 & CCR & $55 / 60$ & $\mathrm{C} 2$ \\
\hline 12 & AJGG & $51 / 60$ & $\mathrm{C} 1$ \\
\hline
\end{tabular}

Table 10. Learners' proficiency table

\footnotetext{
${ }^{2}$ Participants has been chosen in terms of their availability in order to be able to complete the experiment within the established academic deadline. It must also be considered that the present dissertation is but a preliminary study.
} 
Those learners who asked about their result in the QPT were informed of their performance, but this practice was disencouraged as it usually put them in a situation of stress, and presented the experiment as some kind of test, which they were told from the very beginning it was not.

\subsubsection{On-line task procedure}

Once the QPT was completed, all learners were shown a glossary. It consisted of three lists containing all the nouns, adjectives and verbs used in the elaboration of the experiments (see Appendix V). They read it through and made comments on any new words. Only one subject pointed out an unknown element as it was a requirement of the experimental design that the lexicon used was common knowledge.

Right after this they were administered the on-line task in a controlled environment using the same laptop device (Asus A735). They were carefully explained what they would encounter in the experiment and what they were expected to do.

Subsequently they gave their consent to participate in the experiment through a consent form and read the instructions. After any further doubts were cleared, they proceeded to begin the experiment.

Each trial they were presented had the following sequence (cf. Figure 7): (i) After a warning signal that the experiment had begun, participants saw a full context in a single screen and read it carefully, (ii) they then pressed the space bar to continue to the next part of the stimulus which activated a warning sign $(250 \mathrm{~ms})$ that they were doing so and a fixation dot to direct their eyes to the information they would see next, (iii) after a $200 \mathrm{~ms}$ interval they were presented with the first segment (s1) of the probe sentence, and as they kept pressing repeatedly the space bar they saw each of the following segments of the probe (s2, s3 \& s4) separately and on its own in a single screen; (iv) once again, the warning signal $(250 \mathrm{~ms})$ cue the appearance of the verification sentence after a $200 \mathrm{~ms}$ interval. Here subjects had to decide whether the statement was true or false depending on the previous information they had read, for this they had to press the key tagged YES ("n") or NO ("m"); (v) if they chose wrong, a feedback signal $(290 \mathrm{~ms})$ would tell them so. After a $200 \mathrm{~ms}$ interval with a grey square on a white screen, another warning signal preceded the following context, and so on. 


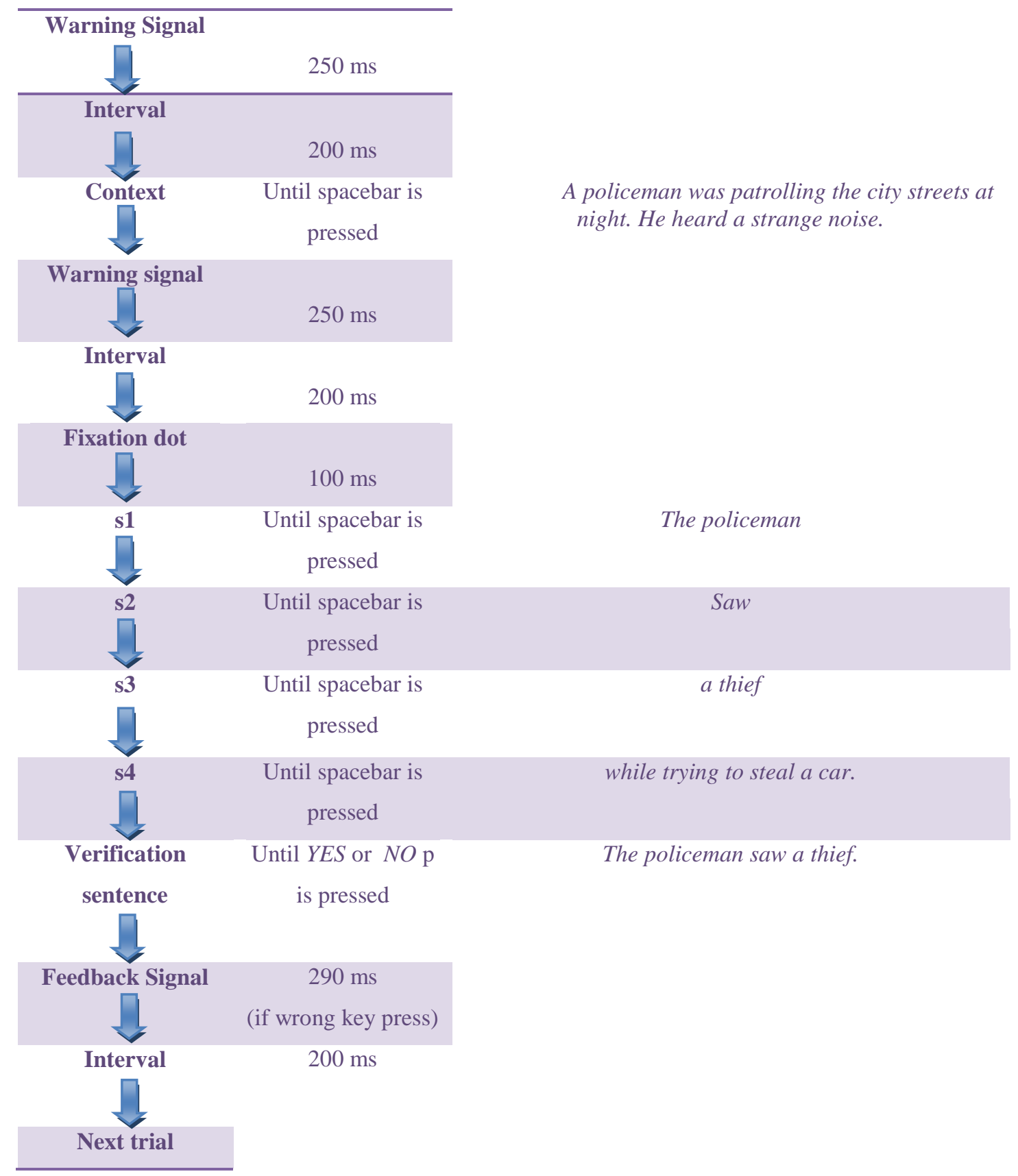

Figure 7. On-line experiment structure

Although none of the subjects has a visual impairment, some of them complained that the font used was too small. The zoom of the screen was increased to $120 \%$ to solve this problem. Also, a fixation dot was implemented in the interval between the context and the s1 of its probe sentence to guide the participants' sight. 
The technique used for the on-line task was a Self-paced Reading (SPR) task, where the sentence was presented phrase by phrase by pressing a button progressively. Each button press was recorded by the OpenSesame software and, thus, provided data about the participants' RTs.

OpenSesame contains a utility that allows to export the data gathered into Excel format which facilitated its future statistical analysis. For a complete table of all the participants see Appendix IV.

\subsubsection{Off-line task procedure}

This task has always been presented in second place, after the on-line task, as it is not a processing task, but an off-line knowledge task. As such, previous knowledge of the stimuli, that is, to have read them before, could have affected the results of the on-line task, but has no effect in the off-line.

First of all learners were explained what they would encounter in the off-line task and what they were expected to do. They subsequently filled in a form about their biodata (initials, gender, age) and L1; after they read the instructions and any further doubts were solved, they proceeded to start the experiment.

The off-line experiment uses the same set of stimuli as the on-line, and has the same general structure. That is, subjects would first see practice block to get acquainted with the experiment and minimise anxiety, to continue on to experimental block.

In these blocks they saw a context followed immediately below by two probe sentences, one in the passive, the other in the active; one of them is informationally incongruent. It is important to point out that they were showed the whole stimuli at once.

Learners were asked to rate each probe sentence on a 5-points Likert scale, indicating which sentence they found more natural/adequate ( 5 maximum) and which they found less natural/adequate $(1$ minimum $)$. In short, this task measures an acceptability response to a given stimulus (i.e., sentence). 
Nevertheless, it is known that optionality is always present in learners, no matter their proficiency level, and expect to maybe find that they have rated congruent and incongruent sentences similarly whether positively or negatively.

As mentioned in the previous section one of the main differences is that, in the off-line task, subjects are not presented a verification sentence. 


\subsection{Experimental design and data analysis}

Considering the experimental design, an Analysis of Variance (ANOVA henceforward) was passed to the data in this study in which subjects were used as the random factor in a mixed factorial design whose structure was $2 \times(2 \times 2)$ for the on-line task and a $(2 \times 2)$ for the off-line; these consisted of three independent variables. The first variable to be considered is "participant type", that is, advanced/near-native L2 English learner or native speaker of English. This is, therefore, a two-level between-groups factor carried out via participant selection.

The two remaining variables have to do with the characteristics of the sentences processed by the participants, this is, they are within-groups factors. The second variable, namely "sentence type", consists, once again of two levels: active/passive. Finally, the third variable depends on the "type of analysis" carried out. In some subjects, it takes into account the informational congruence of sentences depending on their previous context (two-level: congruent/incongruent); in other subjects it considers the "informational status" (two-level: given/new) of both patient and agent entities in the different sentences.

ANOVAs for Item analysis have also been carried out, taking the verb of each sentence as the random factor for the analysis all carried out, once again, in a withinitem factorial design $2 \times(2 \times 2)$ for the online and a $(2 \times 2)$ design for the off-line. Although the factors above mentioned remained the same, "participant type" must be considered as a within-item factor due to the fact that every verb has been processed both by learners and natives.

The rest of variables are considered just in the same way as in the previous subject analysis (See Appendix I for ANOVA entry data).

Considering the dependent variables, for the present analysis, the measure "processing rate" has been used as DV. This measure is a derivation from the direct output obtained by means of the RT. The dependent variable "RT rate" is the most adequate as it allows a better comparison of the results of both natives and learners, because it analyses the proportion of time used during the processing regardless of its total time lapse. 
As such, the aim is to reduce or control the possible effect of the age gap between both types of participants (natives' mean age: 76; learners' mean age: 23 ). ${ }^{3}$

Some of the data show that aging affects RT. In fact, across cognitive aging literature, "four major theories are common adduced to explain differences in cognitive performance between younger and older adults (Park, 2012): (i) slowed processing speed, (ii) shrinking working memory, (iii) inhibitory deficits, and (iv) declining sensory function." (Schrauf, 2008: 115). All in all, a generalised, although increasing, deterioration in language abilities in older ages gas been observed across languages.

In fact, the data presented here indicate that, in general, native speakers are slower reading sentences in their own mother tongue than learners of L2 English (cf. Table 11).

\begin{tabular}{||c||c|c|c|c||}
\hline Sentence type & $\begin{array}{c}\text { Active } \\
\text { congruent } \\
\text { (sentence 1) }\end{array}$ & $\begin{array}{c}\text { Passive } \\
\text { congruent } \\
\text { (sentence 2) }\end{array}$ & $\begin{array}{c}\text { Active } \\
\text { incongruent } \\
\text { (code3) }\end{array}$ & $\begin{array}{c}\text { Passive } \\
\text { incongruent } \\
\text { (Code4) }\end{array}$ \\
\hline \hline Learners & 4120,5 & 4290,7 & 4162,1 & 4301,8 \\
\hline Natives & 4306,9 & 4547,1 & 4421,1 & 4627,5 \\
\hline
\end{tabular}

Table 11. RT means in all contexts

As mentioned before, each subject has read all twenty-four experimental sentences presented progressively in four separate segments. Therefore, for each of the sentences, four reading measures (one for each segment) have been gathered, as can be seen in Table 11.

However, the most relevant information is contained in the first three segments, and it is not necessary to read until the very end of the sentences to extract both the informational congruence and the informational status of the entities of the previous context.

\footnotetext{
${ }^{3}$ This sample of participants has been chosen in terms of their availability in order to be able to complete the experiment within the established academic deadline. It must also be considered that the present work is a preliminary study.
} 
Therefore, the DV RT rate is the coefficient obtained from dividing the RT in each critical segment (s1 and s3, as they contain Entity1 and Entity2), between the total RT of these three segments. Thus, the calculations provide the proportion of time dedicated to the processing of each relevant segment in each of the four experimental conditions specifically designed for a subsequent statistical analysis and interpretation.

Even though RT rate is not sensitive to the absolute RT for the first three segments $(\mathrm{s} 1+\mathrm{s} 2+\mathrm{s} 3)$, it is indeed sensitive to the RT employed in each of its individual elements.

This fact calls for two different considerations: (i) that statistical contrasts must only be made among equivalent sentences, namely active/active, passive/passive. In Figure 2 it can be seen that the verb (s2) differs in length and structure depending on the voice (saw vs. was seen); (ii) this DV allows us to detect the existence, or not, of differences in the RT rate among active and passive sentences as well as congruent and incongruent sentences from a general point of view (A. Contrast), an agent point of view (B. Contrast) and a patient point of view (C. Contrast) (cf. Table 12).

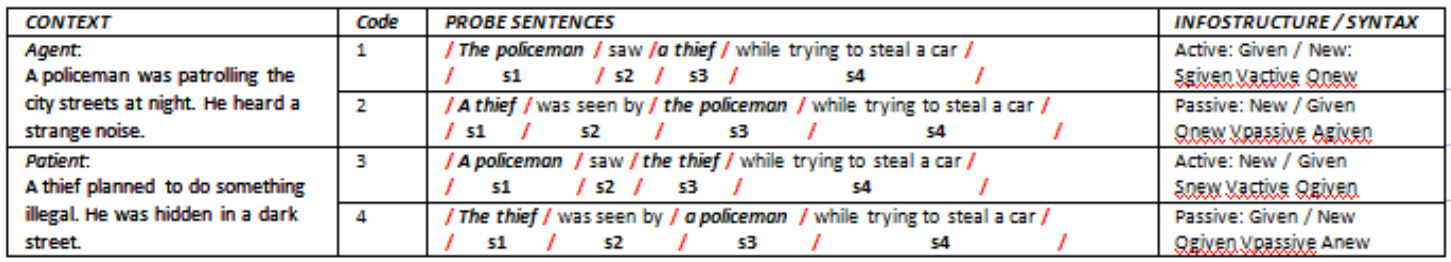

Table 12. Example showing the division in segments to justify necessity and to establish $R T$ rate as $D V$ 


\section{RESULTS}

\subsection{ON-LINE TASK RESULTS}

\subsubsection{Contrast of the processing of active and passive sentences, both congruent}

and incongruent, between natives and learners

Due to their previous contexts, both active and passive sentences are informationally congruent when they show given information in preverbal subject position, and new information in postverbal complement position. That is, they present the information structure given-new. Also due to their previous contexts, those informationally incongruent sentences present the exact opposite pattern, that is, \#new-given.

The statistical contrasts in this section measure the possible differences between learners and natives in the processing of active and passive sentences with opposing information structures (cf. Table 13).

\begin{tabular}{|c|c|c|c|}
\hline CONTEXT & Code & PROBE SENTENCES & INFOSTRUCTURE / SYNTAX \\
\hline \multirow[t]{2}{*}{$\begin{array}{l}\text { Agent: } \\
\text { a E1 } \mathrm{V}_{\text {pagt }}\end{array}$} & 1 & $\checkmark$ the $E 1_{\text {agent }} V$ a $E 2_{\text {patient }}$ while ... & $\begin{array}{l}\text { Active: } \checkmark \text { Given / New: } \\
\text { S }_{\text {given }} \mathrm{V}_{\text {active }} \mathrm{O}_{\text {oew }}\end{array}$ \\
\hline & 2 & $\#$ a $E 2_{\text {patient }} V_{\text {pas }}$ by the $E 1_{\text {agent }}$ while .... & $\begin{array}{l}\text { Passive:\# New/Given } \\
\mathrm{O}_{\text {gex }} \mathrm{V}_{\text {passixe }} \mathrm{A}_{\text {given }}\end{array}$ \\
\hline \multirow[t]{2}{*}{$\begin{array}{l}\text { Patient: } \\
\text { a E2 } \mathrm{V}_{\text {past }}\end{array}$} & 3 & \# a E1 agent $V$ the $E 2_{\text {patient }}$ while ... & $\begin{array}{l}\text { Active: \# New/Given } \\
\mathrm{S}_{\text {new }} \mathrm{V}_{\text {attive }} \mathrm{O}_{\text {given }}\end{array}$ \\
\hline & 4 & $\checkmark$ the $E 2_{\text {patient }} \mathrm{V}_{\text {pass }}$ by a $\mathrm{E} 1_{\text {agent }}$ while .... & $\begin{array}{l}\text { Passive: } \checkmark \text { Given / New } \\
\mathrm{O}_{\text {gixen }} V_{\text {passixes }} A_{\text {new }}\end{array}$ \\
\hline
\end{tabular}

Table 13. On -line task general contrasts

\subsubsection{1 [Contrast A1] Active Sentences: sentence1 vs. \#sentence 3.}

This contrast sheds light on the question of the observation of possible processing differences between learners and natives concerning congruent active sentences (sentence 1) vs. incongruent active sentences (sentence 3) (cf. Table 13).

ANOVA results show a main effect of factor "participant type", both in subject $\left(F(1,22)=8,202, p=0,009, \eta^{2}=0,373\right)$ and item analyses $\left(F(1,23)=13,3, p=0,001, \eta^{2}=\right.$ $0.578)$. However, no effect of congruency is shown in its subject analysis $(F(1,22)=$ $1,159, p=0,293)$, although results are almost significant in its item analysis $(F(1,23)=$ $\left.4,22, p=0,051, \eta^{2}=0.184\right)$. 
Regarding interaction, it was non-significant for subject analysis and for item analysis $(F(1,22)=0,565, p=0,46 ; \mathrm{y}(F(1,23)=1,55, p=0,225$, respectively $)$. For a graphic representation of the results, see Figure 8.

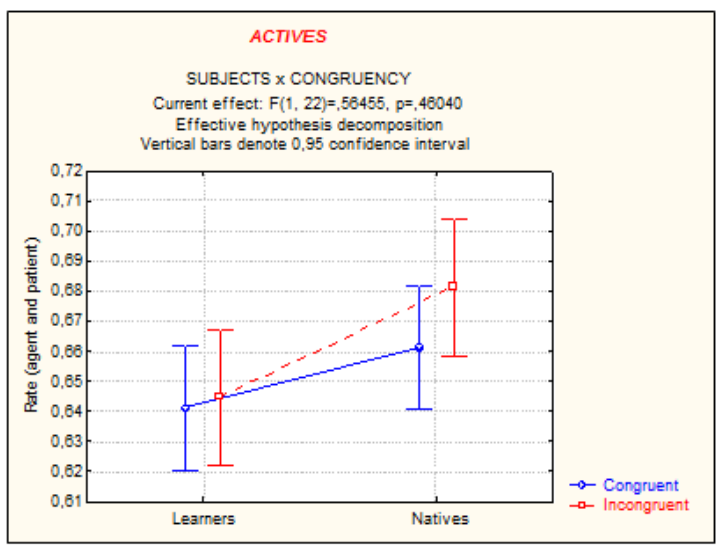

Figure 8. A Contrast Actives

Comparisons made indicate that there are no significant differences between learners and natives in congruent active sentences, neither in subject analysis $(F(1,22)=2,076$, $p=0,1639)$ or item analysis $(F(1,23)=2,348, p=0,139)$. The opposite can be said of incongruent sentences where there are significant differences in both subject analysis $\left(F(1,22)=5,598, p=0,027, \eta^{2}=0,254\right)$ and item analysis $\left(F(1,23)=10,081, \mathrm{p}=0,004, \eta^{2}=\right.$ $0.438)$.

Finally, regarding congruency, differences are non-significant within the learner sample, both in subject $(F(1,22)=0,052, p=0,820)$, and in item analysis $(F(1,23)=$ $0,265, \mathrm{p}=0,611)$. The native sample, nevertheless. presents no differences in subject analysis $(F(1,22)=1,670, \mathrm{p}=0,209)$ and significant differences in item analysis $\left(F(1,23)=7,331, \mathrm{p}=0,012, \eta^{2}=0.319\right)$, indicating that natives devote a proportionally longer amount of time to processing incongruent active sentences than congruent active sentences. 
In general, when analysed using RT rate, results show the following pattern:

1. There are no differences between natives and learners when processing congruent active sentences (learners: $0.641=$ natives:0.661).

2. There are differences between learners and natives, being the natives' RT rates higher, when processing incongruent active sentences (learners: 0.645 < natives: $0.681)$.

3. Among learners, there are no processing differences between congruent and incongruent active sentences (congruent: 0.641 = incongruent: 0.645 ).

4. Among natives, there are processing differences between congruent and incongruent active sentences (congruent: $0.661<$ incongruent: 0.681 ).

Therefore, comparisons between-groups support the IH predictions that learners will exhibit deficits in their on-line processing, that is, their RT rates remain constant whether they are processing a congruent or incongruent sentence as they do not discriminate one from the other. Within-group comparisons further support this prediction: all learners show similar deficits, whereas all natives behave similarly in correctly discriminating between congruent from incongruent active sentences.

However, as pointed out previously, it is natives that employ a proportionally longer amount of time in processing incongruent active sentences.

\subsubsection{2 [Contrast A2] Passive Sentences: sentence4 vs. \#sentence2}

The target of this section is the same as the previous one, but the elements to be analysed will be congruent passive sentences (sentence 4) and incongruent passive sentences (sentence 2) (cf. Table 13).

ANOVA results show a main effect of "participant type factor" in item analysis $\left(F(1,23)=6,359 p=0,019, \eta^{2}=0.276\right)$ but not in subject analysis $(F(1,22)=1,078$, $p=0,31)$. Sentence congruency factor is non-significant both in subject $(F(1,22)=0,526$, $p=0,476)$ and item analysis $(F(1,23)=0.352, p=0,559)$. 
There is, however, an interaction between both factors in subject, $(F(1,22)=$ $\left.8,893, p=0,007, \eta^{2}=0.404\right)$ and item analyses $\left(F(1,23)=6,061, p=0,022, \eta^{2}=0.263\right)$ which indicates that natives and learners do not process congruent and incongruent passives equally. For a graphic representation of results, see Figure 9.

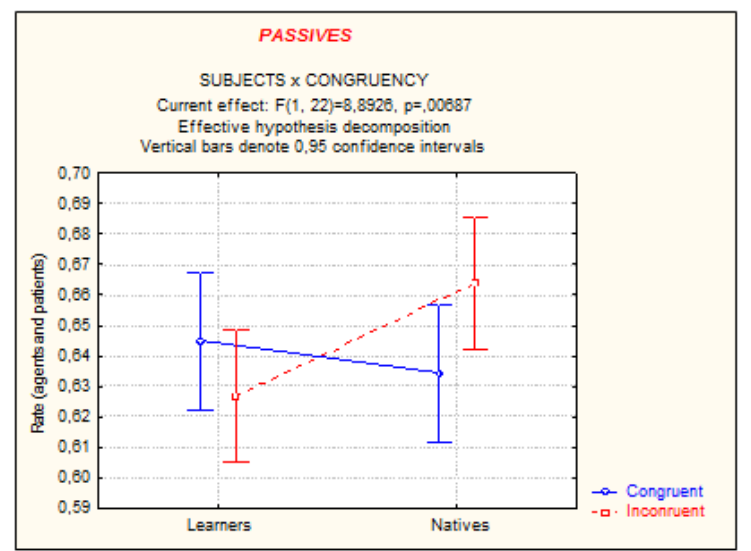

Figure 9. A Contrast Passives

Comparisons indicate that there are no differences between learners and natives when they process congruent passive sentences $(F(1,22)=0,472, p=0,498,(F(1,23)=0,026$, $\mathrm{p}=0,873$, subject and item analysis respectively). Nevertheless, there are differences when processing incongruent passive sentences in both subject, $(F(1,22)=6,211$, $\left.p=0,0207, \eta^{2}=0.282\right)$ and item analysis $\left(F(1,23)=8,722, p=0,007, \eta^{2}=0.379\right)$ which indicates that natives devote a proportionally longer amount of time to processing incongruent passive sentences when compared to learners.

Regarding congruency, there are no significant differences within the learners sample, neither in subject $(F(1,22)=2,546, p=0,125)$ nor in item analyses $(F(1,23)=$ $0,713, p=0,407)$. In the native sample, there are, however, differences both in subject $\left(F(1,22)=6,872, p=0,015, \eta^{2}=0.312\right)$ and item analyses $\left(F(1,23)=5,810, p=0,024, \eta^{2}=\right.$ 0.253), which means that natives take longer to process incongruent passives, as mentioned above. 
In general, when analysed using RT rate, results show the following pattern:

1. There are no differences between natives and learners when processing congruent passive sentences (learners: $0.645=$ natives:0.634).

2. There are differences between learners and natives, being the natives' RT rates higher, when processing incongruent passive sentences (learners: 0.627 < natives: $0.664)$.

3. Among learners, there are no processing differences between congruent and incongruent passive sentences (congruent: $0.645=$ incongruent: 0.627 ).

4. Among natives, there are processing differences between congruent and incongruent passive sentences (congruent: 0.634 < incongruent: 0.664 ).

Therefore, comparisons between-groups support the IH predictions that learners will exhibit deficits in their on-line processing, that is, their RT rates remain constant whether they are processing a congruent or incongruent sentence as they do not discriminate one from the other. Within-group comparisons further support this prediction: all learners show similar deficits, whereas all natives behave similarly in correctly discriminating between congruent from incongruent active sentences.

However, as pointed out previously, it is natives that employ a proportionally longer amount of time in processing incongruent passive sentences.

\subsubsection{Contrast of the processing of agent entities given and new in active and passive sentences between natives and learners}

In active sentences agent entities are in preverbal position, segment 1, with the informational status of given when congruent (sentence 1) and new status when (sentence 3). In passives, however, agent entities go in postverbal position, segment 3. Their informational status is given for incongruents (sentence 2) and new for congruents (sentence 4). Thus, the statistical contrasts carried out in this section measure the existence, or lack thereof, of differences between learners and natives in the processing of agents entities with given or new status in active and passive sentences separately (see Appendix I for ANOVA entry data). 


\subsubsection{1 [Contrast B1] Active sentences: segment1 (E1: agent) vs. \#sentence 3}

This contrast sheds light on the question of the observation of possible processing differences between learners and natives when processing active sentences with different informational status given vs. new (cf. Table 13).

ANOVA results show a main effect of factor "participant type", both in subjects $\left(F(1,22)=4,313, \mathrm{p}=0,050, \eta^{2}=0.196\right)$ and item analysis $\left(F(1,23)=9,717, p=0,005, \eta^{2}=\right.$ 0.422). However, "informational status" factor is non-significant in subject analysis $(F(1,22)=1,165, p=0,293)$ and significant in item analysis $(F(1,23)=4,662, p=0,0042$, $\left.\eta^{2}=0.203\right)$.

Regarding interaction, it is non-significant for subjects analy1sis and for item analysis $\left(F(1,23)=8,533, p=0,008, \eta^{2}=0.371\right)$, but it is indeed in subject analysis $(F(1,22)=2,45, p=0,132)$. This indicates that the processing of given and new agent entities depends on the subject being a learner or a native speaker. For a graphical representation of results, see Figure 10 below:

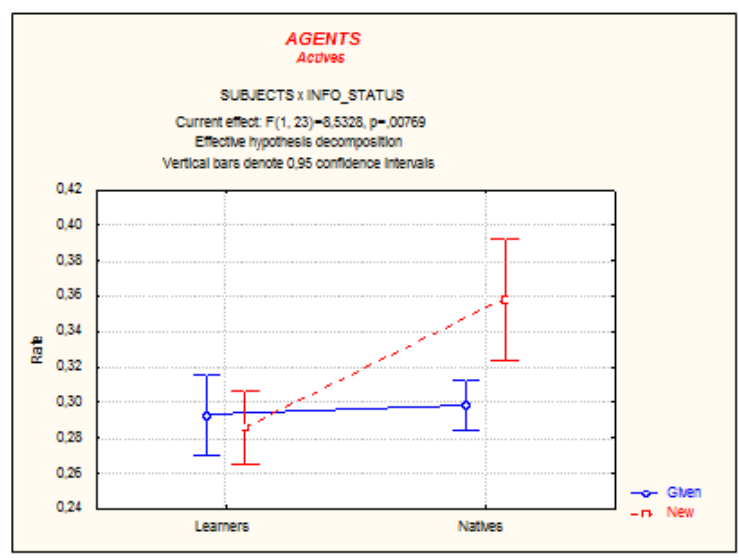

Figure 10. B Contrast Actives

Comparisons between natives and learners indicate that these samples show clear differences in the processing of given vs. new agent entities. Regarding given agent there no processing either differences between both types of participants or in the subject $(F(1,22)=0,110, p=0,742)$ and item analyses $(F(1,23)=0,153, p=0,699)$. However, when processing new agents differences do show up in the subject $(F(1,22)=$ 4,962, $\left.p=0,036, \eta^{2}=0.226\right)$ and item analyses $\left(F(1,23)=13,726, p=0,001, \eta^{2}=0.598\right)$, 
which indicates that natives devote a longer amount of time to the processing of these agents.

Regarding the information status of agent entities, differences are nonsignificant within the learner sample, both in the subject $(F(1,22)=0,117, p=0,734)$ and in the item analysis $(F(1,23)=0,656, \mathrm{p}=0,611)$. The native sample, however, presents near-significant differences in subject analysis $\left(F(1,22)=3,496, p=0,075, \eta^{2}=0.164\right)$ and highly significant ones in item analysis $\left(F(1,23)=11,525, p=0,002, \eta^{2}=0.501\right)$, all of which indicates, as above mentioned, that natives take longer to read new agents.

In general, when analysed using RT rate, results show the following pattern:

1. There are no significant differences between natives and learners in the processing of given agent entities (learners: $0.301=$ natives: 0.308 ).

2. There are clear differences between the processing of new agent entities by natives and learners, the former showing higher RT rates (learners: $0.292<$ natives: 0.356).

3. Within the learner sample there are no processing differences between new and given agent entities in active sentences (given: $0.308=$ new: 0.292 ).

4. Natives do show differences in the processing of given and new agent entities in active sentences (given: $0.308<$ new: 0.356 ).

Therefore, comparisons between-groups support the IH predictions that learners will exhibit deficits in their on-line processing, that is, their RT rates remain constant regardless of the information status of the entity they are processing as they do not discriminate new from given. Within-group comparisons further support this prediction: all learners show similar deficits, whereas all natives behave similarly in correctly discriminating between new and given agent entities in active sentences.

However, as pointed out previously, it is natives that employ a proportionally longer amount of time in processing new agent entities. 


\subsubsection{2 [Contrast B2] Passive sentences: segment3 (E1: agent) in \#sentence2 vs, sentence 4}

This contrast sheds light on the question of the observation of possible processing differences between learners and natives when processing passive sentences with different informational status given vs. new (cf. Table 13).

ANOVA results show no main effect of factor "participant type", neither in subject $(F(1,22)=2,627, p=0,119)$ nor in item analyses, although the latter is nearsignificant $\left(F(1,23)=3,898, p=0,06, \eta^{2}=0.169\right)$. "Informational status" factor is nonsignificant in subject analysis $(F(1,22)=0,758, p=0,393)$ and in item analysis $(F(1,23)=$ $2,615, p=0,119)$. No interaction is observed between both factors in subject $(F(1,22)=$ 2,648, $p=0,118)$ or item analyses $(F(1,23)=0,767, p=0,39)$. For a graphical representation of results, see Figure 11 below:

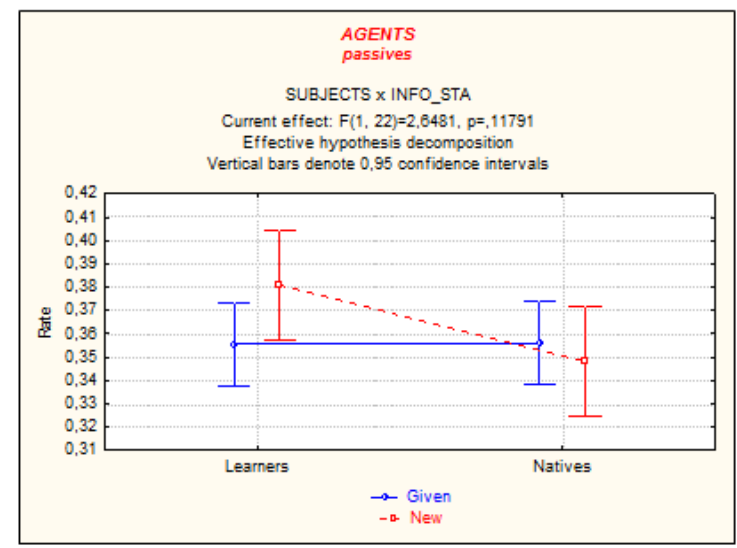

Figure 11. Contrast in Passives

Comparisons between learners and natives show that there are no processing given agent entities either in the subject $(F(1,22)=0,000, p=0,975)$, or item analyses $(F(1,23)=0,273, p=0,60)$. No differences are spotted in the processing of new agent entities, although the ones present are close to significance in both subject $(F(1,22)=$ 4,167, $\left.p=0,053, \eta^{2}=0.189\right)$ and item analyses $\left(F(1,23)=3,629, p=0,069, \eta^{2}=0.158\right)$, which indicates that learners tend to devote a longer amount of time to the processing of new agent entities. 
Regarding the information status factor of agent entities, there are no significant differences within the learner group, neither in subject analysis (though barely) $\left(F(1,22)=3,119, p=0,091, \eta^{2}=0.142\right)$, nor in item analysis $(F(1,23)=2,122, \mathrm{p}=0,159)$. Within the native sample no differences are shown in the subject $(F(1,22)=0,286$, $\mathrm{p}=0,597)$ or item analyses $(F(1,23)=0,410, p=0,528)$, which shows that natives devote proportionally the same amount of time to the processing of new and given agent entities.

In general, results obtained analysing RT rate or the proportion of time employed by natives and learners to the processing of new and given agent entities in passive sentences, show the following pattern:

1. There are no significant differences between natives and learners in the processing of given agent entities (learners: $0.356=$ natives: 0.356 ).

2. There is a tendency for natives to show higher RT rates than natives in the processing of new agent entities (learners: 0.381 > natives: 0.348 ).

3. There a near-significant processing differences between given and new agent entities in passive sentences within the learner sample given: $0.356=$ new: 0.381 ).

4. There are no differences at all, within the native sample, in the processing of given vs. new agent entities in passive sentences (given: $0.356=$ new: 0.348 ).

Results in this section do not conform to the IH's predictions as, in this subject, within-group comparisons reflect that it is learners that in fact discriminate between given and new agent entities (if only marginally), whereas natives show no such differentiation in passive sentences. 


\subsubsection{Contrast of the processing of patient entities given and new in active and passive sentences between learners and natives}

In active sentences patient entities are in postverbal position, segment 1 , with the informational status of given in incongruent actives (sentence 3) and status new in congruent actives (sentence 1). In passives, however, patient entities go in preverbal position, segment 1 . Their informational status is given for congruents (sentence 4) and new for incongruents (sentence 2). Thus, statistical contrasts carried out in this section measure the existence, or lack thereof, of differences between learners and natives in the processing of patients with given or new status in active and passive sentences separately (see Appendix I for ANOVA entry data).

\subsubsection{1 [Contrast C1] Active sentences: segment3 (E2: patient) in \#sentence3 vs, sentence 1}

This contrast sheds light on the question of the observation of possible differences between learners and natives when processing patient entities in active sentences with different information status (cf. Table 13).

ANOVA results show no main effect of factor "participant type", neither in subject $(F(1,22)=0,507, p=0,484)$ nor in item analyses $(F(1,23)=1,783, p=0,195)$. "Informational status" factor is non-significant both in subject analysis $(F(1,22)=2,8$, $p=0,108)$ and in item analysis $(F(1,23)=0,666, p=0,423$,$) No interaction is observed$ between both factors in subject $(F(1,22)=2,648, p=0,118)$ or item analyses $(F(1,23)=$ $8,779, p=0,007, \eta^{2}=0.382$ ). For a graphical representation of results, see Figure 12 below: 


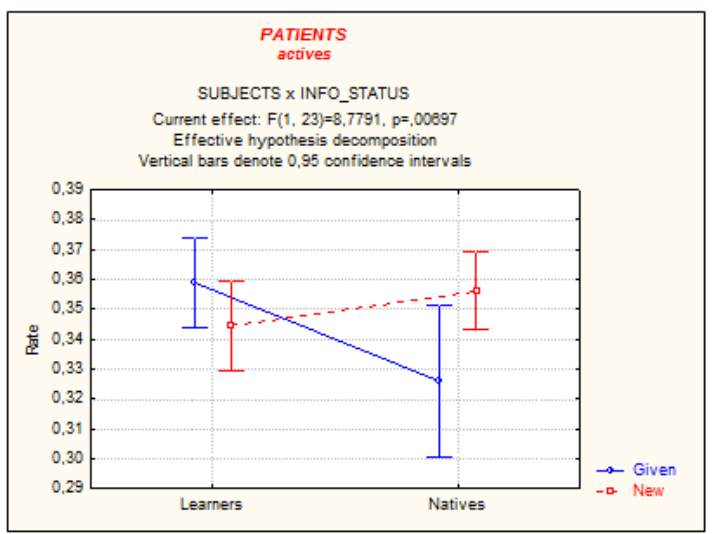

Figure 12. C Contrast Actives 1

Comparisons between learners and natives show a clear difference in the processing of given vs. new patients. There is no processing differences for given patient entities in the subject analysis $(F(1,22)=2,061, p=0,165)$ but differences are spotted in the item analysis $\left(F(1,23)=6,165, p=0,020, \eta^{2}=0.268\right)$. No differences are shown in the processing of new patient entities, in either subject $(F(1,22)=1,381, \mathrm{p}=0,252)$ or item analyses $(F(1,23)=2,136, p=0,157)$, which indicates that learners tend to devote a longer amount of time to the processing of new agents.

Regarding the "information status" factor of patients, there are no significant differences within the learner group, neither in subject analysis $(F(1,22)=0,520$, $p=0,478)$, nor in item analysis $(F(1,23)=1,745, p=0,199)$. Within the native sample, though no differences are shown in the subject $(F(1,22)=2,707, p=0,114)$, there are significant ones in the item analysis $\left(F(1,23)=5,017, p=0,035, \eta^{2}=0.218\right)$, which shows that natives devote proportionally a longer amount of time to the processing of new patient entities than given ones. 
In general, the results obtained analysing RT rate or the proportion of time employed by natives and learners to the processing of new and given patient entities in active sentences, show the following pattern:

1. There are significant differences between natives and learners in the processing of given patient entities in active sentences (learners: 0.359 > natives: 0.326).

2. There are no significant differences between natives and learners in the processing of new patient entities in active sentences (learners: 0.344 = natives: 0.356 ).

3. There a no significant processing differences between given and new patient entities in active sentences within the learner sample (given: $0.359=$ new: 0.344).

4. There are processing differences, within the native sample, in the processing of given vs. new patient entities in active sentences (given: $0.326=$ new: 0.356 ).

Therefore, comparisons between-groups support the IH predictions that learners will exhibit deficits in their on-line processing, that is, their RT rates remain constant regardless of the information status of the entity they are processing as they do not discriminate new from given. Within-group comparisons further support this prediction: all learners show similar deficits, whereas all natives behave similarly in correctly discriminating between new and given patient entities in active sentences.

Curiously enough, as pointed out previously, natives that employ a proportionally longer amount of time in processing new patient entities which happen to appear in congruent contexts in active sentences. 


\subsubsection{2 [Contrast C2] Passive sentences: segment1 (E2:patient) in sentence4 vs. \#sentence 2}

This contrast sheds light on the question of the observation of possible differences between learners and natives when processing patient entities in passive sentences with different information status (cf. Table 13)

ANOVA results show no main effect of factor "participant type" in subject analysis (though barely) $\left(F(1,22)=4,048, p=0,057, \eta^{2}=0.184\right)$ but a significant difference in item analysis, $\left(F(1,23)=11,9, p=0,002, \eta^{2}=0.517\right)$. "Informational status" factor is non-significant in subject analysis $(F(1,22)=1,089, \mathrm{p}=0,308)$ but, once again, it is significant in item analysis, $\left(F(1,23)=4,7, p=0,041, \eta^{2}=0.204\right)$. No interaction is observed between both factors in subject $(F(1,22)=0,282, p=0,601)$, or item analyses $(F(1,23)=1,64, p=0,213)$. For a graphical representation of results, see Figure 13 below:

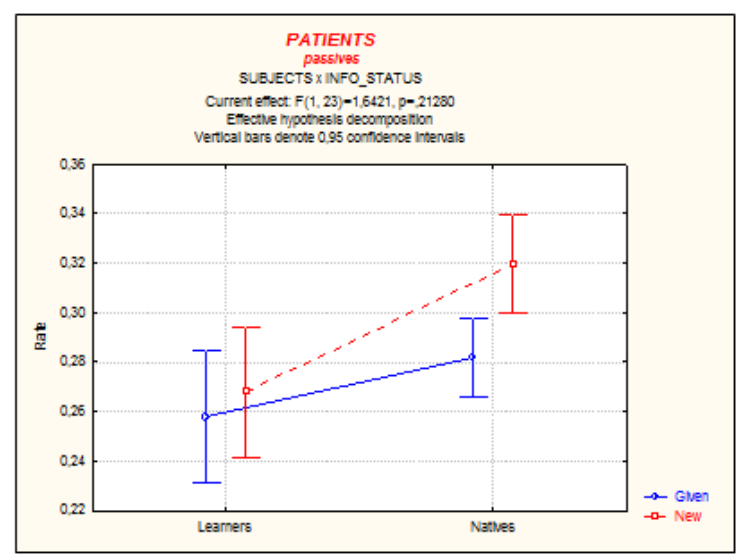

Figure 13. C Contrast Passives 
Comparisons between learners and natives show that there are no differences in the processing of given patient entities either in the subject $(F(1,22)=0,854, p=0,365)$ or item analyses $(F(1,23)=2,068, p=0,164)$. No differences are spotted in the processing of new patient entities, although the ones present are close to significance in both $\operatorname{subject}\left(F(1,22)=5,353, p=0,030, \eta^{2}=0.243\right)$ and item analyses $(F(1,23)=12,902$, $p=0,002, \eta^{2}=0.561$, which indicates that natives tend to devote a longer amount of time to the processing of new patient entities.

Regarding the information status factor of patient entities, there are no significant differences within the learner group, neither in subject analysis $(F(1,22)=$ $0,131, p=0,720)$, nor in item analysis $(F(1,23)=0,254, p=0,620)$. Within the native sample, although no differences are shown in the subject analysis $F(1,22)=1,239$, $p=0,278)$ some are present in the item analysis, $\left(F(1,23)=12,990, p=0,001, \eta^{2}=0.565\right)$ which shows that natives devote proportionally the more amount time to the processing of new patient entities.

In general, the results obtained analysing RT rate or the proportion of time employed by natives and learners to the processing of new and given patient entities in passive sentences show the following pattern:

1. There are significant differences between natives and learners in the processing of given patient entities in passive sentences (learners: $0.258>$ natives: 0.282 ).

2. There are clearly significant differences between natives and learners in the processing of new patient entities in passive sentences (learners: 0.268 = natives: $0.320)$.

3. There no significant processing differences between given and new patient entities in passive sentences within the learner sample (given: $0.258=$ new: 0.268 ).

4. There are significant processing differences, within the native sample, in the processing of given vs. new patient entities in passive sentences (given: $0.282=$ new: 0.320). 
Therefore, comparisons between-groups support the IH predictions that learners will exhibit deficits in their on-line processing, that is, their RT rates remain constant regardless of the information status of the entity they are processing as they do not discriminate new from given. Within-group comparisons further support this prediction: all learners show similar deficits, whereas all natives behave similarly in correctly discriminating between new and given patient entities in active sentences.

Once again, natives employ a proportionally longer amount of time in processing new patient entities which happen to appear in congruent contexts in passive sentences.

\subsubsection{Synthesis of on-line results}

The data analysis carried out in this study is complex and, therefore, its presentation has had a mainly statistical focus. The purpose of this section is to provide a general view of the results considering the task performed by the subjects and which has been previously described.

The participants, learners and natives, have (i) read short previous context, (ii) they have progressively read, segment by segment, a probe sentence related to this previous context, and (iii) they have answered if a verification statement was correct or incorrect (in order to test that they had been reading comprehensively).

The probe sentence was either informationally congruent or incongruent with the previous context and was formulated in either the passive or the active voice. The software used recorded the RT of each segment of this probe sentence, thus gathering an on-line measure of one of these segments, agents/patients, given/new.

Regarding the predictions made in this study, they conform to the assumption by the IH that: advanced and near-native learners will experience processing deficits at the syntax-discourse interface, which will be obvious in the on-line task as they need to integrate simultaneously syntactic and discursive information. By contrast, no deficits are predicted in the off-line task as they can make use of both their linguistic and metalinguistic knowledge. 
In particular, in the on-line task, learners' results are expected to be differentiated from those of the natives in the sense that they will reflect deficits in processing. As such, the prediction is that learners will show higher RT rates than natives in all contexts, but primarily, in incongruent ones regardless of the entity processed. That is, given the same prior context, participants prefer obeying information structure than violating it, independently of whether the compliance appears in an active or passive sentence (for more detailed information see Method section).

Chart 1 for active sentences and Chart 2 for passive sentences show the average $R T$ rate of each one of the segments of each participant, be it native or learner, showing as well if the contrasts between these averages are significant and their size effect $\left(\eta^{2}\right)$, as has been indicated in previous sections. The segments are presented in the same order as they were shown in the probe sentences.

\begin{tabular}{|c|c|c|c|c|c|c|c|c|c|}
\hline \multirow[b]{2}{*}{$\begin{array}{c}\text { Sentence's } \\
\text { phrases }\end{array}$} & \multicolumn{3}{|c|}{ Congruent actives } & \multicolumn{3}{|c|}{ Incongruent actives } & \multicolumn{3}{|c|}{ Significance within } \\
\hline & $\begin{array}{c}(1) \\
\text { Agent } \\
\text { Given }\end{array}$ & $\begin{array}{c}\text { (2) } \\
\text { Patient } \\
\text { New }\end{array}$ & $\begin{array}{c}\text { (3) } \\
\text { Agent } \\
\text { and } \\
\text { patient }\end{array}$ & $\begin{array}{c}(4) \\
\text { Agent } \\
\text { New }\end{array}$ & $\begin{array}{c}(5) \\
\text { Patient } \\
\text { given }\end{array}$ & $\begin{array}{c}(6) \\
\text { Agent and } \\
\text { patient }\end{array}$ & $(1)-(4)$ & $(2)-(5)$ & (3)-(6) \\
\hline Learners & 0.301 & 0.344 & 0.641 & 0.292 & 0.359 & 0.645 & NS & NS & NS \\
\hline Natives & 0.308 & 0.356 & 0.661 & 0.356 & 0.326 & 0.681 & $\begin{array}{c}S \\
\left(\eta^{2}=0,501\right)\end{array}$ & $\begin{array}{c}S \\
\left(\eta^{2}=0,218\right)\end{array}$ & $\begin{array}{c}S \\
\left(n^{2}=0,319\right)\end{array}$ \\
\hline $\begin{array}{l}\text { Significance } \\
\text { between }\end{array}$ & NS & NS & NS & $\begin{array}{c}S \\
\left(\eta^{2}=0,598\right)\end{array}$ & $\begin{array}{c}S \\
\left(\eta^{2}=0,268\right)\end{array}$ & $\begin{array}{c}S \\
\left(\eta^{2}=0,438\right)\end{array}$ & & & \\
\hline
\end{tabular}

Chart 1. RT rate average for actives plus significance and size effect

\begin{tabular}{|c|c|c|c|c|c|c|c|c|c|}
\hline \multirow[b]{2}{*}{$\begin{array}{l}\text { Sentence's } \\
\text { phrases }\end{array}$} & \multicolumn{3}{|c|}{ Congruent passives } & \multicolumn{3}{|c|}{ Incongruent passives } & \multicolumn{3}{|c|}{ Significance within } \\
\hline & $\begin{array}{c}\text { (1) } \\
\text { Patient } \\
\text { Given }\end{array}$ & $\begin{array}{c}(2) \\
\text { Agent } \\
\text { New }\end{array}$ & $\begin{array}{c}\text { (3) } \\
\text { Patient } \\
\text { and } \\
\text { Agent }\end{array}$ & $\begin{array}{c}\text { (4) } \\
\text { Patient } \\
\text { New }\end{array}$ & $\begin{array}{c}\text { (5) } \\
\text { Agent } \\
\text { Given }\end{array}$ & $\begin{array}{c}(6) \\
\text { Patient } \\
\text { and Agent }\end{array}$ & $(1)-(4)$ & $\begin{array}{l}(2)- \\
(5)\end{array}$ & $(3)-(6)$ \\
\hline Learners & 0.258 & 0.381 & 0.645 & 0.268 & 0.356 & 0.627 & N.S & NS & NS \\
\hline Natives & 0.282 & 0.348 & 0.634 & 0.320 & 0.356 & 0.664 & $\begin{array}{c}S \\
\left(\eta^{2}=0,565\right)\end{array}$ & NS & $\begin{array}{c}S \\
\left(\eta^{2}=0,312\right)\end{array}$ \\
\hline $\begin{array}{l}\text { Significance } \\
\text { between }\end{array}$ & NS & NS & NS & $\begin{array}{c}S \\
\left(n^{2}=0,561\right)\end{array}$ & NS & $\begin{array}{c}S \\
\left(n^{2}=0,379\right)\end{array}$ & & & \\
\hline
\end{tabular}

Chart 2. RT rate average for passive sentences plus significance and size effect 
As it can be observed in the data there is an emerging differential pattern between learners and natives in both sentence types. Both in active and passive sentence processing, learners exhibit a deficit: they do not discriminate when comparing patient and agent entities, along with their information statuses, in congruent vs. incongruent sentences; whereas natives do show processing differences in their RT rates.

This result shows that differences between natives and learners can be primarily seen in those elements belonging to incongruent active and passive sentences. Therefore, it supports the IH prediction that advanced/near-native learners will only show processing deficits, as compared to native speakers, only in on-line tasks. 


\subsection{OFF-LINE TASK RESULTS}

\subsection{1 [Contrast D1] Contrast in agent contexts: agent1 vs. \#agent2}

Given the design of the off-line task (cf. Table 14), there is a (2x2) design, that is, type of group depending on language (L1/L2) x congruence (given-new/\#new-given) in agent contexts. The DV is the rating score given by the subject on a 5-points Likert scale.

\begin{tabular}{|c|c|c|}
\hline CONTEXT & PROBE SENTENCES & $\begin{array}{c}\text { INFOSTRUCTURE / } \\
\text { SYNTAX }\end{array}$ \\
\hline \multirow[t]{2}{*}{$\begin{array}{l}\text { Agent: } \\
\text { a E1 } V_{\text {past }}\end{array}$} & $\checkmark(1)$ the $E 1_{\text {agent }} V$ a $E 2_{\text {patient }}$ Adjunct ... & $\begin{array}{l}\text { Active: } \checkmark \text { Given / New: } \\
\mathrm{S}_{\text {given }} \mathrm{V}_{\text {active }} \mathrm{O}_{\text {new }}\end{array}$ \\
\hline & $\begin{array}{l}\# \quad \text { (2) a } E 2_{\text {patient }} \\
\text { Adjunct } \ldots\end{array}$ & $\begin{array}{l}\text { Passive: \# New / Given } \\
\mathrm{O}_{\text {new }} \mathrm{V}_{\text {passive }} \mathrm{A}_{\text {given }}\end{array}$ \\
\hline
\end{tabular}

Table 14. Off-line task design template for agent contexts

First of all, a preliminary visual inspection of the data is provided in order to asses, if broadly, the results obtained. This chart contains the descriptive statistics for the results to be discussed below (cf. Chart 3):

Descriptive Statistics

\begin{tabular}{|ll|l|l|l|}
\hline & Group & Mean & $\begin{array}{l}\text { Std. } \\
\text { Deviation }\end{array}$ & $\mathrm{N}$ \\
\hline agent1 & Natives & 4,17083 &, 726359 & 12 \\
& Learners & 4,50000 &, 472095 & 12 \\
& Total & 4,35628 &, 628336 & 24 \\
\hline \#agent2 & Natives & 3,33217 &, 915866 & 12 \\
& Learners & 3,03846 &, 618499 & 12 \\
& Total & 3,17650 &, 905080 & 24 \\
\hline
\end{tabular}

Chart 3. Descriptive Statistics for agent 1/\#agent 2 in agent contexts 
As mentioned in previous sections, the data obtained from the subjects has been analysed by performing a-mixed two-way ANOVA (Analysis of Variance) to it. The between-group factor is group (natives/learners) and the within-group factor is congruence (congruent/incongruent). However, before performing an ANOVA to the data, two statistical assumptions need to be checked, namely: (i) whether the data are normally distributed and (ii) whether the variance of the data is similar in all samples.

Regarding (i) normality of distribution: The DV scores are normally distributed (see Appendix II for one-sample Kolmogorov-Smirnov test), $p<0.05$ for each sample in the agent context. As for (ii) similarity of variance: The variance of the data is similar in all samples for the within-group factor, that is, congruence (see Appendix II for Mauchly's $W=1, p>0.05$ n.s.) and for the between-groups factors: agent1context $(F=4.215 p=0.052$ just about n.s., $)$ and \#agent2 context $(F=0.079, p=0.781$ n.s $)$ (see Appendix II for Levene's Test of Equality of Error Variances).

Thus, since it can be safely assumed that the data are normally distributed and that their variance is homogeneous, we can proceed now to performing a two-way mixed ANOVA in the agent contexts (group [L1/L2] x congruence [given-new/\#newgiven]) to check whether there are any main effects of L1 and of congruence and any interaction between both.

In the agent contexts, there is a highly significant main effect of congruence $\left(F=32,653, p<0.01 \mathrm{sig}, \eta^{2}=0.597\right)$, a non-significant main effect of group $(F<0.0153$, $p=0.902$ n.s., $\left.\eta^{2}=0.110\right)$ and a non-significant congruence $\mathrm{x}$ group interaction $(F=2.730$, $p=0.113$ n.s., $\eta^{2}=0.110$ ). This implies that both the native and learner groups behave similarly by significantly preferring information structure congruence to incongruence (i.e., information structure violations). This is further supported by $\eta^{2}=0.110$, which implies that around $11 \%$ of the variation is accounted for by congruence (see Appendix II for Tests of Between-Subjects and Within-Subjects Effects).

These results can be visually contrasted in the error bar chart (cf. Figure 14). Both groups clearly and significantly prefer information structure congruence (givennew: natives 4.17, learners 4.50) to incongruence (\#new-given: natives 3.33, learners 3.04), as shown by the red arrowed lines, but there are no differences between the groups in any of the contexts (given-new/\#new-given), as shown by the end-dot blue lines. 
These findings support the Interface Hypothesis, which does not predict any differences between (very) advanced learners and natives regarding their knowledge (in an off-line task) of the properties constraining information structure at the syntaxdiscourse interface.

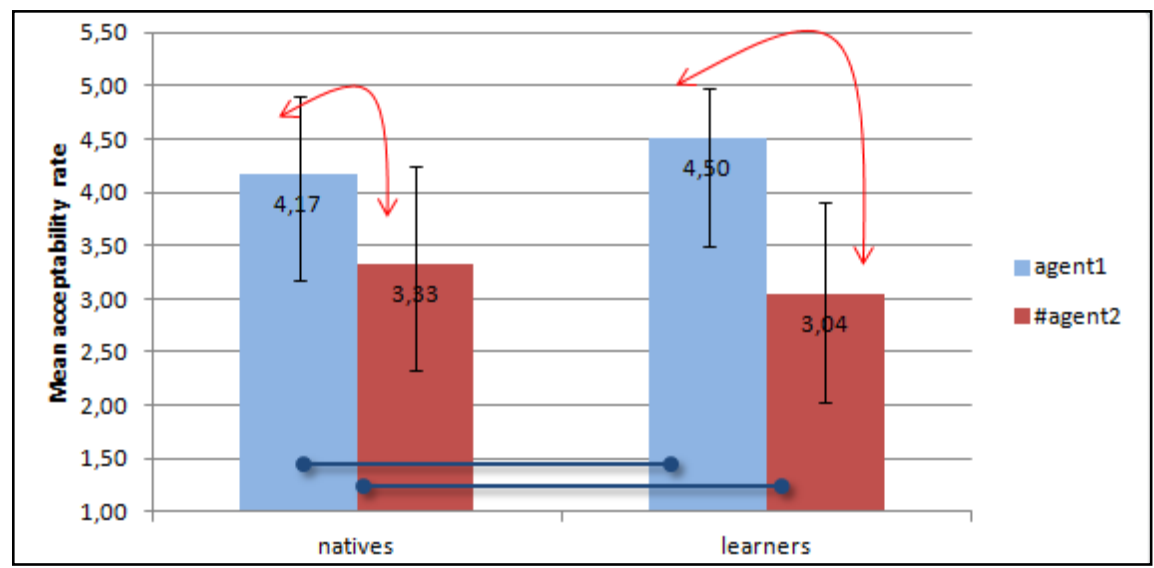

Figure 14. Results on agent contexts (group x congruence) ${ }^{4}$

\subsection{2 [Contrast D2] Contrast in patient contexts: \#patient3 vs. patient 4}

Let us turn now to the off-line results for the patient contexts (cf. Table 15). First of all, a preliminary visual inspection of the data is provided once again in order to asses if broadly, the results obtained in patient contexts.

\begin{tabular}{|c|c|c|}
\hline \multirow[t]{2}{*}{$\begin{array}{l}\text { Patient: } \\
\text { a E2 } \mathrm{V}_{\text {past }}\end{array}$} & \# (3) a $E 1_{\text {agent }} V$ the $E 2_{\text {patient }}$ while ... & $\begin{array}{l}\text { Active: \# New / Given } \\
S_{\text {new }} \vee_{\text {active }} O_{\text {given }}\end{array}$ \\
\hline & $\checkmark(4)$ the $E 2_{\text {patient }} V_{\text {pass }}$ by a $E 1_{\text {agent }}$ while .... & $\begin{array}{l}\text { Passive: } \checkmark \text { Given / New } \\
\mathrm{O}_{\text {given }} \mathrm{V}_{\text {passive }} \mathrm{A}_{\text {new }}\end{array}$ \\
\hline
\end{tabular}

Table 15. Off-line task design template patient contexts

\footnotetext{
${ }^{4}$ In the chart, statistically significant differences are visually represented by red lines, whereas non-significant differences are shown by blue lines. Arrowed lines show within-group contrasts, whereas end-dot lines show between-group contrasts.
} 
This chart (cf. Chart 4) shows the descriptive statistics for the results to be discussed below:

Descriptive Statistics

\begin{tabular}{|ll|l|l|l|}
\hline & Group & Mean & $\begin{array}{l}\text { Std. } \\
\text { Deviation }\end{array}$ & $\mathrm{N}$ \\
\hline \#patient3 & natives & 4,04158 &, 798093 & 12 \\
& learners & 3,82692 &, 602268 & 12 \\
& Total & 3,96533 &, 695826 & 24 \\
\hline patient4 & natives & 3,65283 &, 830883 & 12 \\
& learners & 3,98076 &, 729436 & 12 \\
& Total & 3,84031 &, 788239 & 24 \\
\hline
\end{tabular}

Chart 4. Descriptive Statistics for \#patient 3/patient 4

For the following part of the analysis, it is important to once again keep in mind the way the off-line task has been designed: group (L1/L2) x congruence (given-new/\#newgiven), all rated in a 1-5 Likert scale. Just as was done in the previous section, a series of tests have been passed to the data before performing the ANOVA to ensure its (i) normality of distribution and (ii) similarity of variance.

Regarding (i) normality of distribution: The DV scores are normally distributed (see Appendix II for one-sample Kolmogorov-Smirnov test), $p<0.05$ for each sample in the patient context. As for (ii) similarity of variance, the variance of the data is similar in all samples for the within-group factor, that is, congruence (see Appendix I for Mauchly's $W=1, p>0.05$ n.s.) and for the between-groups factors: \#patient3 context $(F=2.361 p=0.139$ n.s. $)$ and patient 4 context $(F=0.141, \mathrm{p}=0.711$ n.s. $)$ (see Appendix II for Levene's Test of Equality of Error Variances). 
Therefore, the two-way mixed ANOVA can be calculated safely once more, with group (natives/learners) as the between-group factor and congruence (congruent/incongruent) as the within-group factor. The results for the patient contexts show that there is a non-significant main effect of congruence $(F=0.370 p<0.549$ n.s, $\left.\eta^{2}=0.017\right)$, a non-significant main effect of group $\left(F=0.2459 \mathrm{p}=0.624\right.$ n.s., $\left.\eta^{2}=0.017\right)$ and, also, a non-significant congruence $\mathrm{x}$ group interaction $\left(F=1.645, p=0.213\right.$ n.s., $\eta^{2}$ $=0.070$ ). This implies that, although both the native and learner groups behave similarly, they do not seem to discriminate significantly between information structure congruence or incongruence. This is further supported by $\eta^{2}=0.017$, which implies that only $17 \%$ of the variation is accounted for by congruence in the patient contexts, in contrast to the contrasts discussed above for agent contexts, where $\eta^{2}=-0.597$ (i.e., around 58\%) (see Appendix II for Tests of Between-Subjects and Within-Subjects Effects).

These results can be visually contrasted in the error bar chart (cf. Figure 15). In this subject, it is only the leaner group that prefers information structure congruence (given-new: 3.98 for learners and 3.65 for natives, $p<0.05$, n.s) to incongruence (\#newgiven: 3.83 for learners and 4.04 for natives, $p<0.05, \mathrm{n} . \mathrm{s}$ ), though the differences between groups in either condition are non-significant, as illustrated by the end-dot blue line. Additionally, note that the within-group contrasts are also non-significant (blue arrowed lines) for both groups, which implies that neither the learner group nor the native group are statistically discriminating between the congruent vs. incongruent condition (though, as stated above, there is a slight though non-significant mathematical difference here: natives prefer incongruent to congruent, but learners prefer the opposite). Therefore, there are no significant within- and between-group differences in the behaviour of both samples, which implies that learners behave like natives. 


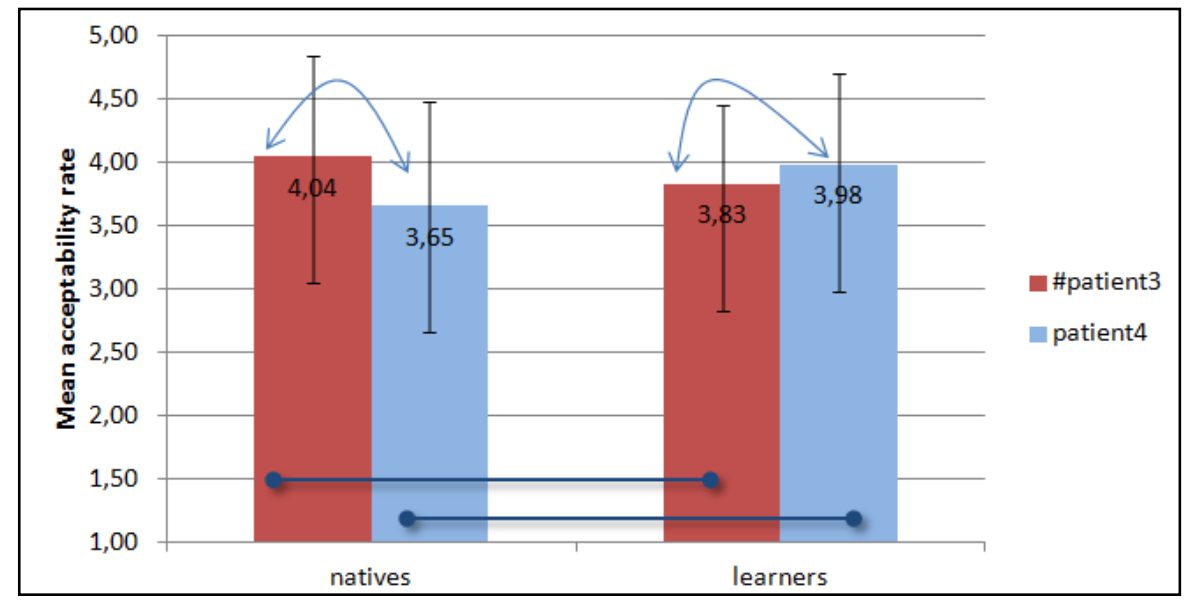

Figure 15. Results for \#patient 3/patient 4 in patient contexts.

Interestingly, the error bar chart shows that learners prefer to obey information structure (3.98) rather than violating it (3.83), but only by a narrow margin. This, nevertheless, indicates that their intuitions are somewhat stronger than natives'. Natives, on the other hand, show a reversed pattern. That is, their tendency is to violate information structure (4.04 vs. 3.65) in patient contexts, which is contrary to prediction, as explained above. See error bars for statistical significance.

These findings once again support the IH, which does not predict any differences between (very) advanced learners and natives regarding their knowledge (in off-line tasks) of the properties constraining information structure at the syntax-discourse interface. However, it is interesting to note that both samples of subjects are rating as "acceptable" a sentence that is informationally incongruent (though grammatically correct). This finding calls for a further explanation.

Probably, the main cause for such results could be due to a priming effect. Syntactic priming is "the tendency for a speaker to produce a syntactic structure that occurred in the recent discourse rather than an alternative structure. Researchers have suggested that it occurs due to the residual activation of the morpho-syntactic information stored with individual lexical items" (Kim and McDonough, 2008: 149). 
Bear in mind that, in the stimuli, all contexts have been written in the active voice, both in the so-called agent contexts (where agent simply refers to the fact that the first-mentioned entity in the context (E1) will be the agent in the probe sentences, and patient refers to the first-mentioned entity in the context (E2), which is the patient in the probe sentences). In other words, aside the information structure of the probes, recall that from a purely syntactic point of view the scenario is as follows:

\begin{tabular}{|c|l|}
\hline $\begin{array}{c}\text { Agent contexts } \\
\text { (active voice) }\end{array}$ & Probe sentence 1 (active voice) [given-new] \\
\cline { 2 - 2 } $\begin{array}{c}\text { Patient context } \\
\text { (active voice) }\end{array}$ & Probe sentence 2 (passive voice) [\#new-given] \\
\cline { 2 - 2 } & Probe sentence 3 (active voice) [\#new-given] \\
\hline
\end{tabular}

Table 8. Syntactic structure of the experiments

This design might have triggered a syntactic priming effect in the patient scenarios so that the active sentence, which theoretically violates the standard information packaging (sentence3: \#new-given), is rated just the same as the passive sentence, which does conform to the standard information packaging principle (sentence 4: given-new). All in all, it seems that a sentence in the active voice is accepted (even if it does not conform to the information packaging principle) when its previous context is in the active as well. Still, it is crucial to observe that, in such patient scenarios, the theoretically predicted probe sentence (sentence4 (passive voice) [given-new]) is also highly accepted, which implies that both natives and learners certainly obey the given-new principle despite it being realised by a passive sentence (which happen to be less frequent than active sentences in English and, therefore, it could be expected that they are always less preferable than actives, which is not the subject here).

In other words, it seems that there are two factors simultaneously at play here: an effect of congruence (given-new principle), which is the factor being manipulated, and an unwanted effect of voice priming (active-voice bias which overrides the givennew principle). 
Interestingly, consider the examples (16) and (17) below, where a pronoun (he) is used to mark given information, which is the most natural option, and a full NP ( $a$ thief/a policeman) marks new information, which is the most natural option given that the indefinite article typically encodes discourse-new information. In (16i) the congruent information structure (given-new) happens to be realised by an active sentence, whereas in (16ii) the incongruent information structure (\#new-given) is realised by a passive sentence. In (17i) the pattern is reversed: the congruent information structure (given-new) is realised this time by a passive sentence, and the (theoretically) incongruent information structure (new-given) in (17ii) is realised by an active sentence. We say 'theoretically' because, according to the given-new principle discussed in chapter 2, the passive sentence (17i) should be preferable to the active sentence (17ii). But, intuitively speaking (and judging by the native results above in patient contexts), (17ii) is also pragmatically natural and acceptable. It seems, therefore, that there is a gradient acceptability scale (18) where voice and information structure interact in English, showing that the given-new principle is pragmatically acceptable independently of voice (active/passive), but when information structure is theoretically violated (i.e., new-given scenarios), an active voice is preferable to a passive voice. This, to our knowledge, is an unexplored area

[16] A policeman was patrolling the city streets at night.

i. $\quad$ He saw a thief while trying to steal a car. (given-new) (active)

ii. A thief was seen by him while trying to steal a car. (\#new-given) (passive)

[17] A thief was robbing a bank at gunpoint.

i. He was shot by a policeman. (given-new) (passive)

ii. A policeman shot him. (\#new-given) (active)

[18] given-new active/passive $>$ new-given active $>$ new-given passive. 
Therefore, it could be useful for further research to design an experiment that would cancel out this unwanted effect, for example, by designing contexts in the active voice (as done here) followed by an active and a passive probe sentence, and, additionally, contexts in the passive voice followed by an active and a passive probe sentence as well.

\subsection{3 [Contrast D3] Contrast in distractor contexts: distractor1 vs. \#distractor2}

Although it is not standard practice to present results for the distractors, in this section we do so since, as we will see below, their results provide insights for future research. Distractors (or fillers) have been designed according to the following table (cf. Table 16).

\begin{tabular}{|l|c|l|}
\hline \multicolumn{1}{|c|}{ CONTEXT } & \multicolumn{1}{|c|}{ PROBE SENTENCES } & \multicolumn{1}{c|}{$\begin{array}{c}\text { INFOSTRUCTURE / } \\
\text { SYNTAX }\end{array}$} \\
\hline Agent: & $\checkmark$ (1) Anne told her mother the good news. & $\begin{array}{l}\text { Active: } \checkmark \text { Given / New: } \\
\text { SVO: } \mathrm{S}_{\text {given }} \mathrm{V}_{\text {active }} \mathrm{O}_{\text {new }}\end{array}$ \\
$\begin{array}{l}\text { Anne Phillips had just } \\
\text { found out that she had } \\
\text { won the lottery. She } \\
\text { was very happy and } \\
\text { excited. }\end{array}$ & $\begin{array}{l}\text { \# (2) It was Anne who told her mother } \\
\text { the good news. }\end{array}$ & $\begin{array}{l}\text { Cleft: \# It was Given who } \\
\text { New }\end{array}$ \\
CLEFT: It was $\mathrm{S}_{\text {given }}$ who \\
$\mathrm{V}_{\text {active } \mathrm{O}_{\text {new }}}$
\end{tabular}

Table 16. Distractors' design template

In this type of design, subjects would be expected to give a higher acceptability rate to those sentences providing a topic continuity (given-new pattern), that is, the ones referring to entity (E1) which has already been mentioned. As such, the most natural answer would follow an SVO structure conforming to the pattern given-new $(\checkmark 1)$, rather than an it-cleft sentence (\#2), which does not conform to the given-new pattern (see Ward et al., 2002; Ward and Birner 2004 for the information structure of it-cleft sentences).

Interestingly, it-cleft sentences are a type of non-canonical structure that are used to package information structure in a certain way, i.e., when the speaker wants to emphasise or bring out a previously mentioned entity among a series of elements.

\footnotetext{
5 Note: the article 'the' often appears in parentheses since in some stimuli E1 was a proper noun, so no article was needed since proper nouns obviously retain the definite features.
} 
In these subjects the reading is that it is E1 (and not E2(/E3)) who performed the action, so that its information structure pattern would be something like this:

Context: $\mathrm{E} 1_{\text {focus }}, \mathrm{E} 2_{\text {focus }}, \mathrm{E} 3_{\text {focus }} \rightarrow$ Probe: It was $\mathrm{E} 1_{\text {contrastive-topic }}$ who did it

$$
\text { (and not } \mathrm{E} 2_{\text {topic }} \text { or } \mathrm{E} 3_{\text {topic }} \text { ) }
$$

Let us see some more examples from the distractors used in this experiment: [19]

Leonardo DiCaprio was at the Oscars ceremony. They were about to announce the name of the winner.

i. $\quad \checkmark$ Leonardo DiCaprio gave the winner a firm handshake.

ii. $\quad$ \# It was Leonardo DiCaprio who gave the winner a firm handshake.

[20] A man was preparing dinner. He was unsure what to cook first.

i. $\quad \checkmark$ The man decided to serve chicken as a starter.

ii. \# It was the man who decided to serve chicken as a starter.

In both examples, one entity (E1) is introduced in the context (Leonardo DiCaprio, a man) and it is brought up again in both probe sentences. However, as it can be seen there are no entities with which to contrast this E1. In example [19], no other actor's name is provided and in example [20] there is not even another human entity to contrast the man with. In this sense, the use of clefts is helpful when it comes to detecting if the subjects might have problems with the distribution of information in general at the syntax-discourse interface. That is, sometimes they might not discriminate as incongruent or incorrect an example in which there is actually no contrast or where elements that need no extra focus are emphasised.

Once again, a preliminary visual inspection of the data is provided in order to assess, if broadly, the results obtained to be discussed below (cf. Chart 5). 


\section{Descriptive Statistics}

\begin{tabular}{|ll|l|l|l|}
\hline & Group & Mean & Deviation & N \\
\hline distractor1 & Natives & 4,65975 &, 465240 & 12 \\
& Learners & 4,73608 &, 372920 & 12 \\
& Total & 4,69792 &, 421216 & 24 \\
\hline \#\#distracto & Natives & 2,33333 & 1,183907 & 12 \\
r2 & Learners & 1,42308 &, 454305 & 12 \\
& Total & 1,89239 &, 985872 & 24 \\
\hline
\end{tabular}

Chart 5. Descriptive Statistics for distractor 1/distractor 2

Just as was done in the previous contexts, a series of tests have been passed to the data before performing the ANOVA to ensure (i) normality of distribution and (ii) similarity of variance. Regarding (i) normality of distribution: The DV scores are normally distributed (see Appendix II for one-sample Kolmogorov-Smirnov test), $p<0.05$ for each sample in both distractor contexts. However, as for (ii) similarity of variance, the data is similar for all samples in distractor 1 context for the within-group factor, that is, congruence (see Appendix II Mauchly's $W=1, p>0.05, \mathrm{n} . \mathrm{s}$ ) and for the between-groups factors: distractor1 context ( $F=1.561 p=0.225$ n.s.). However, for \#distractor2 context similarity does not apply in the between-group factor- $(F=14,963 p=0.011 \text {, sig })^{6}$ (see appendix II for Levene's Test of Equality of Error Variances).

The ANOVA is once again calculated for those contexts that hold the aforementioned assumptions. The results show that there is a highly significant main effect of congruence $\left(F=211.619 p<0.001 \mathrm{sig}, \eta^{2}=0.906\right)$, a non-significant main effect of group $\left(F=3.6009 p=0.0709\right.$ n.s., $\left.\eta^{2}=0.1407\right)$ and a significant congruence $\mathrm{x}$ group interaction $\left(F=6.158, p=0.021, \eta^{2}=0.219\right)$.

\footnotetext{
${ }^{6}$ Note that the $\mathrm{SD}$ is high in the native group $(\mathrm{SD}=1.18)$ but low in the learner group $(\mathrm{SD}=0.45)$ for the incongruent condition. This entails that the native group is not behaving homogeneously when rating pragmatically illicit it-cleft sentences. This issue merits further research.
} 
This implies that both the native and learner groups behave rather similarly by significantly preferring information structure congruence (SVO) to incongruence (i.e., information structure violations with it-cleft sentences). This is supported, even if marginally, by the value $\eta^{2}=0.906$, which implies that $90 \%$ of the variation is accounted for by congruence (see Appendix II for Tests of Between-Subjects and Within-Subjects Effects).

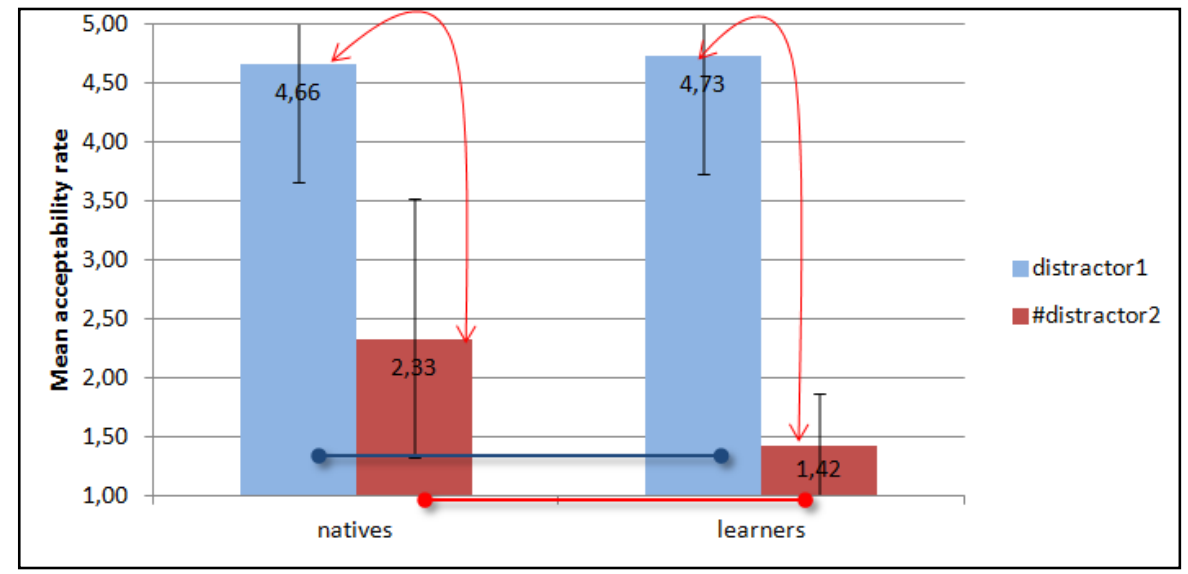

Figure 16. Results for distractor 1/\#distractor2 in distractor contexts

The error bar chart (cf. Figure 16) shows that both natives and learners clearly prefer to obey information structure (4.66 and 4.732) rather than violating it (2.33 and 1.42). As the red arrowed lines indicate, there is a statistically significant difference within each group regarding their choice, as well as a significant difference between both groups (red dot line) regarding their discrimination of only informationally incongruent constructions (\#it-clefts), but a non-significant between-group difference regarding the informationally congruent construction $(S V O)$. That is, learners show lower acceptability rates (1.42) than natives (2.33) when judging the pragmatically incongruent condition.

These findings support the Interface Hypothesis, which does not predict any differences between (very) advanced learners and natives regarding their knowledge (in off-line task) of the properties constraining information structure at the syntax-discourse interface. 
The only significant difference, as explained above, is that, given that learners rate more severely incongruent structures in distractor 2 condition than natives do, they seem to have a higher sensibility for judging if a sentence is pragmatically incorrect in this task. But the crucial finding in the distractor condition is that the pragmatically illicit sentence (it-cleft) is rated very severely by both groups (values below 2.33 out of $5)$, while in the experimental agent contexts, the pragmatically illicit sentences were rated low but not severely (rates below 3.33 out of 5 ). This indicates that both natives and learners are highly sensitive to the congruence factor, particularly in subjects where, from an information-structure point of view, the information structure (it-cleft) is highly incompatible with the preceding context. Hence, there seems to be a gradience in the acceptability of information structure violations ('\#' indicating a mild informationstructure violation and '\#\#' a severe violation). Future research will need to determine whether such a gradience can be replicated in both natives and learners with several non-canonical structures (passives, it-clefts, left dislocations, etc), as gradience in information-structure violations at the syntax-discourse interface is not predicted by the $\mathrm{IH}$.

\subsubsection{Probe sentence condition analysis in the off-line task}

To continue with the same structure of analysis carried out in the previous sections, here is a preview of the data analysed by each probe sentence condition (namely: agent1, \#agent2, \#patient3, patient4). It must be pointed out that no ANOVA has been passed to the data so the analysis carried out will be only of descriptive nature.

First of all, let us synthesise the previous off-line results. It must be pointed out that in all samples and versions (cf. Figure 17) agentl shows the highest marks and \#agent2 the lowest, disregarding distractors, as they are not a part of the experimental stimuli. The rest of conditions show lower or higher averages depending on the version and the group, but even these do not vary much from each other. 


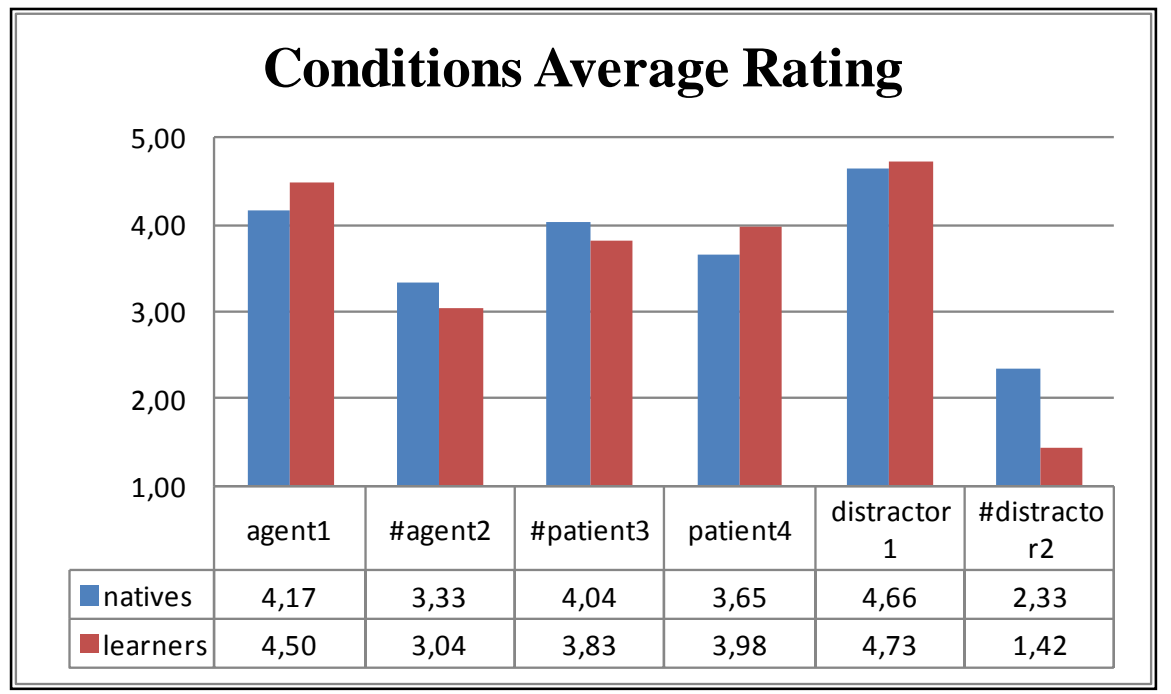

Figure 17. Rating for all conditions in all groups and versions

Delving into a more detailed analysis now, here are grouped the verbs that showed the highest and lowest marks more than once (in all versions, samples and conditions). This table shows which verbs in the probe sentences were rated as being more (un)natural/(in)adequate as a whole.

\begin{tabular}{|l|l|}
\hline $\begin{array}{c}\text { Verbs that have the lowest } \\
\text { ratings more than once } \\
\text { per condition }\end{array}$ & $\begin{array}{c}\text { Verbs that have the highest } \\
\text { ratings more than once } \\
\text { per condition }\end{array}$ \\
\hline \#distractor2 watch $(\mathrm{x} 2)$ & \#agent2 convince $(\mathrm{x} 2)$ \\
\hline \#distractor2 attend $(\mathrm{x} 2)$ & \#patient3 see $(\mathrm{x} 2)$ \\
\hline \#distractor2 draw $(\mathrm{x} 2)$ & \#patient3 help $(\mathrm{x} 2)$ \\
\hline \#distractor2 buy $(\mathrm{x} 2)$ & distractor1 decide $(\mathrm{x} 2)$ \\
\hline patient4 feed $(\mathrm{x} 2)$ & distractor1 sell $(\mathrm{x} 2)$ \\
\hline \#patient3 fascinate $(\mathrm{x} 2)$ & distractor1 refuse $(\mathrm{x} 3)$ \\
\hline \#agent3 stop $(\mathrm{x} 2)$ & \#distractor2 draw $(\mathrm{x} 2)$ \\
\hline
\end{tabular}

Table 17. Verbs grouped by acceptability rate frequency per condition 
This analysis of the data obtained has been organised to provide information on: scores, score variation and standard deviation scores on each probe sentence condition. This more exhaustive examination of results should (i) shed light on the adequacy of the stimuli presented to the subjects, pointing out which of them might have proved to be more/less problematic in competence terms; (ii) the information gathered from said examination should also be of help for improving the experimental design for further research.

\subsubsection{Learners}

\subsection{Learners: Version 1}

The chart below presents relevant data on the item analysis of the results obtained by the learner group in version 01 of the off-line task (cf. Table 18). It is based on the overall ratings of the sentences presented in each probe sentence condition (agentl, \#agent2, \#patient3 and patient4). Bear in mind that each of them contains in total 4 sentences.

\begin{tabular}{|c|c|c|c|c|}
\hline $\begin{array}{c}\text { V01 } \\
\text { Learners }\end{array}$ & \multicolumn{5}{|c|}{} \\
\hline $\begin{array}{c}\text { Highest } \\
\text { Score }\end{array}$ & $\begin{array}{c}\text { Lowest } \\
\text { score }\end{array}$ & $\begin{array}{c}\text { Greatest } \\
\text { Variation }\end{array}$ & $\begin{array}{c}\text { Highest } \\
\text { SD }\end{array}$ & $\begin{array}{c}\text { Lowest } \\
\text { SD }\end{array}$ \\
\hline 5.00 & 1.50 & $4.80-3.00(\mathrm{p} 4)$ & 0.74 & 0.36 \\
$(\mathrm{x} 8)$ & & $4.80-2.70(\mathrm{a} 2)$ & & \\
\hline
\end{tabular}

Table 18. Learners V01 item-analysis chart

There were five items in total rated 5.00 across all probe sentence condition, and only one item rated 1.50 (\#distractor2). Although variation will be analysed in more detail below, the contexts patient4 and \#agent2 show the greatest variation in item rating. 
The probe sentence condition rated highest was distractorl (5.00, followed by agent1 (4.64). On the contrary, the probe sentence condition rated lowest was \#distractor2 (1.50) followed, if by a long run, by \#agent2 (3.38). This is, in fact, the rating pattern that is repeated throughout the remaining data.

The rest of the items show a slightly varying, but balanced, average that always ranges between the highest and lowest marks.

Therefore, as expected, the probe sentence condition showing the highest SD is \#agent2 (0.74), whereas the probe sentence condition with lowest SD is agent1 (0.36). These findings also help establish the pattern that, the lower and further away from the mean the score given, the highest the SD will be.

This preference showed by the subjects in rating probe sentence conditions agent1 and distractor1, both of which, as a reminder, are congruent, is reflected in the verbal selection too (cf. Table 19).

\begin{tabular}{|c|c|c|c|}
\hline Context & $\begin{array}{c}\text { Verbs with } \\
\text { highest rating }\end{array}$ & $\begin{array}{c}\text { Verbs with } \\
\text { lowest rating }\end{array}$ & $\begin{array}{c}\text { Probe Sentence } \\
\text { Condition }\end{array}$ \\
\hline agent1 & choose & buy & \#distractor2 \\
\hline distractor1 & attend & attend & \#distractor2 \\
\hline distractor1 & ask & support & \#patient4 \\
\hline distractor1 & lick & choose & \#agent2 \\
\hline distractor1 & refuse & punish & \#agent2 \\
\hline distractor1 & sell & & \\
\hline distractor1 & sing & & \\
\hline
\end{tabular}

Table 19. Verbs rated by acceptability rate 
Once more, the pattern is repeated: learners perfectly discriminate between congruent and incongruent contexts when rating. However, the table also shows that some verbs (i.e. attend, choose) are repeated in both columns. This means that the type of verb does not affect the subject's rating of the sentences, which is what has been looked for all along while designing the experiments. That is to say, the monotransitive verbs chosen were high frequency items, all of them prone to be passivised easily, so that they would not slow down or interfere with the subjects' processing and rating (see Methods and Procedures section).

Finally, here is presented a mean rate variation chart that accounts for internal variation in the rating of each condition.

\begin{tabular}{|c|c|c|c|c|c|c|}
\hline $\begin{array}{c}\text { V01 Rate } \\
\text { Variation }\end{array}$ & \multicolumn{7}{|l|}{} \\
\hline $\begin{array}{c}\text { Probe } \\
\text { Condition }\end{array}$ & Agent1 & \#Agent2 & \#Patient3 & Patient4 & Distractor1 & $\begin{array}{c}\text { \#Distractor } \\
\mathbf{2}\end{array}$ \\
\hline $\begin{array}{c}\text { Mean } \\
\text { Range }\end{array}$ & $5.00-4.30$ & $3.80-2.70$ & $4.80-3.00$ & $5.00-3.00$ & $5.00-4.30$ & $2.20-1.30$ \\
\hline Variation & 0.70 & 1.10 & 1.80 & 2.00 & 0.70 & 0.90 \\
\hline
\end{tabular}

Chart 6. Variation rate for Learners V01

It shows that learners act more homogeneously when judging agent and distractors 1 and \#2 probe sentence condition, but their rating scores vary more for \#patient3 and patient 4 probe sentence condition. Considering these are the ones in which the congruent probe sentence is in the passive but the context is in the active, the variation could be due to the already-mentioned priming effect (see Contrast in patient contexts: \#patient3 vs. patient4). 


\subsection{Learners: Version 2}

The chart below presents relevant data on the item analysis of the results obtained by the learner group in version 02 of the off-line task (cf. Chart 7).

\begin{tabular}{|c|c|c|c|c|}
\hline $\begin{array}{c}\mathrm{V02} \\
\text { Learners }\end{array}$ & & & & \\
\hline $\begin{array}{c}\text { Highest } \\
\text { Score }\end{array}$ & $\begin{array}{l}\text { Lowest } \\
\text { score }\end{array}$ & $\begin{array}{c}\text { Greatest } \\
\text { Variation }\end{array}$ & $\begin{array}{l}\text { Highest } \\
\text { SD }\end{array}$ & $\begin{array}{l}\text { Lowest } \\
\text { SD }\end{array}$ \\
\hline $\begin{array}{l}5.00 \\
(\mathrm{x} 1)\end{array}$ & $\begin{array}{l}1.00 \\
(\mathrm{X} 3)\end{array}$ & $\begin{array}{l}4.80-3.20 \\
\text { (patient4) }\end{array}$ & 1.22 & 0.25 \\
\hline
\end{tabular}

Chart 7. Learners V02 item-analysis chart

There was only one item in total rated 5.00 across all probe sentence condition, and three items rated 1.00 (\#distractor2). Although variation will be analysed in more depth below, the probe sentence condition patient 4 shows the greatest item rating variation.

The probe sentence condition rated highest was distractorl (5.00), followed by agent1 (4.43). On the contrary, the probe sentence condition rated lowest was \#distractor2 (1.00) followed by \#agent2 (2.67). Regarding standard deviation levels, the probe sentence condition showing the condition with highest SD is \#agent2 (1.22), whereas, weirdly, the probe sentence condition with lowest SD is \#distractor2 (0.25).

Regarding verbal selection (cf. Table 20):

\begin{tabular}{|c|c|c|c|}
\hline Context & $\begin{array}{c}\text { Verbs with } \\
\text { highest rating }\end{array}$ & $\begin{array}{c}\text { Verbs with } \\
\text { lowest rating }\end{array}$ & $\begin{array}{c}\text { Probe Sentence } \\
\text { Condition }\end{array}$ \\
\hline distractor1 & Draw & Draw & \#distractor2 \\
\hline distractor1 & Lick & Attend & \#distractor2 \\
\hline distractor1 & Refuse & Wash & \#distractor2 \\
\hline patient4 & Shoot & Visit & \#agent2 \\
\hline patient4 & Stop & & \\
\hline
\end{tabular}

Table 20. Verbs rated by acceptability frequency 
In this subject, it is probe sentence condition patient4, not agent1, that accompanies distractorl in the highest rated column. Also, again, the presence of common verbs in both columns shows that lexical priming seems not to be affecting the experiment's results.

Finally, here is presented a variation rate table (cf. Chart 8) that accounts for internal variation in the mean rate of each probe sentence condition.

\begin{tabular}{|c|c|c|c|c|c|c|}
\hline $\begin{array}{c}\text { V02 Rate } \\
\text { Variation }\end{array}$ & \multicolumn{7}{|l|}{} \\
\hline $\begin{array}{c}\text { Probe } \\
\text { Condition }\end{array}$ & Agent1 & \#Agent2 & \#Patient3 & Patient4 & Distractor1 & \#Distractor2 \\
\hline $\begin{array}{c}\text { Mean } \\
\text { Range }\end{array}$ & $4.80-4.00$ & $3.20-2.20$ & $4.20-3.20$ & $4.80-3.20$ & $5.00-4.30$ & $1.50-1.00$ \\
\hline Variation & 0.80 & 1.00 & 1.00 & 1.60 & 1.70 & 0.50 \\
\hline
\end{tabular}

Chart 8. Variation rate for Learners V02

The rates given in the second version of the off-line task are, once again, quite homogeneous. Nevertheless, in this subject, learners act more homogeneously when judging agent1 and distractor 2 probe sentence conditions, that is to say, the items in these conditions were the ones they found easier to rate as natural or unnatural. For them, active context + active sentence is the most congruent scenario, whereas active context + it-cleft is the most incongruent one. Also, they show the highest variation in distractorl context which may be due to an error in the design of the stimuli, as this context is the easiest one to rate as adequate. 


\subsubsection{Natives}

\subsection{Natives: Version 1}

The chart below presents relevant data on the item analysis of the results obtained by the native group in version 01 of the off-line task (cf. Chart 9).

\begin{tabular}{|c|c|c|c|c|}
\hline $\begin{array}{c}\text { V01 } \\
\text { Natives }\end{array}$ & & & & \\
\hline $\begin{array}{l}\text { Highest } \\
\text { Score }\end{array}$ & $\begin{array}{c}\text { Lowest } \\
\text { score }\end{array}$ & $\begin{array}{c}\text { Greatest } \\
\text { Variation }\end{array}$ & $\begin{array}{l}\text { Highest } \\
\text { SD }\end{array}$ & $\begin{array}{c}\text { Lowest } \\
\text { SD }\end{array}$ \\
\hline $\begin{array}{c}4.82 \\
(x 12)\end{array}$ & $\begin{array}{l}1.80 \\
(\mathrm{x} 2)\end{array}$ & $\begin{array}{c}4.80-2.70 \\
\text { (agent } 1)\end{array}$ & 1.22 & 0.39 \\
\hline
\end{tabular}

There were, in total, twelve items rated 4.82 across all probe sentence conditions, and two items rated 1.80 (\#distractor2). Although variation will be analysed in more depth below, the condition agent 1 shows the greatest item rating variation.

The probe sentence condition rated highest was distractorl(4.82), followed by agent1 (4.29). On the contrary, the one rated lowest was \#distractor2 (1.80) followed (by far) by \#agent2 (3.21). This time, the probe sentence condition showing the highest $\mathrm{SD}$ is \#distractor2 (1.22), whereas the condition with lowest SD is distractor1 (0.39).

Remember that the condition rated highest by learners was also distractorl and lowest was \#distractor2, which shows that, as expected, learners are behaving in a native-like manner in the off-line task. 
Regarding verbal selection (cf. Table 21):

\begin{tabular}{|c|c|c|c|}
\hline Context & $\begin{array}{c}\text { Verbs with } \\
\text { highest rating }\end{array}$ & $\begin{array}{c}\text { Verbs with } \\
\text { lowest rating }\end{array}$ & $\begin{array}{c}\text { Probe Sentence } \\
\text { Condition }\end{array}$ \\
\hline agent1 & convince & shoot & \#agent2 \\
\hline distractor1 & ask & attend & \#distractor2 \\
\hline distractor1 & attend & watch & \#distractor2 \\
\hline distractor1 & buy & & \\
\hline distractor1 & decide & & \\
\hline distractor1 & draw & & \\
\hline distractor1 & lick & & \\
\hline distractor1 & refuse & & \\
\hline distractor1 & sing & & \\
\hline distractor1 & throw & & \\
\hline distractor1 & wash & & \\
\hline distractor1 & watch & & \\
\hline distractorl & ask & & \\
\hline
\end{tabular}

Table 21. Verbs rated by acceptability rate

The pattern is repeated again and distractorl probe sentence condition is accompanied by agent1 in the highest rated column. Whereas, \#agent2 and \#distractor2 are, once again, as in the learner sample results, in the low rate column. Also, verb repetition occurs again, e.g.: attend, watch. This shows that lexical priming does not seem to be affecting the experiment's results.

Finally, here is presented a variation rate table (cf. Chart 10) that accounts for internal variation in the rating of each individual condition in every one of the contexts.

\begin{tabular}{|c|c|c|c|c|c|c|}
\hline $\begin{array}{c}\text { V01 Rate } \\
\text { Variation }\end{array}$ & \multicolumn{7}{|c|}{} \\
\hline $\begin{array}{c}\text { Probe } \\
\text { Condition }\end{array}$ & Agent1 & \#Agent2 & \#Patient3 & Patient4 & Distractor1 & \#Distractor2 \\
\hline Mean & $4.80-2.70$ & $4.00-2.00$ & $4.50-3.00$ & $4.70-3.20$ & $4.70-4.80$ & $2.30-1.80$ \\
\hline Variation & 2.10 & 2.00 & 1.50 & 1.50 & 0.10 & 0.50 \\
\hline
\end{tabular}

Chart 10. Variation rate for Learners V01

In this subject, it is natives that act more homogeneously when judging \#distractor 2 and distractorl probe sentence conditions. This last condition shows the lowest variation score in all groups and versions (0.10). 
Curiously enough, it is agent 1 that shows the highest variation rate, when in this probe sentence condition subjects are usually fairly homogeneous. This could be maybe due to a practice effect that enhanced the subjects' performance as they progressed through the task.

\subsection{Natives: Version 2}

The chart below presents relevant data on the item analysis of the results obtained by the native group in version 01 of the off-line task (cf. Chart 11).

\begin{tabular}{|c|c|c|c|c|}
\hline $\begin{array}{c}\text { V02 } \\
\text { Natives }\end{array}$ & & & & \\
\hline $\begin{array}{c}\text { Highest } \\
\text { Score }\end{array}$ & $\begin{array}{c}\text { Lowest } \\
\text { score }\end{array}$ & $\begin{array}{c}\text { Greatest } \\
\text { Variation } \\
\end{array}$ & $\begin{array}{l}\text { Highest } \\
\text { SD } \\
\end{array}$ & $\begin{array}{c}\text { Lowest } \\
\text { SD } \\
\end{array}$ \\
\hline 4.50 & 2.13 & $\begin{array}{l}\text { 4.00-2.70 } \\
\text { (\#agent2) }\end{array}$ & 1.22 & 0.48 \\
\hline
\end{tabular}

Chart 11. Learners V02 item-analysis

There was only one item in total rated 4.50 across all probe sentence conditions, and three items rated 2.13 (\#distractor2). Although variation will be analysed in more depth below, \#agent 2 shows the greatest item rating variation.

The probe sentence condition rated highest was distractorl (4.50), followed by agent1 (4.29). On the contrary, the one rated lowest was \#distractor2 (2.13) followed (by far) by \#agent2 (3.21). This time, the probe sentence condition showing the highest $\mathrm{SD}$ is \#distractor2 (1.22), whereas the condition with lowest SD is distractor1 (0.48). 
Regarding verbal selection (cf. Table 22):

\begin{tabular}{|c|c|c|c|}
\hline Context & $\begin{array}{c}\text { Verbs with } \\
\text { highest rating }\end{array}$ & $\begin{array}{c}\text { Verbs with } \\
\text { lowest rating }\end{array}$ & $\begin{array}{c}\text { Probe Sentence } \\
\text { Condition }\end{array}$ \\
\hline agent1 & Visit & wash & \#distractor2 \\
\hline distractor1 & Decide & decide & \#distractor2 \\
\hline distractor1 & Wash & refuse & \#distractor2 \\
\hline distractor1 & refuse & & \\
\hline distractor1 & attend & & \\
\hline \#patient3 & help & & \\
\hline
\end{tabular}

Table 22. Verbs rated by acceptability rate

The pattern is repeated again and distractorlis accompanied by agentl in the highest rated column. Whereas, this time alone, \#distractor2 is in the low rate column, although it counts with the highest marks given to this condition in all groups and versions, namely 2.2 and 2.30 .

Also, verb repetition occurs again, e.g., attend, decide and refuse. This shows that lexical priming is not affecting the experiment's results.

Finally, here is presented a variation rate chart that accounts for internal variation in the mean rate of probe sentence condition.

\begin{tabular}{|c|c|c|c|c|c|c|}
\hline $\begin{array}{c}\text { V01 Rate } \\
\text { Variation }\end{array}$ & \multicolumn{1}{|c|}{ PAgent2 } & \#Patient3 & Patient4 & Distractor1 & \#Distractor2 \\
\hline $\begin{array}{c}\text { Probe } \\
\text { Condition }\end{array}$ & Agent1 & \#A & & & \\
\hline Mean Range & $4.50-3.50$ & $4.00-2.70$ & $4.50-3.50$ & $4.20-3.20$ & $4.80-4.30$ & $2.80-2.20$ \\
\hline Variation & 1.00 & 1.30 & 1.00 & 1.00 & 0.50 & 0.60 \\
\hline \multicolumn{7}{|c|}{ Chart 12. Variation rate for Learners V02 } \\
\hline
\end{tabular}

In this subject, natives have been quite homogeneous in all probe sentence conditions, showing less variation, as expected, in agent1, distractor1 and \#distractor2; \#agent2 shows the highest variation rate. 
All in all, there is a pattern that repeats itself throughout this analysis: agentl is the condition with the highest rating, whereas \#distractor2 shows the lowest ratings. A paired samples T-Test (cf. Figure 18) was therefore passed to these two conditions to ensure that the differences between their ratings were significant.

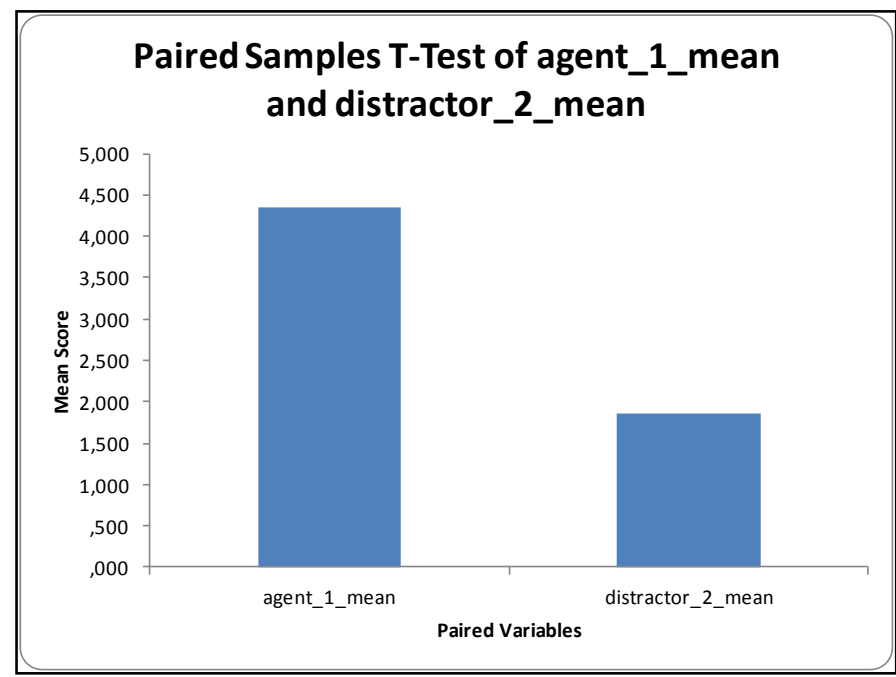

Figure 18. EZAnalyse T-Test results for agent1 mean vs. \#distractor2 mean 
The tool to perform the t-test was the Excel complement EZAnalyze. The results report for "agent_1_mean with distractor_2_mean" was as follows:

\begin{tabular}{|l|l|}
\hline \multirow{2}{*}{ Mean } & 1,861 (distractor_2_mean) \\
\cline { 2 - 2 } & 4,342 (agent_1_mean) \\
\hline Std. Dev.: &, 597 (agent_1_mean) \\
\cline { 2 - 2 } &, 949 (distractor_2_mean) \\
\hline N Pairs & 27 \\
\hline Mean Difference & 2,48 \\
\hline SE of Diff. &, 214 \\
\hline Eta Squared &, 833 \\
\hline T-Score & 11,590 \\
\hline P &, 000 \\
\hline
\end{tabular}

Chart 13. EZAnalyse results for T-Test of agent1 mean vs. \#distractor2 mean

This data shows that the difference between agent1 mean and \#distractor2 mean is significant for both groups' means. This supports the initial predictions that learners would behave in native-like ways in the off-line task as they are discriminating between a congruent and an incongruent scenario following a similar rating pattern to that of native speakers.

\subsubsection{Subject analysis in the off-line task}

A detailed subject analysis of the data will enable to pin point particular learners that have behaved in unconventional ways due to knowledge/competence deficits. This subject analysis has been carried out by examining the best and worst performers on each group in each version, and it is mainly based on their SD levels. 


\subsubsection{Learners}

\subsection{Learners: Version 1}

In version 01, the best learner performer is subject MVR (female, 23, C2 [QPT 55/60]). This subject shows one instance of $0.00 \mathrm{SD}$ and is fairly congruent in the markings provided. Also the learner, more or less, conforms to the rating pattern hypothesised in this study (cf. Table 23):

\begin{tabular}{|c|c|c|c|c|c|c|}
\hline Context & Agent1 & \#agent2 & \#patient3 & patient4 & distractor1 & \#distractor2 \\
\hline Score & 4.29 & 4.17 & 4.58 & 4.50 & 5.00 & 2.50 \\
\hline SD & 0.29 & 0.60 & 0.67 & 0.52 & 0.00 & 0.90 \\
\hline
\end{tabular}

Table 23. Subject MVR mean scores per condition

In this subject, it would have been expected that \#patient 3 condition's mean were lower than patient4's. This may, once again, be due to the already mentioned priming effect.

On the other hand, the worst learner performance was by subject TSR (female, 24, C2 [QPT 55/60]), showing an SD score always well above 1.00, except for distractor 1 condition. This shows that her SD variability is quite high, which sets her apart from the other learners. Her ratings conform mostly to that of the other learners, except for condition \#patient3, and this might be due to a priming effect (cf. Table 24):

\begin{tabular}{|c|c|c|c|c|c|c|}
\hline Context & agent1 & \#agent2 & \#patient3 & patient4 & distractor1 & \#distractor2 \\
\hline Score & 4.75 & 2.25 & 4.00 & 3.50 & 4.83 & 1.58 \\
\hline SD & 0.45 & 1.60 & 1.21 & 1.57 & 0.58 & 1.16 \\
\hline
\end{tabular}

Table 94. Subject TSR mean scores per condition 


\subsection{Learners: Version 2}

In version 02 the best learner performer is subject PLO (male, 23, C2 [QPT 58/60]). This subject shows four instances of $0.00 \mathrm{SD}$ and is fairly congruent in the markings provided. Also the learner conforms totally to the rating pattern hypothesised in this study (cf. Table 25):

\begin{tabular}{|c|c|c|c|c|c|c|}
\hline Context & agent1 & \#agent2 & \#patient3 & patient4 & distractor1 & \#distractor2 \\
\hline Score & 5.00 & 3.50 & 3.75 & 5.00 & 5.00 & 1.00 \\
\hline SD & 0.00 & 1.00 & 0.62 & 0.00 & 0.00 & 0.00 \\
\hline
\end{tabular}

Table 25. Subject PLO mean scores per condition

On the other hand, the worst learner performance was by subject EGZ (female, 23, C2, [QTP 56/60]). This learner provided the lowest mark to an experimental item in \#agent2 condition (cf. Table 26): as can be seen the ratings are quite unbalanced, giving almost the higher ratings in the experimental probe sentence conditions to incongruent \#agent2 and \#patient3, whereas performance in both distractors is quite adequate.

\begin{tabular}{|c|c|c|c|c|c|c|}
\hline Context & agent1 & \#agent2 & \#patient3 & patient4 & distractor1 & \#distractor2 \\
\hline Score & 4.67 & 1.33 & 4.00 & 2.33 & 5.00 & 1.00 \\
\hline SD & 1.15 & 1.20 & 1.60 & 1.97 & 0.00 & 0.00 \\
\hline
\end{tabular}

Table 26. Subject EGZ mean scores per context 


\subsubsection{Natives}

\subsection{Natives: Version 1}

In version 01 the best native performer is subject LAM (female, 67). This subject shows two instances of $0.00 \mathrm{SD}$ and is fairly congruent in the markings provided. Also the learner conforms totally to the rating pattern hypothesised in this study (cf. Table 27):

\begin{tabular}{|c|c|c|c|c|c|c|}
\hline Context & agent1 & \#agent2 & \#patient3 & patient4 & distractor1 & \#distractor2 \\
\hline Score & 3.25 & 2.67 & 2.5 & 3.50 & 4.00 & 2.00 \\
\hline SD & 1.14 & 1.00 & 0.90 & 0.90 & 0.00 & 0.00 \\
\hline
\end{tabular}

Table 27. Subject LAM mean scores per condition

On the other hand, the worst learner performance was by subject KP (female, 69). This learner provided the lowest mark to an experimental item in probe sentence condition \#agent2 (cf. Table 28).

As can be seen, although this native does adapt to the rating pattern hypothesised, the SD ratio is very high as the marks provided in every condition are too high and as such, not congruent with that of the rest of subjects.

\begin{tabular}{|c|c|c|c|c|c|c|}
\hline Context & agent1 & \#agent2 & \#patient3 & patient4 & distractor1 & \#distractor2 \\
\hline Score & 3.83 & 3.75 & 3.67 & 4.50 & 5.00 & 1.00 \\
\hline SD & 1.80 & 1.90 & 1.61 & 1.17 & 0.00 & 0.00 \\
\hline
\end{tabular}

Table 28. Subject KP mean scores per condition 


\subsection{Natives: Version 2}

In version 02 the best native performer is subject MCA (male, 69). This subject shows two instances of $0.00 \mathrm{SD}$ and is fairly congruent in the markings provided. Also the learner conform, more or less, to the rating pattern hypothesised in this study (cf. Table):

This subject showed the lowest SD levels of its group in all conditions.

\begin{tabular}{|c|c|c|c|c|c|c|}
\hline Context & agent1 & \#agent2 & \#patient3 & patient4 & distractor1 & \#distractor2 \\
\hline Score & 4.80 & 4.01 & 4.83 & 4.17 & 5.00 & 4.00 \\
\hline SD & 0.39 & 0.40 & 0.49 & 0.39 & 0.00 & 0.00 \\
\hline
\end{tabular}

Table 29. Subject MCA mean scores per condition

On the other hand, the worst learner performance was by subject RNP (male, 70) who shows the highest SDs of its group in all conditions (cf. Table 30):

\begin{tabular}{|c|c|c|c|c|c|c|}
\hline Context & agent1 & \#agent2 & \#patient3 & patient4 & distractor1 & \#distractor2 \\
\hline Score & 2.90 & 2.98 & 3.25 & 3.33 & 4.00 & 1.58 \\
\hline SD & 0.85 & 1.00 & 0.97 & 0.89 & 0.70 & 0.90 \\
\hline
\end{tabular}

Table 30. Subject RNP mean scores per condition

All in all, in this section are reported the general means (both of scores and SDs) for each group in each version, pointing out those participants whose results deviate from the norm. There is no doubt that there is internal variation between the subjects results, to a greater or lesser extent; for this reason it would be helpful for further research to be able to choose a more homogeneous sample in terms of sex, gender, educational and social background, ect, in order to minimise elements that may distort the results obtained. 
Due to the academic limitations of this dissertation it was not possible to do so, but a more detailed investigation of subjects' profiles would have been useful in order to obtain better and easier to analyse results.

\subsubsection{Synthesis of off-line results}

Let us first recall the predictions made in this study so that they can be contrasted with the results obtained: according to the $\mathrm{IH}$, advanced and near-native learners will experience processing deficits at the syntax-discourse interface, which will be obvious in the on-line task as they need to integrate simultaneously syntactic and discursive information. By contrast, no deficits are predicted in the off-line task as they can make use of both their linguistic and metalinguistic knowledge.

In particular in the off-line task, learners are not predicted to have deficits, so they will show higher acceptability rates for those sentences whose information structure has not been violated: $(1)>(2)$ and $(3)<(4)$. That is, given the same prior condition, participants prefer obeying info structure than violating it, independently of whether the compliance appears in an active or passive sentence (for more detailed information see Methods and Procedures Section).

All in all, it has been observed that most of the data gathered supports the hypothesis posed by this study. The following spidergram (cf. Figure 19) shows that, within experimental probe sentence conditions, learners and natives do not show significant differences in their behaviour. It is, indeed, in condition patient4 that their means vary a bit more. The possible explanations for this phenomenon, the priming effect, has been explained in detailed in this section (see Contrast in patient contexts: \#patient3 and patient 4). 


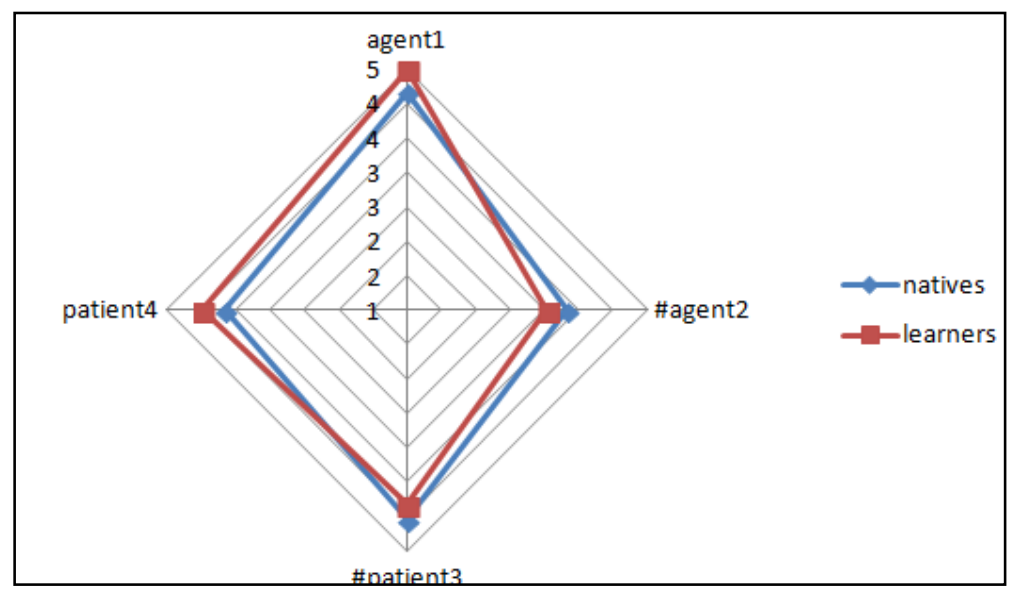

Figure 19. Spidergram with means per condition

If distractors are considered as well, the following spidergram (cf. Figure 20) shows that is in rating distractor 1 and \#distractor2 conditions that learners and natives present the highest variation.

On the one hand, this difference is due to a flaw in the design of the distractors: in most subjects E2 (second entity presented) acts as Focus, that it, it has not been mentioned before, which conforms to the design pattern of both active and passive sentences. However, in some other subjects, this same E2 is presented as Topic, that is, it has already been mentioned in the previous context. This could cause confusion and deficit problems for both learners and natives when rating the sentences. As such, the distractors' design will be improved for further research.

On the other hand, the probe sentences for the distractors (namely SVO and \#itcleft) were the easiest to discriminate in terms of adequacy because, as mentioned before, $i t$-clefts are only used for contrast and/or highlighting. This could be the other reason of subjects giving such high marks to the congruent sentence and such low marks to the incongruent one. Summing up, what matters to us is information structure and the intuitions of both learners and natives are clear and head in the same direction. 


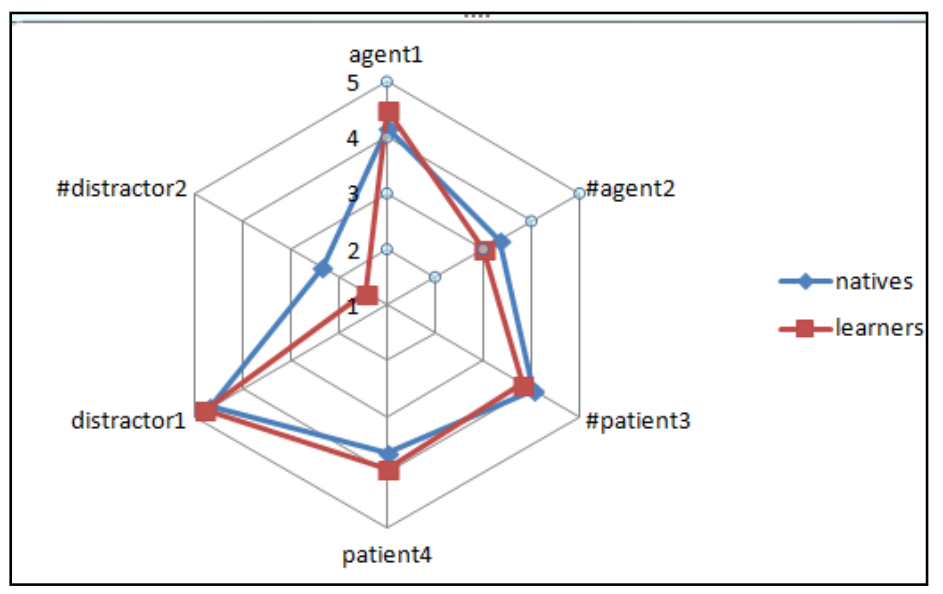

Figure 20. Spidergram with meanss per condition (all included) 


\section{CONCLUSION}

\subsection{General conclusion}

The role of information structure in passive sentences has been a neglected area of research in L2 acquisition and processing. The experiments present in this study have been designed to test the IH on passive constructions (vs. active sentences) in L2 English acquisition from the point of view of their information structure distribution, i.e., how they are constrained at the syntax-discourse interface.

Subjects were first administered the on-line task from which two different measures were collected: (i) Total reading time and (ii) RT rate, a coefficient obtained from calculating the critical segments of each sentence read by the readers. This last measure was implemented late in the study, when all data had been gathered, as a palliative for the age gap between both groups of participants, natives and learners as explained in section 3.4. Experimental design and data analysis.

In general, on-line task results support the IH both through between-groups comparisons and within-group comparisons. The former show that learners do present deficits in their on-line processing as their RT rates remain constant disregarding congruency and information status, as they do not differentiate between congruent/incongruent or new/given entity in neither active nor passive voice; whereas natives' rates are indeed higher when presented with an incongruent sentence or information status. The latter show that the learner sample is homogenous in its deficits, in as much as all natives behave also similarly in correctly discriminating congruency and information status in both active and passive constructions.

There was indeed one contrast, namely B. Contrast for agents in congruent and incongruent passive contexts, in which learners outperformed natives in correctly discriminating both congruency and information status, being all their RT rates lower. This might be due to the priming effect already mentioned in previous sections (see Results section part 2. Off-line Task. Contrast in patient contexts: \#patient3 and patient 4). 
Regarding the off-line task, most of the data gathered supports the hypothesis posed by this study. In experimental conditions, learners and natives do not show significant differences in their behaviour. It is, indeed, in context patient4 that their means vary a bit more a possible explanation for this phenomenon is the priming effect again). As it can be seen, these results match those of the on-like task explained in the paragraph above, that it: is it in patient contexts that results vary a bit more.

\subsection{Limitations}

The presence of a priming effect was something that was taken into account from the very first moment of experimental design. It was debated that it might affect all conditions, as participants might show preference for a more common and canonical structure such as the active voice with a new-given structure, which means that voice (active) may be overriding the standard given-new principle. A way to avoid this voice effect would have been to design not only a double set of probes sentences, as has already been done, but also a double set of contexts. In this way, it would have been necessary to add 24 counterpart passive contexts to the already existing 24 active ones. Thus, every subject would not only read 24 sentences and 24 contexts, 48 sentences and 48 contexts, and so on.

\begin{tabular}{|l|l|}
\hline \multirow{2}{*}{ Active Context Agent (x12) } & Probe 1 Active (agent1) \\
\cline { 2 - 2 } & Probe 2 Passive (\#agent2) \\
\hline \multirow{2}{*}{ Active Context Patient (x12) } & Probe 3 Active (\#patient3) \\
\cline { 2 - 2 } & Probe 4 Passive (patient4) \\
\hline Total: 24 & \\
&
\end{tabular}

Table 31. Current experiment design 


\begin{tabular}{|l|l|}
\hline \multirow{2}{*}{ Active Context Agent (x12) } & Probe 1 Active (agent1) \\
\cline { 3 - 3 } Passive Context Agent (x12) & Probe 2 Passive (\#agent2) \\
\cline { 2 - 3 } Active Context Patient (x12) & Probe 4 Passive (patient4) \\
\cline { 2 - 2 } & Probe 2 Passive (\#agent2) \\
\hline \multirow{2}{*}{ Passive Context Patient (x12) } & Probe 3 Active (\#patient3) \\
\cline { 2 - 3 } & Probe 4 Passive (patient4) \\
\hline Total: 48 & \\
\hline
\end{tabular}

Table 32. Extended experiment design (the future stimuli shown in the shaded boxes)

As aforementioned, this study counts with strong logistic restrictions due to the academic context where it has been developed. These restrictions have to do not only with its time-span, but also with the availability of resources. It must be considered that, actually, two experiments were designed, one for each task. Designing an extended version would have required more time and material than we counted with as well as more subjects, which were hard enough to find. As aforementioned, two programmes were used for the implementation of the experiments: LimeSurvey is a user-friendly software for which not much experience is needed, OpenSesame, however, is a relatively new social sciences software. It was chosen, on the one hand, because we would rather use an open source free software for the experiments, and on the other, because it has been reviewed to work better than other similar software such as PyschoPy. Learning to use it, however, took a long time, as well as a lot of trial and error work and it may not have been possible without advice. 
Another challenge after the experiments were up and running was to fit all experimental procedures in merely two weeks. The design of the stimuli took longer than planned (from January to May, 4 months) and by June we were already running out of time. Nevertheless, it was imperative to ensure that all participants took the experiment with the same device and under similar circumstances to ensure the reliability of their results. Schedules and places were carefully planned although several last minute dropouts took place and were replaced, albeit with difficulty.

The place where participants were passed the experiment was particularly important. Subjects were already nervous because all of them felt they were undergoing a test of some kind, their questions and reactions were that of people sitting an exam, in fact, all of them asked, by the end of the experiment, what their scores had been, although I had carefully explained that their responses were not being rated as such.

I found that the presence of the verification sentences and the sound stimuli used when they chose incorrectly if a verification sentence was true or false put participants under a lot of stress. Every time a verification sentence appeared on the screen, they would squint and concentrate, and whenever they chose incorrectly they would flinch and apologise. Even those who only chose incorrectly once or twice admitted they thought they must have done horribly, as they were never sure what to choose. Therefore, for further research it would be desirable to design the experiments in a way that minimises the subjects' exposure to stress, so that their data are more natural.

Finally organising all the data also took a long time as we had to make sure there were no mistakes, either in content or format, before passing the ANOVA to the data, which took many hours of work with Excel. It was necessary to eliminate all outliers that could hinder the normal distribution of our sample. We might have been able to provide a more powerful statistical analysis if we had been able to conduct a prior pilot test to our subjects but, as mentioned before, we worked against severe time and resource limitations. 


\subsection{Avenues for future research}

As discussed in the section above, the most obvious area of future research would be to improve the experimental design in order to avoid any possible priming effects, which have been thoroughly discussed in this dissertation.

As an additional area for further research, it would be important to work with more robust statistics by using further utilities of the statistical software employed for this study (IBM-SPSS Statistics) or implementing other new software. We could for example, make use of boxplots, a different kind of graph which visually shows quartiles and outliers.

There are other avenues for future research. For example, within the analysis of the results obtained for the off-line task, there is a section in which we analyse distractors in depth, which are the non-experimental, or "filler" part of the experiment, used to distract subjects from our real goal. It was added as interesting and insightful data emerged when the results were calculated and analysed. However, we are aware that one of the reasons for these outstanding results is that these stimuli were not properly designed. As mentioned throughout the whole dissertation, the variability of indefinite/definite articles is key to our experiment as they are the element marking which entities are new and which are old. Nevertheless, in these items E1 was a proper noun, so no article was needed since the proper noun obviously retains the definite/topic features which might have thwarted the participants' processing. As such, it would be necessary for further experiments to correct and conform the design of these elements in order to properly balance the study.

All in all the results obtained and analysed in this study support the general predictions of $\mathrm{IH}$ and shed light on the otherwise underexplored area of information structure distribution and processing of passive sentences in L2 English acquisition, fitting into the body of literature produced up to now on the syntax-discourse interface and adding valuable information on passive constructions. The data gathered also provide new findings on how both learners and natives process passive constructions at the syntax-discourse level and point out the deficits in said processing, adding to the corpora of interface knowledge. 
Our aim is to delve deeper into this subject in further doctoral research by means of Event Related Potentials. An ERP is "the measured brain response that is the direct result of a specific sensory, cognitive, or motor event" (Luck, 2005: 21). The study of the brain in this way provides a non-invasive method of evaluating brain functioning by means of electroencephalography (EEG). The timing of the gathered responses is thought to provide a measure of the timing of the brain's communication or timing of information processing, which is what we are mainly interested.

In this way, the use of ERPs will not only enable a better understanding of the mechanisms involved in the processing of information structure in passive constructions at the syntax discourse level, but may also shed light on other equally important and underexplored areas covered by the $\mathrm{IH}$.

All in all, it must be noted that this study is but a preliminary research and, as such, has inherent limitations that will be dealt with in further doctoral investigation. 


\section{REFERENCES}

Barrett, H. C., \& Kurzban, R. (2006). Modularity in cognition: framing the debate. Psychological review, 113(3), 628.

Biber, D. J. (1999). Grammar of spoken and written English. Longman: Harlow.

Birner, B. W. (2002). Information packaging. In R. \&. Huddleston, The Cambridge grammar of the English language (pp. 1363-447). Cambridge: Cambridge University Press.

Bos, P., Hollebrandse, B., \& Sleeman., P. (2004). Introduction: The pragmatics-syntax and the semantics-syntax interface in acquisition. International Review of Applied Linguistics in Language Teaching, 101-110.

Chomsky, N. (1981). A Note on Non-control PRO. Journal of Linguistic Research, 1, 111.

Chomsky, N. (1986). Knowledge of language: Its nature, origin, and use. Westport: Greenwood Publishing Group.

Chomsky, N. (1995). The minimalist program (Vol. (Vol. 28)). Cambridge, MA: MIT press.

Chomsky, N. (2000). New horizons in the study of language and mind. Cambridge: Cambridge University Press.

Cosmides, L., \& Tooby, J. (1994). Origins of domain specificity: The evolution of functional organization. In L. A. Hirschfeld, Mapping the mind: Domain specificity in cognition and culture (pp. 85-116). Cambridge: Cambridge University Press.

Crawford, J. L. (2012). Developmental perspectives on the acquisition of the passive. (PhD dissertation, University of Connecticut).

Daneman, M., \& Carpenter, P. A. (1980). Individual differences in working memory and reading. Journal of verbal learning and verbal behavior, 19(4), 450-466.

Downing, A. \&. (2002). A university course in English grammar. London: Psychology Press.

Fodor, J. A. (1983). The modularity of mind: An essay on faculty psychology. Palatino: MIT press.

Halliday, M. A. (1967). Notes on transitivity and theme in English: Part 2. Journal of linguistics, 3(02), 199-244. 
Hertel, T. J. (2003). Lexical and discourse factors in the second language acquisition of Spanish word order. Second Language Research, 19(4), 273-304.

Hopp, H. (2006). Syntactic features and reanalysis in near-native processing. Second Language Research, 22(3), 369-397.

Hopp, H. (2009). The syntax-discourse interface in near-native L2 acquisition: Off-line and on-line performance. Bilingualism: Language and Cognition, 12(4), 463483.

Huddleston, R. D., \& Pullum, G. K. (2005). A student's introduction to English grammar. Cambridge: Cambridge University Press.

Jackendoff, R. (2002). Foundations of language: Brain, meaning, grammar, evolution. Oxford: Oxford University Press.

Jiang, N. (2013). Conducting reaction time research in second language studies. New York: Routledge.

Johnson-Laird, P. (1983). Mental Models. Towards a Cognitive Science of Language, Inference and Conciousness. Cambridge: Harvard University Press.

Kamide, Y. S. (2003). Integration of syntactic and semantic information in predictive processing: cross-linguistic evidence from German and English. Journal of Psycholinguistic Research, 32,1,37-35.

Kim, Y., \& McDonough, K. (2008). Learners' production of passives during syntactic priming activities. Applied Linguistics, 29(1), 149-154.

Lambrecht, K. (1996). Information structure and sentence form: Topic, focus, and the mental representations of discourse referents (Vol. (Vol. 71)). Cambridge: Cambridge university press.

Lozano, C. (2009). Pronominal deficits at the interface: new data from the CEDEL corpus. In C. M. Bretones Callejas, Applied Linguistics Now: Understanding Language and Mind (pp. 213-227). Almería: Universidad de Almería.

Lozano, C. (2009). Selective deficits at the syntax-discourse interface. In N. L. Snape, Representational deficits in SLA: Studies in honor of Roger Hawkins (pp. 127166). Philadelphia: John Benjamins.

Lozano, C., \& Mendikoetxea, A. (2010). Interface conditions on postverbal subjects: a corpus study of L2 English. Bilingualism. Language and Cognition, 13(4): 475497.

Luck, S. J. (2005). Ten simple rules for designing ERP experiments. In C. T. Handy, Event-related potentials: A methods handbook (pp. 20-32). Cambriged, MA: MIT press. 
Marinis, T. B. (2010). Using on-line processing methods in language acquisition research. In E. Bloom, \& S. (. Unsworth, Experimental methods in language acquisition research (Vol. (Vol. 27), pp. 139-162). Philadelphia: John Benjamins Publishing.

Mathôt, S. S., \& Theeuwes, J. (2012). OpenSesame: An open-source, graphical experiment builder for the social sciences. Behavior Research Methods, 44(2), 314-324.

Messenger, K. B. (2011). Evidence for (shared) abstract structure underlying children's short and full passives. Cognition, 121(2), 268-274.

Myhill, D. (2010). Ways of Knowing. In T. Locke, Beyond the Grammar Wars: A Resource for Teachers and Students on Developing Language Knowledge in the English/Literacy Classroom (pp. 129-148). London: Routledge.

Park, D. (. (2012). Cognitive aging: A primer. New York: Psychology Press.

Pinker, S. (1997). How the mind works. New York: Norton.

Press, O. U. (2004). Test, Q.P: Paper and Pen Test. Oxford: Oxford University Press.

Prince, E. F. (1981). Toward a taxonomy of given-new information. In P. Cole, Radical Pragmatics (pp. 223-255.). New York: Academic Press.

Prince, E. F. (1992). The ZPG letter: Subjects, definiteness, and information-status. In W. C. Mann, Discourse description: diverse analyses of a fund raising text (Vol. (Vol. 16), pp. 295-325). Philadelphia: John Benjamins Publishing.

Reinhart, T. (2006). Interface strategies. Cambridge, MA: MIT Press.

Rothman, J., \& Slabakova, R. (2011). The Mind-Context Divide: On acquisition at the linguistic interfaces. Lingua, 121(4), 568-576.

Schmitz, C. (2010). Limesurvey [computer software].

Schrauf, R. W. (2008). Bilingualism and aging. In A. A. (Eds.), An Introduction to Bilingualism: Principles and Processes (pp. 105-127). New York: Routledge.

Serratrice, L., Sorace, A., \& Paoli, S. (2004). Crosslinguistic influence at the syntaxpragmatics interface: Subjects and objects in English-Italian bilingual and monolingual acquisition. Bilingualism: Language and cognition, , 7(03), 183205.

Slabakova, R. \&. Ivanov, I. (2011). A more careful look at the syntax-discourse interface. Lingua, 121(4), 637-651.

Sorace, A. \&. (2006). Anaphora resolution in near-native speakers of Italian. Second Language Research, 22(3), 339-368. 
Sorace, A., \& Filiaci, F. (2006). Anaphora resolution in near-native speakers of Italian. Second Language Research, 22(3), 339-368.

Sorace, A., \& Serratrice, L. (2009). Internal and external interfaces in bilingual language development: Beyond structural overlap. International Journal of Bilingualism, 13(2), 195-210.

Sorace, A. (2011). Pinning down the concept of "interface" in bilingualism. Linguistic Approaches to Bilingualism, 1(1), 1-33.

Sperber, D. (1994). The modularity of thought and the epidemiology of representations. In A. H. (Eds.), Mapping the mind: Domain Specificity in Cognition and Culture (pp. 39-67). Cambridge: Cambridge University Press.

Tsimpli, I. M. (2004). First language attrition and syntactic subjects: A study of Greek and Italian near-native speakers of English. International Journal of Bilingualism, , 8(3), 257-77.

Tsimpli, I. M., Sorace, A., Heycock, C., \& Filiaci, F. (2004). First language attrition and syntactic subjects: A study of Greek and Italian near-native speakers of English. International Journal of Bilingualism, 8(3), 257-77.

Ward, G., Birner, B., \& Huddleston, R. (2002). Information packaging. In R. \&. Huddleston, The Cambridge Grammar of English. Language. (pp. 1363-1448). Cambridge: Cambridge University Press.

Ward, G., \& Birner, B. (2004). Information structure and non-canonical syntax. In L. \&. Horn, The handbook of pragmatics (Vol. 26) (pp. 153-174). Cornwall: John Wiley \& Sons.

White, L. (2009). Grammatical theory: Interfaces and L2 knowledge. In W. C. Ritchie, The new handbook of second language acquisition (pp. 49-68). Brill: Emeral Group Publishing.

White, L. (2011). The interface hypothesis: How far does it extend? Linguistic Approaches to Bilingualism, 1(1), 108-110. 


\section{APPENDIX I: ON-LINE TASK}

7.1 ON-LINE TASK RAW DATA.

\begin{tabular}{|c|c|c|c|c|c|c|c|c|c|}
\hline \multirow[b]{2}{*}{ Subjects } & \multicolumn{9}{|c|}{$\begin{array}{l}\text { RTs for active congruent segments (sentence1) and incongruent (sentence3), grouped } \\
\text { by subjects. }\end{array}$} \\
\hline & L1 & code1_s1 & code1_s2 & code1_s3 & code1_S4 & code3_s1 & code3_s2 & code3_s3 & code3_S4 \\
\hline 1 & Spanish & 807,50 & 833,33 & 977,50 & 1304,67 & 842,33 & 882,17 & 943,17 & 1593,00 \\
\hline 2 & Spanish & 539,83 & 468,67 & 496,67 & 826,50 & 578,17 & 616,17 & 574,17 & 890,50 \\
\hline 3 & Spanish & 500,00 & 712,33 & 763,00 & 717,83 & 624,86 & 841,27 & 780,22 & 811,54 \\
\hline 4 & Spanish & 482,83 & 550,33 & 548,83 & 1217,83 & 552,67 & 740,83 & 699,33 & 1003,83 \\
\hline 5 & Spanish & 415,33 & 717,67 & 625,33 & 1477,67 & 468,31 & 938,99 & 1033,84 & 1459,30 \\
\hline 6 & Spanish & 1081,33 & 949,83 & 771,00 & 968,00 & 633,80 & 887,20 & 1082,40 & 1102,60 \\
\hline 7 & Spanish & 772,50 & 1390,71 & 1293,33 & 1904,36 & 1288,60 & 1333,80 & 1434,72 & 1917,20 \\
\hline 8 & Spanish & 388,00 & 463,83 & 450,67 & 672,33 & 443,83 & 482,17 & 488,17 & 710,00 \\
\hline 9 & Spanish & 770,25 & 838,00 & 852,25 & 744,25 & 813,17 & 996,38 & 745,33 & 1411,35 \\
\hline 10 & Spanish & 462,20 & 438,00 & 412,20 & 873,80 & 427,33 & 383,17 & 390,17 & 720,17 \\
\hline 11 & Spanish & 641,83 & 905,83 & 669,33 & 640,83 & 607,33 & 799,00 & 739,00 & 906,67 \\
\hline 12 & Spanish & 334,00 & 381,17 & 401,00 & 647,33 & 363,17 & 466,50 & 403,83 & 684,00 \\
\hline 13 & English & 410,17 & 429,67 & 487,00 & 769,67 & 511,67 & 455,17 & 422,33 & 660,17 \\
\hline 14 & English & 823,00 & 1221,75 & 1234,00 & 1781,75 & 866,50 & 979,75 & 1185,25 & 1436,75 \\
\hline 15 & English & 781,20 & 1092,00 & 1096,60 & 1096,80 & 1513,78 & 945,25 & 843,50 & 1031,75 \\
\hline 16 & English & 833,60 & 569,40 & 631,60 & 610,00 & 235,75 & 517,25 & 534,25 & 528,75 \\
\hline 17 & English & 776,75 & 825,50 & 916,75 & 1425,75 & 1646,33 & 911,67 & 939,17 & 1333,83 \\
\hline 18 & English & 719,83 & 966,67 & 1001,33 & 1083,67 & 902,75 & 1160,25 & 919,50 & 964,50 \\
\hline 19 & English & 692,67 & 560,50 & 580,67 & 976,00 & 719,67 & 581,00 & 592,33 & 1164,33 \\
\hline 20 & English & 579,33 & 649,00 & 660,33 & 1113,50 & 755,50 & 457,33 & 519,67 & 875,33 \\
\hline 21 & English & 1012,83 & 948,33 & 949,00 & 1189,50 & 1094,00 & 816,00 & 828,83 & 1273,33 \\
\hline 22 & English & 584,60 & 872,60 & 920,40 & 1193,80 & 850,00 & 819,80 & 775,80 & 1536,20 \\
\hline 23 & English & 988,83 & 1190,17 & 1180,33 & 1416,33 & 965,67 & 1163,17 & 1153,00 & 1461,83 \\
\hline \multirow[t]{2}{*}{24} & English & 1138,60 & 1242,20 & 1307,20 & 1863,20 & 1178,40 & 1197,60 & 1420,64 & 1907,20 \\
\hline & \multicolumn{9}{|c|}{$\begin{array}{l}\text { RTs for passive congruent segments (sentence } 4 \text { ) and incongruent (sentence } 2 \text { ), grouped } \\
\text { by subjects. }\end{array}$} \\
\hline Subjects & L1 & code4_s1 & code4_s2 & code4_s3 & code4_S4 & code2_s1 & code2_s2 & code2_s3 & code2_S4 \\
\hline 1 & Spanish & 638,83 & 908,67 & 1203,33 & 1370,67 & 846,80 & 999,40 & 1327,20 & 1667,40 \\
\hline 2 & Spanish & 574,33 & 531,17 & 479,50 & 612,00 & 415,17 & 548,50 & 607,83 & 838,00 \\
\hline 3 & Spanish & 504,67 & 734,00 & 785,67 & 845,00 & 700,00 & 868,83 & 953,83 & 899,33 \\
\hline 4 & Spanish & 526,00 & 859,17 & 918,50 & 1137,50 & 533,83 & 987,50 & 791,17 & 892,17 \\
\hline 5 & Spanish & 472,33 & 819,00 & 850,33 & 1271,00 & 642,83 & 976,83 & 932,17 & 1457,50 \\
\hline 6 & Spanish & 944,50 & 1265,67 & 1381,83 & 1681,00 & 1173,40 & 1097,00 & 1010,00 & 821,00 \\
\hline 7 & Spanish & 995,80 & 1715,54 & 1631,16 & 1645,40 & 777,25 & 1564,25 & 1106,25 & 1824,00 \\
\hline 8 & Spanish & 445,33 & 534,67 & 581,83 & 808,33 & 447,00 & 527,67 & 589,33 & 1029,83 \\
\hline 9 & Spanish & 864,83 & 681,33 & 746,83 & 1239,00 & 637,00 & 1153,80 & 947,60 & 1268,00 \\
\hline 10 & Spanish & 297,40 & 794,00 & 958,50 & 971,00 & 512,33 & 517,67 & 493,50 & 1602,17 \\
\hline 11 & Spanish & 529,67 & 855,00 & 887,00 & 1014,83 & 833,17 & 1349,83 & 1145,67 & 957,17 \\
\hline 12 & Spanish & 424,40 & 386,80 & 397,40 & 474,80 & 353,60 & 474,00 & 459,80 & 499,00 \\
\hline 13 & English & 515,40 & 473,80 & 590,80 & 601,40 & 465,17 & 480,33 & 626,83 & 927,67 \\
\hline 14 & English & 774,25 & 1080,25 & 1210,50 & 1560,00 & 1128,50 & 978,50 & 1078,25 & 1726,75 \\
\hline 15 & English & 750,40 & 1265,80 & 1045,60 & 1104,20 & 849,40 & 1160,75 & 1142,40 & 1105,75 \\
\hline 16 & English & 397,40 & 468,20 & 461,20 & 612,40 & 519,50 & 619,25 & 612,00 & 700,00 \\
\hline 17 & English & 1125,75 & 1571,00 & 1060,75 & 1092,50 & 849,00 & 1004,75 & 1186,75 & 1325,00 \\
\hline 18 & English & 774,80 & 1286,60 & 1080,80 & 983,00 & 984,83 & 973,50 & 971,67 & 986,50 \\
\hline 19 & English & 591,50 & 503,83 & 520,50 & 650,17 & 609,67 & 493,50 & 488,67 & 639,67 \\
\hline 20 & English & 437,33 & 529,00 & 555,33 & 825,67 & 588,00 & 642,80 & 699,60 & 962,60 \\
\hline 21 & English & 957,17 & 896,67 & 873,33 & 933,33 & 859,33 & 825,83 & 844,33 & 1001,17 \\
\hline 22 & English & 706,75 & 1339,50 & 1122,75 & 1731,25 & 805,50 & 1176,67 & 1011,83 & 1344,83 \\
\hline 23 & English & 814,67 & 1243,00 & 1188,83 & 1479,33 & 904,17 & 1160,67 & 1237,17 & 1242,33 \\
\hline 24 & English & 1158,65 & 1518,50 & 1604,75 & 1925,22 & 1232,71 & 1467,50 & 1489,68 & 2009,52 \\
\hline
\end{tabular}


RTs for active congruent segments (sentence1), grouped by items.

\begin{tabular}{|c|c|c|c|c|c|c|c|c|}
\hline verb & code1_s1_English & code1_s2_English & code1_s3_English & code1_s4_English & code1_s1_Spanish & code1_s2_Spanish & code1_s3_Spanish & code1_s4_Spanish \\
\hline bite & 930,00 & 993,00 & 1039,33 & 1240,67 & 746,00 & 613,33 & 488,33 & 904,67 \\
\hline convince & 647,33 & 719,67 & 817,33 & 1093,67 & 676,33 & 780,67 & 898,33 & 1621,00 \\
\hline choose & 582,00 & 702,00 & 713,33 & 1029,00 & 834,50 & 567,50 & 701,00 & 1133,00 \\
\hline fascinate & 723,33 & 1023,00 & 995,67 & 1388,33 & 544,00 & 719,67 & 653,00 & 1289,33 \\
\hline feed & 991,67 & 929,33 & 1062,67 & 1303,00 & 561,00 & 618,67 & 680,67 & 1509,67 \\
\hline find & 1071,00 & 995,00 & 1005,00 & 1233,50 & 445,33 & 491,00 & 455,33 & 1047,33 \\
\hline forget & 680,67 & 769,00 & 886,00 & 1362,00 & 441,33 & 438,00 & 591,00 & 854,00 \\
\hline help & 703,00 & 736,00 & 796,00 & 1334,00 & 758,33 & 891,67 & 943,89 & 984,33 \\
\hline hug & 697,50 & 905,00 & 953,50 & 713,50 & 542,67 & 688,67 & 631,00 & 834,67 \\
\hline hurt & 736,33 & 777,67 & 647,33 & 992,67 & 495,67 & 1050,00 & 754,33 & 1672,33 \\
\hline identify & 631,00 & 680,33 & 640,00 & 840,00 & 567,67 & 1169,33 & 758,67 & 1489,67 \\
\hline insult & 678,50 & 702,00 & 756,50 & 873,00 & 420,67 & 729,33 & 653,67 & 1125,00 \\
\hline invite & 738,00 & 807,67 & 792,67 & 863,33 & 629,00 & 634,67 & 677,33 & 812,00 \\
\hline kill & 801,67 & 981,33 & 1175,33 & 1332,00 & 430,33 & 671,33 & 567,00 & 987,00 \\
\hline kiss & 428,00 & 534,90 & 570,50 & 706,00 & 448,67 & 592,67 & 585,67 & 796,67 \\
\hline protect & 885,67 & 844,67 & 747,33 & 1554,33 & 632,00 & 681,67 & 638,67 & 917,33 \\
\hline punish & 643,50 & 1190,84 & 979,00 & 1300,50 & 969,65 & 712,67 & 657,33 & 397,67 \\
\hline push & 774,33 & 760,67 & 755,67 & 828,67 & 457,33 & 781,00 & 740,67 & 971,33 \\
\hline save & 633,33 & 812,33 & 731,00 & 1002,67 & 870,67 & 866,33 & 793,00 & 699,33 \\
\hline see & 705,00 & 772,00 & 953,67 & 1592,33 & 454,00 & 599,00 & 583,33 & 1275,00 \\
\hline shot & 674,00 & 904,67 & 1212,67 & 969,33 & 558,00 & 789,67 & 856,00 & 568,67 \\
\hline stop & 829,00 & 1192,00 & 990,00 & 1124,00 & 438,00 & 729,50 & 647,50 & 776,00 \\
\hline support & 791,33 & 966,00 & 1136,67 & 1282,00 & 746,33 & 1162,38 & 816,33 & 863,67 \\
\hline visit & 792,67 & 948,67 & 955,67 & 2066,67 & 398,00 & 504,50 & 618,50 & 1740,00 \\
\hline
\end{tabular}

RTs for active incongruent segments (sentence3), grouped by items.

\begin{tabular}{|c|c|c|c|c|c|c|c|c|}
\hline verb & code3_s1_English & code3_s2_English & code3_s3_English & code3_s4_English & code3_s1_Spanish & code3_s2_Spanish & code3_s3_Spanish & code3_s4_Spanish \\
\hline bite & 581,67 & 788,33 & 715,33 & 700,33 & 510,00 & 927,67 & 816,33 & 793,00 \\
\hline convince & 1297,67 & 1035,00 & 969,67 & 1472,00 & 749,67 & 804,00 & 671,67 & 1011,67 \\
\hline choose & 1629,98 & 1054,00 & 820,50 & 693,50 & 554,00 & 912,00 & 770,67 & 650,67 \\
\hline fascinate & 668,67 & 649,00 & 1268,73 & 1931,67 & 548,33 & 589,33 & 662,67 & 1441,00 \\
\hline feed & 1330,67 & 797,00 & 793,33 & 1167,33 & 377,00 & 476,00 & 401,00 & 867,00 \\
\hline find & 579,67 & 699,67 & 748,33 & 1087,33 & 267,00 & 500,50 & 560,50 & 1000,50 \\
\hline forget & 833,67 & 1218,92 & 1113,00 & 1459,33 & 587,33 & 588,67 & 686,00 & 611,33 \\
\hline help & 653,33 & 733,67 & 825,67 & 834,00 & 600,33 & 810,00 & 921,67 & 1443,00 \\
\hline hug & 851,00 & 888,33 & 819,00 & 1129,67 & 614,33 & 639,00 & 677,67 & 1117,00 \\
\hline hurt & 1419,33 & 955,00 & 1034,67 & 1432,00 & 396,67 & 482,67 & 577,67 & 1405,33 \\
\hline identify & 1105,67 & 1191,33 & 951,33 & 1510,67 & 499,67 & 911,67 & 1150,72 & 1217,67 \\
\hline insult & 893,00 & 893,33 & 1244,26 & 1435,00 & 619,00 & 564,67 & 592,33 & 778,00 \\
\hline invite & 1038,00 & 780,00 & 702,00 & 742,00 & 753,67 & 1123,08 & 1136,89 & 695,67 \\
\hline kill & 661,67 & 649,67 & 652,00 & 757,67 & 990,48 & 809,00 & 1016,00 & 1110,67 \\
\hline kiss & 708,00 & 770,33 & 846,67 & 1107,00 & 506,33 & 864,33 & 902,00 & 1303,00 \\
\hline protect & 607,00 & 648,00 & 756,00 & 1806,00 & 448,00 & 719,00 & 569,00 & 1389,00 \\
\hline punish & 668,33 & 721,33 & 771,00 & 1086,33 & 566,00 & 530,00 & 544,67 & 695,67 \\
\hline push & 1122,00 & 719,00 & 746,67 & 1201,33 & 427,33 & 759,00 & 530,67 & 1156,33 \\
\hline save & 1298,00 & 422,41 & 403,27 & 449,00 & 456,00 & 563,33 & 552,33 & 617,33 \\
\hline see & 947,00 & 662,50 & 625,50 & 1645,00 & 702,00 & 672,67 & 713,67 & 954,67 \\
\hline shot & 814,00 & 602,00 & 674,00 & 838,67 & 484,00 & 569,67 & 560,00 & 611,67 \\
\hline stop & 1107,00 & 940,50 & 1021,00 & 2089,00 & 710,33 & 886,00 & 866,00 & 844,00 \\
\hline support & 631,00 & 691,33 & 641,67 & 964,00 & 758,33 & 603,67 & 645,67 & 876,67 \\
\hline visit & 853,50 & 1019,50 & 871,50 & 1778,00 & 664,00 & 871,33 & 944,33 & 1646,23 \\
\hline
\end{tabular}


RTs for passive congruent segments (sentence4), grouped by items.

\begin{tabular}{|c|c|c|c|c|c|c|c|c|}
\hline verb & code4_s1_English & code4_s2_English & code4_s3_English & code4_s4_English & code4_s1_Spanish & code4_s2_Spanish & code4_s3_Spanish & code4_s4_Spanish \\
\hline bite & 687,33 & 747,00 & 716,00 & 686,67 & 385,67 & 696,67 & 777,33 & 632,33 \\
\hline convince & 764,00 & 1611,33 & 1347,00 & 1417,00 & 666,33 & 980,67 & 780,33 & 1089,00 \\
\hline choose & 700,00 & 953,67 & 803,67 & 904,33 & 428,00 & 1090,33 & 1068,33 & 1069,67 \\
\hline fascinate & 912,50 & 979,50 & 1153,50 & 1393,50 & 375,00 & 569,67 & 687,33 & 1410,00 \\
\hline feed & 910,00 & 1082,00 & 1166,00 & 869,00 & 717,33 & 846,33 & 926,67 & 1215,00 \\
\hline find & 477,00 & 608,50 & 625,00 & 670,00 & 392,67 & 602,33 & 835,33 & 972,00 \\
\hline forget & 675,00 & 1078,50 & 851,00 & 1041,50 & 1063,42 & 1404,72 & 1222,67 & 998,67 \\
\hline help & 931,33 & 820,00 & 843,33 & 1396,33 & 495,00 & 1262,33 & 1542,33 & 1272,00 \\
\hline hug & 1038,67 & 1400,33 & 1129,33 & 1284,33 & 758,67 & 694,67 & 559,00 & 934,00 \\
\hline hurt & 785,00 & 1353,00 & 1283,00 & 1309,00 & 810,67 & 1505,67 & 1573,55 & 1689,09 \\
\hline identify & 680,67 & 866,67 & 752,33 & 1631,00 & 763,33 & 1060,67 & 1024,00 & 1098,00 \\
\hline insult & 671,67 & 1461,33 & 957,33 & 926,00 & 665,00 & 803,33 & 741,67 & 1032,33 \\
\hline invite & 680,00 & 691,00 & 775,67 & 1148,00 & 378,50 & 477,50 & 441,50 & 610,00 \\
\hline kill & 755,50 & 943,00 & 1012,00 & 1258,00 & 637,67 & 686,67 & 789,33 & 876,00 \\
\hline kiss & 672,67 & 759,00 & 738,33 & 786,00 & 526,50 & 1170,50 & 979,50 & 1461,00 \\
\hline protect & 660,00 & 603,67 & 715,00 & 899,00 & 476,00 & 802,00 & 1417,67 & 1153,67 \\
\hline punish & 1143,50 & 1258,50 & 1145,00 & 1384,00 & 519,00 & 700,00 & 804,33 & 983,67 \\
\hline push & 803,00 & 1289,00 & 1168,00 & 1087,00 & 335,00 & 832,00 & 913,67 & 828,67 \\
\hline save & 738,00 & 919,00 & 921,00 & 1101,00 & 813,67 & 762,67 & 751,33 & 1152,33 \\
\hline see & 500,33 & 616,00 & 647,33 & 887,33 & 511,00 & 739,67 & 663,67 & 1206,00 \\
\hline shot & 690,00 & 879,00 & 842,33 & 920,33 & 811,00 & 729,67 & 637,00 & 758,67 \\
\hline stop & 438,50 & 488,00 & 868,50 & 505,00 & 380,67 & 517,00 & 520,00 & 713,00 \\
\hline support & 1130,38 & 1630,50 & 1306,00 & 1260,00 & 545,67 & 606,33 & 714,33 & 1005,33 \\
\hline visit & 644,33 & 945,67 & 1005,33 & 1685,33 & 597,00 & 709,67 & 787,33 & 1716,89 \\
\hline
\end{tabular}

RTs for passive incongruent segments (sentence2), grouped by items.

\begin{tabular}{|c|c|c|c|c|c|c|c|c|}
\hline verb & code2_s1_English & code2_s2_English & code2_s3_English & code2_s4_English & code2_s1_Spanish & code2_s2_Spanish & code2_s3_Spanish & code2_s4_Spanish \\
\hline bite & 799,33 & 1360,21 & 1048,33 & 847,33 & 631,67 & 1196,67 & 755,67 & 491,00 \\
\hline convince & 549,00 & 495,00 & 430,72 & 650,00 & 607,67 & 714,33 & 879,67 & 1402,00 \\
\hline choose & 972,00 & 823,00 & 905,50 & 1075,00 & 775,33 & 715,67 & 564,67 & 989,67 \\
\hline fascinate & 703,67 & 794,33 & 872,00 & 1004,00 & 753,33 & 1040,33 & 957,00 & 1432,33 \\
\hline feed & 660,33 & 652,00 & 674,33 & 1230,00 & 499,33 & 575,33 & 1007,00 & 1276,67 \\
\hline find & 957,67 & 1287,00 & 1190,33 & 1337,33 & 1120,00 & 1091,67 & 1228,33 & 700,33 \\
\hline forget & 971,33 & 981,67 & 896,67 & 1072,00 & 478,00 & 875,00 & 1000,33 & 1080,33 \\
\hline help & 783,00 & 797,33 & 761,33 & 900,67 & 725,67 & 907,67 & 799,33 & 1075,67 \\
\hline hug & 680,00 & 703,00 & 722,67 & 926,00 & 320,00 & 1382,00 & 680,00 & 1110,33 \\
\hline hurt & 735,33 & 1021,33 & 1276,67 & 1745,00 & 431,67 & 724,33 & 694,67 & 1572,33 \\
\hline identify & 1018,00 & 942,00 & 1036,33 & 1397,67 & 914,33 & 798,33 & 888,33 & 1903,80 \\
\hline insult & 793,33 & 868,33 & 1305,67 & 1166,33 & 604,00 & 628,67 & 600,33 & 982,00 \\
\hline invite & 1188,50 & 839,00 & 824,50 & 1546,00 & 583,67 & 726,67 & 740,00 & 1116,67 \\
\hline kill & 1137,00 & 1159,67 & 1068,00 & 1040,00 & 802,67 & 917,00 & 1019,33 & 888,00 \\
\hline kiss & 1400,50 & 940,50 & 1212,00 & 1327,00 & 699,67 & 923,00 & 864,67 & 936,33 \\
\hline protect & 1096,00 & 1080,67 & 1163,00 & 1263,67 & 302,00 & 1319,00 & 796,00 & 1068,00 \\
\hline punish & 550,33 & 647,67 & 682,33 & 746,67 & 327,50 & 792,50 & 576,00 & 723,00 \\
\hline push & 440,00 & 510,00 & 488,00 & 1087,00 & 409,50 & 473,00 & 461,50 & 716,00 \\
\hline save & 836,00 & 794,67 & 784,00 & 822,33 & 536,00 & 633,00 & 818,67 & 902,67 \\
\hline see & 770,33 & 707,67 & 1001,67 & 1494,67 & 508,50 & 621,50 & 1040,50 & 1978,01 \\
\hline shot & 1078,00 & 676,00 & 1034,00 & 934,67 & 694,50 & 739,50 & 602,00 & 613,50 \\
\hline stop & 676,00 & 875,00 & 741,50 & 1063,00 & 874,33 & 1052,00 & 948,00 & 861,33 \\
\hline support & 671,33 & 968,67 & 835,00 & 844,67 & 604,00 & 1161,00 & 874,00 & 1067,50 \\
\hline visit & 868,67 & 1305,33 & 1308,67 & 1802,40 & 1132,48 & 1651,00 & 1306,21 & 1597,50 \\
\hline
\end{tabular}


Global 'RT rates' (s1+s3) actives and passives grouped by subjects.

\begin{tabular}{|c|c|c|c|c|c|}
\hline Subjects & L1 & act_cong_s1s3 & act_incong_s1s3 & pas_cong_s1s3 & Pas_incong_s1s3 \\
\hline 1 & Spanish & 0,681731381 & 0,669311508 & 0,669675856 & 0,685069641 \\
\hline 2 & Spanish & 0,688628059 & 0,651587975 & 0,664879075 & 0,65097041 \\
\hline 3 & Spanish & 0,639385758 & 0,625493957 & 0,637411493 & 0,655589323 \\
\hline 4 & Spanish & 0,652128108 & 0,628251234 & 0,627043843 & 0,572972973 \\
\hline 5 & Spanish & 0,591848341 & 0,615348222 & 0,617587549 & 0,617203318 \\
\hline 6 & Spanish & 0,661036103 & 0,659214873 & 0,64764291 & 0,665589562 \\
\hline 7 & Spanish & 0,55850944 & 0,687004271 & 0,596352665 & 0,54629831 \\
\hline 8 & Spanish & 0,643889955 & 0,659045374 & 0,657667271 & 0,662617221 \\
\hline 9 & Spanish & 0,659418817 & 0,610009823 & 0,702863788 & 0,578659071 \\
\hline 10 & Spanish & 0,666260286 & 0,680871738 & 0,612664032 & 0,660212231 \\
\hline 11 & Spanish & 0,591414825 & 0,627563704 & 0,623624358 & 0,594482275 \\
\hline 12 & Spanish & 0,658503808 & 0,621807864 & 0,679960285 & 0,631816063 \\
\hline 13 & English & 0,676171335 & 0,672345531 & 0,700126582 & 0,694509222 \\
\hline 14 & English & 0,627373237 & 0,67681016 & 0,647553018 & 0,692802763 \\
\hline 15 & English & 0,632298471 & 0,738953328 & 0,586583056 & 0,631805998 \\
\hline 16 & English & 0,720141551 & 0,598174403 & 0,647120892 & 0,646294445 \\
\hline 17 & English & 0,672290592 & 0,739312777 & 0,581902861 & 0,669544483 \\
\hline 18 & English & 0,640354685 & 0,610980721 & 0,590541659 & 0,66774744 \\
\hline 19 & English & 0,694356085 & 0,693079768 & 0,688189789 & 0,689980107 \\
\hline 20 & English & 0,656371338 & 0,736026936 & 0,652354874 & 0,667012018 \\
\hline 21 & English & 0,67413092 & 0,702062922 & 0,671209436 & 0,673519141 \\
\hline 22 & English & 0,632991252 & 0,664785738 & 0,577311455 & 0,606991761 \\
\hline 23 & English & 0,645713435 & 0,64557412 & 0,617126136 & 0,648495861 \\
\hline 24 & English & 0,663177874 & 0,697484086 & 0,651380359 & 0,677348431 \\
\hline \multicolumn{2}{|l|}{ Promedio } & 0,651171902 & 0,662962543 & 0,639532218 & 0,645313836 \\
\hline \multicolumn{2}{|c|}{ Desv. Estándar } & 0,03516658 & 0,041587817 & 0,036972511 & 0,040326115 \\
\hline \multicolumn{2}{|c|}{$\begin{array}{l}\text { Kolmogorov-Smirnov } \\
\text { Lilliefors }\end{array}$} & $\begin{array}{l}d=, 12908, p>.20 \\
p>.20\end{array}$ & $\begin{array}{l}d=, 13138, p>.20 ; \\
p>.20\end{array}$ & $\begin{array}{l}d=, 12298, p>.20 ; \\
p>.20\end{array}$ & $\begin{array}{l}d=, 17637, p>.20 ; \\
p<, 10\end{array}$ \\
\hline
\end{tabular}


Global (s1+s3) 'RT rates' in actives (codes 1, 3) and passives (codes 4, 2) grouped by items.

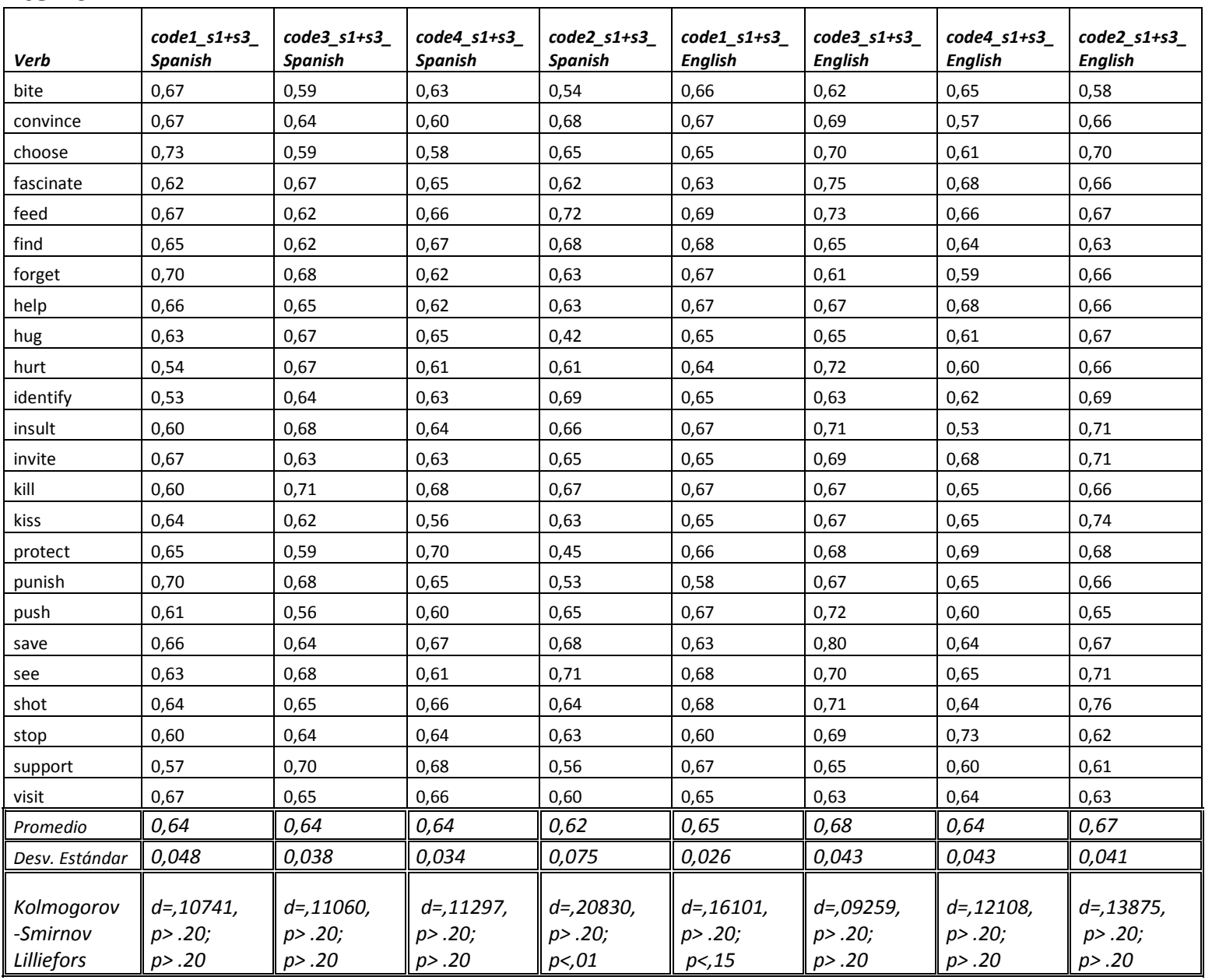


7.2 A1. ANALYSIS BY SUBJECTS IN ACTIVES.

\begin{tabular}{|c|c|c|c|c|c|c|}
\hline \multicolumn{7}{|c|}{ A1.:By subjects. Rate's means table in actives } \\
\hline SUBJECTS & INFOSTRUCTURE & Mean & Std.Err. & $-95,00 \%$ & $95,00 \%$ & $\mathbf{N}$ \\
\hline Learners & congruent & 0,641 & 0,010 & 0,620 & 0,662 & 12 \\
\hline Learners & incongruent & 0,645 & 0,011 & 0,622 & 0,667 & 12 \\
\hline Natives & congruent & 0,661 & 0,010 & 0,641 & 0,682 & 12 \\
\hline Natives & incongruent & 0,681 & 0,011 & 0,659 & 0,704 & 12 \\
\hline Learners & All & 0,643 & 0,007 & 0,628 & 0,657 & 12 \\
\hline Natives & All & 0,671 & 0,007 & 0,657 & 0,686 & 12 \\
\hline All & Congruency & 0,651 & 0,007 & 0,637 & 0,666 & 24 \\
\hline All & Incongruency & 0,663 & 0,008 & 0,647 & 0,679 & 24 \\
\hline \multicolumn{7}{|c|}{ ANOVA by subjects in ACTIVES } \\
\hline Effect & SS & $\begin{array}{l}\text { Degr. of } \\
\text { freedom }\end{array}$ & MS & $\mathbf{F}$ & $\mathbf{p}$ & \\
\hline Subjects & 0,01 & 1 & 0,01 & 8,202 & $0,009 *$ & \\
\hline Congruency & 0,002 & 1 & 0,002 & 1,159 & 0,293 & \\
\hline Congruency $\mathrm{x}$ Subjects & 0,001 & 1 & 0,001 & 0,565 & 0,46 & \\
\hline \multicolumn{7}{|c|}{ Planned comparisons by subjects in ACTIVES } \\
\hline \multicolumn{7}{|c|}{ Learners versus natives } \\
\hline \multicolumn{7}{|c|}{ in congruent actives: $F(1,22)=2,076, p=0,163$} \\
\hline \multicolumn{7}{|c|}{ in incongruent actives: $F(\mathbf{1}, \mathbf{2 2})=5,598, p=0,027$} \\
\hline \multicolumn{7}{|c|}{ Congruency: } \\
\hline \multicolumn{7}{|c|}{ in Learners: $\mathrm{F}(1,22)=0,052, p=0,820$} \\
\hline \multicolumn{7}{|c|}{ in Natives: $F(1,22)=1,670, p=0,209$} \\
\hline
\end{tabular}

\begin{tabular}{|c|c|c|c|c|c|c|}
\hline \multicolumn{7}{|c|}{ A1: By items: Rate's means table in actives } \\
\hline SUBJECTS & INFOSTRUCTURE & Mean & Std.Err. & $-95,00 \%$ & $95,00 \%$ & $\mathbf{N}$ \\
\hline Learners & congruent & 0,637 & 0,010 & 0,617 & 0,658 & 24 \\
\hline Learners & incongruent & 0,645 & 0,008 & 0,628 & 0,661 & 24 \\
\hline Natives & congruent & 0,654 & 0,005 & 0,644 & 0,665 & 24 \\
\hline Natives & incongruent & 0,684 & 0,009 & 0,666 & 0,702 & 24 \\
\hline Learners & All & 0,641 & 0,007 & 0,625 & 0,656 & 24 \\
\hline Natives & All & 0,669 & 0,007 & 0,655 & 0,683 & 24 \\
\hline All & Congruency & 0,646 & 0,008 & 0,630 & 0,662 & 24 \\
\hline All & Incongruency & 0,664 & 0,008 & 0,648 & 0,681 & 24 \\
\hline \multicolumn{7}{|c|}{ ANOVA by items in actives } \\
\hline Effect & ss & \begin{tabular}{|l|} 
Degr. of \\
freedom
\end{tabular} & MS & $\mathbf{F}$ & $\mathbf{P}$ & \\
\hline Subjects & 0,019 & 1 & 0,019 & 13,3 & $0,001^{*}$ & \\
\hline Congruency & 0,008 & 1 & 0,008 & 4,22 & 0,051 & \\
\hline Congruency $\mathrm{x}$ Subjects & 0,003 & 1 & 0,003 & 1,55 & 0,225 & \\
\hline \multicolumn{7}{|c|}{ Planned comparisons by items in actives } \\
\hline \multicolumn{7}{|c|}{ Learners versus natives } \\
\hline \multicolumn{7}{|c|}{ in congruent actives: $F(1,23)=2,348, p=0,139$} \\
\hline \multicolumn{7}{|c|}{ in incongruent actives: $F(\mathbf{1}, \mathbf{2 3})=\mathbf{1 0 , 0 8 1 , p = 0 , 0 0 4}$} \\
\hline \multicolumn{7}{|l|}{ Congruency: } \\
\hline \multicolumn{7}{|c|}{ in Learners: $F(1,23)=0,265, p=0,611$} \\
\hline \multicolumn{7}{|c|}{ in Natives: $F(1,23)=7,331, p=0,012$} \\
\hline
\end{tabular}


7.3 A2. ANALYSIS BY SUBJECTS IN PASSIVES.

\begin{tabular}{|c|c|c|c|c|c|c|}
\hline \multicolumn{7}{|c|}{ A2. By Subjects in Passives: Rate's means table } \\
\hline SUBJECTS & INFOSTRUCTURE & Mean & Std.Err. & $-95,00 \%$ & $95,00 \%$ & $\mathbf{N}$ \\
\hline Learners & Congruent & 0,645 & 0,011 & 0,622 & 0,667 & 12 \\
\hline Learners & Incongruent & 0,627 & 0,011 & 0,605 & 0,649 & 12 \\
\hline Natives & Congruent & 0,634 & 0,011 & 0,612 & 0,657 & 12 \\
\hline Natives & Incongruent & 0,664 & 0,011 & 0,642 & 0,686 & 12 \\
\hline Learners & All & 0,636 & 0,009 & 0,617 & 0,655 & 12 \\
\hline Natives & All & 0,649 & 0,009 & 0,630 & 0,668 & 12 \\
\hline All & Congruency & 0,640 & 0,008 & 0,624 & 0,655 & 24 \\
\hline All & Incongruency & 0,645 & 0,007 & 0,630 & 0,661 & 24 \\
\hline \multicolumn{7}{|c|}{ ANOVA by subjects in PASSIVES } \\
\hline Effect & SS & Degr. freedom & MS & $\mathbf{F}$ & $\mathbf{P}$ & \\
\hline Subjects & 0,002 & 1 & 0,002 & 1,078 & 0,31 & \\
\hline Congruency & 0 & 1 & 0 & 0,526 & 0,476 & \\
\hline $\begin{array}{ll}\begin{array}{l}\text { Congruency } \\
\text { Subjects }\end{array} & \mathrm{x} \\
\end{array}$ & 0,007 & 1 & 0,007 & 8,893 &, $007 *$ & \\
\hline \multicolumn{7}{|c|}{ Planned comparisons by subjects in PASSIVES } \\
\hline \multicolumn{7}{|c|}{ Learners versus natives: } \\
\hline \multicolumn{7}{|c|}{ in congruent passives: $\mathrm{F}(1,22)=0,472, p=0,498$} \\
\hline \multicolumn{7}{|c|}{ in incongruent passives: $F(\mathbf{1}, \mathbf{2 2})=6,211, p=0,0207$} \\
\hline \multicolumn{7}{|c|}{ Congruency: } \\
\hline \multicolumn{7}{|c|}{ in Learners: $F(1,22)=2,546, p=0,125$} \\
\hline \multicolumn{7}{|c|}{ in Natives: $F(1,22)=6,872, p=0,015$} \\
\hline
\end{tabular}

\begin{tabular}{|c|c|c|c|c|c|c|}
\hline \multicolumn{7}{|c|}{ A2. By items in Passives: Rate's means table } \\
\hline SUBJECTS & INFOSTRUCTURE & Mean & Std.Err. & $-95,00 \%$ & $95,00 \%$ & $\mathbf{N}$ \\
\hline Learners & Congruent & 0,637 & 0,007 & 0,623 & 0,652 & 24 \\
\hline Learners & Incongruent & 0,622 & 0,015 & 0,590 & 0,653 & 24 \\
\hline Natives & Congruent & 0,636 & 0,009 & 0,618 & 0,654 & 24 \\
\hline Natives & incongruent & 0,667 & 0,008 & 0,650 & 0,684 & 24 \\
\hline Learners & All & 0,630 & 0,010 & 0,608 & 0,651 & 24 \\
\hline Natives & All & 0,651 & 0,008 & 0,635 & 0,668 & 24 \\
\hline All & Congruency & 0,637 & 0,009 & 0,618 & 0,655 & 24 \\
\hline All & Incongruency & 0,644 & 0,014 & 0,616 & 0,672 & 24 \\
\hline \multicolumn{7}{|c|}{ ANOVA by items in PASSIVES } \\
\hline Effect & ss & Degr.of freedom & MS & $\mathbf{F}$ & $\mathbf{P}$ & \\
\hline Subjects & 0,011 & 1 & 0,011 & 6,359 & $0,019 *$ & \\
\hline Congruency & 0,001 & 1 & 0,001 & 0,352 & 0,559 & \\
\hline Congruency $\mathrm{x}$ Subjects & 0,013 & 1 & 0,013 & 6,061 & $0,022 *$ & \\
\hline \multirow{2}{*}{\multicolumn{7}{|c|}{$\begin{array}{l}\text { Planned comparisons by items in PASSIVES } \\
\text { Learners versus natives: }\end{array}$}} \\
\hline & & & & & & \\
\hline \multicolumn{7}{|c|}{ in congruent passives: $F(1,23)=0,026, p=0,873$} \\
\hline \multicolumn{7}{|c|}{ in incongruent passives: $F(\mathbf{1}, \mathbf{2 3})=\mathbf{8 , 7 2 2 , p = 0 , 0 0 7}$} \\
\hline \multicolumn{7}{|l|}{ Congruency: } \\
\hline \multicolumn{7}{|c|}{ in Learners: $F(1,23)=0,713, p=0,407$} \\
\hline in Natives: $F(1,23)=5,8$ & $p=0,024$ & & & & & \\
\hline
\end{tabular}




\subsection{APPENDIX B: AGENTS}

\section{Agents: ANALYSIS BY SUBJECTS: RT rates in actives and passives.}

\begin{tabular}{|c|c|c|c|c|c|}
\hline Subjects & L1 & agent_active_given & agent_active_new & agent_passive_given & agent_passive_new \\
\hline 1 & Spanish & 0,308402292 & 0,315756591 & 0,418226508 & 0,437443199 \\
\hline 2 & Spanish & 0,358653527 & 0,326924889 & 0,386785449 & 0,302523659 \\
\hline 3 & Spanish & 0,253121836 & 0,278165475 & 0,37810518 & 0,388111312 \\
\hline 4 & Spanish & 0,305204383 & 0,277327089 & 0,342126126 & 0,398712198 \\
\hline 5 & Spanish & 0,236208531 & 0,191841725 & 0,365292927 & 0,397042802 \\
\hline 6 & Spanish & 0,385891869 & 0,243450872 & 0,307889282 & 0,384697476 \\
\hline 7 & Spanish & 0,208849637 & 0,302388886 & 0,320861431 & 0,375427075 \\
\hline 8 & Spanish & 0,297888676 & 0,313847967 & 0,376811594 & 0,37253228 \\
\hline 9 & Spanish & 0,313046129 & 0,31827983 & 0,346041484 & 0,32570141 \\
\hline 10 & Spanish & 0,352179214 & 0,355913381 & 0,323925172 & 0,467583785 \\
\hline 11 & Spanish & 0,289505338 & 0,28309509 & 0,344181855 & 0,390462216 \\
\hline 12 & Spanish & 0,299238465 & 0,294419673 & 0,357153954 & 0,328810194 \\
\hline 13 & English & 0,309132019 & 0,368326335 & 0,398664405 & 0,373924051 \\
\hline 14 & English & 0,251010294 & 0,285832096 & 0,33851346 & 0,394942904 \\
\hline 15 & English & 0,263048017 & 0,506006628 & 0,362373317 & 0,341498465 \\
\hline 16 & English & 0,409711983 & 0,183142358 & 0,349564472 & 0,347603256 \\
\hline 17 & English & 0,308356491 & 0,470762045 & 0,390314093 & 0,282302063 \\
\hline 18 & English & 0,267811744 & 0,302682313 & 0,331626849 & 0,343962829 \\
\hline 19 & English & 0,377715169 & 0,380172566 & 0,306983562 & 0,322124807 \\
\hline 20 & English & 0,30674197 & 0,436075036 & 0,362411935 & 0,364950712 \\
\hline 21 & English & 0,348032759 & 0,399440151 & 0,333794558 & 0,320234676 \\
\hline 22 & English & 0,245878197 & 0,34756297 & 0,337953685 & 0,354291575 \\
\hline 23 & English & 0,294354038 & 0,294246102 & 0,374671916 & 0,366189229 \\
\hline 24 & English & 0,30873102 & 0,297665959 & 0,384983235 & 0,368421053 \\
\hline \multicolumn{2}{|l|}{ Promedio } & 0,304113066 & 0,323888585 & 0,355802352 & 0,364562218 \\
\hline \multicolumn{2}{|l|}{ Desvest } & 0,049569302 & 0,076443404 & 0,028944169 & 0,041444614 \\
\hline \multicolumn{2}{|c|}{$\begin{array}{l}\text { Kolmogorov-Smirnov } \\
\text { Lilliefors }\end{array}$} & $\begin{array}{l}d=, 17849, p>.20 \\
p>.10\end{array}$ & $\begin{array}{l}d=, 15420, p>.20 \\
p>.15\end{array}$ & $\begin{array}{l}d=, 09036, p>.20 \\
p>.20\end{array}$ & $\begin{array}{l}d=, 12164, p>.20 \\
p<, 20\end{array}$ \\
\hline
\end{tabular}


Agents: ANALYSIS BY ITEMS: RT rates actives (codes 1, 3) and passives (codes 2, 4).

\begin{tabular}{|c|c|c|c|c|c|c|c|c|}
\hline Verb & $\begin{array}{l}\text { code1_s1_ } \\
\text { Learners }\end{array}$ & $\begin{array}{l}\text { code3_s1_ } \\
\text { Learners }\end{array}$ & $\begin{array}{l}\text { code2_s3_ } \\
\text { Learners }\end{array}$ & $\begin{array}{l}\text { code4_s3_ } \\
\text { Learners }\end{array}$ & $\begin{array}{l}\text { code1_s1_ } \\
\text { Natives }\end{array}$ & $\begin{array}{l}\text { code3_s1_ } \\
\text { Natives }\end{array}$ & $\begin{array}{l}\text { code2_s3_ } \\
\text { Natives }\end{array}$ & $\begin{array}{l}\text { code4_s3_ } \\
\text { Natives }\end{array}$ \\
\hline bite & 0,40 & 0,23 & 0,29 & 0,42 & 0,31 & 0,28 & 0,33 & 0,33 \\
\hline convince & 0,29 & 0,34 & 0,40 & 0,32 & 0,30 & 0,39 & 0,29 & 0,36 \\
\hline choose & 0,40 & 0,25 & 0,27 & 0,41 & 0,29 & 0,47 & 0,34 & 0,33 \\
\hline fascinate & 0,28 & 0,30 & 0,35 & 0,42 & 0,26 & 0,26 & 0,37 & 0,38 \\
\hline feed & 0,30 & 0,30 & 0,48 & 0,37 & 0,33 & 0,46 & 0,34 & 0,37 \\
\hline find & 0,32 & 0,20 & 0,36 & 0,46 & 0,35 & 0,29 & 0,35 & 0,37 \\
\hline forget & 0,30 & 0,32 & 0,43 & 0,33 & 0,29 & 0,26 & 0,31 & 0,33 \\
\hline help & 0,29 & 0,26 & 0,33 & 0,47 & 0,31 & 0,30 & 0,33 & 0,33 \\
\hline hug & 0,29 & 0,32 & 0,29 & 0,28 & 0,27 & 0,33 & 0,34 & 0,32 \\
\hline hurt & 0,22 & 0,27 & 0,38 & 0,40 & 0,34 & 0,42 & 0,42 & 0,38 \\
\hline identify & 0,23 & 0,20 & 0,34 & 0,36 & 0,32 & 0,34 & 0,35 & 0,33 \\
\hline insult & 0,23 & 0,35 & 0,33 & 0,34 & 0,32 & 0,29 & 0,44 & 0,31 \\
\hline invite & 0,32 & 0,25 & 0,36 & 0,34 & 0,32 & 0,41 & 0,29 & 0,36 \\
\hline kill & 0,26 & 0,35 & 0,37 & 0,37 & 0,27 & 0,34 & 0,32 & 0,37 \\
\hline kiss & 0,28 & 0,22 & 0,35 & 0,37 & 0,28 & 0,30 & 0,34 & 0,34 \\
\hline protect & 0,32 & 0,26 & 0,33 & 0,53 & 0,36 & 0,30 & 0,35 & 0,36 \\
\hline punish & 0,41 & 0,34 & 0,34 & 0,40 & 0,23 & 0,31 & 0,36 & 0,32 \\
\hline push & 0,23 & 0,25 & 0,34 & 0,44 & 0,34 & 0,43 & 0,34 & 0,36 \\
\hline save & 0,34 & 0,29 & 0,41 & 0,32 & 0,29 & 0,61 & 0,32 & 0,36 \\
\hline see & 0,28 & 0,34 & 0,48 & 0,35 & 0,29 & 0,42 & 0,40 & 0,37 \\
\hline shot & 0,25 & 0,30 & 0,30 & 0,29 & 0,24 & 0,39 & 0,37 & 0,35 \\
\hline stop & 0,24 & 0,29 & 0,33 & 0,37 & 0,28 & 0,36 & 0,32 & 0,48 \\
\hline support & 0,27 & 0,38 & 0,33 & 0,38 & 0,27 & 0,32 & 0,34 & 0,32 \\
\hline visit & 0,26 & 0,27 & 0,32 & 0,38 & 0,29 & 0,31 & 0,38 & 0,39 \\
\hline Promedio & 0,29 & 0,29 & 0,35 & 0,38 & 0,30 & 0,36 & 0,35 & 0,35 \\
\hline Desv. Estándar & 0,055 & 0,050 & 0,054 & 0,058 & 0,033 & 0,082 & 0,036 & 0,036 \\
\hline $\begin{array}{l}\text { Kolmogorov- } \\
\text { Smirnov } \\
\text { Lilliefors }\end{array}$ & $\begin{array}{l}d=, 10741, \\
p>.20 \\
p>.20\end{array}$ & $\begin{array}{l}d=, 11060 \\
p>.20 \\
p>.20\end{array}$ & $\begin{array}{l}d=, 11297 \\
p>.20 \\
p>.20\end{array}$ & $\begin{array}{l}d=, 20830 \\
p>.20 \\
p<, 01\end{array}$ & $\begin{array}{l}d=, 16101 \\
p>.20 \\
p<, 15\end{array}$ & $\begin{array}{l}d=, 09259 \\
p>.20 \\
p>.20\end{array}$ & $\begin{array}{l}d=, 12108, \\
p>.20 \\
p>.20\end{array}$ & $\begin{array}{l}d=, 13875 \\
p>.20 \\
p>.20\end{array}$ \\
\hline
\end{tabular}


7.4.1 B1: Agents in Actives by subjects and by items.

\begin{tabular}{|c|c|c|c|c|c|c|}
\hline \multicolumn{7}{|c|}{ B1. By subjects: Agents in Actives: Rate's means table } \\
\hline SUBJECTS & INFO_STATUS & Mean & Std.Err. & $-95,00 \%$ & $95,00 \%$ & $\mathbf{N}$ \\
\hline Learners & given & 0,301 & 0,015 & 0,270 & 0,331 & 12 \\
\hline Learners & New & 0,292 & 0,020 & 0,250 & 0,334 & 12 \\
\hline Natives & given & 0,308 & 0,015 & 0,277 & 0,338 & 12 \\
\hline Natives & new & 0,356 & 0,020 & 0,314 & 0,398 & 12 \\
\hline Learners & All & 0,296 & 0,012 & 0,271 & 0,321 & 12 \\
\hline Natives & All & 0,332 & 0,012 & 0,307 & 0,357 & 12 \\
\hline All & Givennes & 0,304 & 0,010 & 0,283 & 0,326 & 24 \\
\hline All & Newness & 0,324 & 0,014 & 0,294 & 0,354 & 24 \\
\hline \multicolumn{7}{|c|}{ ANOVA AGENTS in ACTIVES } \\
\hline Effect & SS & $\begin{array}{l}\text { Degr of } \\
\text { freedom }\end{array}$ & MS & $\mathbf{F}$ & $\mathbf{p}$ & \\
\hline SUBJECTS & 0,015 & 1 & 0,015 & 4,313 & $0,050 *$ & \\
\hline INFO_STA & 0,005 & 1 & 0,005 & 1,165 & 0,292 & \\
\hline SUBJECTS xINFO_STA & 0,01 & 1 & 0,01 & 2,45 & 0,132 & \\
\hline \multicolumn{7}{|c|}{ Planned comparisons Agents in Actives } \\
\hline \multicolumn{7}{|c|}{ Learners versus natives } \\
\hline \multicolumn{7}{|c|}{ in given agents: $F(1,22)=0,110, p=0,742$} \\
\hline \multicolumn{7}{|c|}{ in new agents: $F(1,22)=4,962, p=0,036$} \\
\hline \multicolumn{7}{|c|}{ Info_status } \\
\hline \multicolumn{7}{|c|}{ in Learners: $F(1,22)=0,117, p=0,734$} \\
\hline \multicolumn{7}{|c|}{ in Natives: $F(1,22)=3,496, p=0,075$} \\
\hline
\end{tabular}

\begin{tabular}{|c|c|c|c|c|c|c|}
\hline \multicolumn{7}{|c|}{ B1. By items. Agents in Actives: Rate's means table } \\
\hline SUBJECTS & INFO_STATUS & \begin{tabular}{|l|l} 
Mean \\
\end{tabular} & Std.Err. & $-95,00 \%$ & $95,00 \%$ & $\mathbf{N}$ \\
\hline Learners & given & 0,293 & 0,011 & 0,270 & 0,316 & 24 \\
\hline Learners & new & 0,286 & 0,010 & 0,265 & 0,307 & 24 \\
\hline Natives & given & 0,298 & 0,007 & 0,285 & 0,312 & 24 \\
\hline Natives & new & 0,358 & 0,017 & 0,323 & 0,393 & 24 \\
\hline Learners & All & 0,289 & 0,010 & 0,268 & 0,310 & 24 \\
\hline Natives & All & 0,328 & 0,013 & 0,301 & 0,355 & 24 \\
\hline All & Givennes & 0,296 & 0,009 & 0,278 & 0,313 & 24 \\
\hline All & Newness & 0,322 & 0,014 & 0,293 & 0,351 & 24 \\
\hline \multicolumn{7}{|c|}{ ANOVA AGENTS in ACTIVES } \\
\hline Effect & SS & $\begin{array}{l}\begin{array}{l}\text { Degr of } \\
\text { freedom }\end{array} \\
\end{array}$ & MS & $\mathbf{F}$ & $\mathbf{p}$ & \\
\hline SUBJECTS & 0,036 & 1 & 0,036 & 9,717 & $0,005^{*}$ & \\
\hline INFO_STATUS & 0,017 & 1 & 0,017 & 4,662 & $0,042 *$ & \\
\hline SUBJECTS xINFO_STATUS & 0,027 & 1 & 0,027 & 8,533 & $0,008^{*}$ & \\
\hline \multicolumn{7}{|c|}{ Planned comparisons Agents in Actives } \\
\hline \multicolumn{7}{|c|}{ Learners versus natives } \\
\hline \multicolumn{7}{|c|}{ in given agents: $F(1,23)=0,153, p=0,699$} \\
\hline \multicolumn{7}{|c|}{ in new agents: $F(1,23)=13,726, p=0,001$} \\
\hline \multicolumn{7}{|l|}{ Info_status } \\
\hline \multicolumn{7}{|c|}{ in Learners: $F(1,23)=0,2041, p=0,656$} \\
\hline
\end{tabular}


7.4.2 B2. Agents in Passives by subjects and by items.

\begin{tabular}{|c|c|c|c|c|c|c|}
\hline \multicolumn{7}{|c|}{ B2. By subjects: Agents in Passives: Rate's means table } \\
\hline SUBJECTS & INFO_STATUS & Mean & Std.Err. & $-95,00 \%$ & $95,00 \%$ & $\mathrm{~N}$ \\
\hline Learners & given & 0,356 & 0,009 & 0,338 & 0,373 & 12 \\
\hline Learners & new & 0,381 & 0,011 & 0,357 & 0,404 & 12 \\
\hline Natives & given & 0,356 & 0,009 & 0,338 & 0,374 & 12 \\
\hline Natives & new & 0,348 & 0,011 & 0,325 & 0,372 & 12 \\
\hline Learners & All & 0,368 & 0,007 & 0,354 & 0,383 & 12 \\
\hline Natives & All & 0,352 & 0,007 & 0,338 & 0,367 & 12 \\
\hline All & Givennes & 0,356 & 0,006 & 0,343 & 0,368 & 24 \\
\hline All & Newness & 0,365 & 0,008 & 0,348 & 0,381 & 24 \\
\hline \multicolumn{7}{|c|}{ ANOVA AGENTS in PASSIVES } \\
\hline Effect & SS & Degr of freedom & MS & $\mathrm{F}$ & $\mathrm{p}$ & \\
\hline SUBJECTS & 0,003 & 1 & 0,003 & 2,627 & 0,119 & \\
\hline INFO_STA & 0,001 & 1 & 0,001 & 0,758 & 0,393 & \\
\hline SUBJECTS xINFO_STA & 0,003 & 1 & 0,003 & 2,648 & 0,118 & \\
\hline \multicolumn{7}{|c|}{ Planned comparisons Agents in Passives } \\
\hline \multicolumn{7}{|c|}{ Learners versus natives } \\
\hline \multicolumn{7}{|c|}{ in given agents: $F(1,22)=0,000, p=0,975$} \\
\hline \multicolumn{7}{|c|}{ in new agents: $F(1,22)=4,167, p=0,053$} \\
\hline \multicolumn{7}{|c|}{ Info_status } \\
\hline \multicolumn{7}{|c|}{ in Learners: $F(1,22)=3,119, p=0,091$} \\
\hline \multicolumn{7}{|c|}{ in Natives: $F(1,22)=0,286, p=0,597$} \\
\hline
\end{tabular}

\begin{tabular}{|c|c|c|c|c|c|c|}
\hline \multicolumn{7}{|c|}{ B2. By items Agents in Passives: Rate's means table } \\
\hline SUBJECTS & INFO_STATUS & Mean & Std.Err. & $-95,00 \%$ & $95,00 \%$ & $\mathrm{~N}$ \\
\hline Learners & given & 0,354 & 0,011 & 0,331 & 0,377 & 24 \\
\hline Learners & new & 0,380 & 0,012 & 0,355 & 0,404 & 24 \\
\hline Natives & given & 0,347 & 0,007 & 0,332 & 0,362 & 24 \\
\hline Natives & new & 0,354 & 0,007 & 0,339 & 0,369 & 24 \\
\hline Learners & All & 0,367 & 0,010 & 0,345 & 0,388 & 24 \\
\hline Natives & All & 0,351 & 0,007 & 0,336 & 0,365 & 24 \\
\hline All & Givennes & 0,351 & 0,009 & 0,331 & 0,370 & 24 \\
\hline All & Newness & 0,367 & 0,010 & 0,346 & 0,388 & 24 \\
\hline \multicolumn{7}{|c|}{ ANOVA AGENTS in PASSIVES } \\
\hline Effect & SS & Degr of freedom & MS & $\mathrm{F}$ & $\mathrm{p}$ & \\
\hline SUBJECTS & 0,006 & 1 & 0,006 & 3,898 & 0,06 & \\
\hline INFO_STATUS & 0,006 & 1 & 0,006 & 2,615 & 0,119 & \\
\hline $\begin{array}{ll}\text { SUBJECTS } & \mathrm{x} \\
\text { INFO_STATUS }\end{array}$ & 0,002 & 1 & 0,002 & 0,767 & 0,39 & \\
\hline \multicolumn{7}{|c|}{ Planned comparisons Agents in Passives } \\
\hline \multicolumn{7}{|c|}{ Learners versus natives } \\
\hline \multicolumn{7}{|c|}{ in given agents: $F(1,23)=0,273, p=0,606$} \\
\hline \multicolumn{7}{|c|}{ in new agents: $F(1,23)=3,629, p=0,069$} \\
\hline \multicolumn{7}{|l|}{ Info_status } \\
\hline \multicolumn{7}{|c|}{ in Learners: $F(1,23)=2,122, p=0,159$} \\
\hline in Natives: $F(1,23)=0,4$ & $0, p=0,528$ & & & & & \\
\hline
\end{tabular}


7.4.3 B2. Agents analysis by subjects in passives.

\begin{tabular}{|c|c|c|c|c|c|c|}
\hline \multicolumn{7}{|c|}{ B2. Agents by Subjects in Passives: Rate's means table } \\
\hline SUBJECTS & INFOSTRUCTURE & Mean & Std.Err. & $-95,00 \%$ & $95,00 \%$ & $\mathbf{N}$ \\
\hline Learners & \begin{tabular}{|l|} 
Congruent \\
\end{tabular} & 0,645 & 0,011 & 0,622 & 0,667 & 12 \\
\hline Learners & Incongruent & 0,627 & 0,011 & 0,605 & 0,649 & 12 \\
\hline Natives & Congruent & 0,634 & 0,011 & 0,612 & 0,657 & 12 \\
\hline Natives & Incongruent & 0,664 & 0,011 & 0,642 & 0,686 & 12 \\
\hline Learners & All & 0,636 & 0,009 & 0,617 & 0,655 & 12 \\
\hline Natives & All & 0,649 & 0,009 & 0,630 & 0,668 & 12 \\
\hline All & Congruency & 0,640 & 0,008 & 0,624 & 0,655 & 24 \\
\hline All & Incongruency & 0,645 & 0,007 & 0,630 & 0,661 & 24 \\
\hline \multicolumn{7}{|c|}{ ANOVA by subjects in PASSIVES } \\
\hline Effect & Ss & Degr. freedom & MS & $\mathbf{F}$ & $\mathbf{p}$ & \\
\hline Subjects & 0,002 & 1 & 0,002 & 1,078 & 0,31 & \\
\hline Congruency & 0 & 1 & 0 & 0,526 & 0,476 & \\
\hline $\begin{array}{ll}\text { Congruency } & \mathrm{x} \\
\text { Subjects } & \\
\end{array}$ & 0,007 & 1 & 0,007 & 8,893 &, $007 *$ & \\
\hline \multicolumn{7}{|c|}{ Planned comparisons by subjects in PASSIVES } \\
\hline \multicolumn{7}{|c|}{ Learners versus natives: } \\
\hline \multicolumn{7}{|c|}{ in congruent passives: $\mathrm{F}(1,22)=0,472, p=0,498$} \\
\hline \multicolumn{7}{|c|}{ in incongruent passives: $F(\mathbf{1}, \mathbf{2 2})=6,211, p=0,0207$} \\
\hline \multicolumn{7}{|c|}{ Congruency: } \\
\hline \multicolumn{7}{|c|}{ in Learners: $F(1,22)=2,546, p=0,125$} \\
\hline \multicolumn{7}{|c|}{ in Natives: $F(1,22)=6,872, p=0,015$} \\
\hline
\end{tabular}

\begin{tabular}{|c|c|c|c|c|c|c|}
\hline \multicolumn{7}{|c|}{ B2. Agents by items in Passives: RT rate's means table } \\
\hline SUBJECTS & INFOSTRUCTURE & Mean & Std.Err. & $-95,00 \%$ & $95,00 \%$ & $\mathbf{N}$ \\
\hline Learners & congruent & 0,637 & 0,007 & 0,623 & 0,652 & 24 \\
\hline Learners & incongruent & 0,622 & 0,015 & 0,590 & 0,653 & 24 \\
\hline Natives & congruent & 0,636 & 0,009 & 0,618 & 0,654 & 24 \\
\hline Natives & incongruent & 0,667 & 0,008 & 0,650 & 0,684 & 24 \\
\hline Learners & All & 0,630 & 0,010 & 0,608 & 0,651 & 24 \\
\hline Natives & All & 0,651 & 0,008 & 0,635 & 0,668 & 24 \\
\hline All & Congruency & 0,637 & 0,009 & 0,618 & 0,655 & 24 \\
\hline All & Incongruency & 0,644 & 0,014 & 0,616 & 0,672 & 24 \\
\hline \multicolumn{7}{|c|}{ ANOVA by items in PASSIVES } \\
\hline Effect & SS & Degr.of freedom & MS & $\mathbf{F}$ & $\mathbf{p}$ & \\
\hline Subjects & 0,011 & 1 & 0,011 & 6,359 & $0,019 *$ & \\
\hline Congruency & 0,001 & 1 & 0,001 & 0,352 & 0,559 & \\
\hline Congruency $\mathrm{x}$ Subjects & 0,013 & 1 & 0,013 & 6,061 & $0,022^{*}$ & \\
\hline \multicolumn{7}{|c|}{ Planned comparisons by items in PASSIVES } \\
\hline \multicolumn{7}{|c|}{ Learners versus natives: } \\
\hline \multicolumn{7}{|c|}{ in congruent passives: $F(1,23)=0,026, p=0,873$} \\
\hline \multicolumn{7}{|c|}{ in incongruent passives: $F(\mathbf{1}, \mathbf{2 3})=\mathbf{8 , 7 2 2 ,} p=0,007$} \\
\hline \multicolumn{7}{|l|}{ Congruency: } \\
\hline \multicolumn{7}{|c|}{ in Learners: $F(1,23)=0,713, p=0,407$} \\
\hline in Natives: $F(1,23)=5,8$ & $p=0,024$ & & & & & \\
\hline
\end{tabular}




\subsection{APPENDIX C: PATIENTS}

\section{C: Patients: ANALYSIS BY SUBJECTS:}

RT rates in actives and passives.

\begin{tabular}{|c|c|c|c|c|c|}
\hline Subjects & L1 & patient_active_given & patient_active_new & patient_passive_given & patient_passive_new \\
\hline 1 & Spanish & 0,353554917 & 0,37332909 & 0,232232657 & 0,266843134 \\
\hline 2 & Spanish & 0,324663085 & 0,329974532 & 0,362355415 & 0,264184961 \\
\hline 3 & Spanish & 0,347328483 & 0,386263922 & 0,249300181 & 0,277484144 \\
\hline 4 & Spanish & 0,350924145 & 0,346923725 & 0,228331645 & 0,230846847 \\
\hline 5 & Spanish & 0,423506497 & 0,35563981 & 0,220544747 & 0,251910391 \\
\hline 6 & Spanish & 0,415764001 & 0,275144234 & 0,262945434 & 0,35770028 \\
\hline 7 & Spanish & 0,384615385 & 0,349659803 & 0,220925589 & 0,225436879 \\
\hline 8 & Spanish & 0,345197407 & 0,34600128 & 0,285134991 & 0,285805627 \\
\hline 9 & Spanish & 0,291729993 & 0,346372688 & 0,377162378 & 0,232617587 \\
\hline 10 & Spanish & 0,324958356 & 0,314081073 & 0,145080248 & 0,336287058 \\
\hline 11 & Spanish & 0,3444686614 & 0,301909487 & 0,233162142 & 0,250300421 \\
\hline 12 & Spanish & 0,327388191 & 0,359265343 & 0,351150091 & 0,27466211 \\
\hline 13 & English & 0,304019196 & 0,367039317 & 0,326202532 & 0,295844817 \\
\hline 14 & English & 0,390978064 & 0,376362943 & 0,252610114 & 0,354289302 \\
\hline 15 & English & 0,2329467 & 0,369250455 & 0,245084591 & 0,269432681 \\
\hline 16 & English & 0,415032045 & 0,310429568 & 0,299517636 & 0,296729973 \\
\hline 17 & English & 0,268550732 & 0,363934101 & 0,299600798 & 0,27923039 \\
\hline 18 & English & 0,308298407 & 0,37254294 & 0,24657883 & 0,336120592 \\
\hline 19 & English & 0,312907202 & 0,316640916 & 0,366064982 & 0,382996545 \\
\hline 20 & English & 0,2999519 & 0,349629368 & 0,287404162 & 0,304600083 \\
\hline 21 & English & 0,302622771 & 0,326098162 & 0,35097476 & 0,339724583 \\
\hline 22 & English & 0,317222767 & 0,387113055 & 0,22301988 & 0,269038076 \\
\hline 23 & English & 0,351328018 & 0,351359397 & 0,250936906 & 0,273823945 \\
\hline 24 & English & 0,399818127 & 0,354446855 & 0,282959307 & 0,292365195 \\
\hline \multicolumn{2}{|l|}{ Promedio } & 0,339073958 & 0,347058836 & 0,274970001 & 0,289511484 \\
\hline \multicolumn{2}{|l|}{ Desvest } & 0,048045089 & 0,028070339 & 0,057821532 & 0,042343697 \\
\hline \multicolumn{2}{|c|}{$\begin{array}{l}\text { Kolmogorov-Smirnov } \\
\text { Lilliefors }\end{array}$} & $\begin{array}{l}d=, 13155, p>.20 \\
p>.10\end{array}$ & $\begin{array}{l}d=, 19331, p>.20 \\
p>.05\end{array}$ & $\begin{array}{l}d=, 15051, p>.20 \\
p>.20\end{array}$ & $\begin{array}{l}d=, 14065, p>.20 \\
p<, 20\end{array}$ \\
\hline
\end{tabular}




\section{C: Patients: ANALYSIS BY ITEMS:}

RT rates actives (codes 1,3$)$ and passives (codes 2,4$)$.

\begin{tabular}{|c|c|c|c|c|c|c|c|c|}
\hline Verb & $\begin{array}{l}\text { code3_s3_ } \\
\text { Spanish }\end{array}$ & $\begin{array}{l}\text { code1_s3_ } \\
\text { Spanish }\end{array}$ & $\begin{array}{l}\text { code4_s1_ } \\
\text { Spanish }\end{array}$ & $\begin{array}{l}\text { code2_s1_ } \\
\text { Spanish }\end{array}$ & $\begin{array}{l}\text { code3_s3_ } \\
\text { English }\end{array}$ & $\begin{array}{l}\text { code1_s3_ } \\
\text { English }\end{array}$ & $\begin{array}{l}\text { code4_s1_ } \\
\text { English }\end{array}$ & $\begin{array}{l}\text { code2_s1 } \\
\text { English }\end{array}$ \\
\hline Bite & 0,36 & 0,26 & 0,21 & 0,24 & 0,34 & 0,35 & 0,32 & 0,25 \\
\hline convince & 0,30 & 0,38 & 0,27 & 0,28 & 0,29 & 0,37 & 0,21 & 0,37 \\
\hline choose & 0,34 & 0,33 & 0,17 & 0,38 & 0,23 & 0,36 & 0,28 & 0,36 \\
\hline fascinate & 0,37 & 0,34 & 0,23 & 0,27 & 0,49 & 0,36 & 0,30 & 0,30 \\
\hline feed & 0,32 & 0,37 & 0,29 & 0,24 & 0,27 & 0,36 & 0,29 & 0,33 \\
\hline Find & 0,42 & 0,33 & 0,21 & 0,33 & 0,37 & 0,33 & 0,28 & 0,28 \\
\hline forget & 0,37 & 0,40 & 0,29 & 0,20 & 0,35 & 0,38 & 0,26 & 0,34 \\
\hline help & 0,40 & 0,36 & 0,15 & 0,30 & 0,37 & 0,36 & 0,36 & 0,33 \\
\hline Hug & 0,35 & 0,34 & 0,38 & 0,13 & 0,32 & 0,37 & 0,29 & 0,32 \\
\hline identify & 0,45 & 0,30 & 0,27 & 0,35 & 0,29 & 0,33 & 0,30 & 0,34 \\
\hline insult & 0,33 & 0,36 & 0,30 & 0,33 & 0,41 & 0,35 & 0,22 & 0,27 \\
\hline invite & 0,38 & 0,35 & 0,29 & 0,28 & 0,28 & 0,34 & 0,32 & 0,42 \\
\hline Kill & 0,36 & 0,34 & 0,30 & 0,29 & 0,33 & 0,40 & 0,28 & 0,34 \\
\hline Kiss & 0,40 & 0,36 & 0,20 & 0,28 & 0,36 & 0,37 & 0,31 & 0,39 \\
\hline protect & 0,33 & 0,33 & 0,18 & 0,12 & 0,38 & 0,30 & 0,33 & 0,33 \\
\hline punish & 0,33 & 0,28 & 0,26 & 0,19 & 0,36 & 0,35 & 0,32 & 0,29 \\
\hline push & 0,31 & 0,37 & 0,16 & 0,30 & 0,29 & 0,33 & 0,25 & 0,31 \\
\hline save & 0,35 & 0,31 & 0,35 & 0,27 & 0,19 & 0,34 & 0,29 & 0,35 \\
\hline See & 0,34 & 0,36 & 0,27 & 0,23 & 0,28 & 0,39 & 0,28 & 0,31 \\
\hline shot & 0,35 & 0,39 & 0,37 & 0,34 & 0,32 & 0,43 & 0,29 & 0,39 \\
\hline visit & 0,38 & 0,41 & 0,29 & 0,28 & 0,32 & 0,35 & 0,25 & 0,25 \\
\hline Promedio & 0,36 & 0,34 & 0,26 & 0,27 & 0,33 & 0,36 & 0,28 & 0,32 \\
\hline $\begin{array}{l}\text { Desv. } \\
\text { Estándar }\end{array}$ & 0,036 & 0,036 & 0,063 & 0,062 & 0,060 & 0,031 & 0,037 & 0,047 \\
\hline $\begin{array}{l}\text { Kolmogorov- } \\
\text { Smirnov } \\
\text { Lilliefors }\end{array}$ & $\begin{array}{l}d=.12036 \\
p>.20 \\
p>.20\end{array}$ & $\begin{array}{l}d=.10621 \\
p>.20 \\
p>.20\end{array}$ & $\begin{array}{l}d=.13951, \\
p>.20 \\
p>.20\end{array}$ & $\begin{array}{l}d=, 13782 \\
p>.20 \\
p>.20\end{array}$ & $\begin{array}{l}d=.11824 \\
p>.20 \\
p>.20\end{array}$ & $\begin{array}{l}d=, 11084 \\
p>.20 \\
p>.20\end{array}$ & $\begin{array}{l}d=, 16710 \\
p>.20 \\
p<, 10\end{array}$ & $\begin{array}{l}d=, 07798, \\
p>.20 ; \\
p>.20\end{array}$ \\
\hline
\end{tabular}


7.5.1 C1: Patients in Actives by subjects and by items.

\begin{tabular}{|c|c|c|c|c|c|c|}
\hline \multicolumn{7}{|c|}{ C1. By subjects. Patients in Actives: Rate's means table } \\
\hline SUBJECTS & INFO_STATUS & \begin{tabular}{|l|} 
Mean \\
\end{tabular} & Std.Err. & $-95,00 \%$ & $95,00 \%$ & $\mathbf{N}$ \\
\hline Learners & Given & 0,353 & 0,014 & 0,325 & 0,381 & 12 \\
\hline Learners & New & 0,340 & 0,008 & 0,324 & 0,357 & 12 \\
\hline Natives & Given & 0,325 & 0,014 & 0,297 & 0,353 & 12 \\
\hline Natives & New & 0,354 & 0,008 & 0,337 & 0,370 & 12 \\
\hline Learners & All & 0,347 & 0,007 & 0,332 & 0,361 & 12 \\
\hline Natives & All & 0,340 & 0,007 & 0,325 & 0,354 & 12 \\
\hline All & Givennes & 0,339 & 0,010 & 0,319 & 0,359 & 24 \\
\hline All & Newness & 0,347 & 0,006 & 0,335 & 0,359 & 24 \\
\hline \multicolumn{7}{|c|}{ ANOVA Patients in ACTIVES } \\
\hline Effect & SS & $\begin{array}{l}\text { Degr of } \\
\text { freedom }\end{array}$ & MS & $\mathbf{F}$ & $\mathbf{p}$ & \\
\hline SUBJECTS & 0,001 & 1 & 0,001 & 0,507 & 0,484 & \\
\hline INFO_STA & 0,001 & 1 & 0,001 & 0,427 & 0,52 & \\
\hline SUBJECTS XINFO_STA & 0,005 & 1 & 0,005 & 2,8 & 0,108 & \\
\hline \multicolumn{7}{|c|}{ Planned comparisons of Patients in Actives } \\
\hline \multicolumn{7}{|c|}{ Learners versus natives } \\
\hline \multicolumn{7}{|c|}{ in given patients: $F(1,22)=2,061, p=0,165$} \\
\hline \multicolumn{7}{|c|}{ in new patients: $F(1,22)=1,381, p=0,252$} \\
\hline \multicolumn{7}{|c|}{ Info_status } \\
\hline \multicolumn{7}{|c|}{ in Learners: $F(1,22)=0,520, p=0,478$} \\
\hline \multicolumn{7}{|c|}{ in Natives: $F(1,22)=2,707, p=0,114$} \\
\hline
\end{tabular}

\begin{tabular}{|c|c|c|c|c|c|c|}
\hline \multicolumn{7}{|c|}{ C1. By items. Patients in Actives: Rate's means table } \\
\hline SUBJECTS & INFO_STATUS & \begin{tabular}{|l|} 
Mean \\
\end{tabular} & Std.Err. & $-95,00 \%$ & $95,00 \%$ & $\mathbf{N}$ \\
\hline Learners & given & 0,359 & 0,007 & 0,344 & 0,374 & 24 \\
\hline Learners & new & 0,344 & 0,007 & 0,329 & 0,359 & 24 \\
\hline Natives & given & 0,326 & 0,012 & 0,300 & 0,351 & 24 \\
\hline Natives & new & 0,356 & 0,006 & 0,343 & 0,369 & 24 \\
\hline Learners & All & 0,352 & 0,007 & 0,338 & 0,366 & 24 \\
\hline Natives & All & 0,341 & 0,010 & 0,320 & 0,361 & 24 \\
\hline All & Givennes & 0,342 & 0,011 & 0,320 & 0,364 & 24 \\
\hline All & Newness & 0,350 & 0,008 & 0,334 & 0,366 & 24 \\
\hline \multicolumn{7}{|c|}{ ANOVA Patients in ACTIVES } \\
\hline Effect & SS & \begin{tabular}{|l|}
$\begin{array}{l}\text { Degr of } \\
\text { freedom }\end{array}$ \\
\end{tabular} & MS & $\mathbf{F}$ & p & \\
\hline SUBJECTS & 0,003 & 1 & 0,003 & 1,783 & 0,195 & \\
\hline INFO_STATUS & 0,002 & 1 & 0,002 & 0,666 & 0,423 & \\
\hline SUBJECTS*INFO_STATUS & 0,012 & 1 & 0,012 & 8,779 &, $007^{*}$ & \\
\hline \multicolumn{7}{|c|}{ Planned comparisons of Patients in Actives } \\
\hline \multicolumn{7}{|c|}{ Learners versus natives } \\
\hline \multicolumn{7}{|c|}{ in given patients: $F(1,23)=6,165, p=0,020$} \\
\hline \multicolumn{7}{|c|}{ in new patients: $F(1,23)=2,136, p=0,157$} \\
\hline \multicolumn{7}{|l|}{ Info_status } \\
\hline \multicolumn{7}{|c|}{ in Learners: $F(1,23)=1,745, p=0,199$} \\
\hline in Natives: $\mathbf{F}(\mathbf{1}, \mathbf{2 3})=\mathbf{5}, \mathbf{0 1 7}$ & & & & & & \\
\hline
\end{tabular}


7.5.2 C2. Patients in Passives by subjects and by items.

\begin{tabular}{|c|c|c|c|c|c|c|}
\hline \multicolumn{7}{|c|}{ C2. By subjects. Patients in Passives: Rate's means table } \\
\hline SUBJECTS & INFO_STATUS & Mean & Std.Err. & $-95,00 \%$ & $95,00 \%$ & $\mathbf{N}$ \\
\hline Learners & \begin{tabular}{|l|} 
given \\
\end{tabular} & 0,264 & 0,017 & 0,229 & 0,299 & 12 \\
\hline Learners & New & 0,271 & 0,011 & 0,248 & 0,294 & 12 \\
\hline Natives & given & 0,286 & 0,017 & 0,251 & 0,321 & 12 \\
\hline Natives & new & 0,308 & 0,011 & 0,285 & 0,331 & 12 \\
\hline Learners & All & 0,268 & 0,010 & 0,246 & 0,289 & 12 \\
\hline Natives & All & 0,297 & 0,010 & 0,276 & 0,318 & 12 \\
\hline All & Givennes & 0,275 & 0,012 & 0,250 & 0,300 & 24 \\
\hline All & Newness & 0,290 & 0,008 & 0,273 & 0,306 & 24 \\
\hline \multicolumn{7}{|c|}{ ANOVA Patients in PASSIVES } \\
\hline Effect & SS & Degr of freedom & MS & $\mathbf{F}$ & $\mathbf{p}$ & \\
\hline SUBJECTS & 0,01 & 1 & 0,01 & 4,048 & 0,057 & \\
\hline INFO_STATUS & 0,003 & 1 & 0,003 & 1,089 & 0,308 & \\
\hline $\begin{array}{ll}\text { SUBJECTS } & \mathrm{x} \\
\text { INFO_STATUS } & \end{array}$ & 0,001 & 1 & 0,001 & 0,282 & 0,601 & \\
\hline \multicolumn{7}{|c|}{ Planned comparisons of Patients in Passives } \\
\hline \multicolumn{7}{|c|}{ Learners versus natives } \\
\hline \multicolumn{7}{|c|}{ in given patients: $F(1,22)=0,854, p=0,365$} \\
\hline \multicolumn{7}{|c|}{ in new patients: $F(1,22)=5,353, p=0,030$} \\
\hline \multicolumn{7}{|c|}{ Info_status } \\
\hline \multicolumn{7}{|c|}{ in Learners: $F(1,22)=0,131, p=0,720$} \\
\hline \multicolumn{7}{|c|}{ in Natives: $F(1,22)=1,239, p=0,278$} \\
\hline
\end{tabular}

\begin{tabular}{|c|c|c|c|c|c|c|}
\hline \multicolumn{7}{|c|}{ C2. By items. Patients in Passives: Rate's means table } \\
\hline SUBJECTS & INFO_STATUS & Mean & Std.Err. & $-95,00 \%$ & $95,00 \%$ & $\mathbf{N}$ \\
\hline Learners & given & 0,258 & 0,013 & 0,231 & 0,285 & 24 \\
\hline Learners & New & 0,268 & 0,013 & 0,241 & 0,294 & 24 \\
\hline Natives & given & 0,282 & 0,008 & 0,266 & 0,297 & 24 \\
\hline Natives & New & 0,320 & 0,010 & 0,300 & 0,340 & 24 \\
\hline Learners & All & 0,263 & 0,012 & 0,238 & 0,288 & 24 \\
\hline Natives & All & 0,301 & 0,010 & 0,281 & 0,321 & 24 \\
\hline All & Givennes & 0,270 & 0,009 & 0,251 & 0,289 & 24 \\
\hline All & Newness & 0,294 & 0,012 & 0,268 & 0,319 & 24 \\
\hline \multicolumn{7}{|c|}{ ANOVA Patients in PASSIVES } \\
\hline Effect & SS & Degr of freedom & MS & $\mathbf{F}$ & $\mathbf{P}$ & \\
\hline SUBJECTS & 0,034 & 1 & 0,034 & 11,9 & $0,002 *$ & \\
\hline INFO_STATUS & 0,014 & 1 & 0,014 & 4,7 & $0,041 *$ & \\
\hline SUBJECTS*INFO_STATUS & 0,005 & 1 & 0,005 & 1,64 & 0,213 & \\
\hline \multicolumn{7}{|c|}{ Planned comparisons of Patients in Passives } \\
\hline \multicolumn{7}{|c|}{ Learners versus natives } \\
\hline \multicolumn{7}{|c|}{ in given patients: $F(1,23)=2,068, p=0,164$} \\
\hline \multicolumn{7}{|c|}{ in new patients: $F(1,23)=12,902, p=0,002$} \\
\hline \multicolumn{7}{|l|}{ Info_status } \\
\hline \multicolumn{7}{|c|}{ in Learners: $F(1,23)=0,254, p=0,620$} \\
\hline in Natives: $\mathbf{F}(\mathbf{1}, \mathbf{2 3})=\mathbf{1 2 , 9 9 0}$ & $0, p=0,001$ & & & & & \\
\hline
\end{tabular}




\section{APPENDIX II: OFF-LINE TASK}

\subsubsection{OFF-LINE TASK RAW DATA}

\subsubsection{Learners and Natives agent1}

8.1.1.2

\begin{tabular}{|c|c|c|c|c|c|c|c|c|c|c|c|c|c|c|c|c|c|c|c|c|}
\hline $\begin{array}{l}\text { 윽 } \\
\text { 인 }\end{array}$ & 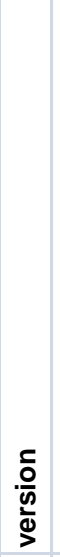 & 으 & $\begin{array}{l}\frac{0}{0} \\
\frac{\pi}{0} \\
\frac{0}{0} \\
\text { ह } \\
ن\end{array}$ & 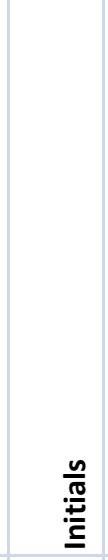 & $\begin{array}{l}\text { 윽 } \\
\text { 닌 }\end{array}$ & 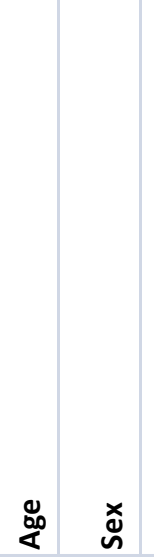 & 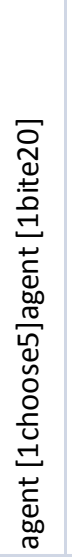 & 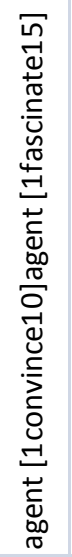 & 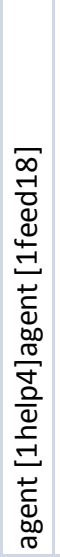 & 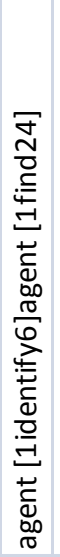 & 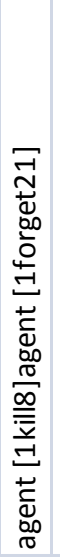 & 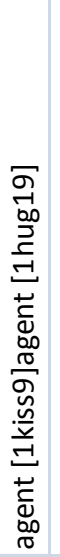 & 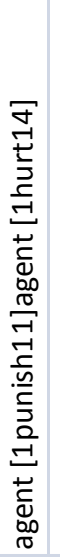 & 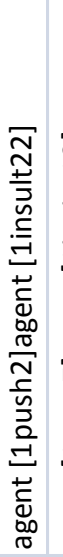 & 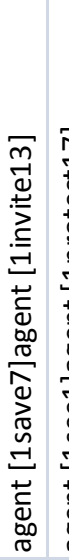 & 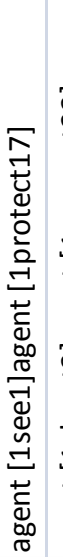 & 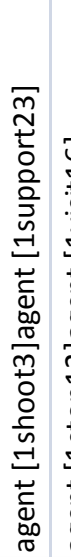 & 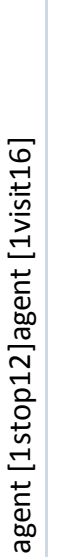 & 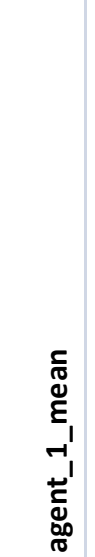 & 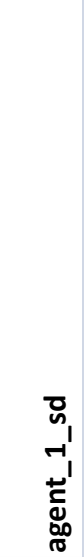 \\
\hline learners & 1 & 6 & 2014 & MRR & L2 & 23 male & 5 & 4 & 5 & 5 & 4 & 5 & 5 & 5 & 4 & 5 & 5 & 5 & 4,75 & \\
\hline learners & 1 & 9 & 2014 & TSR & L2 & 25 femal & 5 & 5 & 4 & 5 & 5 & 5 & 5 & 5 & 5 & 4 & 4 & 5 & 4,75 & \\
\hline learners & 1 & 12 & 2014 & $+\mathrm{MVR}$ & L2 & 24 femal & 5 & 4 & 5 & 5 & 5 & 5 & 5 & 5 & 5 & 5 & 5 & 5 & 4,917 & \\
\hline learners & 1 & 13 & 2014 & EJP & L2 & 24 femal & 5 & 3 & 5 & 5 & 5 & 5 & 5 & 5 & 5 & 5 & 5 & 5 & 4,833 & \\
\hline learners & 1 & 14 & 2014 & + $\mathrm{CMO}$ & L2 & 24 male & 5 & 4 & 4 & 5 & 4 & 5 & 3 & 4 & 3 & 5 & 5 & 4 & 4,25 & \\
\hline learners & 1 & 23 & 2014 & AJGG & L2 & 22 male & 4 & 5 & 5 & 5 & 4 & 3 & 4 & 4 & 4 & 5 & 5 & 5 & 4,417 & \\
\hline learners & 2 & 3 & 1980 & PLO & L2 & 22 male & 5 & 5 & 5 & 5 & 5 & 5 & 5 & 5 & 5 & 5 & 5 & 5 & 5 & \\
\hline learners & 2 & 5 & 1980 & EGZ & L2 & 23 femal & 5 & 5 & 5 & 5 & 1 & 5 & 5 & 5 & 5 & 5 & 5 & 5 & 4,667 & \\
\hline learners & 2 & 10 & 2014 & MLGP & L2 & 23 femal & 5 & 4 & 5 & 4 & 5 & 1 & 2 & 4 & 2 & 3 & 2 & 2 & 3,25 & \\
\hline learners & 2 & 7 & 1980 & NALI & L2 & 23 male & 4 & 5 & 4 & 4 & 5 & 5 & 5 & 5 & 5 & 5 & 5 & 5 & 4,75 & \\
\hline learners & 2 & 8 & 1980 & $A C V$ & L2 & 29 male & 5 & 4 & 4 & 4 & 4 & 4 & 4 & 5 & 5 & 4 & 4 & 4 & 4,25 & \\
\hline learners & 2 & 10 & 1980 & CCR & L2 & 24 femal & 5 & 1 & 5 & 5 & 5 & 5 & 5 & 5 & 5 & 5 & 5 & 5 & 4,667 & \\
\hline learners & 2 & 12 & 1980 & MAJ & L2 & 29 femal & 4 & 3 & 3 & 3 & 5 & 5 & 5 & 5 & 3 & 3 & 5 & 4 & 4 & \\
\hline natives & 1 & 17 & 2014 & PAJ & L1 & 70 male & 5 & 5 & 5 & 5 & 5 & 5 & 5 & 4 & 5 & 5 & 5 & 5 & 4,917 & \\
\hline natives & 1 & 18 & 2014 & PEH & L1 & 71 femal & 4 & 5 & 4 & 4 & 4 & 5 & 4 & 5 & 5 & 3 & 4 & 4 & 4,25 & \\
\hline natives & 1 & 19 & 2014 & & L1 & 69 femal & 5 & 5 & 1 & 5 & 5 & 5 & 5 & 3 & 5 & 1 & 5 & 1 & 3,833 & \\
\hline natives & 1 & 20 & 2014 & 4 HMILH & L1 & 77 femal & 5 & 5 & 5 & 5 & 5 & 4 & 5 & 5 & 5 & 1 & 5 & 4 & 4,5 & \\
\hline natives & 1 & 21 & 2014 & DMP & L1 & 67 femal & 5 & 5 & 5 & 5 & 5 & 5 & 5 & 5 & 5 & 5 & 5 & 5 & 5 & \\
\hline natives & 1 & 22 & 2014 & 4. LAM & L1 & 67 femal & 4 & 4 & 4 & 2 & 4 & 4 & 4 & 4 & 2 & 1 & 4 & 2 & 3,25 & \\
\hline natives & 2 & 6 & 1980 & BJO & L1 & 61 male & 5 & 5 & 5 & 5 & 5 & 5 & 5 & 5 & 5 & 5 & 4 & $5^{\prime}$ & 5 & \\
\hline natives & 2 & 13 & 1980 & LAG & L1 & 65 femal & 3 & 3 & 3 & 4 & 2 & 4 & 3 & 4 & 4 & 4 & 4 & $4^{r}$ & 3,4 & \\
\hline natives & 2 & 15 & 1980 & $P W$ & L1 & 76 male & 5 & 3 & 3 & 5 & 5 & 5 & 3 & 5 & 5 & 5 & 4 & $5^{\prime}$ & 4,4 & \\
\hline natives & 2 & 16 & 1980 & $M C A$ & L1 & 69 male & 4 & 5 & 5 & 5 & 5 & 5 & 5 & 5 & 5 & 4 & 5 & $5^{r}$ & 4,8 & \\
\hline natives & 2 & 18 & 1980 & RNP & L1 & 70 male & 4 & 2 & 4 & 2 & 2 & 3 & 2 & 4 & 3 & 3 & 3 & $4^{\prime}$ & 2,9 & \\
\hline natives & 2 & 20 & 1980 & & L1 & 75 male & 4 & 3 & 4 & 4 & 4 & 4 & 4 & 4 & 3 & 4 & 4 & 4 & 3,8 & \\
\hline
\end{tabular}




\subsubsection{Learners and Natives \#agent2}

\begin{tabular}{|c|c|c|c|c|c|c|c|c|c|c|c|c|c|c|c|c|c|c|c|c|c|}
\hline $\begin{array}{l}\text { 윽 } \\
\text { 은 }\end{array}$ & 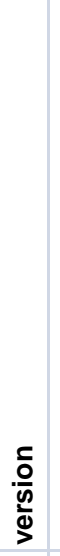 & 므 & $\begin{array}{l}\frac{0}{0} \\
\frac{\pi}{0} \\
\frac{0}{0} \\
\frac{0}{0}\end{array}$ & 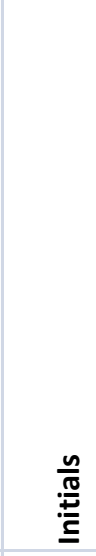 & $\begin{array}{l}\text { 윽 } \\
\text { 인 }\end{array}$ & 落 & 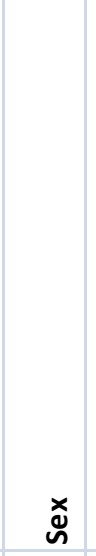 & 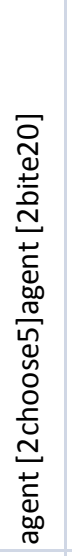 & 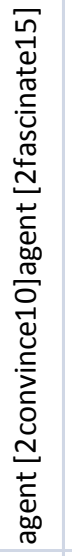 & 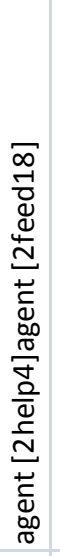 & 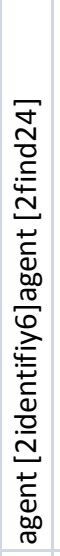 & 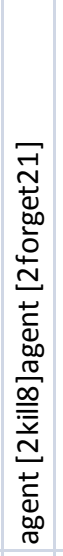 & 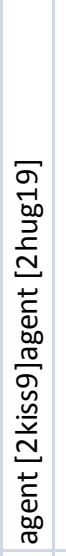 & 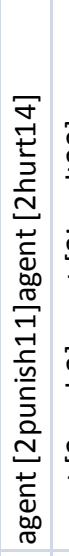 & 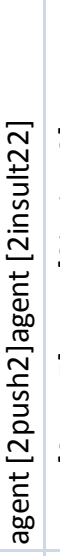 & 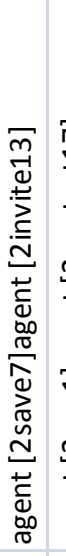 & 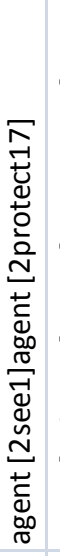 & 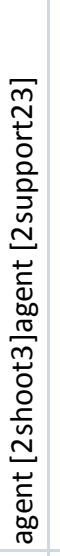 & 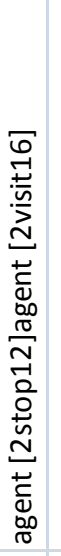 & 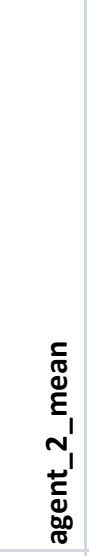 & 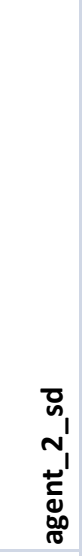 \\
\hline learners & 1 & 6 & 2014 & MRR & L2 & 23 & male & 3 & 5 & 2 & 4 & 5 & 2 & 3 & 3 & 5 & 3 & 3 & 3 & 3,417 & \\
\hline learners & 1 & 9 & 2014 & TSR & L2 & 25 & femal & 1 & 2 & 3 & 1 & 1 & 1 & 4 & 1 & 2 & 5 & 5 & 1 & 2,25 & \\
\hline learners & 1 & 12 & 2014 & MVR & L2 & 24 & femal & 4 & 5 & 4 & 4 & 3 & 4 & 4 & 4 & 5 & 4 & 5 & 4 & 4,167 & \\
\hline learners & 1 & 13 & 2014 & EJP & L2 & 24 & femal & 4 & 5 & 4 & 4 & 3 & 4 & 4 & 4 & 4 & 4 & 4 & 3 & 3,917 & \\
\hline learners & 1 & 14 & 2014 & $\mathrm{CMO}$ & L2 & 24 & male & 2 & 3 & 3 & 3 & 2 & 3 & 5 & 2 & 4 & 3 & 3 & 3 & 3 & \\
\hline learners & 1 & 23 & 2014 & AJGG & L2 & 22 & male & 5 & 3 & 3 & 3 & 5 & 5 & 3 & 2 & 3 & 4 & 3 & 3 & 3,5 & \\
\hline learners & 2 & 3 & 1980 & PLO & L2 & 22 & male & 4 & 4 & 4 & 4 & 2 & 3 & 4 & 4 & 5 & 4 & 2 & 2 & 3,5 & \\
\hline learners & 2 & 5 & 1980 & EGZ & L2 & 23 & femal & 1 & 1 & 1 & 1 & 5 & 1 & 1 & 1 & 1 & 1 & 1 & 1 & 1,333 & \\
\hline learners & 2 & 10 & 2014 & MLGP & L2 & 23 & femal & 2 & 2 & 2 & 3 & 3 & 2 & 4 & 3 & 1 & 4 & 1 & 5 & 2,667 & \\
\hline learners & 2 & 7 & 1980 & NALI & L2 & 23 & male & 5 & 4 & 5 & 5 & 3 & 4 & 3 & 4 & 3 & 4 & 4 & 2 & 3,833 & \\
\hline learners & 2 & 8 & 1980 & ACV & L2 & 29 & male & 2 & 3 & 1 & 2 & 1 & 1 & 2 & 1 & 1 & 2 & 2 & 1 & 1,583 & \\
\hline learners & 2 & 10 & 1980 & $\mathrm{CCR}$ & L2 & 24 & femal & 4 & 5 & 3 & 4 & 2 & 2 & 2 & 3 & 4 & 3 & 3 & 2 & 3,083 & \\
\hline learners & 2 & 12 & 1980 & MAJ & L2 & 29 & femal & 3 & 4 & 4 & 5 & 2 & 3 & 3 & 3 & 5 & 4 & 2 & 1 & 3,25 & \\
\hline natives & 1 & 17 & 2014 & PAJ & L1 & 70 & male & 4 & 3 & 4 & 4 & 4 & 3 & 3 & 5 & 4 & 4 & 3 & 4 & 3,75 & \\
\hline natives & 1 & 18 & 2014 & PEH & L1 & 71 & femal & 5 & 4 & 5 & 5 & 5 & 4 & 5 & 4 & 5 & 5 & 3 & 5 & 4,583 & \\
\hline natives & 1 & 19 & 2014 & & L1 & 69 & femal & 5 & 5 & 5 & 5 & 5 & 1 & 5 & 5 & 2 & 1 & 1 & 5 & 3,75 & \\
\hline natives & 1 & 20 & 2014 & HMILH & L1 & 77 & femal & 2 & 2 & 4 & 4 & 4 & 5 & 4 & 2 & 2 & 5 & 2 & 5 & 3,417 & \\
\hline natives & 1 & 21 & 2014 & DMP & L1 & 67 & femal & 1 & 1 & 1 & 1 & 1 & 1 & 1 & 1 & 2 & 1 & 1 & 1 & 1,083 & \\
\hline natives & 1 & 22 & 2014 & LAM & L1 & 67 & femal & 2 & 2 & 2 & 4 & 2 & 2 & 2 & 2 & 4 & 4 & 2 & 4 & 2,667 & \\
\hline natives & 2 & 6 & 1980 & BJO & L1 & 61 & male & 3 & 3 & 3 & 3 & 3 & 3 & 3 & 4 & 4 & 3 & 2 & 2 & 3 & \\
\hline natives & 2 & 13 & 1980 & LAG & L1 & 65 & femal & 2 & 4 & 4 & 3 & 4 & 3 & 4 & 3 & 2 & 2 & 2 & 3 & 3 & \\
\hline natives & 2 & 15 & 1980 & PW & L1 & 76 & male & 4 & 5 & 5 & 3 & 3 & 4 & 5 & 4 & 3 & 4 & 5 & 3 & 4 & \\
\hline natives & 2 & 16 & 1980 & MCA & L1 & 69 & male & 5 & 4 & 4 & 4 & 4 & 4 & 4 & 4 & 4 & 5 & 4 & 4 & 4,167 & \\
\hline natives & 2 & 18 & 1980 & RNP & L1 & 70 & male & 3 & 4 & 3 & 3 & 3 & 2 & 4 & 2 & 4 & 5 & 2 & 2 & 3,083 & \\
\hline natives & 2 & 20 & 1980 & & L1 & 75 & male & 3 & 4 & 2 & 2 & 2 & 3 & 3 & 2 & 4 & 2 & 3 & 2 & 2,667 & \\
\hline
\end{tabular}




\subsubsection{Learners and Natives patient3}

\begin{tabular}{|c|c|c|c|c|c|c|c|c|c|c|c|c|c|c|c|c|c|c|c|}
\hline $\begin{array}{l}\text { 음 } \\
\text { 힣 }\end{array}$ & $\begin{array}{l}\frac{5}{0} \\
\frac{0}{0} \\
\frac{0}{J}\end{array}$ & 으 & $\begin{array}{l}\frac{0}{0} \\
\frac{\pi}{0} \\
\frac{0}{\circ} \\
\text { 임 }\end{array}$ & $\begin{array}{l}\frac{n}{\pi} \\
\stackrel{\Xi}{\Xi}\end{array}$ & $\begin{array}{l}\frac{0}{3} \\
\text { ํํㄴ }\end{array}$ & $\stackrel{\text { 总 }}{<}$ & 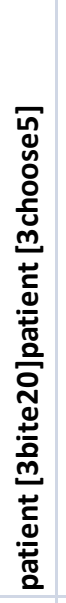 & 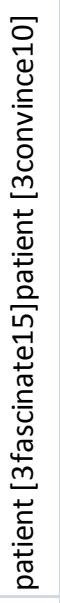 & 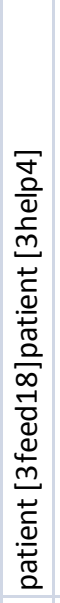 & 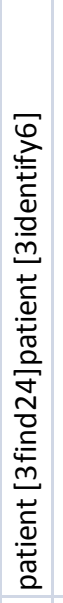 & 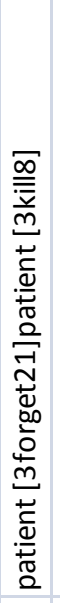 & 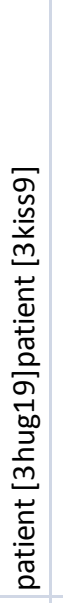 & 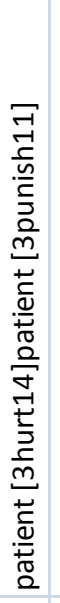 & 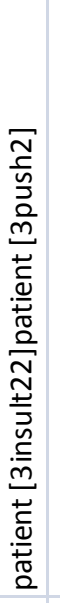 & 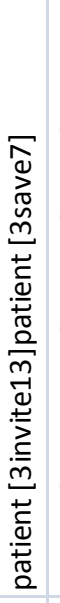 & 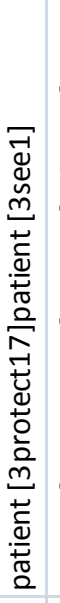 & 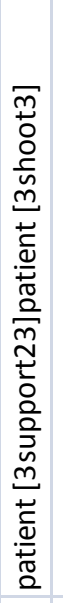 & 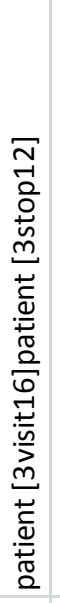 & 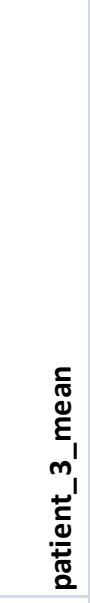 \\
\hline learners & 1 & & 2014 & 4. MRR & L2 & 23 male & 5 & 4 & 5 & 4 & 2 & 5 & 3 & 5 & 4 & 5 & 5 & 5 & 4,333 \\
\hline learners & 1 & & 2014 & 4. TSR & L2 & 25 femal & 3 & 3 & 5 & 5 & 5 & 5 & 2 & 5 & 4 & 5 & 2 & 4 & 4 \\
\hline learners & 1 & 12 & 2014 & $4 \mathrm{MVR}$ & L2 & 24 femal & 5 & 4 & 5 & 4 & 5 & 5 & 3 & 5 & 4 & 5 & 5 & 5 & 4,583 \\
\hline learners & 1 & 13 & 2014 & 4. EJP & L2 & 24 femal & 5 & 1 & 5 & 3 & 5 & 5 & 5 & 4 & 5 & 5 & 5 & 5 & 4,417 \\
\hline learners & 1 & 14 & 2014 & 4. CMO & L2 & 24 male & 5 & 3 & 3 & 2 & 1 & 4 & 3 & 3 & 3 & 4 & 2 & 4 & 3,083 \\
\hline learners & 1 & 23 & 2014 & 4 AJGG & L2 & 22 male & 4 & 4 & 4 & 5 & 4 & 4 & 4 & 4 & 4 & 2 & 4 & 4 & 3,917 \\
\hline learners & 2 & 3 & 1980 & 0 PLO & L2 & 22 male & 3 & 4 & 4 & 4 & 4 & 2 & 4 & 4 & 4 & 4 & 4 & 4 & 3,75 \\
\hline learners & 2 & & 1980 & $0 \cdot \mathrm{EGZ}$ & L2 & 23 femal & 5 & 3 & 5 & 1 & 5 & 5 & 5 & 5 & 5 & 5 & 1 & 3 & 4 \\
\hline learners & 2 & 10 & 2014 & 4. MLGP & L2 & 23 femal & 2 & 3 & 4 & 2 & 2 & 5 & 3 & 3 & 2 & 5 & 5 & 2 & 3,167 \\
\hline learners & 2 & 7 & 1980 & $0 . \mathrm{NALI}$ & L2 & 23 male & 5 & 4 & 4 & 5 & 5 & 5 & 5 & 4 & 5 & 5 & 4 & 4 & 4,583 \\
\hline learners & 2 & & 1980 & $0 \mathrm{ACV}$ & L2 & 29 male & 4 & 2 & 3 & 4 & 3 & 3 & 3 & 3 & 2 & 2 & 2 & 2 & 2,75 \\
\hline learners & 2 & 10 & 1980 & 0 CCR & L2 & 24 femal & 4 & 4 & 5 & 4 & 2 & 5 & 4 & 4 & 4 & 5 & 4 & 4 & 4,083 \\
\hline learners & 2 & 12 & 1980 & $0 . \mathrm{MAJ}$ & L2 & 29 femal & 4 & 2 & 5 & 2 & 3 & 2 & 4 & 2 & 3 & 5 & 3 & 2 & 3,083 \\
\hline natives & 1 & 17 & 2014 & 4. PAJ & L1 & 70 male & 5 & 5 & 5 & 5 & 5 & 4 & 5 & 5 & 5 & 4 & 5 & 5 & 4,833 \\
\hline natives & 1 & 18 & 2014 & 4. PEH & L1 & 71 femal & 5 & 3 & 5 & 5 & 3 & 4 & 3 & 4 & 5 & 5 & 4 & 5 & 4,25 \\
\hline natives & 1 & 19 & 2014 & & L1 & 69 femal & 2 & 1 & 3 & 5 & 1 & 5 & 5 & 5 & 5 & 5 & 4 & 3 & 3,667 \\
\hline natives & 1 & 20 & 2014 & 4. HMILH & L1 & 77 femal & 5 & 4 & 5 & 5 & 5 & 4 & 5 & 3 & 5 & 5 & 5 & 5 & 4,667 \\
\hline natives & 1 & 21 & 2014 & 4. DMP & L1 & 67 femal & 5 & 3 & 5 & 5 & 5 & 5 & 5 & 5 & 5 & 5 & 5 & 5 & 4,833 \\
\hline natives & 1 & 22 & 2014 & 4. LAM & L1 & 67 femal & 2 & 2 & 2 & 2 & 2 & 2 & 4 & 2 & 2 & 2 & 4 & 4 & 2,5 \\
\hline natives & 2 & 6 & 1980 & $0 . \mathrm{BJO}$ & L1 & 61 male & 3 & 4 & 5 & 4 & 4 & 5 & 4 & 5 & 5 & 5 & 5 & 5 & 4,5 \\
\hline natives & 2 & 13 & 1980 & 0 LAG & L1 & 65 femal & 3 & 4 & 4 & 2 & 3 & 3 & 2 & 2 & 4 & 3 & 3 & 4 & 3,083 \\
\hline natives & 2 & 15 & 1980 & O.PW & L1 & 76 male & 5 & 5 & 5 & 5 & 3 & 3 & 5 & 4 & 5 & 4 & 5 & 5 & 4,5 \\
\hline natives & 2 & 16 & 51980 & $0 . M C A$ & L1 & 69 male & 5 & 5 & 5 & 4 & 5 & 5 & 5 & 5 & 5 & 4 & 5 & 5 & 4,833 \\
\hline natives & 2 & 18 & 1980 & 0. RNP & L1 & 70 male & 2 & 2 & 4 & 4 & 5 & 4 & 4 & 3 & 2 & 3 & 3 & 3 & 3,25 \\
\hline natives & 2 & 20 & 1980 & & L1 & 75 male & 4 & 4 & 4 & 2 & 4 & 4 & 4 & 4 & 4 & 3 & 3 & 3 & 3,583 \\
\hline
\end{tabular}




\subsubsection{Learners and Natives \#patient4}

\begin{tabular}{|c|c|c|c|c|c|c|c|c|c|c|c|c|c|c|c|c|c|c|c|c|c|}
\hline $\begin{array}{l}\text { 음 } \\
\text { 잏 }\end{array}$ & $\begin{array}{l}\frac{\overline{0}}{\omega} \\
\frac{\bar{d}}{\supset}\end{array}$ & 으 & $\begin{array}{l}\frac{0}{0} \\
\frac{\pi}{0} \\
\frac{0}{0} \\
\frac{1}{0} \\
0\end{array}$ & $\begin{array}{l}\frac{n}{N !} \\
\stackrel{\underline{\Xi}}{\Xi}\end{array}$ & $\begin{array}{l}\text { 옴 } \\
\text { 인 }\end{array}$ & $\underset{0}{\stackrel{0}{\alpha}}$ & $\stackrel{\times}{\varpi}$ & 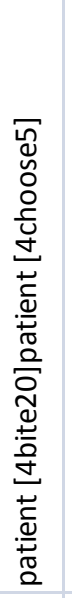 & 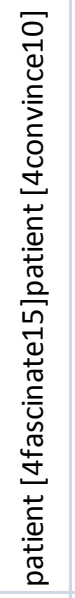 & 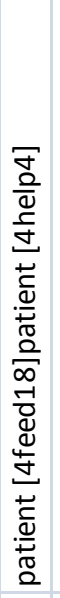 & 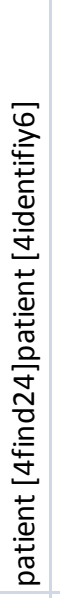 & 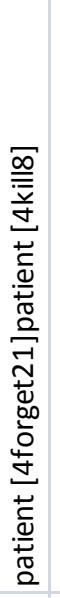 & 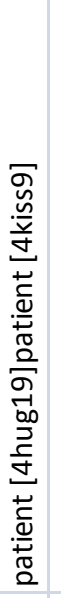 & 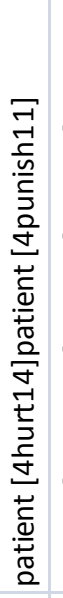 & 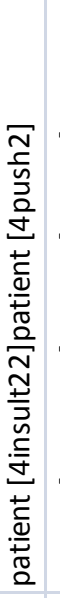 & 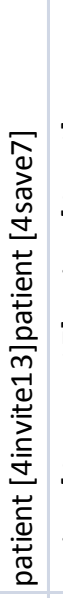 & 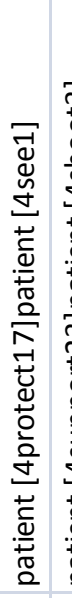 & 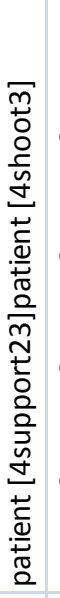 & 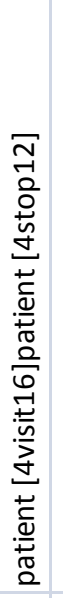 & 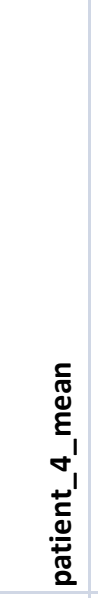 & 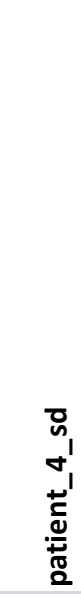 \\
\hline learners & 1 & 6 & 2014 & MRR & L2 & 23 & 3 male & 2 & 5 & 4 & 5 & 5 & 4 & 5 & 4 & 5 & 1 & 4 & 4 & 4 & \\
\hline learners & 1 & 9 & 2014 & TSR & L2 & & femal & 5 & 5 & 4 & 4 & 1 & 2 & 5 & 2 & 5 & 2 & 5 & 2 & 3,5 & \\
\hline learners & 1 & 12 & 2014 & MVR & L2 & & femal & 5 & 5 & 4 & 5 & 5 & 4 & 5 & 4 & 5 & 4 & 4 & 4 & 4,5 & \\
\hline learners & 1 & 13 & 2014 & EJP & L2 & 24 & femal & 3 & 5 & 4 & 5 & 4 & 4 & 4 & 5 & 4 & 4 & 4 & 4 & 4,167 & \\
\hline learners & 1 & 14 & 2014 & $\mathrm{CMO}$ & L2 & 24 & male & 2 & 5 & 5 & 5 & 5 & 2 & 5 & 5 & 5 & 3 & 5 & 3 & 4,167 & \\
\hline learners & 1 & 23 & 2014 & AJGG & L2 & 22 & male & 4 & 5 & 5 & 4 & 5 & 5 & 5 & 5 & 5 & 4 & 5 & 3 & 4,583 & \\
\hline learners & 2 & 3 & 1980 & PLO & L2 & 22 & male & 5 & 5 & 5 & 5 & 5 & 5 & 5 & 5 & 5 & 5 & 5 & 5 & 5 & \\
\hline learners & 2 & 5 & 1980 & EGZ & L2 & 23 & femal & 1 & 5 & 1 & 5 & 1 & 1 & 1 & 1 & 1 & 1 & 5 & 5 & 2,333 & \\
\hline learners & 2 & 10 & 2014 & MLGP & L2 & 23 & femal & 5 & 5 & 2 & 4 & 4 & 2 & 4 & 4 & 5 & 2 & 1 & 3 & 3,417 & \\
\hline learners & 2 & 7 & 1980 & NALI & L2 & 23 & 3 male & 4 & 5 & 5 & 4 & 4 & 4 & 4 & 5 & 4 & 3 & 5 & 5 & 4,333 & \\
\hline learners & 2 & 8 & 1980 & ACV & L2 & 29 & male & 1 & 4 & 4 & 1 & 4 & 4 & 4 & 4 & 4 & 4 & 5 & 4 & 3,583 & \\
\hline learners & 2 & 10 & 1980 & CCR & L2 & 24 & femal & 5 & 5 & 4 & 5 & 5 & 4 & 5 & 5 & 5 & 4 & 5 & 5 & 4,75 & \\
\hline learners & 2 & 12 & 1980 & MAJ & L2 & 29 & femal & 1 & 4 & 2 & 4 & 5 & 4 & 3 & 4 & 4 & 1 & 4 & 5 & 3,417 & \\
\hline natives & 1 & 17 & 2014 & PAJ & L1 & 70 & male & 4 & 4 & 2 & 4 & 4 & 5 & 3 & 4 & 3 & 5 & 4 & 4 & 3,833 & \\
\hline natives & 1 & 18 & 2014 & PEH & L1 & 71 & femal & 3 & 5 & 5 & 5 & 5 & 5 & 4 & 5 & 5 & 5 & 5 & 5 & 4,75 & \\
\hline natives & 1 & 19 & 2014 & & L1 & 69 & femal & 5 & 5 & 5 & 5 & 5 & 2 & 5 & 2 & 5 & 5 & 5 & 5 & 4,5 & \\
\hline natives & 1 & 20 & 2014 & HMILH & L1 & 77 & femal & 3 & 5 & 2 & 2 & 3 & 5 & 2 & 5 & 2 & 3 & 2 & 2 & 3 & \\
\hline natives & 1 & 21 & 2014 & DMP & L1 & 67 & femal & 1 & 5 & 1 & 1 & 3 & 1 & 1 & 1 & 1 & 1 & 3 & 1 & 1,667 & \\
\hline natives & 1 & 22 & 2014 & LAM & L1 & 67 & femal & 4 & 4 & 4 & 4 & 4 & 4 & 2 & 4 & 4 & 4 & 2 & 2 & 3,5 & \\
\hline natives & 2 & 6 & 1980 & BJO & L1 & 61 & male & 4 & 5 & 3 & 5 & 5 & 4 & 5 & 4 & 4 & 4 & 4 & 4 & 4,25 & \\
\hline natives & 2 & 13 & 1980 & LAG & L1 & 65 & femal & 4 & 3 & 3 & 4 & 4 & 2 & 4 & 4 & 3 & 4 & 4 & 3 & 3,5 & \\
\hline natives & 2 & 15 & 1980 & PW & L1 & 76 & 5 male & 4 & 4 & 4 & 3 & 5 & 5 & 3 & 5 & 4 & 5 & 4 & 4 & 4,167 & \\
\hline natives & 2 & 16 & 1980 & MCA & L1 & 69 & male & 4 & 4 & 4 & 5 & 4 & 4 & 4 & 4 & 4 & 5 & 4 & 4 & 4,167 & \\
\hline natives & 2 & 18 & 1980 & RNP & L1 & 70 & male & 4 & 4 & 3 & 2 & 4 & 3 & 2 & 2 & 4 & 4 & 4 & 4 & 3,333 & \\
\hline natives & 2 & 20 & 1980 & & L1 & 75 & male & 3 & 3 & 2 & 4 & 3 & 3 & 2 & 3 & 3 & 4 & 4 & 4 & 3,167 & \\
\hline
\end{tabular}




\subsubsection{Learners and Natives distractor 1}

\begin{tabular}{|c|c|c|c|c|c|c|c|c|c|c|c|c|c|c|c|c|c|c|c|c|}
\hline $\begin{array}{l}\text { 을 } \\
\text { 인 }\end{array}$ & 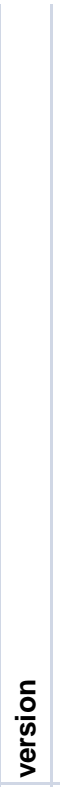 & 므 & $\begin{array}{l}\frac{0}{0} \\
\frac{\pi}{d} \\
\frac{0}{0} \\
\frac{0}{\delta} \\
\mathcal{O}\end{array}$ & $\begin{array}{l}\frac{\omega}{\pi} \\
\stackrel{\underline{N}}{\Xi}\end{array}$ & $\begin{array}{l}\text { 옥 } \\
\text { 온 }\end{array}$ & 总 & 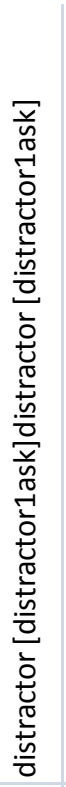 & 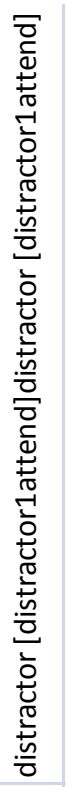 & 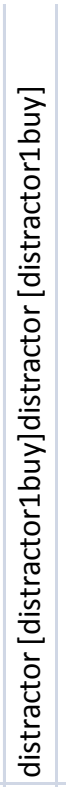 & 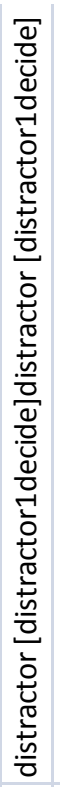 & 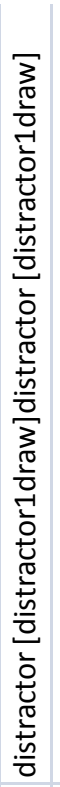 & 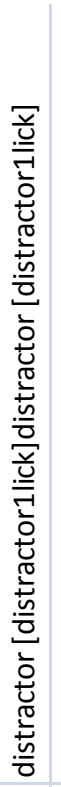 & 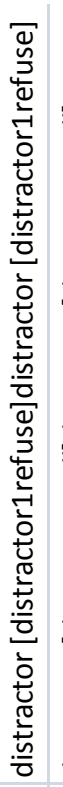 & 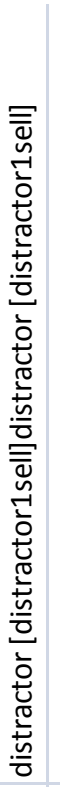 & 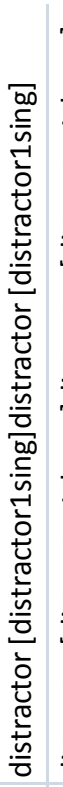 & 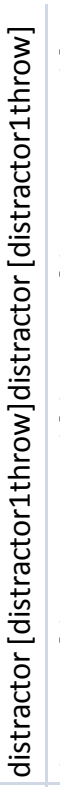 & 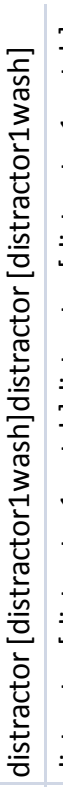 & 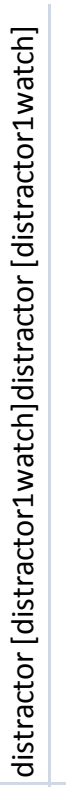 & 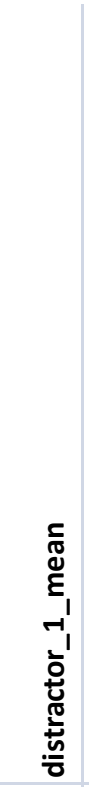 & 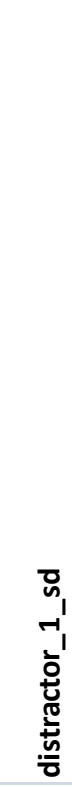 \\
\hline learners & 1 & 6 & 2014 & MRR & L2 & 23 male & 5 & 5 & 5 & 5 & 5 & 5 & 5 & 5 & 5 & 5 & 5 & 5 & 5 & \\
\hline learners & 1 & 9 & 2014 & TSR & L2 & 25 femal & 5 & 5 & 3 & 5 & 5 & 5 & 5 & 5 & 5 & 5 & 5 & 5 & 4,833 & \\
\hline learners & 1 & 12 & 2014 & MVR & L2 & 24 femal & 5 & 5 & 5 & 5 & 5 & 5 & 5 & 5 & 5 & 5 & 5 & 5 & 5 & \\
\hline learners & 1 & 13 & 2014 & EJP & L2 & 24 femal & 5 & 5 & 5 & 5 & 5 & 5 & 5 & 5 & 5 & 5 & 5 & 5 & 5 & \\
\hline learners & 1 & 14 & 2014 & $\mathrm{CMO}$ & L2 & 24 male & 4 & 5 & 5 & 4 & 4 & 5 & 5 & 5 & 5 & 5 & 5 & 5 & 4,75 & \\
\hline learners & 1 & 23 & 2014 & AJGG & L2 & 22 male & 4 & 3 & 3 & 4 & 4 & 5 & 5 & 5 & 5 & 3 & 5 & 5 & 4,25 & \\
\hline learners & 2 & 3 & 1980 & PLO & L2 & 22 male & 5 & 5 & 5 & 5 & 5 & 5 & 5 & 5 & 5 & 5 & 5 & 5 & 5 & \\
\hline learners & 2 & 5 & 1980 & EGZ & L2 & 23 femal & 5 & 5 & 5 & 5 & 5 & 5 & 5 & 5 & 5 & 5 & 5 & 5 & 5 & \\
\hline learners & 2 & 10 & 2014 & MLGP & L2 & 23 femal & 5 & 5 & 5 & 5 & 1 & 5 & 5 & 5 & 5 & 2 & 2 & 4 & 4,083 & \\
\hline learners & 2 & 7 & 1980 & NALI & L2 & 23 male & 5 & 5 & 4 & 5 & 5 & 5 & 5 & 5 & 5 & 5 & 5 & 5 & 4,917 & \\
\hline learners & 2 & 8 & 1980 & ACV & L2 & 29 male & 4 & 4 & 3 & 5 & 4 & 4 & 4 & 4 & 4 & 4 & 4 & 4 & 4 & \\
\hline learners & 2 & 10 & 1980 & CCR & L2 & 24 femal & 5 & 5 & 5 & 5 & 5 & 5 & 5 & 5 & 5 & 5 & 5 & 5 & 5 & \\
\hline learners & 2 & 12 & 1980 & MAJ & L2 & 29 femal & 3 & 5 & 5 & 5 & 5 & 5 & 4 & 4 & 5 & 5 & 5 & 5 & 4,667 & \\
\hline natives & 1 & 17 & 2014 & PAJ & L1 & 70 male & 5 & 5 & 5 & 5 & 5 & 5 & 5 & 5 & 5 & 5 & 5 & 5 & 5 & \\
\hline natives & 1 & 18 & 2014 & PEH & L1 & 71 femal & 5 & 5 & 5 & 5 & 5 & 5 & 5 & 5 & 4 & 5 & 5 & 5 & 4,917 & \\
\hline natives & 1 & 19 & 2014 & & L1 & 69 femal & 5 & 5 & 5 & 5 & 5 & 5 & 5 & 5 & 5 & 5 & 5 & 5 & 5 & \\
\hline natives & 1 & 20 & 2014 & HMILH & L1 & 77 femal & 5 & 5 & 5 & 5 & 5 & 5 & 5 & 5 & 5 & 5 & 5 & 5 & 5 & \\
\hline natives & 1 & 21 & 2014 & DMP & L1 & 67 femal & 5 & 5 & 5 & 5 & 5 & 5 & 5 & 5 & 5 & 5 & 5 & 5 & 5 & \\
\hline natives & 1 & 22 & 2014 & LAM & L1 & 67 femal & 4 & 4 & 4 & 4 & 4 & 4 & 4 & 4 & 4 & 4 & 4 & 4 & 4 & \\
\hline natives & 2 & 6 & 1980 & BJO & L1 & 61 male & 5 & 5 & 5 & 5 & 5 & 5 & 5 & 5 & 5 & 5 & 5 & 5 & 5 & \\
\hline natives & 2 & 13 & 1980 & LAG & L1 & 65 femal & 4 & 4 & 3 & 4 & 4 & 4 & 4 & 4 & 4 & 4 & 4 & 4 & 3,917 & \\
\hline natives & 2 & 15 & 1980 & PW & L1 & 76 male & 4 & 5 & 5 & 5 & 4 & 5 & 5 & 5 & 5 & 5 & 5 & 5 & 4,833 & \\
\hline natives & 2 & 16 & 1980 & MCA & L1 & 69 male & 5 & 5 & 5 & 5 & 5 & 5 & 5 & 5 & 5 & 5 & 5 & 5 & 5 & \\
\hline natives & 2 & 18 & 1980 & RNP & L1 & 70 male & 4 & 5 & 4 & 5 & 4 & 3 & 5 & 3 & 4 & 4 & 4 & 3 & 4 & \\
\hline natives & 2 & 20 & 1980 & & L1 & 75 male & 4 & 4 & 4 & 4 & 4 & 5 & 5 & 4 & 4 & 4 & 5 & 4 & 4,25 & \\
\hline
\end{tabular}




\subsubsection{Learners and Native \#distractor2}

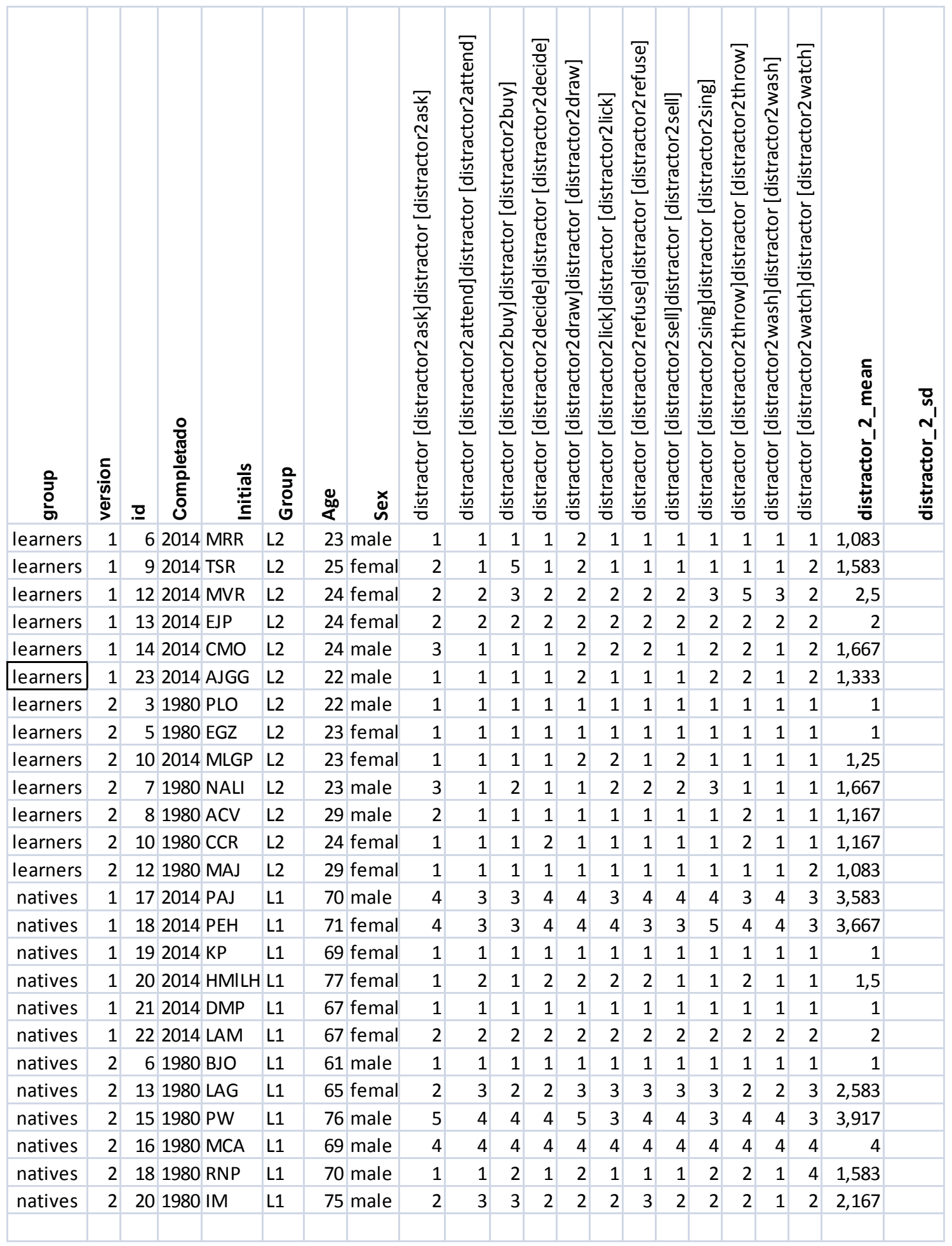




\subsection{APPENDIX A: AGENT CONTEXTS.}

One-Sample Kolmogorov-Smirnov Test

\begin{tabular}{|c|c|c|c|c|}
\hline Group & & & agent1 & \#agent2 \\
\hline \multirow[t]{8}{*}{ Natives } & $\mathrm{N}$ & & 12 & 12 \\
\hline & Normal Parameters ${ }^{\mathrm{a}, \mathrm{b}}$ & Mean & 4,17083 & 3,33217 \\
\hline & & Std. Deviation & ,726359 & ,915866 \\
\hline & Most Extreme Differences & Absolute &, 140 &, 151 \\
\hline & & Positive & ,127 & ,086 \\
\hline & & Negative &,- 140 &,- 151 \\
\hline & Kolmogorov-Smirnov Z & & ,485 &, 521 \\
\hline & Asymp. Sig. (2-tailed) & & 0,9725 & 0,9486 \\
\hline \multirow[t]{8}{*}{ Learners } & $\mathrm{N}$ & & 12 & 12 \\
\hline & Normal Parameters ${ }^{\mathrm{a}, \mathrm{b}}$ & Mean & 4,54172 & 3,02083 \\
\hline & & Std. Deviation & ,472095 & ,906161 \\
\hline & Most Extreme Differences & Absolute & ,271 &, 169 \\
\hline & & Positive & ,166 &, 110 \\
\hline & & Negative &,- 271 &,- 169 \\
\hline & Kolmogorov-Smirnov Z & & ,940 &, 585 \\
\hline & Asymp. Sig. (2-tailed) & & 0,3401 & 0,8829 \\
\hline
\end{tabular}

a. Test distribution is Normal.

b. Calculated from data.

\subsubsection{Error Bar Chat agent1 and \#agent2.}

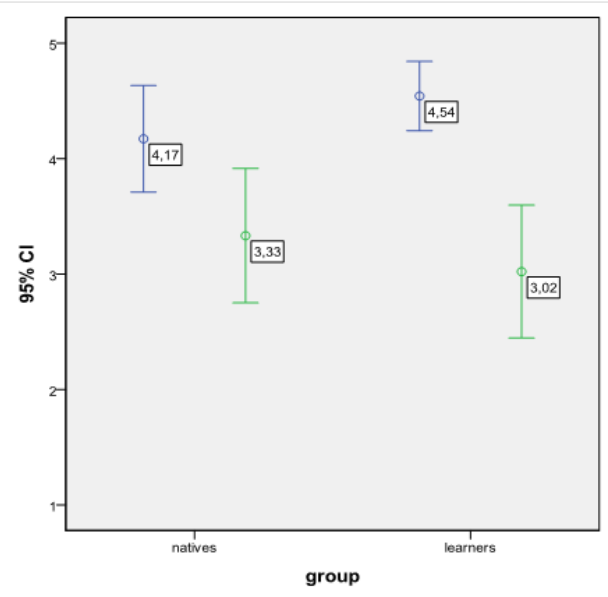

I agent1
I \#agent2 
Mauchly's Test of Sphericity

Measure:MEASURE_1

\begin{tabular}{|c|c|c|c|c|c|c|c|}
\hline \multirow[b]{2}{*}{ Within Subjects Effect } & \multirow[b]{2}{*}{ Mauchly's W } & \multirow[b]{2}{*}{$\begin{array}{l}\text { Approx. Chi- } \\
\text { Square }\end{array}$} & \multirow[b]{2}{*}{ Df } & \multirow[b]{2}{*}{ Sig. } & \multicolumn{3}{|l|}{ Epsilon $^{a}$} \\
\hline & & & & & $\begin{array}{l}\text { Greenhouse- } \\
\text { Geisser }\end{array}$ & Huynh-Feldt & Lower-bound \\
\hline congruence_agent & 1 &, 000 & 0 & & 1,000 & 1,000 & 1,000 \\
\hline
\end{tabular}

Tests the null hypothesis that the error covariance matrix of the orthonormalized transformed dependent variables is proportional to an identity matrix.

a. May be used to conform the degrees of freedom for the averaged tests of significance. Corrected tests are displayed in the Tests of Within-Subjects Effects table.

\begin{tabular}{|l|r|r|r|r|}
\hline \multicolumn{1}{|c|}{ Levene's Test of Equality of Error Variances $^{\text {a }}$} \\
\hline & $\mathrm{F}$ & $\mathrm{df1}$ & \multicolumn{1}{c|}{$\mathrm{df2}$} & \multicolumn{1}{c|}{ Sig. } \\
\hline agent1 & 4,215 & 1 & 22 &, 052 \\
\#agent2 &, 079 & 1 & 22 &, 781 \\
\hline
\end{tabular}

Tests the null hypothesis that the error variance of the dependent variable is equal across groups.

a. Design: Intercept + group

Within Subjects Design: congruence_agent

\begin{tabular}{|c|c|c|c|c|c|c|c|}
\hline \multicolumn{8}{|c|}{ Multivariate Tests ${ }^{\mathrm{b}}$} \\
\hline \multicolumn{2}{|l|}{ Effect } & Value & $\mathrm{F}$ & $\begin{array}{c}\text { Hypothesis } \\
\text { df }\end{array}$ & Error df & Sig. & $\begin{array}{l}\text { Partial Eta } \\
\text { Squared }\end{array}$ \\
\hline \multirow[t]{5}{*}{ congruence_agent } & Pillai's Trace &, 597 & $32,653^{a}$ & 1,000 & 22,000 & ,000 &, 597 \\
\hline & Wilks' Lambda & ,403 & $32,653^{a}$ & 1,000 & 22,000 & ,000 &, 597 \\
\hline & Hotelling's Trace & 1,484 & $32,653^{a}$ & 1,000 & 22,000 &, 000 & , 597 \\
\hline & Roy's Largest & 1,484 & $32,653^{a}$ & 1,000 & 22,000 & ,000 &, 597 \\
\hline & Root & & & & & & \\
\hline \multirow{5}{*}{$\begin{array}{l}\text { congruence_agent * } \\
\text { group }\end{array}$} & Pillai's Trace & ,110 & $2,730^{\mathrm{a}}$ & 1,000 & 22,000 & ,113 & , 110 \\
\hline & Wilks' Lambda & ,890 & $2,730^{\mathrm{a}}$ & 1,000 & 22,000 & ,113 &, 110 \\
\hline & Hotelling's Trace & , 124 & $2,730^{\mathrm{a}}$ & 1,000 & 22,000 & ,113 & , 110 \\
\hline & Roy's Largest & , 124 & $2,730^{\mathrm{a}}$ & 1,000 & 22,000 & ,113 & ,110 \\
\hline & Root & & & & & & \\
\hline
\end{tabular}
a. Exact statistic
b. Design: Intercept + group

Within Subjects Design: congruence_agent 
Tests of Within-Subjects Contrasts

Measure:MEASURE 1

\begin{tabular}{|ll|r|r|r|r|r|r|}
\hline Source & congruence_agent & $\begin{array}{c}\text { Type III Sum of } \\
\text { Squares }\end{array}$ & df & Mean Square & F & Sig. & $\begin{array}{c}\text { Partial Eta } \\
\text { Squared }\end{array}$ \\
\hline congruence_agent & Linear & 16,703 & 1 & 16,703 & 32,653 &, 000 &, 597 \\
\hline congruence_agent * group Linear & 1,396 & 1 & 1,396 & 2,730 &, 113 &, 110 \\
\hline Error(congruence_agent) & Linear & 11,253 & 22 &, 512 & & & \\
\hline
\end{tabular}

Tests of Within-Subjects Effects

Measure:MEASURE_1

\begin{tabular}{|c|c|c|c|c|c|c|c|}
\hline Source & & $\begin{array}{c}\text { Type III Sum of } \\
\text { Squares }\end{array}$ & $d f$ & Mean Square & $\mathrm{F}$ & Sig. & $\begin{array}{l}\text { Partial Eta } \\
\text { Squared }\end{array}$ \\
\hline \multirow[t]{4}{*}{ congruence_agent } & Sphericity Assumed & 16,703 & 1 & 16,703 & 32,653 &, 000 & ,597 \\
\hline & Greenhouse-Geisser & 16,703 & 1,000 & 16,703 & 32,653 &, 000 & ,597 \\
\hline & Huynh-Feldt & 16,703 & 1,000 & 16,703 & 32,653 &, 000 &, 597 \\
\hline & Lower-bound & 16,703 & 1,000 & 16,703 & 32,653 &, 000 &, 597 \\
\hline \multirow[t]{4}{*}{ congruence_agent * group } & Sphericity Assumed & 1,396 & 1 & 1,396 & 2,730 &, 113 & , 110 \\
\hline & Greenhouse-Geisser & 1,396 & 1,000 & 1,396 & 2,730 &, 113 & 110 \\
\hline & Huynh-Feldt & 1,396 & 1,000 & 1,396 & 2,730 &, 113 & , 110 \\
\hline & Lower-bound & 1,396 & 1,000 & 1,396 & 2,730 &, 113 &, 110 \\
\hline \multirow[t]{4}{*}{ Error(congruence_agent) } & Sphericity Assumed & 11,253 & 22 &, 512 & & & \\
\hline & Greenhouse-Geisser & 11,253 & 22,000 &, 512 & & & \\
\hline & Huynh-Feldt & 11,253 & 22,000 &, 512 & & & \\
\hline & Lower-bound & 11,253 & 22,000 &, 512 & & & \\
\hline
\end{tabular}

Tests of Between-Subjects Effects

Measure:MEASURE_1

Transformed Variable:Average

\begin{tabular}{|l|l|l|l|l|l|l|}
\hline Source & $\begin{array}{l}\text { Type III Sum of } \\
\text { Squares }\end{array}$ & $\mathrm{df}$ & Mean Square & F & Sig. & $\begin{array}{l}\text { Partial Squared } \\
\text { Intercept }\end{array}$ \\
680,913 & 1 & 680,913 & 981,574 &, 000 &, 978 \\
Group &, 011 & 1 &, 011 & 0,0153 & 0,9026 &, 001 \\
Error & 15,261 & 22 &, 694 & & & \\
\hline
\end{tabular}




\subsection{APPENDIX B: PATIENT CONTEXTS,}

One-Sample Kolmogorov-Smirnov Test

\begin{tabular}{|c|c|c|c|c|}
\hline group & & & \#patient3 & patient4 \\
\hline \multirow[t]{8}{*}{ natives } & $\mathrm{N}$ & & 12 & 12 \\
\hline & \multirow[t]{2}{*}{ Normal Parameters ${ }^{\mathrm{a}, \mathrm{b}}$} & Mean & 4,04158 & 3,65283 \\
\hline & & Std. Deviation & ,798093 & ,830883 \\
\hline & \multirow[t]{3}{*}{ Most Extreme Differences } & Absolute & ,217 &, 149 \\
\hline & & Positive &, 161 & ,093 \\
\hline & & Negative &,- 217 &,- 149 \\
\hline & \multicolumn{2}{|l|}{ Kolmogorov-Smirnov Z } & ,752 &, 515 \\
\hline & \multicolumn{2}{|l|}{ Asymp. Sig. (2-tailed) } & 0,6234 & 0,9536 \\
\hline \multirow[t]{8}{*}{ learners } & $\mathrm{N}$ & & 12 & 12 \\
\hline & \multirow[t]{2}{*}{ Normal Parameters ${ }^{\mathrm{a}, \mathrm{b}}$} & Mean & 3,88908 & 4,02778 \\
\hline & & Std. Deviation & ,602268 & ,729436 \\
\hline & \multirow[t]{3}{*}{ Most Extreme Differences } & Absolute &, 187 & , 159 \\
\hline & & Positive & ,135 & ,091 \\
\hline & & Negative &,- 187 &,- 159 \\
\hline & \multicolumn{2}{|l|}{ Kolmogorov-Smirnov Z } & ,648 &, 551 \\
\hline & \multicolumn{2}{|l|}{ Asymp. Sig. (2-tailed) } & 0,7947 & 0,9220 \\
\hline
\end{tabular}

a. Test distribution is Normal.

b. Calculated from data.

\subsubsection{Error Bar Chart: \#patient3 and patient 4}

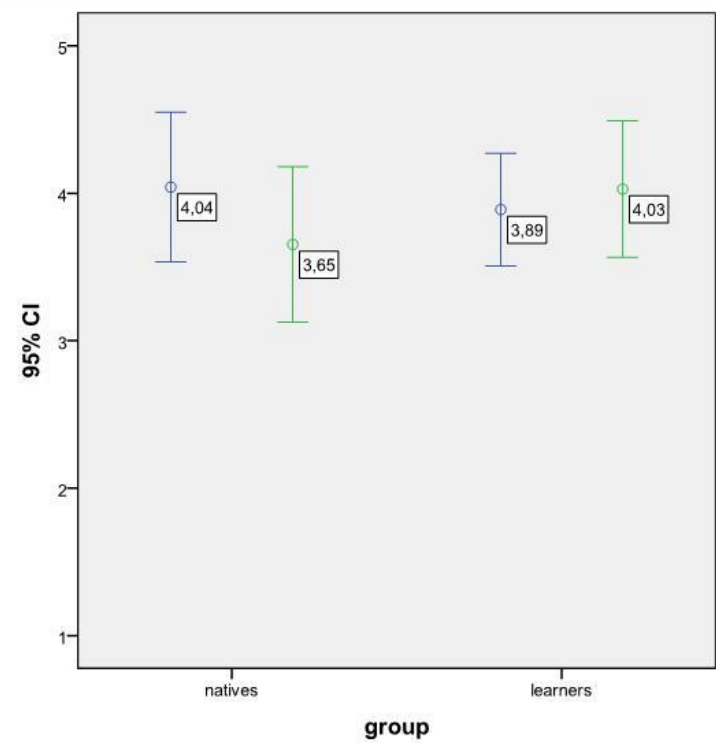

I \#patient3
I patient4 
Mauchly's Test of Sphericity

Measure:MEASURE_1

\begin{tabular}{|c|c|c|c|c|c|c|c|}
\hline \multirow[b]{2}{*}{$\begin{array}{l}\text { Within Subjects } \\
\text { Effect }\end{array}$} & \multirow[b]{2}{*}{ Mauchly's W } & \multirow[b]{2}{*}{$\begin{array}{l}\text { Approx. Chi- } \\
\text { Square }\end{array}$} & \multirow[b]{2}{*}{ df } & \multirow[b]{2}{*}{ Sig. } & \multicolumn{3}{|c|}{ Epsilon $^{a}$} \\
\hline & & & & & $\begin{array}{c}\text { Greenhouse- } \\
\text { Geisser }\end{array}$ & Huynh-Feldt & Lower-bound \\
\hline congruence_patient & 1 &, 000 & 0 & & 1,000 & 1,000 & 1,000 \\
\hline
\end{tabular}

Tests the null hypothesis that the error covariance matrix of the orthonormalized transformed dependent variables is proportional to an identity matrix.

a. May be used to adjust the degrees of freedom for the averaged tests of significance. Corrected tests are displayed in the Tests of Within-Subjects Effects table.

b. Design: Intercept + group

Within Subjects Design: congruence_patient

Levene's Test of Equality of Error Variances ${ }^{a}$

\begin{tabular}{|l|r|r|r|r|}
\hline & $\mathrm{F}$ & $\mathrm{df1}$ & $\mathrm{df2}$ & \multicolumn{1}{c|}{ Sig. } \\
\hline \#patient3 & 2,361 & 1 & 22 &, 139 \\
patient4 &, 141 & 1 & 22 &, 711 \\
\hline
\end{tabular}

Tests the null hypothesis that the error variance of the dependent variable is equal across groups.

a. Design: Intercept + group

Within Subjects Design: congruence_patient

Multivariate Tests ${ }^{\mathrm{b}}$

\begin{tabular}{|ll|r|r|r|r|r|r|}
\hline Effect & & Value & \multicolumn{1}{c|}{ F } & Hypothesis df & Error df & \multicolumn{1}{c|}{$\begin{array}{c}\text { Partial Eta } \\
\text { Squared }\end{array}$} \\
\hline congruence_patient & Pillai's Trace &, 017 &, $370^{\mathrm{a}}$ & 1,000 & 22,000 &, 549 &, 017 \\
& Wilks' Lambda &, 983 &, $370^{\mathrm{a}}$ & 1,000 & 22,000 &, 549 &, 017 \\
& Hotelling's Trace &, 017 &, $370^{\mathrm{a}}$ & 1,000 & 22,000 &, 549 &, 017 \\
& Roy's Largest Root &, 017 &, $370^{\mathrm{a}}$ & 1,000 & 22,000 &, 549 &, 017 \\
\hline congruence_patient * group & Pillai's Trace &, 070 & $1,645^{\mathrm{a}}$ & 1,000 & 22,000 &, 213 &, 070 \\
& Wilks' Lambda &, 930 & $1,645^{\mathrm{a}}$ & 1,000 & 22,000 &, 213 &, 070 \\
& Hotelling's Trace &, 075 & $1,645^{\mathrm{a}}$ & 1,000 & 22,000 &, 213 &, 070 \\
& Roy's Largest Root &, 075 & $1,645^{\mathrm{a}}$ & 1,000 & 22,000 &, 213 &, 070 \\
\hline
\end{tabular}

a. Exact statistic

b. Design: Intercept + group

Within Subjects Design: congruence_patient 


\subsubsection{Test of Within Subjects Contrast}

Measure:MEASURE_1

\begin{tabular}{|ll|r|r|r|r|r|r|}
\hline Source & congruence_patient & $\begin{array}{c}\text { Type III Sum of } \\
\text { Squares }\end{array}$ & df & Mean Square & F & Sig. & $\begin{array}{c}\text { Partial Eta } \\
\text { Squared }\end{array}$ \\
\hline congruence_patient & Linear &, 188 & 1 &, 188 &, 370 &, 549 &, 017 \\
\hline congruence_patient * group & Linear &, 835 & 1 &, 835 & 1,645 &, 213 &, 070 \\
\hline Error(congruence_patient) & Linear & 11,162 & 22 &, 507 & & & \\
\hline
\end{tabular}

Tests of Within-Subjects Effects

Measure:MEASURE 1

\begin{tabular}{|c|c|c|c|c|c|c|c|}
\hline Source & & $\begin{array}{c}\text { Type III Sum of } \\
\text { Squares }\end{array}$ & df & Mean Square & $\mathrm{F}$ & Sig. & $\begin{array}{l}\text { Partial Eta } \\
\text { Squared }\end{array}$ \\
\hline \multirow[t]{4}{*}{ congruence_patient } & Sphericity Assumed & , 188 & 1 & 188 & ,370 & ,549 & ,017 \\
\hline & Greenhouse-Geisser & , 188 & 1,000 & , 188 & ,370 &, 549 &, 017 \\
\hline & Huynh-Feldt &, 188 & 1,000 & , 188 & ,370 &, 549 & 017 \\
\hline & Lower-bound &, 188 & 1,000 & , 188 & ,370 &, 549 &, 017 \\
\hline \multirow{4}{*}{$\begin{array}{l}\text { congruence_patient * } \\
\text { group }\end{array}$} & Sphericity Assumed & ,835 & 1 & ,835 & 1,645 & ,213 & ,070 \\
\hline & Greenhouse-Geisser & ,835 & 1,000 & ,835 & 1,645 & ,213 & ,070 \\
\hline & Huynh-Feldt & ,835 & 1,000 & ,835 & 1,645 & ,213 &, 070 \\
\hline & Lower-bound &, 835 & 1,000 & ,835 & 1,645 & ,213 &, 070 \\
\hline \multirow[t]{4}{*}{ Error(congruence_patient) } & Sphericity Assumed & 11,162 & 22 & ,507 & & & \\
\hline & Greenhouse-Geisser & 11,162 & 22,000 &, 507 & & & \\
\hline & Huynh-Feldt & 11,162 & 22,000 &, 507 & & & \\
\hline & Lower-bound & 11,162 & 22,000 & ,507 & & & \\
\hline
\end{tabular}

Tests of Between-Subjects Effects

Measure:MEASURE_1

Transformed Variable:Average

\begin{tabular}{|l|r|r|r|r|r|r|}
\hline Source & $\begin{array}{c}\text { Type III Sum of } \\
\text { Squares }\end{array}$ & df & Mean Square & F & Sig. & \multicolumn{1}{c|}{$\begin{array}{c}\text { Partial Eta } \\
\text { Squared }\end{array}$} \\
\hline Intercept & 731,136 & 1 & 731,136 & 1211,062 &, 000 &, 982 \\
group & 148 & 1 &, 148 & 0,2459 & 0,6249 & 0,0111 \\
Error & 13,282 & 22 &, 604 & & & \\
\hline
\end{tabular}




\subsection{APPENDIX C: DISTRACTORS.}

One-Sample Kolmogorov-Smirnov Test

\begin{tabular}{|c|c|c|c|c|}
\hline \multicolumn{3}{|l|}{ Group } & distractor 1 & \#distractor2 \\
\hline \multirow[t]{8}{*}{ natives } & $\mathrm{N}$ & & 12 & 12 \\
\hline & \multirow[t]{2}{*}{ Normal Parameters ${ }^{\mathrm{a}, \mathrm{b}}$} & Mean & 4,65975 & 2,33333 \\
\hline & & Std. Deviation & ,465240 & 1,183907 \\
\hline & \multirow[t]{3}{*}{ Most Extreme Differences } & Absolute & ,312 & ,188 \\
\hline & & Positive & ,232 & ,154 \\
\hline & & Negative &,- 312 &,- 188 \\
\hline & \multicolumn{2}{|l|}{ Kolmogorov-Smirnov Z } & 1,080 & 650 \\
\hline & \multicolumn{2}{|l|}{ Asymp. Sig. (2-tailed) } & 0,1936 & 0,7914 \\
\hline \multirow[t]{8}{*}{ learners } & $\mathrm{N}$ & & 12 & 12 \\
\hline & \multirow[t]{2}{*}{ Normal Parameters ${ }^{\mathrm{a}, \mathrm{b}}$} & Mean & 4,73608 & 1,45144 \\
\hline & & Std. Deviation & ,389036 & ,454305 \\
\hline & \multirow[t]{3}{*}{ Most Extreme Differences } & Absolute & ,265 & ,186 \\
\hline & & Positive & ,249 &, 186 \\
\hline & & Negative &,- 265 &,- 160 \\
\hline & \multicolumn{2}{|l|}{ Kolmogorov-Smirnov Z } & ,918 & ,644 \\
\hline & \multicolumn{2}{|l|}{ Asymp. Sig. (2-tailed) } & 0,3682 & 0,8013 \\
\hline
\end{tabular}

a. Test distribution is Normal.

b. Calculated from data.

\subsubsection{Error Bar Chart: distractor1 and \#distractor2}

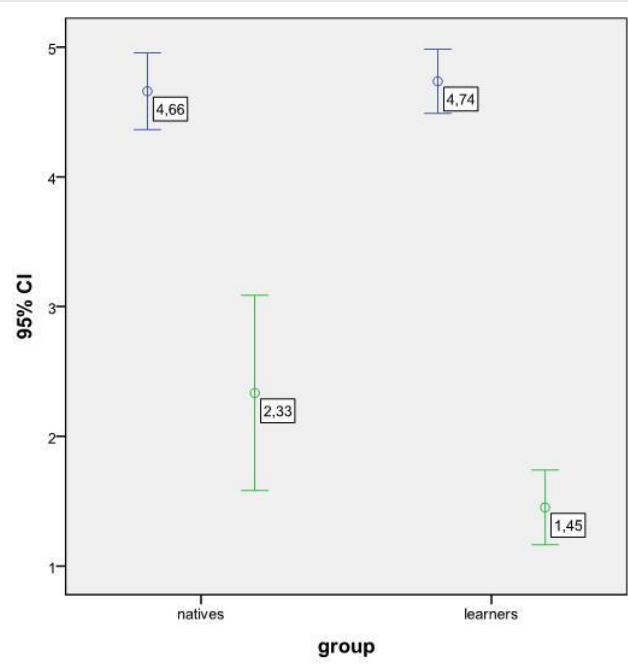

I distractor1
I \#distractor2 
Mauchly's Test of Sphericity ${ }^{\mathrm{b}}$

Measure:MEASURE_1

\begin{tabular}{|c|c|c|c|c|c|c|c|}
\hline \multirow[b]{2}{*}{ Within Subjects Effect } & \multirow[b]{2}{*}{ Mauchly's W } & \multirow[b]{2}{*}{$\begin{array}{l}\text { Approx. Chi- } \\
\text { Square }\end{array}$} & \multirow[b]{2}{*}{ Df } & \multirow[b]{2}{*}{ Sig. } & \multicolumn{3}{|l|}{ Epsilon $^{a}$} \\
\hline & & & & & $\begin{array}{l}\text { Greenhouse- } \\
\text { Geisser }\end{array}$ & Huynh-Feldt & Lower-bound \\
\hline congruence_distractor & 1 &, 000 & 0 & & 1,000 & 1,000 & 1,000 \\
\hline
\end{tabular}

Tests the null hypothesis that the error covariance matrix of the orthonormalized transformed dependent variables is proportional to an identity matrix.

a. May be used to conform the degrees of freedom for the averaged tests of significance. Corrected tests are displayed in the Tests of Within-Subjects Effects table.

b. Design: Intercept + group

Within Subjects Design: congruence_distractor

Levene's Test of Equality of Error Variances ${ }^{a}$

\begin{tabular}{|l|l|l|l|l|}
\hline & $\mathrm{F}$ & $\mathrm{df1}$ & $\mathrm{df2}$ & Sig. \\
\hline distractor1 & 1,561 & 1 & 22 &, 225 \\
\#distractor2 & 14,863 & 1 & 22 &, 001 \\
\hline
\end{tabular}

Tests the null hypothesis that the error variance of the dependent variable is equal across groups. 
Multivariate Tests ${ }^{b}$

\begin{tabular}{|c|c|c|c|c|c|c|c|}
\hline \multicolumn{2}{|l|}{ Effect } & Value & $\mathrm{F}$ & $\begin{array}{c}\text { Hypothesis } \\
\text { df }\end{array}$ & Error df & Sig. & $\begin{array}{l}\text { Partial Eta } \\
\text { Squared }\end{array}$ \\
\hline \multirow{6}{*}{$\begin{array}{l}\text { congruence_distract } \\
\text { or }\end{array}$} & Pillai's Trace & ,906 & 211,169 & 1,000 & 22,000 & ,000 & ,906 \\
\hline & Wilks' Lambda & ,094 & 211,169 & 1,000 & 22,000 & ,000 & ,906 \\
\hline & Hotelling's & 9,599 & 211,169 & 1,000 & 22,000 & ,000 & ,906 \\
\hline & Trace & & & & & & \\
\hline & Roy's Largest & 9,599 & 211,169 & 1,000 & 22,000 & ,000 & ,906 \\
\hline & Root & & a & & & & \\
\hline \multirow{6}{*}{$\begin{array}{l}\text { congruence_distract } \\
\text { or * group }\end{array}$} & Pillai's Trace & ,219 & $6,158^{\mathrm{a}}$ & 1,000 & 22,000 & ,021 & ,219 \\
\hline & Wilks' Lambda & ,781 & $6,158^{\mathrm{a}}$ & 1,000 & 22,000 & ,021 & ,219 \\
\hline & Hotelling's & ,280 & $6,158^{a}$ & 1,000 & 22,000 & ,021 & ,219 \\
\hline & Trace & & & & & & \\
\hline & Roy's Largest & ,280 & $6,158^{\mathrm{a}}$ & 1,000 & 22,000 & ,021 & ,219 \\
\hline & Root & & & & & & \\
\hline
\end{tabular}

a. Exact statistic

b. Design: Intercept + group

Within Subjects Design: congruence_distractor 
Tests of Within-Subjects Effects

Measure:MEASURE_1

\begin{tabular}{|c|c|c|c|c|c|c|c|}
\hline Source & & $\begin{array}{l}\text { Type III Sum } \\
\text { of Squares }\end{array}$ & df & $\begin{array}{l}\text { Mean } \\
\text { Square }\end{array}$ & $F$ & Sig. & $\begin{array}{ll}\text { Partial Eta } \\
\text { Squared }\end{array}$ \\
\hline \multirow[t]{5}{*}{ congruence_distractor } & Sphericity Assumed & 94,452 & 1 & 94,452 & 211,169 & ,000 & ,906 \\
\hline & Greenhouse- & 94,452 & 1,000 & 94,452 & 211,169 & ,000 & ,906 \\
\hline & Geisser & & & & & & \\
\hline & Huynh-Feldt & 94,452 & 1,000 & 94,452 & 211,169 & ,000 & ,906 \\
\hline & Lower-bound & 94,452 & 1,000 & 94,452 & 211,169 &, 000 &, 906 \\
\hline \multirow{5}{*}{$\begin{array}{l}\text { congruence_distractor * } \\
\text { group }\end{array}$} & Sphericity Assumed & 2,755 & 1 & 2,755 & 6,158 & ,021 & ,219 \\
\hline & Greenhouse- & 2,755 & 1,000 & 2,755 & 6,158 & ,021 & ,219 \\
\hline & Geisser & & & & & & \\
\hline & Huynh-Feldt & 2,755 & 1,000 & 2,755 & 6,158 & 021 & ,219 \\
\hline & Lower-bound & 2,755 & 1,000 & 2,755 & 6,158 &, 021 & ,219 \\
\hline \multirow{5}{*}{$\begin{array}{l}\text { Error(congruence_distra } \\
\text { ctor) }\end{array}$} & Sphericity Assumed & 9,840 & 22 & ,447 & & & \\
\hline & Greenhouse- & 9,840 & 22,000 & ,447 & & & \\
\hline & Geisser & & & & & & \\
\hline & Huynh-Feldt & 9,840 & 22,000 & ,447 & & & \\
\hline & Lower-bound & 9,840 & 22,000 & ,447 & & & \\
\hline
\end{tabular}


Tests of Within-Subjects Contrasts

Measure:MEASURE_1

\begin{tabular}{|c|c|c|c|c|c|c|c|}
\hline Source & $\begin{array}{l}\text { congruence_distr } \\
\text { actor }\end{array}$ & \begin{tabular}{|ll} 
Type & III \\
Sum & of \\
Squares & \\
\end{tabular} & df & $\begin{array}{l}\text { Mean } \\
\text { Square }\end{array}$ & $F$ & Sig. & $\begin{array}{l}\text { Partial Eta } \\
\text { Squared }\end{array}$ \\
\hline $\begin{array}{l}\text { congruence_distract } \\
\text { or }\end{array}$ & Linear & 94,452 & 1 & 94,452 & $\begin{array}{l}211,16 \\
9 \\
\end{array}$ & ,000 & ,906 \\
\hline $\begin{array}{l}\text { congruence_distract } \\
\text { or * group }\end{array}$ & Linear & 2,755 & 1 & 2,755 & 6,158 & ,021 & ,219 \\
\hline $\begin{array}{l}\text { Error(congruence_di } \\
\text { stractor) }\end{array}$ & Linear & 9,840 & 22 & ,447 & & & \\
\hline
\end{tabular}

Tests of Between-Subjects Effects

Measure:MEASURE_1

Transformed Variable:Average

\begin{tabular}{|l|l|l|l|l|l|l|}
\hline \multirow{2}{*}{$\begin{array}{l}\text { Type III Sum of } \\
\text { Source }\end{array}$} & Squares & df & Mean Square & F & Sig. & $\begin{array}{l}\text { Squartial } \\
\text { Intercept }\end{array}$ \\
\hline 521,186 & 1 & 521,186 & 964,030 &, 000 &, 978 \\
group & 1,947 & 1 & 1,947 & 3,6 & 0,07 & 0,14 \\
Error & 11,894 & 22 &, 541 & & & \\
\hline
\end{tabular}




\section{APPENDIX III: STIMULI}

\subsection{Practice Block.}

9.1.1 1. KICK (A:POLICEMAN ; O:HOOLIGAN)

\begin{tabular}{|l|l|l|}
\hline CONTEXT & PROBE SENTENCES & $\begin{array}{l}\text { INFOSTRUCTURE / } \\
\text { SYNTAX }\end{array}$ \\
\hline Agent: & $\begin{array}{l}\text { The hooligan kicked a } \\
\text { policeman because he was being } \\
\text { violent. }\end{array}$ & Active: Given / New \\
$\begin{array}{l}\text { A hooligan was at a football } \\
\text { match and his team was losing. } \\
\begin{array}{l}\text { He got very violent and started a } \\
\text { fight. }\end{array}\end{array}$ & $\begin{array}{l}\text { A policeman was kicked by the } \\
\text { hooligan because he was being } \\
\text { violent. }\end{array}$ & Passive: New / Given \\
\hline
\end{tabular}

\subsubsection{LEAD (A:GUIDE ; 0:HIKER)}

\begin{tabular}{|l|l|l|}
\hline CONTEXT & PROBE SENTENCES & INFOSTRUCTURE / SYNTAX \\
\hline Patient: & $\begin{array}{l}\text { A guide led the hiker back } \\
\text { through the path. }\end{array}$ & Active: New / Given \\
$\begin{array}{l}\text { A hiker was following his group } \\
\text { through a complicated mountain } \\
\text { path. Then, he got lost and was } \\
\text { not sure which way to go. }\end{array}$ & $\begin{array}{l}\text { The hiker was led by a guide } \\
\text { back through the path. }\end{array}$ & Passive: Given / New \\
\cline { 2 - 3 } & & Ogiven Vpassive Anew \\
\hline
\end{tabular}

\subsubsection{FOLLOW (A:POLICEMAN ; 0:RIOTER)}

\begin{tabular}{|l|l|l|}
\hline CONTEXT & PROBE SENTENCES & $\begin{array}{l}\text { INFOSTRUCTURE / } \\
\text { SYNTAX }\end{array}$ \\
\hline Agent: & $\begin{array}{l}\text { The policeman followed a rioter } \\
\text { into the building. }\end{array}$ & Active: Given / New \\
$\begin{array}{l}\text { A policeman was immersed in a } \\
\text { violent riot. He had to make sure } \\
\text { the Parliament building } \\
\text { remained secure. }\end{array}$ & $\begin{array}{l}\text { A rioter was followed by the } \\
\text { policeman into the building. }\end{array}$ & Passive: New / Given \\
\cline { 2 - 3 } & \begin{tabular}{l} 
Sgiven Onew \\
\hline
\end{tabular} & Onew Vpassive Agiven \\
\hline
\end{tabular}


9.1.4 4.CARRY (A:SWIMMER; O:WOMAN)

\begin{tabular}{|l|l|l|}
\hline CONTEXT & PROBE SENTENCES & $\begin{array}{l}\text { INFOSTRUCTURE / } \\
\text { SYNTAX }\end{array}$ \\
\hline Patient: & $\begin{array}{l}\text { A swimmer carried the woman } \\
\text { out of the cold water. }\end{array}$ & Active: New / Given \\
\multirow{2}{*}{$\begin{array}{l}\text { A woman was swimming at a } \\
\text { crowded beach. She suddenly } \\
\text { started to drown. }\end{array}$} & $\begin{array}{l}\text { The woman was carried by a } \\
\text { swimmer out of the cold water. }\end{array}$ & Snew Vactive Ogiven \\
\cline { 2 - 3 } & & Ogiven Vpassive Anew \\
\hline
\end{tabular}

\subsubsection{TELL}

\begin{tabular}{|l|l|l|}
\hline CONTEXT & PROBE SENTENCES & $\begin{array}{l}\text { VERIFICATION } \\
\text { SENTENCE }\end{array}$ \\
\hline $\begin{array}{l}\text { Anne Phillips had just found out } \\
\text { that she had won the lottery. She } \\
\text { was very happy and excited. }\end{array}$ & $\begin{array}{l}\text { Anne told her mother the good } \\
\text { news. }\end{array}$ & Anne Phillips won the lottery. \\
& $\begin{array}{l}\text { It was Anne who told her mother } \\
\text { the good news. }\end{array}$ & \\
\hline
\end{tabular}

\subsubsection{WIN}

\begin{tabular}{|l|l|l|}
\hline CONTEXT & PROBE SENTENCES & $\begin{array}{l}\text { VERIFICATION } \\
\text { SENTENCE }\end{array}$ \\
\hline $\begin{array}{l}\text { Leonardo DiCaprio was at the } \\
\text { Oscars ceremony. They were } \\
\text { about to announce the name of } \\
\text { the winner. }\end{array}$ & $\begin{array}{l}\text { Leonardo DiCaprio gave the } \\
\text { winner a firm handshake. }\end{array}$ & $\begin{array}{l}\text { Leonardo DiCpario won the } \\
\text { Oscar. }\end{array}$ \\
& $\begin{array}{l}\text { It was Leonardo DiCaprio who } \\
\text { gave the winner a firm } \\
\text { handshake. }\end{array}$ & \\
\hline
\end{tabular}




\subsection{Experimental Block.}

9.2.1 1. SEE (E1:POLICE; E2:THIEF)

\begin{tabular}{|c|c|c|}
\hline CONTEXT & PROBE SENTENCES & INFOSTRUCTURE / SYNTAX \\
\hline Agent: & $\begin{array}{l}\text { The policeman saw a thief while } \\
\text { trying to steal a car. }\end{array}$ & Active: Given / New: \\
\hline \multirow{2}{*}{$\begin{array}{l}\text { A policeman was patrolling the } \\
\text { city streets at night. He heard a } \\
\text { strange noise. }\end{array}$} & & Sgiven Vactive Onew \\
\hline & $\begin{array}{l}\text { A thief was seen by the } \\
\text { policeman while trying to steal a } \\
\text { car. }\end{array}$ & $\begin{array}{l}\text { Passive: New / Given } \\
\text { Onew Vpassive Agiven }\end{array}$ \\
\hline Patient: & $\begin{array}{l}\text { A policeman saw the thief while } \\
\text { trying to steal a car. }\end{array}$ & Active: New / Given \\
\hline \multirow{2}{*}{$\begin{array}{l}\text { A thief planned to do something } \\
\text { illegal. He was hidden in a dark } \\
\text { street. }\end{array}$} & & Snew Vactive Ogiven \\
\hline & $\begin{array}{l}\text { The thief was seen by a } \\
\text { policeman while trying to steal a } \\
\text { car. }\end{array}$ & $\begin{array}{l}\text { Passive: Given / New } \\
\text { Ogiven Vpassive Anew }\end{array}$ \\
\hline
\end{tabular}

\subsubsection{PUSH (E1:MAN; E2: LADY)}

\begin{tabular}{|l|l|l|}
\hline CONTEXT & PROBE SENTENCES & $\begin{array}{l}\text { INFOSTRUCTURE / } \\
\text { SYNTAX }\end{array}$ \\
\hline Agent: & $\begin{array}{l}\text { The man pushed a lady when the } \\
\text { bus arrived. }\end{array}$ & Active: Given / New \\
$\begin{array}{l}\text { A man was waiting at a busy bus } \\
\text { stop. He was in a hurry. }\end{array}$ & $\begin{array}{l}\text { A lady was pushed by the man } \\
\text { when the bus arrived. }\end{array}$ & Passive: New / Given \\
\hline Patient: & $\begin{array}{l}\text { A man pushed the lady when the } \\
\text { bus arrived. }\end{array}$ & Active: New / Given \\
\hline \multirow{2}{*}{$\begin{array}{l}\text { A lady was waiting at a busy bus } \\
\text { stop. She was looking for her } \\
\text { phone in her bag. }\end{array}$} & $\begin{array}{l}\text { The lady was pushed by a man } \\
\text { when the bus arrived. }\end{array}$ & Passive: Given / New \\
\cline { 2 - 3 } & Snew Vactive Ogiven \\
\hline
\end{tabular}




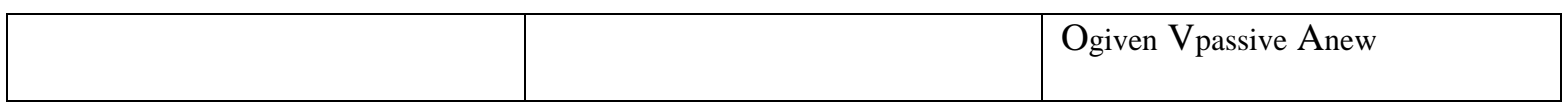




\begin{tabular}{|l|l|l|}
\hline CONTEXT & PROBE SENTENCES & $\begin{array}{l}\text { INFOSTRUCTURE / } \\
\text { SYNTAX }\end{array}$ \\
\hline Agent: & $\begin{array}{l}\text { The cowboy shot an Indian in } \\
\text { the head. }\end{array}$ & Active: Given / New \\
$\begin{array}{l}\text { A cowboy was passing } \\
\text { through enemy territory. } \\
\text { Suddenly, he heard some } \\
\text { shouts behind him. }\end{array}$ & $\begin{array}{l}\text { An Indian was shot by the } \\
\text { cowboy in the head. }\end{array}$ & Passive: New / Given \\
\cline { 2 - 3 } $\begin{array}{l}\text { Patient: } \\
\text { An Indian was in the wild } \\
\text { west frontier. He was } \\
\text { checking that the land was } \\
\text { safe for the rest of his tribe. }\end{array}$ & $\begin{array}{l}\text { A cowboy shot the Indian in } \\
\text { the head. }\end{array}$ & Active: New / Given \\
\cline { 2 - 3 } & cowboy in the head. & Passive: Given / New \\
\hline
\end{tabular}

\subsubsection{HELP (A:SALESGIRL; 0:CLIENT)}

\begin{tabular}{|l|l|l|}
\hline CONTEXT & PROBE SENTENCES & $\begin{array}{l}\text { INFOSTRUCTURE / } \\
\text { SYNTAX }\end{array}$ \\
\hline Agent: & $\begin{array}{l}\text { The salesgirl helped a client } \\
\text { because she was indecisive. }\end{array}$ & Active: Given / New \\
$\begin{array}{l}\text { A salesgirl was working in a } \\
\text { clothes shop. She was } \\
\text { required to go to the ladies' } \\
\text { section. }\end{array}$ & $\begin{array}{l}\text { A client was helped by the } \\
\text { salesgirl because she was } \\
\text { indecisive. }\end{array}$ & Sassive: New / Given \\
\cline { 2 - 3 } & $\begin{array}{l}\text { S salesgirl helped the client } \\
\text { because she was indecisive. }\end{array}$ & Active: New / Given \\
\hline Patient: & \multicolumn{2}{|l}{ Onew Vpassive Agiven } \\
\hline
\end{tabular}


looking for a dress, but she could not decide which type she wanted.
The client was helped by a salesgirl because she was indecisive.
Passive: Given / New

Ogiven Vpassive Anew 


\subsubsection{CHOOSE (A:STUDENT; 0:GIRL)}

\begin{tabular}{|l|l|l|}
\hline CONTEXT & PROBE SENTENCES & $\begin{array}{l}\text { INFOSTRUCTURE / } \\
\text { SYNTAX }\end{array}$ \\
\hline Agent: & $\begin{array}{l}\text { The student chose a girl because } \\
\text { she was pretty. }\end{array}$ & Active: Given / New \\
$\begin{array}{l}\text { A student was deciding who to } \\
\text { invite to the prom. The party } \\
\text { would take place the following } \\
\text { week. }\end{array}$ & $\begin{array}{l}\text { A girl was chosen by the student } \\
\text { because she was pretty. }\end{array}$ & Passive: New / Given \\
\cline { 2 - 3 } \begin{tabular}{l} 
Patient: \\
\multirow{2}{*}{$\begin{array}{l}\text { A girl was impatient for } \\
\text { someone to ask her out to the } \\
\text { prom. The party would take } \\
\text { place the following week. }\end{array}$}
\end{tabular} & $\begin{array}{l}\text { A student chose the girl because } \\
\text { she was pretty. }\end{array}$ & Active: New / Given \\
\cline { 2 - 3 } & $\begin{array}{l}\text { Ohe girl was chosen by a student } \\
\text { because she was pretty. }\end{array}$ & Passive: Given / New \\
\hline
\end{tabular}

\subsubsection{IDENTIFY (A:VICTIM; 0:SUSPECT)}

\begin{tabular}{|l|l|l|}
\hline CONTEXT & PROBE SENTENCES & $\begin{array}{l}\text { INFOSTRUCTURE / } \\
\text { SYNTAX }\end{array}$ \\
\hline Agent: & $\begin{array}{l}\text { The victim identified a suspect } \\
\text { during the identification parade. }\end{array}$ & Active: Given / New \\
$\begin{array}{l}\text { A victim went to the police } \\
\text { station to report the crime after } \\
\text { she was attacked. }\end{array}$ & $\begin{array}{l}\text { A suspect was identified by the } \\
\text { victim during the identification } \\
\text { parade. }\end{array}$ & Passive: New / Given \\
\hline Patient: & $\begin{array}{l}\text { A victim identified the suspect } \\
\text { during the identification parade. }\end{array}$ & Active: New / Given \\
\cline { 2 - 3 } $\begin{array}{l}\text { A suspect was at the police } \\
\text { station because he had } \\
\text { committed several crimes. }\end{array}$ & $\begin{array}{l}\text { The suspect was identified by a } \\
\text { victim during the identification } \\
\text { parade. }\end{array}$ & Passive: Given / New \\
\hline
\end{tabular}


9.2.7 7. SAVE (A:FIREFIGHTER; 0:GIRL)

\begin{tabular}{|c|c|c|}
\hline CONTEXT & PROBE SENTENCES & $\begin{array}{l}\text { INFOSTRUCTURE / } \\
\text { SYNTAX }\end{array}$ \\
\hline Agent: & $\begin{array}{l}\text { The firefighter saved a girl just } \\
\text { in time. }\end{array}$ & Active: Given / New \\
\hline \multirow{3}{*}{$\begin{array}{l}\text { A firefighter entered a building } \\
\text { on fire that was about to be } \\
\text { burned to the ground. }\end{array}$} & & Sgiven Vactive Onew \\
\hline & $\begin{array}{l}\text { A girl was saved by the } \\
\text { firefighter just in time. }\end{array}$ & Passive: New / Given \\
\hline & & Onew Vpassive Agiven \\
\hline \multirow{4}{*}{$\begin{array}{l}\text { Patient: } \\
\text { A girl was inside a building that } \\
\text { was on fire. She was about to die } \\
\text { because of the smoke. }\end{array}$} & $\begin{array}{l}\text { A firefighter saved the girl just } \\
\text { in time. }\end{array}$ & Active: New / Given \\
\hline & & Snew Vactive Ogiven \\
\hline & $\begin{array}{l}\text { The girl was saved by a } \\
\text { firefighter just in time. }\end{array}$ & Passive: Given / New \\
\hline & & Ogiven Vpassive Anew \\
\hline
\end{tabular}

9.2.8 8. KILL (A: ASSASSIN; 0:POLITICIAN)

\begin{tabular}{|l|l|l|}
\hline CONTEXT & PROBE SENTENCES & $\begin{array}{l}\text { INFOSTRUCTURE / } \\
\text { SYNTAX }\end{array}$ \\
\hline Agent: & $\begin{array}{l}\text { The assassin killed a politician in } \\
\text { front of everyone. }\end{array}$ & Active: Given / New \\
$\begin{array}{l}\text { An assassin was preparing his } \\
\text { rifle on a roof top. He sat and } \\
\text { observed the crowd beneath him. }\end{array}$ & $\begin{array}{l}\text { A politician was killed by the } \\
\text { assassin in front of everyone }\end{array}$ & Passive: New / Given \\
\hline \begin{tabular}{l} 
Patient: \\
\multirow{2}{*}{$\begin{array}{l}\text { A politician was parading in his } \\
\text { car in front of a crowd that } \\
\text { waved at him enthusiastically. }\end{array}$}
\end{tabular} & $\begin{array}{l}\text { An assassin killed the politician } \\
\text { in front of everyone. }\end{array}$ & Active: New / Given \\
\cline { 2 - 3 } & $\begin{array}{l}\text { The politician was killed by } \\
\text { an assassin in front of }\end{array}$ & Passive: Given / New \\
\hline
\end{tabular}




\begin{tabular}{|l|l|l|}
\hline & everyone. & \\
\hline
\end{tabular}

\subsubsection{KISS (A:FAN; 0:SINGER)}

\begin{tabular}{|l|l|l|}
\hline CONTEXT & PROBE SENTENCES & $\begin{array}{l}\text { INFOSTRUCTURE / } \\
\text { SYNTAX }\end{array}$ \\
\hline Agent: & $\begin{array}{l}\text { The fan kissed a singer in the } \\
\text { middle of a song. }\end{array}$ & Active: Given / New \\
$\begin{array}{l}\text { A fan was at a boy band concert. } \\
\text { She desperately jumped onto the } \\
\text { stage. }\end{array}$ & $\begin{array}{l}\text { A singer was kissed by the fan in } \\
\text { the middle of a song. }\end{array}$ & Passive: New / Given \\
\cline { 2 - 4 } & $\begin{array}{l}\text { S singer was kissed by the fan in } \\
\text { the middle of a song. }\end{array}$ & Active: New / Given \\
\hline Patient: & $\begin{array}{l}\text { Onew singer was kissed by a fan in } \\
\text { the middle of a song. } \\
\text { concert. He was singing } \\
\text { passionately. }\end{array}$ & Passive: Given / New \\
\cline { 2 - 4 } & Snew Vactive Ogiven \\
\hline
\end{tabular}


9.2.10 10. CONVINCE (A:POLITICIAN; O:VOTER)

\begin{tabular}{|c|c|c|}
\hline CONTEXT & PROBE SENTENCES & $\begin{array}{l}\text { INFOSTRUCTURE / } \\
\text { SYNTAX }\end{array}$ \\
\hline \multirow{4}{*}{$\begin{array}{l}\text { Agent: } \\
\text { A politician was in the middle of } \\
\text { the street. He presented himself } \\
\text { as the best candidate. }\end{array}$} & $\begin{array}{l}\text { The politician convinced a voter } \\
\text { after an intense debate. }\end{array}$ & Active: Given / New \\
\hline & & Sgiven Vactive Onew \\
\hline & $\begin{array}{l}\text { A voter was convinced by the } \\
\text { politician after an intense debate. }\end{array}$ & \\
\hline & & Onew Vpassive Agiven \\
\hline \multirow{4}{*}{$\begin{array}{l}\text { Patient: } \\
\text { A voter was attending a political } \\
\text { meeting. He was considering } \\
\text { who to vote for. }\end{array}$} & $\begin{array}{l}\text { A politician convinced the voter } \\
\text { after an intense debate. }\end{array}$ & Active: New / Given \\
\hline & & Snew Vactive Ogiven \\
\hline & $\begin{array}{l}\text { The voter was convinced by a } \\
\text { politician after an intense debate. }\end{array}$ & Passive: Given / New \\
\hline & & Ogiven Vpassive Anew \\
\hline
\end{tabular}

9.2.11 11. PUNISH (A: SERGEANT; O: SOLDIER)

\begin{tabular}{|c|c|c|}
\hline CONTEXT & PROBE SENTENCES & $\begin{array}{l}\text { INFOSTRUCTURE/ } \\
\text { SYNTAX }\end{array}$ \\
\hline \multirow{4}{*}{$\begin{array}{l}\text { Agent: } \\
\text { A sergeant was inspecting the } \\
\text { barracks in the morning. He was } \\
\text { very angry when he saw how } \\
\text { dirty they were. }\end{array}$} & $\begin{array}{l}\text { The sergeant punished a soldier } \\
\text { for being messy. }\end{array}$ & Active: Given / New \\
\hline & & Sgiven Vactive Onew \\
\hline & $\begin{array}{l}\text { A soldier was punished by the } \\
\text { sergeant for being messy. }\end{array}$ & \\
\hline & & Onew Vpassive Agiven \\
\hline \multirow{4}{*}{$\begin{array}{l}\text { Patient: } \\
\text { A soldier had been drinking the } \\
\text { night before. He had forgotten to } \\
\text { clean the barracks before the } \\
\text { morning inspection. }\end{array}$} & $\begin{array}{l}\text { A sergeant punished the soldier } \\
\text { for being messy. }\end{array}$ & Active: New / Given \\
\hline & & Snew Vactive Ogiven \\
\hline & $\begin{array}{l}\text { The soldier was punished by a } \\
\text { sergeant for being messy. }\end{array}$ & Passive: Given / New \\
\hline & & Ogiven Vpassive Anew \\
\hline
\end{tabular}


9.2.12 12. STOP (A:POLICEMAN ; 0:DRIVER)

\begin{tabular}{|c|c|c|}
\hline CONTEXT & PROBE SENTENCES & $\begin{array}{l}\text { INFOSTRUCTURE / } \\
\text { SYNTAX }\end{array}$ \\
\hline Agent: & $\begin{array}{l}\text { The policeman stopped a driver } \\
\text { because he was drunk. }\end{array}$ & Active: Given / New \\
\hline \multirow{3}{*}{$\begin{array}{l}\text { A policeman was doing alcohol } \\
\text { checks on a Saturday night. He } \\
\text { was in a busy road. }\end{array}$} & & Sgiven Vactive Onew \\
\hline & $\begin{array}{l}\text { A driver was stopped by the } \\
\text { policeman because he was } \\
\text { drunk. }\end{array}$ & Passive: New / Given \\
\hline & & Onew Vpassive Agiven \\
\hline Patient: & $\begin{array}{l}\text { A policeman stopped the driver } \\
\text { because he was drunk. }\end{array}$ & Active: New / Given \\
\hline \multirow{3}{*}{$\begin{array}{l}\text { A driver was coming back from } \\
\text { a party on a Saturday night. He } \\
\text { had drunk more than ten beers. }\end{array}$} & & Snew Vactive Ogiven \\
\hline & $\begin{array}{l}\text { The driver was stopped by a } \\
\text { policeman because he was } \\
\text { drunk. }\end{array}$ & Passive: Given / New \\
\hline & & Ogiven Vpassive Anew \\
\hline
\end{tabular}




\begin{tabular}{|c|c|c|}
\hline CONTEXT & PROBE SENTENCES & $\begin{array}{l}\text { INFOSTRUCTURE / } \\
\text { SYNTAX }\end{array}$ \\
\hline \multirow{4}{*}{$\begin{array}{l}\text { Agent: } \\
\text { An artist was showing his } \\
\text { paintings for the first time in an } \\
\text { exhibition. He wanted to appear } \\
\text { in the local newspaper. }\end{array}$} & $\begin{array}{l}\text { The artist invited a journalist } \\
\text { to the exhibition. }\end{array}$ & Active: Given / New \\
\hline & & Sgiven Vactive Onew \\
\hline & $\begin{array}{l}\text { A journalist was invited by the } \\
\text { artist to the exhibition. }\end{array}$ & \\
\hline & & Onew Vpassive Agiven \\
\hline \multirow{4}{*}{$\begin{array}{l}\text { Patient: } \\
\text { A journalist was working for an } \\
\text { art magazine. He heard about a } \\
\text { new exhibition in town. }\end{array}$} & $\begin{array}{l}\text { An artist invited the journalist to } \\
\text { the exhibition. }\end{array}$ & Active: New / Given \\
\hline & & Snew Vactive Ogiven \\
\hline & $\begin{array}{l}\text { The journalist was invited by an } \\
\text { artist to the exhibition. }\end{array}$ & Passive: Given / New \\
\hline & & Ogiven Vpassive Anew \\
\hline
\end{tabular}

9.2.14 14. HURT (A:GIRL; O:BOY)

\begin{tabular}{|l|l|l|}
\hline CONTEXT & PROBE SENTENCES & $\begin{array}{l}\text { INFOSTRUCTURE / } \\
\text { SYNTAX }\end{array}$ \\
\hline Agent: & $\begin{array}{l}\text { The boy hurt a girl because she } \\
\text { had taken his ball. }\end{array}$ & Active: Given / New \\
$\begin{array}{l}\text { A boy was in a playground. } \\
\text { Suddenly, he couldn't find his } \\
\text { ball. }\end{array}$ & $\begin{array}{l}\text { A girl was hurt by the boy } \\
\text { because she had taken his ball. }\end{array}$ & Sgiven Vactive Onew \\
\hline Patient: & $\begin{array}{l}\text { A boy hurt the girl because she } \\
\text { had taken his ball. }\end{array}$ & Active: New / Given \\
A girl was in a playground. \\
$\begin{array}{l}\text { Suddenly, she saw a ball } \\
\text { bouncing and took it. }\end{array}$ & $\begin{array}{l}\text { The girl was hurt by a boy } \\
\text { because she had taken his ball. }\end{array}$ & Passive: Given / New \\
\hline & & Ogiven Vpassive Anew \\
\hline
\end{tabular}




\begin{tabular}{|l|l|l|}
\hline CONTEXT & PROBE SENTENCES & $\begin{array}{l}\text { INFOSTRUCTURE / } \\
\text { SYNTAX }\end{array}$ \\
\hline Agent: & $\begin{array}{l}\text { The dancer fascinated a man } \\
\text { because she was really sensual. }\end{array}$ & Active: Given / New \\
$\begin{array}{l}\text { A dancer worked in a strip club. } \\
\text { She was performing a new } \\
\text { number in front of a big group } \\
\text { that night. }\end{array}$ & $\begin{array}{l}\text { A man was fascinated by the } \\
\text { dancer because she was really } \\
\text { sensual. }\end{array}$ & Sgiven Vactive Onew \\
\hline \multirow{2}{*}{$\begin{array}{l}\text { A matient: } \\
\text { with a group of friends. They } \\
\text { had booked a special show. }\end{array}$} & $\begin{array}{l}\text { A dancer fascinated the man / Given } \\
\text { because she was really sensual. } \\
\text { dancer because she was really } \\
\text { sensual. }\end{array}$ & Active: New / Given \\
\cline { 2 - 3 } & \multicolumn{2}{|l|}{ Onew Vpassive Agiven } \\
\hline
\end{tabular}

\subsubsection{VISIT (A:WOMAN ; O:NUN)}

\begin{tabular}{|c|c|c|}
\hline CONTEXT & PROBE SENTENCES & $\begin{array}{l}\text { INFOSTRUCTURE / } \\
\text { SYNTAX }\end{array}$ \\
\hline Agent: & $\begin{array}{l}\text { The woman visited a nun } \\
\text { because she wanted religious } \\
\text { advice. }\end{array}$ & Active: Given / New \\
\hline \multirow{3}{*}{$\begin{array}{l}\text { A woman felt she needed to } \\
\text { prove her faith. She decided to } \\
\text { go into a convent. }\end{array}$} & & Sgiven Vactive Onew \\
\hline & $\begin{array}{l}\text { A nun was visited by the woman } \\
\text { because she wanted religious } \\
\text { advice. }\end{array}$ & Passive: New / Given \\
\hline & & Onew Vpassive Agiven \\
\hline Patient: & $\begin{array}{l}\text { A woman visited the nun } \\
\text { because she wanted religious } \\
\text { advice. }\end{array}$ & Active: New / Given \\
\hline \multirow{2}{*}{$\begin{array}{l}\text { A nun was calmly praying in the } \\
\text { chapel because she was } \\
\text { expecting an important visit. }\end{array}$} & & Snew Vactive Ogiven \\
\hline & $\begin{array}{l}\text { The nun was visited by a woman } \\
\text { because she wanted religious } \\
\text { advice. }\end{array}$ & Ogiven Vpassive Anew \\
\hline
\end{tabular}


9.2.17 17. PROTECT (A:PASSERBY ; O:CHILD)

\begin{tabular}{|l|l|l|}
\hline CONTEXT & PROBE SENTENCES & $\begin{array}{l}\text { INFOSTRUCTURE / } \\
\text { SYNTAX }\end{array}$ \\
\hline Agent: & $\begin{array}{l}\text { The passer-by protected a child } \\
\text { just before the wall fell. }\end{array}$ & Active: Given / New \\
$\begin{array}{l}\text { A passer-by was walking along } \\
\text { an old street when he saw that a } \\
\text { wall was about to fall. }\end{array}$ & $\begin{array}{l}\text { A child was protected by the } \\
\text { passer-by just before the wall } \\
\text { fell. }\end{array}$ & Passive: New / Given \\
\hline Patient: & $\begin{array}{l}\text { A passer-by protected the child } \\
\text { just before the wall fell. }\end{array}$ & Active: New / Given \\
\cline { 2 - 3 } $\begin{array}{l}\text { A child was playing in an old } \\
\text { street. He did not see that a wall } \\
\text { close to him was about to fall. }\end{array}$ & $\begin{array}{l}\text { The child was protected by a } \\
\text { passer-by just before the wall } \\
\text { fell. }\end{array}$ & Passive: Given / New \\
\cline { 2 - 3 } & \multicolumn{2}{|l}{} \\
\hline
\end{tabular}

\subsubsection{FEED (A:VOLUNTEER ; 0:CHILD)}

\begin{tabular}{|l|l|l|}
\hline CONTEXT & PROBE SENTENCES & $\begin{array}{l}\text { INFOSTRUCTURE / } \\
\text { SYNTAX }\end{array}$ \\
\hline Agent: & $\begin{array}{l}\text { The volunteer fed a child } \\
\text { because he was seriously ill. }\end{array}$ & Active: Given / New \\
$\begin{array}{l}\text { A volunteer was working in a } \\
\text { refugee camp. The food supplies } \\
\text { had just arrived. }\end{array}$ & $\begin{array}{l}\text { A child was fed by the volunteer } \\
\text { because he was seriously ill. }\end{array}$ & Passive: New / Given \\
\cline { 2 - 3 } \begin{tabular}{l} 
Patient: \\
\multirow{2}{*}{$\begin{array}{l}\text { A child was living in a refugee } \\
\text { camp. He was in a very bad } \\
\text { condition. }\end{array}$}
\end{tabular} & $\begin{array}{l}\text { A volunteer fed the child } \\
\text { because he was seriously ill. }\end{array}$ & Active: New / Given \\
\cline { 2 - 3 } & $\begin{array}{l}\text { The child was fed by a volunteer } \\
\text { because he was seriously ill. }\end{array}$ & Passive: Given / New \\
\hline & \multicolumn{2}{|l}{ Snew Vactive Ogiven } \\
\hline
\end{tabular}


9.2.19 19. HUG (A:FAN ; O:WRITER)

\begin{tabular}{|c|c|c|}
\hline CONTEXT & PROBE SENTENCES & $\begin{array}{l}\text { INFOSTRUCTURE / } \\
\text { SYNTAX }\end{array}$ \\
\hline Agent: & $\begin{array}{l}\text { The fan hugged an actor because } \\
\text { she loved him. }\end{array}$ & Active: Given / New \\
\hline \multirow{3}{*}{$\begin{array}{l}\text { A fan was at the premier of a } \\
\text { film. She was very excited } \\
\text { because the whole cast was } \\
\text { there. }\end{array}$} & & Sgiven Vactive Onew \\
\hline & $\begin{array}{l}\text { An actor was hugged by the fan } \\
\text { because she loved him. }\end{array}$ & Passive: New / Given \\
\hline & & Onew Vpassive Agiven \\
\hline Patient: & $\begin{array}{l}\text { A fan hugged the actor because } \\
\text { she loved him. }\end{array}$ & Active: New / Given \\
\hline \multirow{3}{*}{$\begin{array}{l}\text { An actor was at the premier of } \\
\text { his film. There was a huge } \\
\text { crowd shouting his name. }\end{array}$} & & Snew Vactive Ogiven \\
\hline & $\begin{array}{l}\text { The actor was hugged by a fan } \\
\text { because she loved him. }\end{array}$ & Passive: Given / New \\
\hline & & Ogiven Vpassive Anew \\
\hline
\end{tabular}




\begin{tabular}{|c|c|c|}
\hline CONTEXT & PROBE SENTENCES & $\begin{array}{l}\text { INFOSTRUCTURE / } \\
\text { SYNTAX }\end{array}$ \\
\hline Agent: & $\begin{array}{l}\text { The zombie bit a person in the } \\
\text { arm. }\end{array}$ & Active: Given / New \\
\hline \multirow{3}{*}{$\begin{array}{l}\text { A zombie was very hungry. He } \\
\text { was looking for human flesh in a } \\
\text { camping site. }\end{array}$} & & Sgiven Vactive Onew \\
\hline & $\begin{array}{l}\text { A person was bitten by the } \\
\text { zombie in the arm. }\end{array}$ & \\
\hline & & Onew Vpassive Agiven \\
\hline \multirow{4}{*}{$\begin{array}{l}\text { Patient: } \\
\text { A person in a film was trying to } \\
\text { survive the living dead attack. } \\
\text { He suddenly heard a step behind } \\
\text { him. }\end{array}$} & $\begin{array}{l}\text { A zombie bit the person in the } \\
\text { arm. }\end{array}$ & Active: New / Given \\
\hline & & Snew Vactive Ogiven \\
\hline & $\begin{array}{l}\text { The person was bitten by a } \\
\text { zombie in the arm. }\end{array}$ & Passive: Given / New \\
\hline & & Ogiven Vpassive Anew \\
\hline
\end{tabular}

\subsubsection{FORGET (A:NURSE ; 0:MADMAN)}

\begin{tabular}{|l|l|l|}
\hline CONTEXT & PROBE SENTENCES & $\begin{array}{l}\text { INFOSTRUCTURE / } \\
\text { SYNTAX }\end{array}$ \\
\hline Agent: & $\begin{array}{l}\text { The nurse forgot a madman in a } \\
\text { corridor. }\end{array}$ & Active: Given / New \\
$\begin{array}{l}\text { A nurse was returning home } \\
\text { from an asylum. She was almost } \\
\text { sure she had completed all her } \\
\text { duties. }\end{array}$ & $\begin{array}{l}\text { A madman was forgotten by the } \\
\text { nurse in a corridor. }\end{array}$ & Passive: New / Given \\
\cline { 2 - 3 } $\begin{array}{l}\text { Patient: } \\
\text { A madman noticed that he had } \\
\text { been left all alone by mistake. } \\
\text { He started running down a } \\
\text { corridor in the asylum. }\end{array}$ & $\begin{array}{l}\text { A nurse forgot the madman in a } \\
\text { corridor. }\end{array}$ & Active: New / Given \\
\cline { 2 - 3 } & $\begin{array}{l}\text { The madman was forgotten by a } \\
\text { nurse in a corridor. }\end{array}$ & Passive: Given / New \\
\hline
\end{tabular}




\begin{tabular}{|c|c|c|}
\hline CONTEXT & PROBE SENTENCES & $\begin{array}{l}\text { INFOSTRUCTURE / } \\
\text { SYNTAX }\end{array}$ \\
\hline Agent: & $\begin{array}{l}\text { The woman insulted a politician } \\
\text { because he was corrupt. }\end{array}$ & Active: Given / New \\
\hline \multirow{3}{*}{$\begin{array}{l}\text { A woman attended a conference } \\
\text { on corruption in the government. } \\
\text { She was angry at the speech she } \\
\text { was listening to. }\end{array}$} & & Sgiven Vactive Onew \\
\hline & $\begin{array}{l}\text { A politician was insulted by the } \\
\text { woman because he was corrupt. }\end{array}$ & \\
\hline & & Onew Vpassive Agiven \\
\hline \multirow{4}{*}{$\begin{array}{l}\text { Patient: } \\
\text { A politician was in a conference } \\
\text { giving a speech about } \\
\text { corruption. He noticed tension in } \\
\text { the air. }\end{array}$} & $\begin{array}{l}\text { A woman insulted the politician } \\
\text { because he was corrupt. }\end{array}$ & Active: New / Given \\
\hline & & Snew Vactive Ogiven \\
\hline & $\begin{array}{l}\text { The politician was insulted by a } \\
\text { woman because he was corrupt. }\end{array}$ & Passive: Given / New \\
\hline & & Ogiven Vpassive Anew \\
\hline
\end{tabular}

\subsubsection{SUPPORT (A:COUNSELOR ; O:ADDICT)}

\begin{tabular}{|c|c|c|}
\hline CONTEXT & PROBE SENTENCES & $\begin{array}{l}\text { INFOSTRUCTURE/ } \\
\text { SYNTAX }\end{array}$ \\
\hline \multirow{4}{*}{$\begin{array}{l}\text { Agent: } \\
\text { A counsellor worked in a clinic } \\
\text { helping others to deal with drug } \\
\text { problems. He had an } \\
\text { appointment that afternoon. }\end{array}$} & $\begin{array}{l}\text { The counsellor supported an } \\
\text { addict during the appointment. }\end{array}$ & Active: Given / New \\
\hline & & Sgiven Vactive Onew \\
\hline & $\begin{array}{l}\text { An addict was supported by the } \\
\text { counsellor during the } \\
\text { appointment. }\end{array}$ & Passive: New / Given \\
\hline & & Onew Vpassive Agiven \\
\hline \multirow{4}{*}{$\begin{array}{l}\text { Patient: } \\
\text { An addict decided to go to a } \\
\text { clinic to get help about his drug } \\
\text { addiction. He got an } \\
\text { appointment that same } \\
\text { afternoon. }\end{array}$} & $\begin{array}{l}\text { A counsellor supported the } \\
\text { addict during the appointment. }\end{array}$ & Active: New / Given \\
\hline & & Snew Vactive Ogiven \\
\hline & $\begin{array}{l}\text { The addict was supported by a } \\
\text { counsellor during the } \\
\text { appointment. }\end{array}$ & Passive: Given / New \\
\hline & & Ogiven Vpassive Anew \\
\hline
\end{tabular}




\begin{tabular}{|l|l|l|}
\hline CONTEXT & PROBE SENTENCES & $\begin{array}{l}\text { INFOSTRUCTURE / } \\
\text { SYNTAX }\end{array}$ \\
\hline Agent: & $\begin{array}{l}\text { The soldier found a terrorist } \\
\text { during a mission. }\end{array}$ & Active: Given / New \\
$\begin{array}{l}\text { A soldier was taking part in a } \\
\text { dangerous mission in Syrian } \\
\text { territory. He searched various } \\
\text { buildings with his companions. }\end{array}$ & $\begin{array}{l}\text { A terrorist was found by the } \\
\text { soldier during a mission. }\end{array}$ & Sgiven Vactive Onew \\
\hline Patient: & $\begin{array}{l}\text { A soldier found the terrorist } \\
\text { during a mission. }\end{array}$ & Onew / Given \\
\multirow{2}{*}{$\begin{array}{l}\text { A terrorist was hiding in a safe } \\
\text { house in Syria. Suddenly, he } \\
\text { heard shouts and shots outside. }\end{array}$} & $\begin{array}{l}\text { The terrorist was found by a } \\
\text { soldier during a mission. }\end{array}$ & Passive: Given / New \\
& & Snew Vactive Ogiven \\
\hline
\end{tabular}

\subsection{Distractors.}

\subsubsection{DRAW}

\begin{tabular}{|l|l|l|}
\hline CONTEXT & PROBE SENTENCES & $\begin{array}{l}\text { VERIFICATION } \\
\text { SENTENCE }\end{array}$ \\
\hline $\begin{array}{l}\text { It was the first time Mary Anne } \\
\text { had attended drawing lessons. } \\
\text { She was very excited about it. }\end{array}$ & $\begin{array}{l}\text { Mary Anne drew the model with } \\
\text { no effort. }\end{array}$ & Mary is taking driving lessons. \\
& $\begin{array}{l}\text { It was Mary Anne who drew the } \\
\text { model with no effort. }\end{array}$ & \\
\hline
\end{tabular}

\subsubsection{THROW}

\begin{tabular}{|l|l|l|}
\hline CONTEXT & PROBE SENTENCES & $\begin{array}{l}\text { VERIFICATION } \\
\text { SENTENCE }\end{array}$ \\
\hline $\begin{array}{l}\text { A little boy had been given a } \\
\text { puppy for his tenth birthday. }\end{array}$ & $\begin{array}{l}\text { The little boy threw a ball to the } \\
\text { puppy. }\end{array}$ & The boy has a new puppy. \\
& $\begin{array}{l}\text { It was a little boy threw a ball to } \\
\text { the puppy. }\end{array}$ & \\
\hline
\end{tabular}


9.3.3 27. SING

\begin{tabular}{|l|l|l|}
\hline CONTEXT & PROBE SENTENCES & $\begin{array}{l}\text { VERIFICATION } \\
\text { SENTENCE }\end{array}$ \\
\hline $\begin{array}{l}\text { Montserrat Caballé gave a } \\
\text { concert in Barcelona a couple of } \\
\text { years ago. }\end{array}$ & $\begin{array}{l}\text { Montserrat Caballé sang an } \\
\text { extremely beautiful aria in } \\
\text { Barcelona. }\end{array}$ & $\begin{array}{l}\text { Montserrat Caballé is a horrible } \\
\text { singer. }\end{array}$ \\
& $\begin{array}{l}\text { It was Montserrat Caballé who } \\
\text { sang a beautiful aria in } \\
\text { Barcelona. }\end{array}$ & \\
\hline
\end{tabular}

\subsubsection{BUY}

\begin{tabular}{|l|l|l|}
\hline CONTEXT & PROBE SENTENCES & $\begin{array}{l}\text { VERIFICATION } \\
\text { SENTENCE }\end{array}$ \\
\hline $\begin{array}{l}\text { Peter Griffin had an old car. The } \\
\text { engine had broken a week ago. }\end{array}$ & $\begin{array}{l}\text { Peter Griffin finally saved } \\
\text { money to buy another car. }\end{array}$ & Peter bought a new bicycle. \\
& $\begin{array}{l}\text { It was Peter Griffin who finally } \\
\text { saved money to buy another car. }\end{array}$ & \\
\hline
\end{tabular}

\subsubsection{ASK}

\begin{tabular}{|l|l|l|}
\hline CONTEXT & PROBE SENTENCES & $\begin{array}{l}\text { VERIFICATION } \\
\text { SENTENCE }\end{array}$ \\
\hline $\begin{array}{l}\text { A student was at school. He was } \\
\text { not paying attention because he } \\
\text { felt sleepy. }\end{array}$ & $\begin{array}{l}\text { The teacher asked the student a } \\
\text { difficult question. }\end{array}$ & The student was sleepy. \\
& $\begin{array}{l}\text { It was the teacher who asked the } \\
\text { student a difficult question. }\end{array}$ & \\
\hline
\end{tabular}

\subsubsection{WASH}

\begin{tabular}{|l|l|l|}
\hline CONTEXT & PROBE SENTENCES & $\begin{array}{l}\text { VERIFICATION } \\
\text { SENTENCE }\end{array}$ \\
\hline $\begin{array}{l}\text { Andrew Higgins had just bought } \\
\text { a new bike. He was very fond of } \\
\text { it. }\end{array}$ & $\begin{array}{l}\text { Andrew Higgins washed his new } \\
\text { bike every day. }\end{array}$ & Andrew has a bike. \\
& $\begin{array}{l}\text { It was Andrew Higgins who } \\
\text { washed his bike every day. }\end{array}$ & \\
\hline
\end{tabular}




\begin{tabular}{|l|l|l|}
\hline CONTEXT & PROBE SENTENCES & $\begin{array}{l}\text { VERIFICATION } \\
\text { SENTENCE }\end{array}$ \\
\hline $\begin{array}{l}\text { Laura Lopez has a lot of gold } \\
\text { necklaces that she inherited from } \\
\text { her grandmother. }\end{array}$ & $\begin{array}{l}\text { Laura Lopez will sell some } \\
\text { necklaces to get money. }\end{array}$ & Laura Lopez needs money. \\
& $\begin{array}{l}\text { It is Laura Lopez who will sell } \\
\text { some necklaces to get money. }\end{array}$ & \\
\hline
\end{tabular}

\subsubsection{WATCH}

\begin{tabular}{|l|l|l|}
\hline CONTEXT & PROBE SENTENCES & $\begin{array}{l}\text { VERIFICATION } \\
\text { SENTENCE }\end{array}$ \\
\hline $\begin{array}{l}\text { Paul and Thomas are meeting at } \\
\text { a bar tonight. }\end{array}$ & $\begin{array}{l}\text { Paul and Thomas will watch a } \\
\text { football match this night. }\end{array}$ & $\begin{array}{l}\text { Paul and Thomas hate } \\
\text { football. }\end{array}$ \\
& $\begin{array}{l}\text { It is Paul and Thomas who will } \\
\text { watch a football match tonight. }\end{array}$ & \\
\hline
\end{tabular}

\subsubsection{DECIDE}

\begin{tabular}{|l|l|l|}
\hline CONTEXT & PROBE SENTENCES & $\begin{array}{l}\text { VERIFICATION } \\
\text { SENTENCE }\end{array}$ \\
\hline $\begin{array}{l}\text { A man was preparing dinner. He } \\
\text { was unsure what to cook first. }\end{array}$ & $\begin{array}{l}\text { The man decided to serve } \\
\text { chicken as a starter. }\end{array}$ & $\begin{array}{l}\text { The man was preparing } \\
\text { lunch. }\end{array}$ \\
& $\begin{array}{l}\text { It was the man who decided to } \\
\text { serve chicken as a starter. }\end{array}$ & \\
\hline
\end{tabular}

\subsubsection{ATTEND}

\begin{tabular}{|l|l|l|}
\hline CONTEXT & PROBE SENTENCES & $\begin{array}{l}\text { VERIFICATION } \\
\text { SENTENCE }\end{array}$ \\
\hline $\begin{array}{l}\text { Paul Stevens had been invited to } \\
\text { two birthday parties in the same } \\
\text { day. One was his cousin's and } \\
\text { the other his grandma's. }\end{array}$ & $\begin{array}{l}\text { Paul Stevens attended his } \\
\text { grandma's birthday party. }\end{array}$ & $\begin{array}{l}\text { Paul Stevens attended his } \\
\text { cousin's birthday party. }\end{array}$ \\
\hline $\begin{array}{l}\text { It was Paul Stevens who } \\
\text { attended his grandma's birthday } \\
\text { party. }\end{array}$ & \\
\hline
\end{tabular}


9.3.11 35. LICK

\begin{tabular}{|l|l|l|}
\hline CONTEXT & PROBE SENTENCES & $\begin{array}{l}\text { VERIFICATION } \\
\text { SENTENCE }\end{array}$ \\
\hline $\begin{array}{l}\text { A young woman found an } \\
\text { abandoned kitten near her home. }\end{array}$ & $\begin{array}{l}\text { The kitten licked the young } \\
\text { woman's hand. }\end{array}$ & $\begin{array}{l}\text { The young woman found a } \\
\text { dog. }\end{array}$ \\
& $\begin{array}{l}\text { It was the kitten who licked the } \\
\text { young woman's hand. }\end{array}$ & \\
\hline
\end{tabular}

9.3.12 36. REFUSE

\begin{tabular}{|l|l|l|}
\hline CONTEXT & PROBE SENTENCES & $\begin{array}{l}\text { VERIFICATION } \\
\text { SENTENCE }\end{array}$ \\
\hline $\begin{array}{l}\text { A young politician was } \\
\text { approached by a rich man who } \\
\text { wanted to offer him money } \\
\text { illegally. }\end{array}$ & $\begin{array}{l}\text { The young politician refused the } \\
\text { illegal bribe immediately. }\end{array}$ & $\begin{array}{l}\text { The young politician was } \\
\text { honest. }\end{array}$ \\
& $\begin{array}{l}\text { It was the young politician who } \\
\text { refused the bribe immediately. }\end{array}$ & \\
\hline
\end{tabular}




\section{APPENDIX IV: PARTICIPANTS'DATA}

10.1 Learners

\begin{tabular}{|c|c|c|c|c|c|c|c|c|c|c|c|c|c|c|c|c|c|c|}
\hline 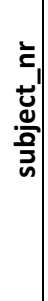 & 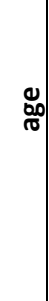 & $\begin{array}{l}\frac{\grave{d}}{0} \\
\frac{1}{0} \\
\text { வ }\end{array}$ & 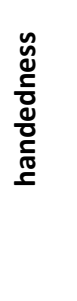 & $ت$ & 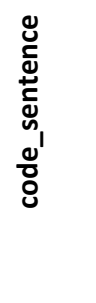 & 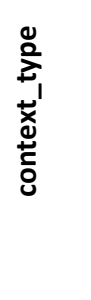 & 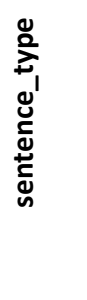 & 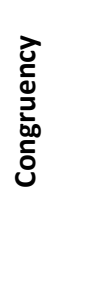 & 온 & 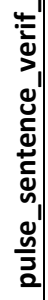 & 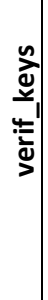 & 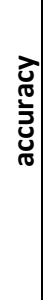 & 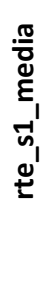 & 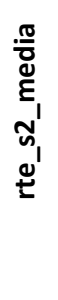 & 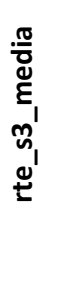 & 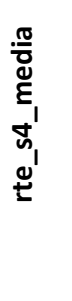 & 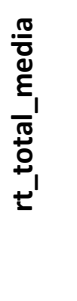 & 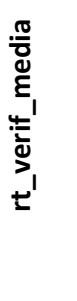 \\
\hline 1 & $\begin{array}{l}2 \\
2 \\
\end{array}$ & $\begin{array}{c}\text { Mal } \\
\mathrm{e}\end{array}$ & $\begin{array}{c}\text { Bima } \\
\text { nual }\end{array}$ & $\begin{array}{l}\text { Spa } \\
\text { nish }\end{array}$ & 1 & agent & active & $\begin{array}{c}\text { congru } \\
\text { ent }\end{array}$ & $\begin{array}{c}\text { forge } \\
t\end{array}$ & $n$ & $n$ & 1 & $\begin{array}{c}80 \\
8 \\
\end{array}$ & 833 & 978 & 1305 & 3923 & 1477 \\
\hline 1 & $\begin{array}{l}2 \\
2\end{array}$ & $\begin{array}{c}\text { Mal } \\
\mathrm{e}\end{array}$ & $\begin{array}{l}\text { Bima } \\
\text { nual }\end{array}$ & $\begin{array}{l}\text { Spa } \\
\text { nish }\end{array}$ & 2 & agent & $\begin{array}{c}\text { passiv } \\
\mathrm{e}\end{array}$ & $\begin{array}{c}\text { incongr } \\
\text { uent }\end{array}$ & $\begin{array}{c}\text { convi } \\
\text { nce }\end{array}$ & $\mathrm{m}$ & $\mathrm{m}$ & 1 & $\begin{array}{c}84 \\
7 \\
\end{array}$ & 999 & 1327 & 1667 & 4841 & 1684 \\
\hline 1 & $\begin{array}{l}2 \\
2\end{array}$ & $\begin{array}{c}\text { Mal } \\
\mathrm{e}\end{array}$ & $\begin{array}{c}\text { Bima } \\
\text { nual }\end{array}$ & $\begin{array}{l}\text { Spa } \\
\text { nish }\end{array}$ & 3 & $\begin{array}{c}\text { patien } \\
\mathrm{t}\end{array}$ & active & $\begin{array}{c}\text { incongr } \\
\text { uent }\end{array}$ & $\begin{array}{c}\text { punis } \\
\mathrm{h}\end{array}$ & $\mathrm{m}$ & $\mathrm{m}$ & 1 & $\begin{array}{c}84 \\
2 \\
\end{array}$ & 882 & 943 & 1593 & 3917 & 1422 \\
\hline 1 & $\begin{array}{l}2 \\
2 \\
\end{array}$ & $\begin{array}{c}\text { Mal } \\
\mathrm{e}\end{array}$ & $\begin{array}{c}\text { Bima } \\
\text { nual }\end{array}$ & $\begin{array}{l}\text { Spa } \\
\text { nish }\end{array}$ & 4 & $\begin{array}{c}\text { patien } \\
\mathrm{t}\end{array}$ & $\begin{array}{c}\text { passiv } \\
\mathrm{e}\end{array}$ & $\begin{array}{c}\text { congru } \\
\text { ent }\end{array}$ & find & $n$ & $\mathrm{n}$ & 1 & $\begin{array}{c}63 \\
9\end{array}$ & 909 & 1203 & 1371 & 4122 & 1384 \\
\hline 2 & $\begin{array}{l}2 \\
3\end{array}$ & $\begin{array}{l}\text { Mal } \\
\text { e }\end{array}$ & Right & $\begin{array}{l}\text { Spa } \\
\text { nish }\end{array}$ & 1 & agent & active & $\begin{array}{l}\text { congru } \\
\text { ent }\end{array}$ & stop & $\mathrm{m}$ & $\mathrm{m}$ & 1 & $\begin{array}{c}54 \\
0\end{array}$ & 469 & 497 & 827 & 2332 & 1549 \\
\hline 2 & $\begin{array}{l}2 \\
3\end{array}$ & $\begin{array}{l}\text { Mal } \\
\mathrm{e}\end{array}$ & Right & $\begin{array}{l}\text { Spa } \\
\text { nish }\end{array}$ & 2 & agent & $\begin{array}{c}\text { passiv } \\
\mathrm{e}\end{array}$ & $\begin{array}{l}\text { incongr } \\
\text { uent }\end{array}$ & kiss & $\mathrm{n}$ & $n$ & 1 & $\begin{array}{c}41 \\
5\end{array}$ & 549 & 608 & 838 & 2188 & 2036 \\
\hline 2 & $\begin{array}{l}2 \\
3\end{array}$ & $\begin{array}{l}\text { Mal } \\
\mathrm{e}\end{array}$ & Right & $\begin{array}{l}\text { Spa } \\
\text { nish }\end{array}$ & 3 & $\begin{array}{l}\text { patien } \\
\mathrm{t}\end{array}$ & active & $\begin{array}{l}\text { incongr } \\
\text { uent }\end{array}$ & $\begin{array}{l}\text { convi } \\
\text { nce }\end{array}$ & $n$ & $n$ & 1 & $\begin{array}{c}57 \\
8\end{array}$ & 616 & 574 & 891 & 2659 & 1752 \\
\hline 2 & $\begin{array}{l}2 \\
3\end{array}$ & $\begin{array}{l}\text { Mal } \\
\mathrm{e}\end{array}$ & Right & $\begin{array}{l}\text { Spa } \\
\text { nish }\end{array}$ & 4 & $\begin{array}{l}\text { patien } \\
\mathrm{t}\end{array}$ & $\begin{array}{c}\text { passiv } \\
\mathrm{e}\end{array}$ & $\begin{array}{l}\text { congru } \\
\text { ent }\end{array}$ & $\begin{array}{c}\text { punis } \\
\mathrm{h}\end{array}$ & $\mathrm{m}$ & $\mathrm{m}$ & 1 & $\begin{array}{c}57 \\
4\end{array}$ & 531 & 480 & 612 & 2197 & 1722 \\
\hline 3 & $\begin{array}{l}2 \\
3\end{array}$ & $\begin{array}{l}\text { Fem } \\
\text { ale }\end{array}$ & Right & $\begin{array}{l}\text { Spa } \\
\text { nish }\end{array}$ & 1 & agent & active & $\begin{array}{c}\text { congru } \\
\text { ent }\end{array}$ & hug & $\mathrm{n}$ & $\mathrm{n}$ & 1 & $\begin{array}{c}50 \\
0\end{array}$ & 712 & 763 & 718 & 2693 & 1898 \\
\hline 3 & $\begin{array}{l}2 \\
3\end{array}$ & $\begin{array}{l}\text { Fem } \\
\text { ale }\end{array}$ & Right & $\begin{array}{l}\text { Spa } \\
\text { nish }\end{array}$ & 2 & agent & $\begin{array}{c}\text { passiv } \\
\mathrm{e}\end{array}$ & $\begin{array}{c}\text { incongr } \\
\text { uent }\end{array}$ & kill & $\mathrm{m}$ & $\mathrm{m}$ & 1 & $\begin{array}{c}70 \\
0\end{array}$ & 869 & 954 & 899 & 3422 & 2337 \\
\hline 3 & $\begin{array}{l}2 \\
3 \\
\end{array}$ & $\begin{array}{l}\text { Fem } \\
\text { ale }\end{array}$ & Right & $\begin{array}{l}\text { Spa } \\
\text { nish }\end{array}$ & 4 & $\begin{array}{c}\text { patien } \\
\mathrm{t}\end{array}$ & $\begin{array}{c}\text { passiv } \\
\mathrm{e}\end{array}$ & $\begin{array}{c}\text { congru } \\
\text { ent }\end{array}$ & insult & $\mathrm{n}$ & $\mathrm{n}$ & 1 & $\begin{array}{c}50 \\
5 \\
\end{array}$ & 734 & 786 & 845 & 2747 & 1887 \\
\hline 4 & $\begin{array}{l}2 \\
5\end{array}$ & $\begin{array}{l}\text { Fem } \\
\text { ale }\end{array}$ & Right & 1 & $\begin{array}{c}\text { Spanis } \\
\mathrm{h}\end{array}$ & agent & active & $\begin{array}{c}\text { congru } \\
\text { ent }\end{array}$ & hurt & $m$ & $\mathrm{~m}$ & 1 & $\begin{array}{c}48 \\
3\end{array}$ & 550 & 549 & 1218 & 2800 & 1570 \\
\hline 4 & $\begin{array}{l}2 \\
5\end{array}$ & $\begin{array}{l}\text { Fem } \\
\text { ale }\end{array}$ & Right & 2 & $\begin{array}{c}\text { Spanis } \\
\mathrm{h}\end{array}$ & agent & $\begin{array}{c}\text { passiv } \\
\mathrm{e}\end{array}$ & $\begin{array}{c}\text { incongr } \\
\text { uent }\end{array}$ & $\begin{array}{c}\text { punis } \\
h\end{array}$ & $\mathrm{n}$ & $n$ & 1 & $\begin{array}{c}53 \\
4\end{array}$ & 988 & 791 & 892 & 3205 & 2279 \\
\hline 4 & $\begin{array}{l}2 \\
5\end{array}$ & $\begin{array}{l}\text { Fem } \\
\text { ale }\end{array}$ & Right & 3 & $\begin{array}{c}\text { Spanis } \\
\mathrm{h}\end{array}$ & $\begin{array}{c}\text { patien } \\
\mathrm{t}\end{array}$ & active & $\begin{array}{c}\text { incongr } \\
\text { uent }\end{array}$ & kill & $\mathrm{n}$ & $\mathrm{n}$ & 1 & $\begin{array}{c}55 \\
3\end{array}$ & 741 & 699 & 1004 & 2997 & 2072 \\
\hline 4 & $\begin{array}{l}2 \\
5\end{array}$ & $\begin{array}{l}\text { Fem } \\
\text { ale }\end{array}$ & Right & 4 & $\begin{array}{c}\text { Spanis } \\
\mathrm{h}\end{array}$ & $\begin{array}{c}\text { patien } \\
\mathrm{t}\end{array}$ & $\begin{array}{c}\text { passiv } \\
\mathrm{e}\end{array}$ & $\begin{array}{c}\text { congru } \\
\text { ent }\end{array}$ & $\begin{array}{c}\text { forge } \\
t\end{array}$ & $\mathrm{~m}$ & $\mathrm{~m}$ & 1 & $\begin{array}{c}52 \\
6 \\
\end{array}$ & 859 & 919 & 1138 & 3441 & 2633 \\
\hline 5 & $\begin{array}{l}2 \\
4\end{array}$ & $\begin{array}{c}\text { Fem } \\
\text { ale }\end{array}$ & Right & $\begin{array}{l}\text { Spa } \\
\text { nish }\end{array}$ & 1 & agent & active & $\begin{array}{c}\text { congru } \\
\text { ent }\end{array}$ & bite & $\mathrm{m}$ & $\mathrm{m}$ & 1 & $\begin{array}{c}41 \\
5\end{array}$ & 718 & 625 & 1478 & 3236 & 2127 \\
\hline 5 & $\begin{array}{l}2 \\
4\end{array}$ & $\begin{array}{l}\text { Fem } \\
\text { ale }\end{array}$ & Right & $\begin{array}{l}\text { Spa } \\
\text { nish }\end{array}$ & 2 & agent & $\begin{array}{c}\text { passiv } \\
\mathrm{e}\end{array}$ & $\begin{array}{c}\text { incongr } \\
\text { uent }\end{array}$ & $\begin{array}{l}\text { choo } \\
\text { se }\end{array}$ & $\mathrm{n}$ & $\mathrm{n}$ & 1 & $\begin{array}{c}64 \\
3\end{array}$ & 977 & 932 & 1458 & 4009 & 2153 \\
\hline 5 & $\begin{array}{l}2 \\
4\end{array}$ & $\begin{array}{l}\text { Fem } \\
\text { ale }\end{array}$ & Right & $\begin{array}{l}\text { Spa } \\
\text { nish }\end{array}$ & 3 & $\begin{array}{c}\text { patien } \\
\mathrm{t}\end{array}$ & active & $\begin{array}{c}\text { incongr } \\
\text { uent }\end{array}$ & $\begin{array}{l}\text { ident } \\
\text { ify }\end{array}$ & $\mathrm{n}$ & $\mathrm{n}$ & 1 & $\begin{array}{c}46 \\
8\end{array}$ & 939 & 1034 & 1459 & 3741 & 2130 \\
\hline 5 & $\begin{array}{l}2 \\
4\end{array}$ & $\begin{array}{c}\text { Fem } \\
\text { ale }\end{array}$ & Right & $\begin{array}{l}\text { Spa } \\
\text { nish }\end{array}$ & 4 & $\begin{array}{c}\text { patien } \\
\mathrm{t}\end{array}$ & $\begin{array}{c}\text { passiv } \\
\mathrm{e}\end{array}$ & $\begin{array}{c}\text { congru } \\
\text { ent }\end{array}$ & shot & $m$ & $m$ & 1 & $\begin{array}{c}47 \\
2\end{array}$ & 819 & 850 & 1271 & 3413 & 2870 \\
\hline 6 & $\begin{array}{l}2 \\
3\end{array}$ & $\begin{array}{c}\text { Mal } \\
\mathrm{e}\end{array}$ & Right & $\begin{array}{l}\text { Spa } \\
\text { nish }\end{array}$ & 1 & agent & active & $\begin{array}{c}\text { congru } \\
\text { ent }\end{array}$ & save & $\mathrm{n}$ & $n$ & 1 & $\begin{array}{l}10 \\
81\end{array}$ & 950 & 771 & 968 & 3770 & 2111 \\
\hline
\end{tabular}




\begin{tabular}{|c|c|c|c|c|c|c|c|c|c|c|c|c|c|c|c|c|c|c|}
\hline 6 & $\begin{array}{l}2 \\
3\end{array}$ & $\begin{array}{c}\text { Mal } \\
\mathrm{e}\end{array}$ & Right & $\begin{array}{l}\text { Spa } \\
\text { nish }\end{array}$ & 2 & agent & $\begin{array}{c}\text { passiv } \\
\mathrm{e}\end{array}$ & $\begin{array}{c}\text { incongr } \\
\text { uent }\end{array}$ & help & $\mathrm{m}$ & $\mathrm{m}$ & 1 & $\begin{array}{l}11 \\
73\end{array}$ & $\begin{array}{c}109 \\
7\end{array}$ & 1010 & 821 & 3855 & 2485 \\
\hline 6 & $\begin{array}{l}2 \\
3\end{array}$ & $\begin{array}{c}\text { Mal } \\
\mathrm{e}\end{array}$ & Right & $\begin{array}{l}\text { Spa } \\
\text { nish }\end{array}$ & 3 & $\begin{array}{c}\text { patien } \\
\mathrm{t}\end{array}$ & active & $\begin{array}{c}\text { incongr } \\
\text { uent }\end{array}$ & kiss & $\mathrm{m}$ & $m$ & 1 & $\begin{array}{c}63 \\
4\end{array}$ & 887 & 1082 & 1103 & 3831 & 2185 \\
\hline 6 & $\begin{array}{l}2 \\
3 \\
\end{array}$ & $\begin{array}{c}\text { Mal } \\
\mathrm{e}\end{array}$ & Right & $\begin{array}{l}\text { Spa } \\
\text { nish }\end{array}$ & 4 & $\begin{array}{c}\text { patien } \\
\mathrm{t}\end{array}$ & $\begin{array}{c}\text { passiv } \\
\mathrm{e} \\
\end{array}$ & $\begin{array}{c}\text { congru } \\
\text { ent }\end{array}$ & hurt & $n$ & $\mathrm{n}$ & 1 & $\begin{array}{c}94 \\
5 \\
\end{array}$ & $\begin{array}{c}126 \\
6 \\
\end{array}$ & 1382 & 1681 & 5273 & 2330 \\
\hline 7 & $\begin{array}{l}2 \\
4 \\
\end{array}$ & $\begin{array}{l}\text { Fem } \\
\text { ale }\end{array}$ & Right & $\begin{array}{l}\text { Spa } \\
\text { nish }\end{array}$ & 1 & agent & active & $\begin{array}{c}\text { congru } \\
\text { ent }\end{array}$ & insult & $\mathrm{m}$ & $m$ & 1 & $\begin{array}{c}77 \\
3 \\
\end{array}$ & $\begin{array}{c}163 \\
3\end{array}$ & 1293 & 2329 & 6028 & 2328 \\
\hline 7 & $\begin{array}{l}2 \\
4 \\
\end{array}$ & $\begin{array}{l}\text { Fem } \\
\text { ale }\end{array}$ & Right & $\begin{array}{l}\text { Spa } \\
\text { nish }\end{array}$ & 2 & agent & $\begin{array}{c}\text { passiv } \\
\mathrm{e}\end{array}$ & $\begin{array}{c}\text { incongr } \\
\text { uent }\end{array}$ & help & $n$ & $\mathrm{n}$ & 1 & $\begin{array}{c}77 \\
7 \\
\end{array}$ & $\begin{array}{c}156 \\
4 \\
\end{array}$ & 1106 & 1824 & 5272 & 2370 \\
\hline 7 & $\begin{array}{l}2 \\
4 \\
\end{array}$ & $\begin{array}{l}\text { Fem } \\
\text { ale }\end{array}$ & Right & $\begin{array}{l}\text { Spa } \\
\text { nish }\end{array}$ & 3 & $\begin{array}{c}\text { patien } \\
\mathrm{t}\end{array}$ & active & $\begin{array}{c}\text { incongr } \\
\text { uent }\end{array}$ & stop & $n$ & $n$ & 1 & $\begin{array}{l}12 \\
89 \\
\end{array}$ & $\begin{array}{c}133 \\
4 \\
\end{array}$ & 1639 & 1917 & 6179 & 1784 \\
\hline 7 & $\begin{array}{l}2 \\
4 \\
\end{array}$ & $\begin{array}{c}\text { Fem } \\
\text { ale }\end{array}$ & Right & $\begin{array}{l}\text { Spa } \\
\text { nish }\end{array}$ & 4 & $\begin{array}{c}\text { patien } \\
\mathrm{t}\end{array}$ & $\begin{array}{c}\text { passiv } \\
\mathrm{e}\end{array}$ & $\begin{array}{c}\text { congru } \\
\text { ent }\end{array}$ & kiss & $\mathrm{m}$ & $\mathrm{m}$ & 1 & $\begin{array}{c}99 \\
6 \\
\end{array}$ & $\begin{array}{c}181 \\
9\end{array}$ & 1692 & 1645 & 6153 & 2611 \\
\hline 8 & $\begin{array}{l}2 \\
9 \\
\end{array}$ & $\begin{array}{c}\text { Mal } \\
\mathrm{e}\end{array}$ & Right & $\begin{array}{l}\text { Spa } \\
\text { nish }\end{array}$ & 1 & agent & active & $\begin{array}{c}\text { congru } \\
\text { ent }\end{array}$ & invite & $n$ & $n$ & 1 & $\begin{array}{c}38 \\
8 \\
\end{array}$ & 464 & 451 & 672 & 1975 & 2096 \\
\hline 8 & $\begin{array}{l}2 \\
9\end{array}$ & $\begin{array}{c}\text { Mal } \\
\mathrm{e}\end{array}$ & Right & $\begin{array}{l}\text { Spa } \\
\text { nish }\end{array}$ & 2 & agent & $\begin{array}{c}\text { passiv } \\
\mathrm{e}\end{array}$ & $\begin{array}{c}\text { incongr } \\
\text { uent }\end{array}$ & $\begin{array}{l}\text { ident } \\
\text { ify }\end{array}$ & $\mathrm{m}$ & $\mathrm{m}$ & 1 & $\begin{array}{c}44 \\
7\end{array}$ & 528 & 589 & 1030 & 2594 & 2062 \\
\hline 8 & $\begin{array}{l}2 \\
9 \\
\end{array}$ & $\begin{array}{c}\text { Mal } \\
\mathrm{e}\end{array}$ & Right & $\begin{array}{l}\text { Spa } \\
\text { nish }\end{array}$ & 3 & $\begin{array}{c}\text { patien } \\
\mathrm{t}\end{array}$ & active & $\begin{array}{c}\text { incongr } \\
\text { uent }\end{array}$ & shot & $\mathrm{m}$ & $\mathrm{m}$ & 1 & $\begin{array}{c}44 \\
4 \\
\end{array}$ & 482 & 488 & 710 & 2124 & 1615 \\
\hline 8 & $\begin{array}{l}2 \\
9 \\
\end{array}$ & $\begin{array}{c}\text { Mal } \\
\mathrm{e}\end{array}$ & Right & $\begin{array}{l}\text { Spa } \\
\text { nish }\end{array}$ & 4 & $\begin{array}{c}\text { patien } \\
\mathrm{t}\end{array}$ & $\begin{array}{c}\text { passiv } \\
\mathrm{e}\end{array}$ & $\begin{array}{c}\text { congru } \\
\text { ent }\end{array}$ & help & $n$ & $n$ & 1 & $\begin{array}{c}44 \\
5 \\
\end{array}$ & 535 & 582 & 808 & 2370 & 2002 \\
\hline 9 & $\begin{array}{l}2 \\
4\end{array}$ & $\begin{array}{c}\text { Mal } \\
\mathrm{e}\end{array}$ & Left & $\begin{array}{l}\text { Spa } \\
\text { nish }\end{array}$ & 1 & agent & active & $\begin{array}{c}\text { congru } \\
\text { ent }\end{array}$ & help & $\mathrm{m}$ & $\mathrm{m}$ & 1 & $\begin{array}{c}77 \\
0\end{array}$ & 838 & 852 & 744 & 3205 & 2600 \\
\hline 9 & $\begin{array}{l}2 \\
4\end{array}$ & $\begin{array}{c}\text { Mal } \\
\mathrm{e}\end{array}$ & Left & $\begin{array}{l}\text { Spa } \\
\text { nish }\end{array}$ & 2 & agent & $\begin{array}{c}\text { passiv } \\
\mathrm{e}\end{array}$ & $\begin{array}{c}\text { incongr } \\
\text { uent }\end{array}$ & kiss & $n$ & $\mathrm{n}$ & 1 & $\begin{array}{c}63 \\
7\end{array}$ & $\begin{array}{c}115 \\
4\end{array}$ & 948 & 1268 & 4006 & 2786 \\
\hline 9 & $\begin{array}{l}2 \\
4 \\
\end{array}$ & $\begin{array}{c}\text { Mal } \\
\mathrm{e}\end{array}$ & Left & $\begin{array}{l}\text { Spa } \\
\text { nish }\end{array}$ & 3 & $\begin{array}{c}\text { patien } \\
\mathrm{t}\end{array}$ & active & $\begin{array}{c}\text { incongr } \\
\text { uent }\end{array}$ & $\begin{array}{c}\text { convi } \\
\text { nce }\end{array}$ & $n$ & $\mathrm{n}$ & 1 & $\begin{array}{c}81 \\
3 \\
\end{array}$ & 996 & 745 & 1411 & 2835 & 2619 \\
\hline 9 & $\begin{array}{l}2 \\
4 \\
\end{array}$ & $\begin{array}{c}\text { Mal } \\
\mathrm{e}\end{array}$ & Left & $\begin{array}{l}\text { Spa } \\
\text { nish }\end{array}$ & 4 & $\begin{array}{c}\text { patien } \\
\mathrm{t}\end{array}$ & $\begin{array}{c}\text { passiv } \\
\mathrm{e}\end{array}$ & $\begin{array}{c}\text { congru } \\
\text { ent }\end{array}$ & $\begin{array}{c}\text { punis } \\
\mathrm{h}\end{array}$ & $\mathrm{m}$ & $\mathrm{m}$ & 1 & $\begin{array}{c}86 \\
5 \\
\end{array}$ & 681 & 747 & 1239 & 3532 & 2964 \\
\hline $\begin{array}{l}1 \\
0\end{array}$ & $\begin{array}{l}2 \\
3 \\
\end{array}$ & $\begin{array}{l}\text { Fem } \\
\text { ale }\end{array}$ & Right & $\begin{array}{l}\text { Spa } \\
\text { nish }\end{array}$ & 1 & agent & active & $\begin{array}{c}\text { congru } \\
\text { ent }\end{array}$ & see & $n$ & $\mathrm{n}$ & 1 & $\begin{array}{c}46 \\
2 \\
\end{array}$ & 438 & 412 & 874 & 2186 & 1863 \\
\hline $\begin{array}{l}1 \\
0\end{array}$ & $\begin{array}{l}2 \\
3 \\
\end{array}$ & $\begin{array}{c}\text { Fem } \\
\text { ale }\end{array}$ & Right & $\begin{array}{l}\text { Spa } \\
\text { nish }\end{array}$ & 2 & agent & $\begin{array}{c}\text { passiv } \\
\mathrm{e}\end{array}$ & $\begin{array}{c}\text { incongr } \\
\text { uent }\end{array}$ & push & $m$ & $\mathrm{~m}$ & 1 & $\begin{array}{c}51 \\
2\end{array}$ & 518 & 494 & 1602 & 3126 & 1870 \\
\hline $\begin{array}{l}1 \\
0\end{array}$ & $\begin{array}{l}2 \\
3 \\
\end{array}$ & $\begin{array}{c}\text { Fem } \\
\text { ale }\end{array}$ & Right & $\begin{array}{l}\text { Spa } \\
\text { nish }\end{array}$ & 3 & $\begin{array}{c}\text { patien } \\
\mathrm{t}\end{array}$ & active & $\begin{array}{c}\text { incongr } \\
\text { uent }\end{array}$ & hug & $\mathrm{m}$ & $\mathrm{m}$ & 1 & $\begin{array}{c}42 \\
7 \\
\end{array}$ & 383 & 390 & 720 & 1921 & 1440 \\
\hline $\begin{array}{l}1 \\
0\end{array}$ & $\begin{array}{l}2 \\
3 \\
\end{array}$ & $\begin{array}{c}\text { Fem } \\
\text { ale }\end{array}$ & Right & $\begin{array}{l}\text { Spa } \\
\text { nish }\end{array}$ & 4 & $\begin{array}{c}\text { patien } \\
\mathrm{t}\end{array}$ & $\begin{array}{c}\text { passiv } \\
\mathrm{e} \\
\end{array}$ & $\begin{array}{c}\text { congru } \\
\text { ent }\end{array}$ & kill & $n$ & $\mathrm{n}$ & 1 & $\begin{array}{c}29 \\
7\end{array}$ & 794 & 959 & 971 & 2971 & 1715 \\
\hline $\begin{array}{l}1 \\
1\end{array}$ & $\begin{array}{l}2 \\
4 \\
\end{array}$ & $\begin{array}{l}\text { Fem } \\
\text { ale }\end{array}$ & Right & $\begin{array}{l}\text { Spa } \\
\text { nish }\end{array}$ & 1 & agent & active & $\begin{array}{c}\text { congru } \\
\text { ent }\end{array}$ & hug & $n$ & $\mathrm{n}$ & 1 & $\begin{array}{c}64 \\
2\end{array}$ & 906 & 669 & 641 & 2858 & 1889 \\
\hline $\begin{array}{l}1 \\
1\end{array}$ & $\begin{array}{l}2 \\
4\end{array}$ & $\begin{array}{c}\text { Fem } \\
\text { ale }\end{array}$ & Right & $\begin{array}{l}\text { Spa } \\
\text { nish }\end{array}$ & 2 & agent & $\begin{array}{c}\text { passiv } \\
\mathrm{e}\end{array}$ & $\begin{array}{c}\text { incongr } \\
\text { uent }\end{array}$ & find & $\mathrm{m}$ & $\mathrm{m}$ & 1 & $\begin{array}{c}83 \\
3\end{array}$ & $\begin{array}{c}135 \\
0\end{array}$ & 1146 & 957 & 4286 & 2105 \\
\hline $\begin{array}{l}1 \\
1\end{array}$ & $\begin{array}{l}2 \\
4\end{array}$ & $\begin{array}{l}\text { Fem } \\
\text { ale }\end{array}$ & Right & $\begin{array}{l}\text { Spa } \\
\text { nish }\end{array}$ & 3 & $\begin{array}{c}\text { patien } \\
\mathrm{t}\end{array}$ & active & $\begin{array}{c}\text { incongr } \\
\text { uent }\end{array}$ & see & $\mathrm{m}$ & $\mathrm{m}$ & 1 & $\begin{array}{c}60 \\
7\end{array}$ & 799 & 739 & 907 & 3052 & 1989 \\
\hline $\begin{array}{l}1 \\
1 \\
\end{array}$ & $\begin{array}{l}2 \\
4 \\
\end{array}$ & $\begin{array}{l}\text { Fem } \\
\text { ale }\end{array}$ & Right & $\begin{array}{l}\text { Spa } \\
\text { nish }\end{array}$ & 4 & $\begin{array}{c}\text { patien } \\
\mathrm{t}\end{array}$ & $\begin{array}{c}\text { passiv } \\
\mathrm{e}\end{array}$ & $\begin{array}{c}\text { congru } \\
\text { ent }\end{array}$ & insult & $n$ & $\mathrm{n}$ & 1 & $\begin{array}{c}53 \\
0 \\
\end{array}$ & 855 & 887 & 1015 & 3287 & 2162 \\
\hline $\begin{array}{l}1 \\
2\end{array}$ & $\begin{array}{l}2 \\
2\end{array}$ & $\begin{array}{c}\text { Mal } \\
\mathrm{e}\end{array}$ & Right & $\begin{array}{l}\text { Spa } \\
\text { nish }\end{array}$ & 1 & agent & active & $\begin{array}{c}\text { congru } \\
\text { ent }\end{array}$ & $\begin{array}{c}\text { ident } \\
\text { ify }\end{array}$ & $m$ & $m$ & 1 & $\begin{array}{r}33 \\
4\end{array}$ & 381 & 401 & 647 & 1764 & 1286 \\
\hline $\begin{array}{l}1 \\
2\end{array}$ & $\begin{array}{l}2 \\
2\end{array}$ & $\begin{array}{c}\text { Mal } \\
\mathrm{e}\end{array}$ & Right & $\begin{array}{l}\text { Spa } \\
\text { nish }\end{array}$ & 2 & agent & $\begin{array}{c}\text { passiv } \\
\mathrm{e}\end{array}$ & $\begin{array}{c}\text { incongr } \\
\text { uent }\end{array}$ & $\begin{array}{l}\text { fasci } \\
\text { nate }\end{array}$ & $n$ & $\mathrm{n}$ & 1 & $\begin{array}{r}35 \\
4 \\
\end{array}$ & 474 & 460 & 499 & 1786 & 1698 \\
\hline $\begin{array}{l}1 \\
2\end{array}$ & $\begin{array}{l}2 \\
2\end{array}$ & $\begin{array}{c}\text { Mal } \\
\mathrm{e}\end{array}$ & Right & $\begin{array}{l}\text { Spa } \\
\text { nish }\end{array}$ & 3 & $\begin{array}{c}\text { patien } \\
\mathrm{t}\end{array}$ & active & $\begin{array}{c}\text { incongr } \\
\text { uent }\end{array}$ & visit & $n$ & $\mathrm{n}$ & 1 & $\begin{array}{r}36 \\
3\end{array}$ & 467 & 404 & 684 & 1918 & 1563 \\
\hline $\begin{array}{l}1 \\
2\end{array}$ & $\begin{array}{l}2 \\
2\end{array}$ & $\begin{array}{c}\text { Mal } \\
\mathrm{e}\end{array}$ & Right & $\begin{array}{l}\text { Spa } \\
\text { nish }\end{array}$ & 4 & $\begin{array}{c}\text { patien } \\
\mathrm{t}\end{array}$ & $\begin{array}{c}\text { passiv } \\
\mathrm{e}\end{array}$ & $\begin{array}{c}\text { congru } \\
\text { ent }\end{array}$ & $\begin{array}{c}\text { forge } \\
t\end{array}$ & $m$ & $m$ & 1 & $\begin{array}{r}42 \\
4\end{array}$ & 387 & 397 & 475 & 1683 & 1867 \\
\hline
\end{tabular}


10.2 Natives

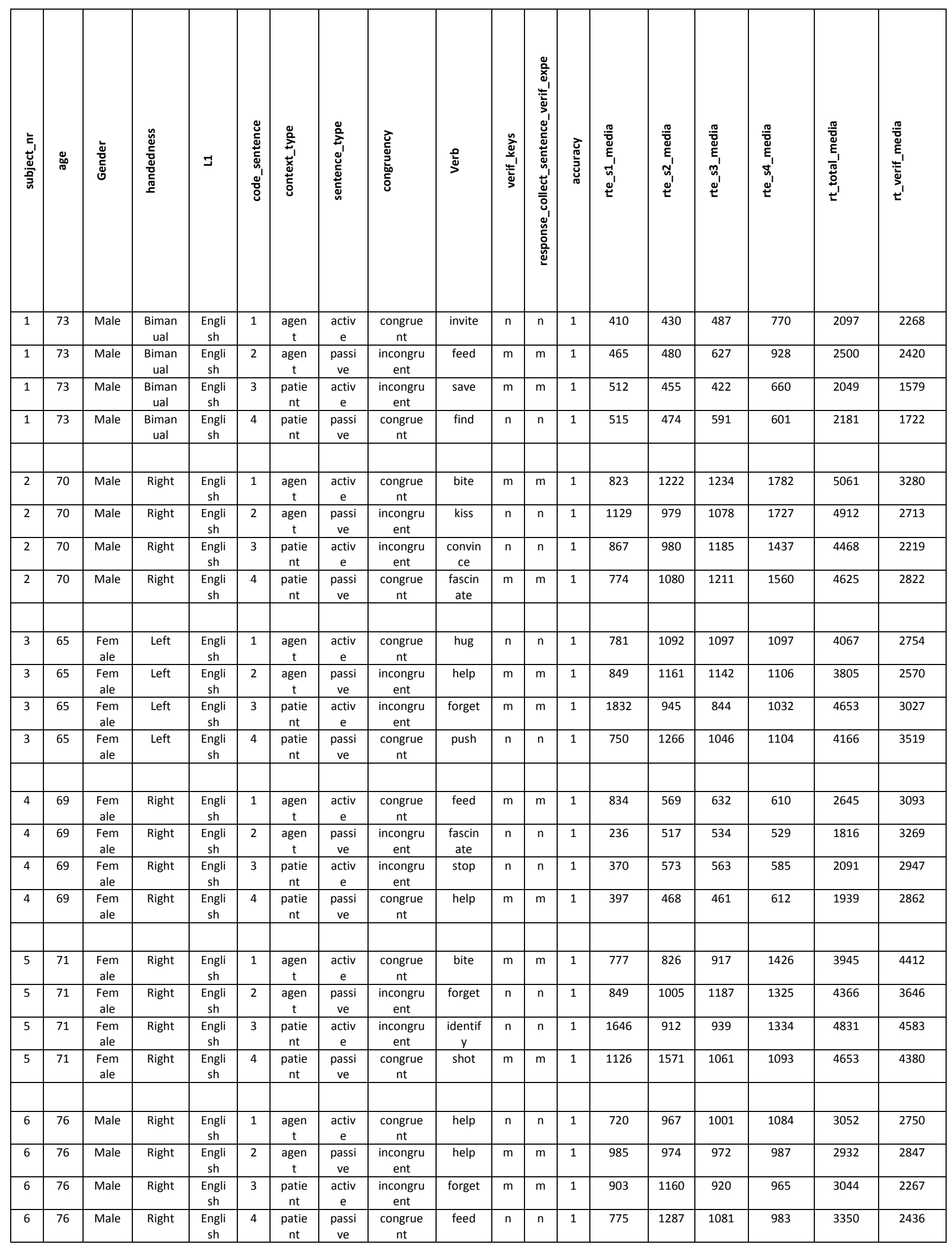




\begin{tabular}{|c|c|c|c|c|c|c|c|c|c|c|c|c|c|c|c|c|c|c|}
\hline 7 & 77 & $\begin{array}{l}\text { Fem } \\
\text { ale }\end{array}$ & Right & $\begin{array}{l}\text { Engli } \\
\text { sh }\end{array}$ & 1 & $\begin{array}{c}\text { agen } \\
\mathrm{t}\end{array}$ & $\begin{array}{c}\text { activ } \\
\mathrm{e}\end{array}$ & $\begin{array}{c}\text { congrue } \\
\text { nt }\end{array}$ & feed & $m$ & $m$ & 1 & 693 & 561 & 581 & 976 & 2810 & 2201 \\
\hline 7 & 77 & $\begin{array}{c}\text { Fem } \\
\text { ale }\end{array}$ & Right & $\begin{array}{l}\text { Engli } \\
\text { sh }\end{array}$ & 2 & $\begin{array}{c}\text { agen } \\
\mathrm{t}\end{array}$ & $\begin{array}{l}\text { passi } \\
\text { ve }\end{array}$ & $\begin{array}{c}\text { incongru } \\
\text { ent }\end{array}$ & $\begin{array}{l}\text { fascin } \\
\text { ate }\end{array}$ & $\mathrm{n}$ & $n$ & 1 & 610 & 494 & 489 & 640 & 2232 & 2071 \\
\hline 7 & 77 & $\begin{array}{l}\text { Fem } \\
\text { ale }\end{array}$ & Right & $\begin{array}{c}\text { Engli } \\
\text { sh }\end{array}$ & 3 & $\begin{array}{c}\text { patie } \\
\text { nt }\end{array}$ & $\begin{array}{c}\text { activ } \\
\mathrm{e}\end{array}$ & $\begin{array}{c}\text { incongru } \\
\text { ent }\end{array}$ & stop & $n$ & $n$ & 1 & 720 & 581 & 592 & 1164 & 3057 & 2274 \\
\hline 7 & 77 & $\begin{array}{l}\text { Fem } \\
\text { ale }\end{array}$ & Right & $\begin{array}{l}\text { Engli } \\
\text { sh }\end{array}$ & 4 & $\begin{array}{c}\text { patie } \\
\text { nt }\end{array}$ & $\begin{array}{l}\text { passi } \\
\text { ve }\end{array}$ & $\begin{array}{c}\text { congrue } \\
\mathrm{nt}\end{array}$ & $\begin{array}{c}\text { choos } \\
\mathrm{e}\end{array}$ & $m$ & $m$ & 1 & 592 & 504 & 521 & 650 & 2266 & 2345 \\
\hline 8 & 69 & Male & Right & $\begin{array}{l}\text { Engli } \\
\text { sh }\end{array}$ & 1 & $\begin{array}{c}\text { agen } \\
t\end{array}$ & $\begin{array}{c}\text { activ } \\
\text { e }\end{array}$ & $\begin{array}{c}\text { congrue } \\
\text { nt }\end{array}$ & forget & $n$ & $n$ & 1 & 579 & 649 & 660 & 1114 & 3002 & 1953 \\
\hline 8 & 69 & Male & Right & $\begin{array}{l}\text { Engli } \\
\text { sh }\end{array}$ & 2 & $\begin{array}{c}\text { agen } \\
\mathrm{t}\end{array}$ & $\begin{array}{l}\text { passi } \\
\text { ve }\end{array}$ & $\begin{array}{c}\text { incongru } \\
\text { ent }\end{array}$ & hurt & $m$ & $m$ & 1 & 588 & 643 & 700 & 963 & 2752 & 2305 \\
\hline 8 & 69 & Male & Right & $\begin{array}{c}\text { Engli } \\
\text { sh }\end{array}$ & 3 & $\begin{array}{c}\text { patie } \\
\text { nt }\end{array}$ & $\begin{array}{c}\text { activ } \\
\text { e }\end{array}$ & $\begin{array}{c}\text { incongru } \\
\text { ent }\end{array}$ & hug & $\mathrm{m}$ & $m$ & 1 & 756 & 457 & 520 & 875 & 2608 & 1704 \\
\hline 8 & 69 & Male & Right & $\begin{array}{l}\text { Engli } \\
\text { sh }\end{array}$ & 4 & $\begin{array}{c}\text { patie } \\
\text { nt }\end{array}$ & $\begin{array}{l}\text { passi } \\
\text { ve }\end{array}$ & $\begin{array}{c}\text { congrue } \\
\mathrm{nt}\end{array}$ & stop & $n$ & $n$ & 1 & 437 & 529 & 555 & 826 & 2347 & 1571 \\
\hline 9 & 67 & $\begin{array}{l}\text { Fem } \\
\text { ale }\end{array}$ & Right & $\begin{array}{c}\text { Engli } \\
\text { sh }\end{array}$ & 1 & $\begin{array}{c}\text { agen } \\
\mathrm{t}\end{array}$ & $\begin{array}{c}\text { activ } \\
\mathrm{e}\end{array}$ & $\begin{array}{c}\begin{array}{c}\text { congrue } \\
\text { nt }\end{array} \\
\end{array}$ & find & $m$ & $\mathrm{~m}$ & 1 & 1013 & 948 & 949 & 1190 & 4100 & 1934 \\
\hline 9 & 67 & $\begin{array}{c}\text { Fem } \\
\text { ale }\end{array}$ & Right & $\begin{array}{c}\text { Engli } \\
\text { sh }\end{array}$ & 2 & $\begin{array}{c}\text { agen } \\
\mathrm{t}\end{array}$ & $\begin{array}{l}\text { passi } \\
\text { ve }\end{array}$ & $\begin{array}{c}\text { incongru } \\
\text { ent }\end{array}$ & $\begin{array}{c}\text { protec } \\
\mathrm{t}\end{array}$ & $n$ & $n$ & 1 & 859 & 826 & 844 & 1001 & 3531 & 2131 \\
\hline 9 & 67 & $\begin{array}{c}\text { Fem } \\
\text { ale }\end{array}$ & Right & $\begin{array}{l}\text { Engli } \\
\text { sh }\end{array}$ & 3 & $\begin{array}{c}\text { patie } \\
\text { nt }\end{array}$ & $\begin{array}{c}\text { activ } \\
\mathrm{e}\end{array}$ & $\begin{array}{c}\text { incongru } \\
\text { ent }\end{array}$ & $\begin{array}{c}\text { convin } \\
\text { ce }\end{array}$ & $n$ & $n$ & 1 & 1094 & 816 & 829 & 1273 & 4012 & 2121 \\
\hline 9 & 67 & $\begin{array}{l}\text { Fem } \\
\text { ale }\end{array}$ & Right & $\begin{array}{c}\text { Engli } \\
\text { sh }\end{array}$ & 4 & $\begin{array}{c}\text { patie } \\
\text { nt }\end{array}$ & $\begin{array}{l}\text { passi } \\
\text { ve }\end{array}$ & $\begin{array}{c}\text { congrue } \\
\mathrm{nt}\end{array}$ & punish & $m$ & $m$ & 1 & 957 & 897 & 873 & 933 & 3661 & 1879 \\
\hline $\begin{array}{l}1 \\
0\end{array}$ & 70 & Male & Right & $\begin{array}{l}\text { Engli } \\
\text { sh }\end{array}$ & 1 & $\begin{array}{c}\text { agen } \\
t\end{array}$ & $\begin{array}{c}\text { activ } \\
\mathrm{e}\end{array}$ & $\begin{array}{c}\text { congrue } \\
\text { nt }\end{array}$ & help & $n$ & $n$ & 1 & 585 & 873 & 920 & 1194 & 3571 & 2353 \\
\hline $\begin{array}{l}1 \\
0\end{array}$ & 70 & Male & Right & $\begin{array}{l}\text { Engli } \\
\text { sh }\end{array}$ & 2 & $\begin{array}{c}\text { agen } \\
\mathrm{t}\end{array}$ & $\begin{array}{l}\text { passi } \\
\text { ve }\end{array}$ & $\begin{array}{c}\text { incongru } \\
\text { ent }\end{array}$ & find & $\mathrm{m}$ & $\mathrm{m}$ & 1 & 806 & 1177 & 1012 & 1345 & 4339 & 2815 \\
\hline $\begin{array}{l}1 \\
0\end{array}$ & 70 & Male & Right & $\begin{array}{l}\text { Engli } \\
\text { sh }\end{array}$ & 3 & $\begin{array}{c}\text { patie } \\
\text { nt }\end{array}$ & $\begin{array}{c}\text { activ } \\
\text { e }\end{array}$ & $\begin{array}{c}\text { incongru } \\
\text { ent }\end{array}$ & kiss & $\mathrm{m}$ & $m$ & 1 & 850 & 820 & 776 & 1536 & 3982 & 2726 \\
\hline $\begin{array}{l}1 \\
0\end{array}$ & 70 & Male & Right & $\begin{array}{l}\text { Engli } \\
\text { sh }\end{array}$ & 4 & $\begin{array}{c}\text { patie } \\
\text { nt }\end{array}$ & $\begin{array}{l}\text { passi } \\
\text { ve }\end{array}$ & $\begin{array}{c}\text { congrue } \\
\mathrm{nt}\end{array}$ & $\begin{array}{c}\text { identif } \\
y\end{array}$ & $n$ & $n$ & 1 & 707 & 1340 & 1123 & 1731 & 4900 & 4232 \\
\hline $\begin{array}{l}1 \\
1\end{array}$ & 67 & $\begin{array}{l}\text { Fem } \\
\text { ale }\end{array}$ & Right & $\begin{array}{l}\text { Engli } \\
\text { sh }\end{array}$ & 1 & $\begin{array}{c}\text { agen } \\
t\end{array}$ & $\begin{array}{c}\text { activ } \\
\mathrm{e}\end{array}$ & $\begin{array}{c}\text { congrue } \\
\text { nt }\end{array}$ & feed & $\mathrm{m}$ & $\mathrm{m}$ & 1 & 989 & 1190 & 1180 & 1416 & 4776 & 1885 \\
\hline $\begin{array}{l}1 \\
1\end{array}$ & 67 & $\begin{array}{c}\text { Fem } \\
\text { ale }\end{array}$ & Right & $\begin{array}{l}\text { Engli } \\
\text { sh }\end{array}$ & 2 & $\begin{array}{c}\text { agen } \\
t\end{array}$ & $\begin{array}{l}\text { passi } \\
\text { ve }\end{array}$ & $\begin{array}{c}\text { incongru } \\
\text { ent }\end{array}$ & shot & $n$ & $n$ & 1 & 904 & 1161 & 1237 & 1242 & 4544 & 2138 \\
\hline $\begin{array}{l}1 \\
1\end{array}$ & 67 & $\begin{array}{c}\text { Fem } \\
\text { ale }\end{array}$ & Right & $\begin{array}{c}\text { Engli } \\
\text { sh }\end{array}$ & 3 & $\begin{array}{c}\text { patie } \\
\text { nt }\end{array}$ & $\begin{array}{c}\text { activ } \\
\mathrm{e}\end{array}$ & $\begin{array}{c}\text { incongru } \\
\text { ent }\end{array}$ & kill & $n$ & $n$ & 1 & 966 & 1163 & 1153 & 1462 & 4744 & 1858 \\
\hline $\begin{array}{l}1 \\
1 \\
\end{array}$ & 67 & $\begin{array}{l}\text { Fem } \\
\text { ale }\end{array}$ & Right & $\begin{array}{l}\text { Engli } \\
\text { sh }\end{array}$ & 4 & $\begin{array}{c}\text { patie } \\
\mathrm{nt}\end{array}$ & $\begin{array}{l}\text { passi } \\
\text { ve }\end{array}$ & $\begin{array}{c}\text { congrue } \\
\text { nt }\end{array}$ & kiss & $\mathrm{m}$ & $m$ & 1 & 815 & 1243 & 1189 & 1479 & 4726 & 2222 \\
\hline $\begin{array}{l}1 \\
2 \\
\end{array}$ & 75 & Male & Right & $\begin{array}{l}\text { Engli } \\
\text { sh }\end{array}$ & 1 & $\begin{array}{c}\text { agen } \\
\mathrm{t}\end{array}$ & $\begin{array}{c}\text { activ } \\
\mathrm{e}\end{array}$ & $\begin{array}{c}\text { congrue } \\
\text { nt }\end{array}$ & invite & $\mathrm{n}$ & $n$ & 1 & 1139 & 1242 & 1307 & 1863 & 5551 & 2576 \\
\hline $\begin{array}{l}1 \\
2 \\
\end{array}$ & 75 & Male & Right & $\begin{array}{l}\text { Engli } \\
\text { sh }\end{array}$ & 2 & $\begin{array}{c}\text { agen } \\
t\end{array}$ & $\begin{array}{l}\text { passi } \\
\text { ve }\end{array}$ & $\begin{array}{c}\text { incongru } \\
\text { ent }\end{array}$ & hurt & $m$ & $m$ & 1 & 1330 & 1468 & 1751 & 2266 & 6814 & 2404 \\
\hline $\begin{array}{l}1 \\
2\end{array}$ & 75 & Male & Right & $\begin{array}{c}\text { Engli } \\
\text { sh }\end{array}$ & 3 & $\begin{array}{c}\text { patie } \\
\text { nt }\end{array}$ & $\begin{array}{c}\text { activ } \\
\mathrm{e}\end{array}$ & $\begin{array}{c}\text { incongru } \\
\text { ent }\end{array}$ & hug & $\mathrm{m}$ & $m$ & 1 & 1178 & 1198 & 1583 & 1907 & 5866 & 2442 \\
\hline $\begin{array}{l}1 \\
2 \\
\end{array}$ & 75 & Male & Right & $\begin{array}{c}\text { Engli } \\
\text { sh }\end{array}$ & 4 & $\begin{array}{c}\text { patie } \\
\text { nt }\end{array}$ & $\begin{array}{l}\text { passi } \\
\text { ve }\end{array}$ & $\begin{array}{c}\text { congrue } \\
\mathrm{nt}\end{array}$ & visit & $n$ & $n$ & 1 & 1233 & 1519 & 1605 & 2053 & 6408 & 3098 \\
\hline
\end{tabular}




\section{APPENDIX V: GLOSSARY}

\subsection{Nouns.}

\begin{tabular}{|c|c|c|c|}
\hline \multicolumn{4}{|c|}{ NOUNS /SUSTANTIVOS } \\
\hline Policeman & Policía & Suspect & Sospechoso \\
\hline Hooligan & Vándalo & Victim & Víctima \\
\hline Guide & Guía & Identification parade & $\begin{array}{l}\text { Ronda de } \\
\text { reconocimiento }\end{array}$ \\
\hline Hiker & Excursionista & Crime & Crimen \\
\hline Rioter & $\begin{array}{l}\text { Persona en un } \\
\text { disturbio }\end{array}$ & Building & Edificio \\
\hline Lottery & Lotería & Firefighter & Bombero \\
\hline Handshake & Apretón de manos & Assassin & Asesino \\
\hline Thief & Ladrón & Politician & Político \\
\hline Noise & Ruido & Rifle & Rifle \\
\hline Hurry & Prisa & Roof & Tejadp \\
\hline Enemy & Enemigo & Crowd & Multitud \\
\hline Shouts & Gritos & Song & Canción \\
\hline Tribe & Tribu & Candidate & Candidato \\
\hline Dress & Vestido & Voter & Votante \\
\hline Prom party & $\begin{array}{l}\text { Fiesta de } \\
\text { graduación }\end{array}$ & Soldier & Soldado \\
\hline Sergeant & Sargento & Driver & Conductor \\
\hline Barracks & Barracones & Artist & Artista \\
\hline Inspection & Inspección & Journalist & Periodista \\
\hline Debate & Debate & Exhibition & Exhibición \\
\hline Alcohol check & $\begin{array}{l}\text { Control de } \\
\text { alcoholemia }\end{array}$ & Paintings & Cuadros \\
\hline Road & Carretera & Newspaper & Periódico \\
\hline Magazine & Revista & Passer-by & Peatón \\
\hline Playground & Parque infantil & Wall & Pared \\
\hline Ball & Pelota & Volunteer & Voluntario \\
\hline Stripclub & Club de striptease & Refugee camp & $\begin{array}{l}\text { Campo de } \\
\text { refugiados }\end{array}$ \\
\hline Show & Espectáculo & Supplies & Suministros \\
\hline Faith & $\mathrm{Fe}$ & Cast & $\begin{array}{l}\text { Reparto de } \\
\text { actores }\end{array}$ \\
\hline Nun & Monja & Camping site & $\begin{array}{l}\text { Lugar de } \\
\text { acampada }\end{array}$ \\
\hline Convent & Convento & Living dead & $\begin{array}{l}\text { Muertos } \\
\text { vivientes }\end{array}$ \\
\hline Advice & Consejo & Film & Película \\
\hline Chapel & Capilla & Asylum & Manicomio \\
\hline Nurse & Enfermera & Speech & Discurso \\
\hline Madman & Loco & Government & Gobierno \\
\hline Corridor & Pasillo & Counsellor & Consejero \\
\hline Duties & Labor & Addict & Adicto \\
\hline Conference & Conferencia & Appointment & Cita \\
\hline Corruption & Corrupción & & \\
\hline
\end{tabular}




\begin{tabular}{|l|l|l|l|}
\hline Soldier & Soldado & Puppy & Cachorro \\
\hline Companion & Compañero & Engine & Motor \\
\hline Mission & Misión & Bicycle / Bike & Bicicleta \\
\hline Terrorist & Terrorista & Money & Dinero \\
\hline Shots & Disparos & Necklace & Collar \\
\hline Safe house & Piso franco & Match & Partido \\
\hline Lesson & Lección & Starter & Entrante \\
\hline Lunch & Almuerzo & Cousin & Primo/a \\
\hline Dinner & Cena & Kitten & Gatito \\
\hline Grandma & Abuela & Bribe & Soborno \\
\hline
\end{tabular}

11.2 Adjectives.

\begin{tabular}{|l|l|l|l|}
\hline \multicolumn{5}{|c|}{ ADJECTIVES/ADJETIVOS } \\
\hline Crowded & Lleno de gente & Ill & Enfermo/a \\
\hline Strange & Extraño & Huge & Enorme \\
\hline Hidden & Escondido & Excited & Emocionado/a \\
\hline Busy & $\begin{array}{l}\text { Ocupado/a / } \\
\text { Ajetreado/a }\end{array}$ & Hungry & Hambriento/a \\
\hline Safe & Seguro/a & Corrupt & Corrupto/a \\
\hline Required & Requerido/a & Dangerous & Peligroso/a \\
\hline Indecisive & Indeciso/a & Sleepy & Somnoliento/a \\
\hline Impatient & Impaciente & Fond & Encariñado/a \\
\hline Angry & Enfadado/a & Unsure & Inseguro/a \\
\hline Dirty & Sucio/a & Honest & Honesto/a \\
\hline Messy & Desordenado/a & Illegal & Ilegal \\
\hline Intense & Intenso/a & Abandoned & Abandonado/a \\
\hline Drunk & Borracho/a & Sensual & Sensual \\
\hline
\end{tabular}

\subsection{Verbs}

\begin{tabular}{|l|l|l|l|}
\hline \multicolumn{2}{|c|}{ VERBS/ VERBOS } & & \\
\hline See & Ver & Bite & Morder \\
\hline Push & Empujar & Forget & olvidar \\
\hline Shoot & Disparar & Insult & insultar \\
\hline Help & Ayudar & Support & Apoyar \\
\hline Choose & Elegir & Find & Encontrar \\
\hline Identify & Identificar & Tell & Contar \\
\hline Save & Salvar/Ahorrar & Throw & Lanzar \\
\hline Kill & Matar & Draw & Dibujar \\
\hline Kiss & besar & Win & Ganar \\
\hline Convince & Convencer & Sing & Cantar \\
\hline Punish & Castigar & Buy & Comprar \\
\hline Stop & Parar & Ask & Preguntar \\
\hline Invite & Invitar & Wash & Lavar \\
\hline Hurt & Herir & Sell & Vender \\
\hline Fascinate & Fascinar & Watch & Ver \\
\hline Visit & visitar & Kick & Patear \\
\hline Protect & Proteger & Lead & Guiar \\
\hline
\end{tabular}




\begin{tabular}{|l|l|l|l|}
\hline Feed & Alimentar & Carry & Llevar \\
\hline Hug & abrazar & Follow & Seguir \\
\hline Commit & Cometer & Steal & Robar \\
\hline Burn & Quemar & Lookfor & Buscar \\
\hline Die & Morir & Report & Denunciar \\
\hline Parade & Desfilar & Attack & Atacar \\
\hline Wave & Saludar & Bounce & Botar \\
\hline Jump & Saltar & Perform & Actuar \\
\hline Sell & Vender & Expect & Esperar \\
\hline Inherit & Heredar & Fall & Caer \\
\hline Meet & Encontrarse & Notice & Darse cuenta \\
\hline Hate & Odiar & Search & Buscar \\
\hline Cook & Cocinar & Draw & Dibujar \\
\hline Prepare & Preparar & Throw & Lanzar \\
\hline Decide & Decidir & Payattention & Prestar atención \\
\hline Attend & Asistir & Approach & Acercarse \\
\hline Lick & Lamer & Refuse & Rechazar \\
\hline Offer & Ofrecer & & \\
\hline
\end{tabular}

